\title{
Archaeological Investigations at the Ice House Site, 41HY161: Early Archaic Technology, Subsistence, and Settlement Along the Balcones Escarpment, Hays County, Texas
}

\section{Erik Oksanen}

Center for Archaeological Studies

Follow this and additional works at: https://scholarworks.sfasu.edu/ita

Part of the American Material Culture Commons, Archaeological Anthropology Commons, Environmental Studies Commons, Other American Studies Commons, Other Arts and Humanities Commons, Other History of Art, Architecture, and Archaeology Commons, and the United States History Commons

Tell us how this article helped you.

This Article is brought to you for free and open access by the Center for Regional Heritage Research at SFA ScholarWorks. It has been accepted for inclusion in Index of Texas Archaeology: Open Access Gray Literature from the Lone Star State by an authorized editor of SFA ScholarWorks. For more information, please contact cdsscholarworks@sfasu.edu. 
Archaeological Investigations at the Ice House Site, 41HY161: Early Archaic Technology, Subsistence, and Settlement Along the Balcones Escarpment, Hays County, Texas

Creative Commons License

(c) (1) (9)

This work is licensed under a Creative Commons Attribution-NonCommercial 4.0 International License 


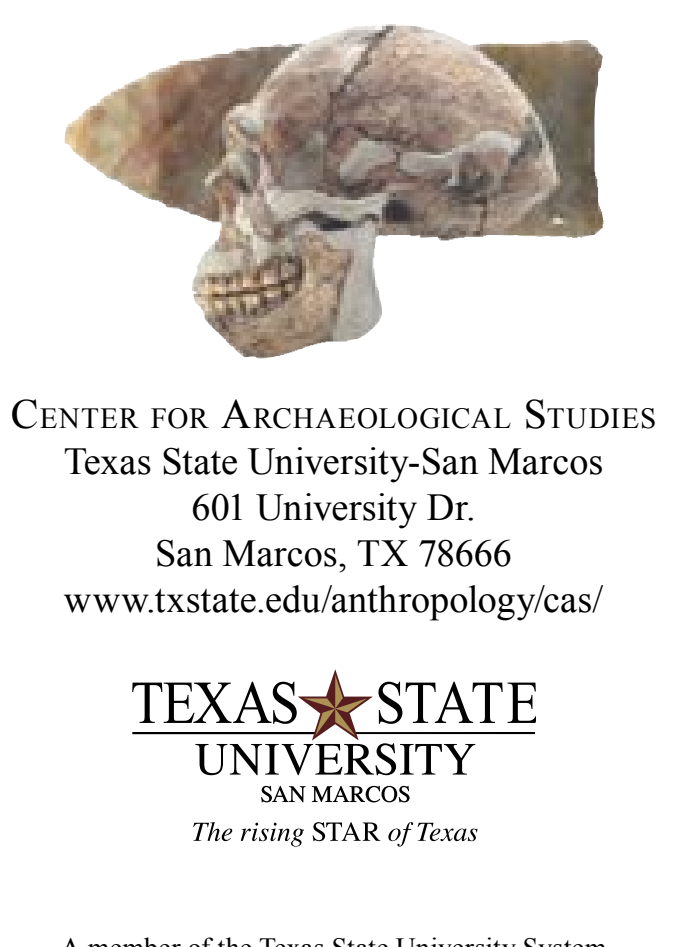

Archaeological Investigations at the Ice House Site, 41HY161: Early Archaic Technology, Subsistence, and Settlement along the Balcones Escarpment, Hays County, Texas

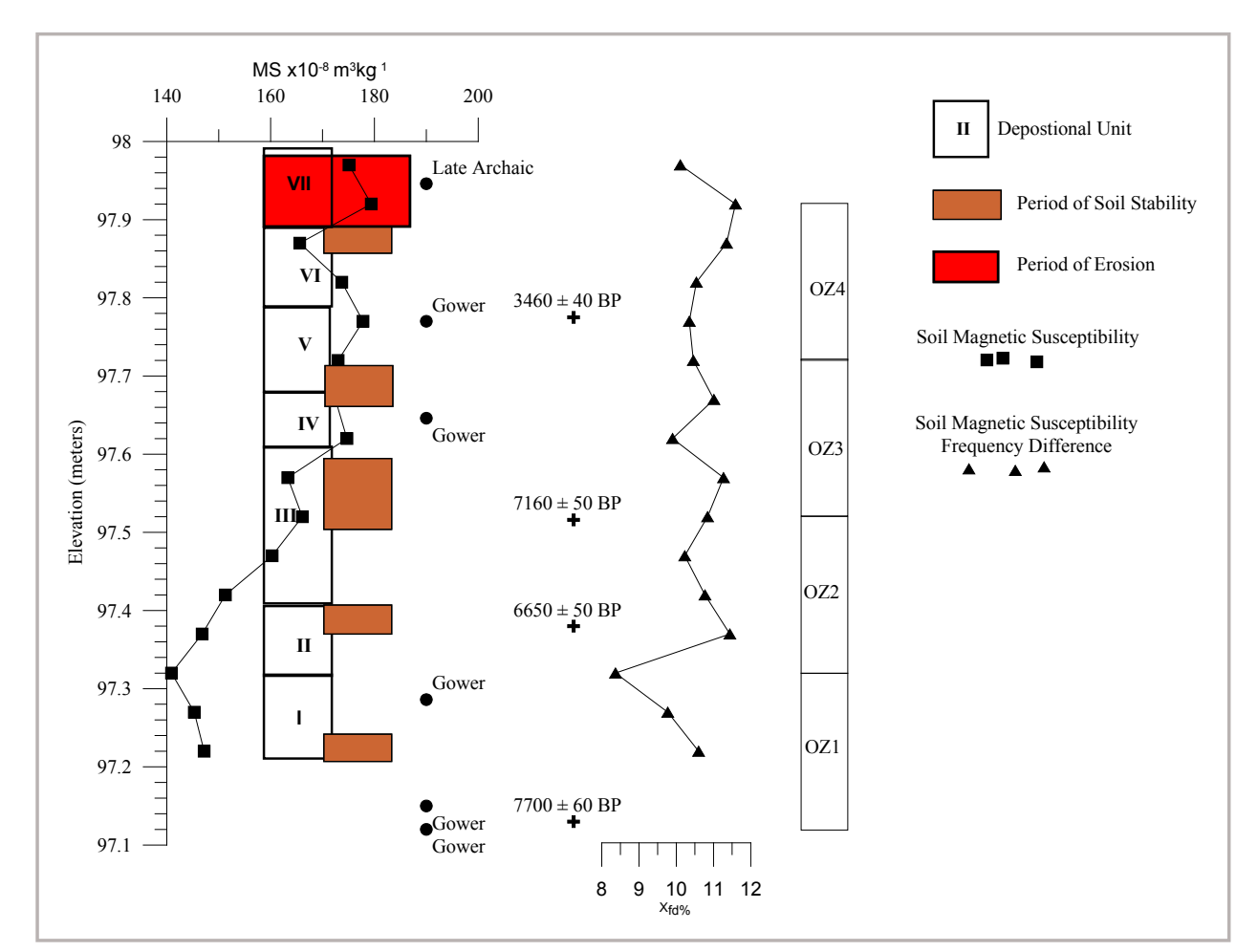

Assembled by Eric Oksanen

With contributions by Barbara Meissner and C. Britt Bousman

Principal Investigator: C. Britt Bousman

Archaeological Studies Report No. 14

Center for Archaeological Studies

Texas State University-San Marcos

$$
2011
$$




\section{Archaeological Investigations at the Ice House Site, 41HY161 \\ Early Archaic Technology, Subsistence and Settlement along the Balcones Escarpment, Hays County, Texas}

assembled by

Eric Oksanen

with contributions by

Barbara Meissner and C. Britt Bousman

Principal Investigator

C. Britt Bousman

Archaeological Studies Report No. 14

Texas Antiquities Permit No. 3438

CENTER FOR ARCHAEOLOGICAL STUDIES

TEXAS STATE UNIVERSITY-SAN MARCOS 


\section{ACKNOWLEDGEMENTS}

The author would like to thank Dr. Elizabeth Erhart, Dr. James Garber and Dr. C. Britt Bousman for their support with this undertaking. My gratitude is extended to Dr. Bousman and his unfailing confidence and optimism, and to whom I owe a great debt and for giving me a truly international education. Through the years, the staff at the Center for Archaeological Studies have assisted in the completion of this research.

Numerous individuals were responsible for the successful field work and analysis. These include Dave Nickels for valuable advice and who ensured the successful completion of the fieldwork, and David Peyton, Lindsey Stoker, Christine Alvarez, Matt Melancon, and Melissa Lehman, for their hard work, and Carole Leezer for support and administrative wizardry. Additional analytical assistance was provided by Holly Meier and Joey Thompson. I especially would like to acknowledge the support of CAS and Texas State University-San Marcos who provided the funding for the project. 


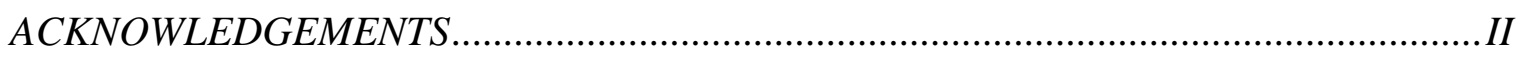

LIST OF TABLES ........................................................................................

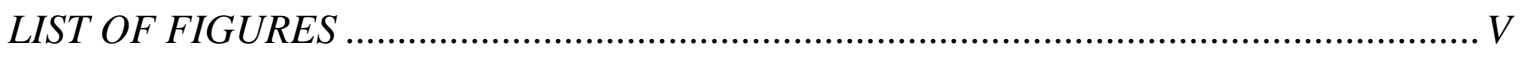

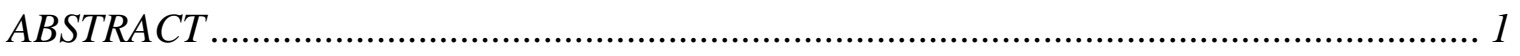

CHAPTER

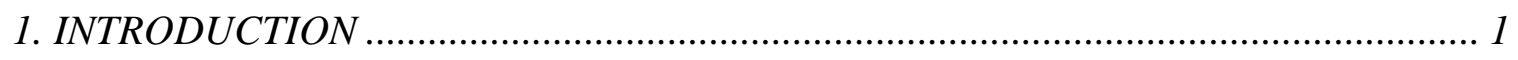

2. REGIONAL ENVIRONMENTAL SETTING ……………………………………... 5

3. CULTURAL HISTORY OF CENTRAL TEXAS....................................................... 45

4. RESEARCH DESIGN AND GOALS …………………........................................ 87

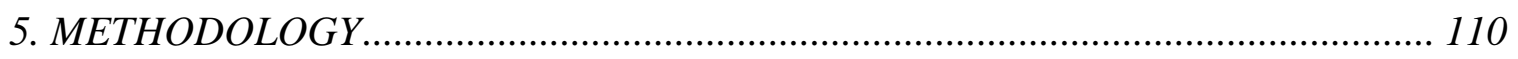

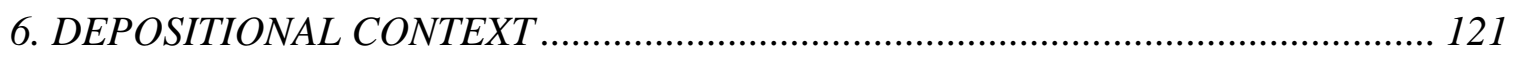

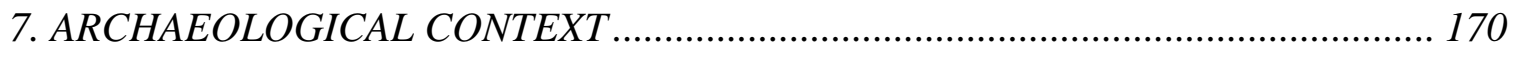

8. INTERPRETATIONS: CONTINUITY AND CHANGE AT THE ICE HOUSE SITE .. 194

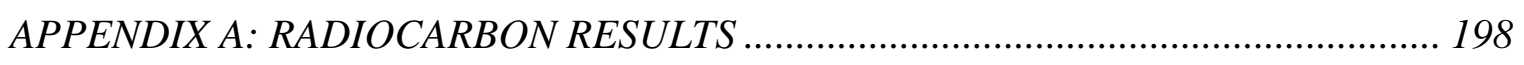

APPENDIX B: VERTEBRATE FAUNAL IDENTIFICATION AND ANALYSIS OF REMAINS FROM 41HY161............................................................................ 208

APPENDIX C: LITHIC ARTIFACT DESCRIPTIONS FROM 41HY161 …………….... 230

APPENDIX D: LITHIC MEASUREMENTS ……………………………………..... 232

REFERENCES CITED ………………………………………………………. 233 


\section{LIST OF TABLES}

Table

Page

1. Soil zone descriptions from east wall of excavation block. 118

2. Provenience of radiocarbon samples and resulting radiocarbon ages. ....................... 121

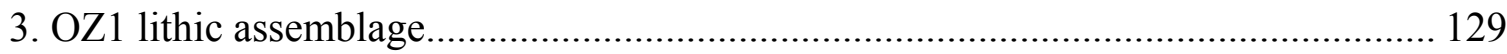

4. Lithic debitage counts and percentages for OZ1 ................................................... 135

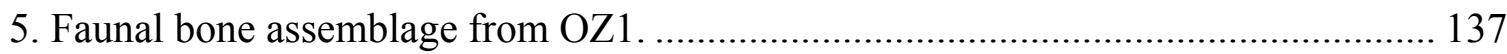

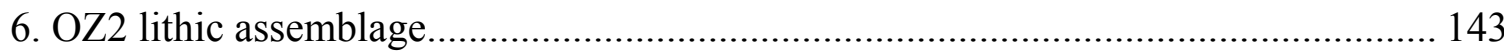

7. Lithic debitage counts and percentages for OZ2 ................................................. 146

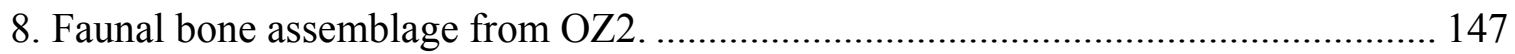

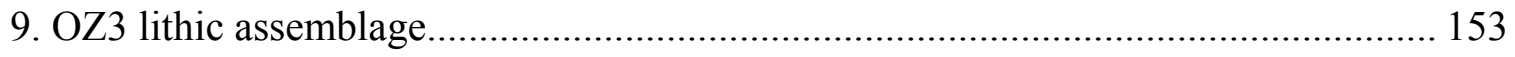

10. Lithic debitage categories counts and percentages for OZ3 ................................. 156

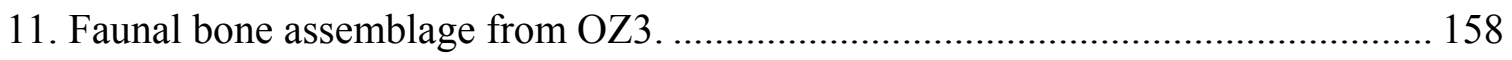

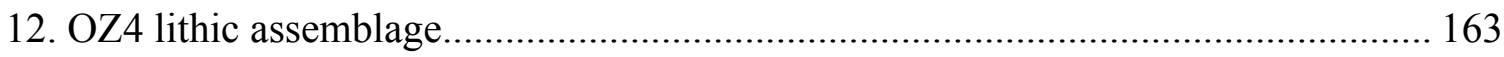

13. Lithic debitage categories counts and percentages for OZ4 .................................. 165

14. Faunal bone assemblage from OZ4 ...................................................................... 166

15. Lithic reduction methods between OZs. ............................................................. 174

16. Debitage adjusted residuals from OZ1, OZ2 and OZ3 ..................................... 176

17. Size categories of faunal remains (NISP) from OZ1, OZ2 and OZ3..................... 179

18. Early Archaic sites selected lithic artifact category totals. ................................... 183

19. Adjusted residuals for comparative Early Archaic lithic categories........................ 184

20. Boone's measures of similarities and differences and Brainerd-Robinson scores between comparative Early Archaic components.............................................. 185

21. Debitage reduction methods from the Armstrong and Icehouse sites. .................... 189

22. Gower point comparative measurements.......................................................... 190

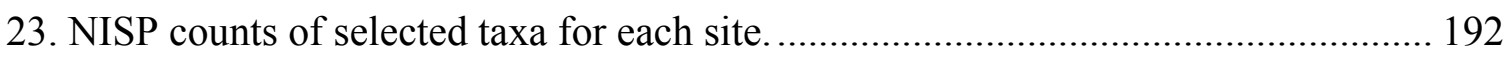

24. Percentage contribution of taxa for each site..................................................... 192 


\section{LIST OF FIGURES}

Figure

Page

1. Location of the Icehouse site, $41 \mathrm{HY} 161$ 4

2. Confluence of Sessom Creek and the San Marcos River looking upstream towards Spring Lake Dam. ................................................................................................. 4

3. Photograph of the excavations at the Icehouse site 41HY161, looking north. .............. 5

4. Natural regions of Texas and location of Hays County. Adapted from Texas Parks and

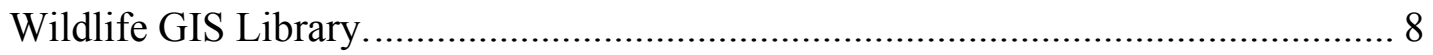

5. Texas vegetation sub-regions. Adapted from Diamond et al. 1987............................ 18

6. Biotic and Faunal Regions of Texas according to a) Blair (1950) and b) Davis and

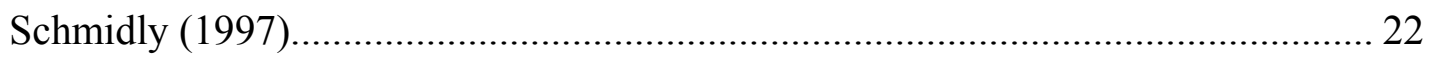

7. Change through time in arboreal pollen percentages from Boriak Bog, Central Texas with data from Bousman (1998a). ........................................................................ 34

8. Location and relationship of the Icehouse site (41HY161) to local sites.................... 46

9. Fishpond where prehistoric burial was previously excavated. ................................... 47

10. Central Texas Archaeological Region according to Prewitt (1981).......................... 52

11. Cultural Chronology for Central Texas based on Collins (2004: Figure 9.3a).......... 53

12. Selected Central Texas Early Archaic Sites........................................................ 54

13. Optimal foraging travel time to hunting areas and time spent hunting. Adapted from MacArthur and Pianka 1966: Figure 2 ............................................................. 76

14. Installed flood control structure near Sessom Drive.............................................. 97

15. South wall and floor of excavation block showing modern disturbance ................... 97

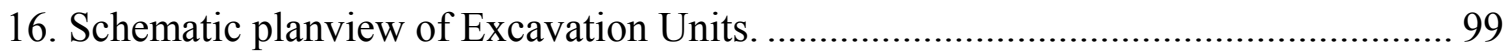

17. Schematic profile of Excavation Units............................................................ 100

18. Schematic of east wall of excavation block showing soil zones. ........................... 118

19. Schematic profile of soil magnetic susceptibility results, projectile point elevations and elevation of radiocarbon results. .......................................................... 120

20. Mapped artifact schematics collapsed and projected on a) east and b) north wall

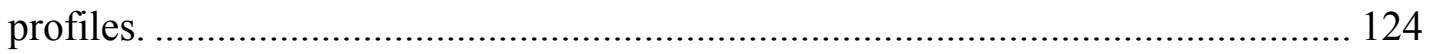

21. Debitage and bone (NISP) totals by excavation level. ....................................... 125

22. Schematic representation of Occupation Zones and unit designations................... 126

23. Schematic of Occupation Zone elevations with magnetic soil susceptibility, radiocarbon dates and projectile points............................................................... 127

24. Debitage counts from Units 6 and 9. .................................................................. 128

25. Crayfish burrowing into floor of excavation block at $97.12 \mathrm{~m}$ elevation ................. 128

26. OZ1 Projectile points and bifaces.................................................................. 130

27. OZ1 Flake tools, cores and burins and burin spalls........................................... 131

28. Planview of OZ1 plotted artifact distribution.................................................. 140 


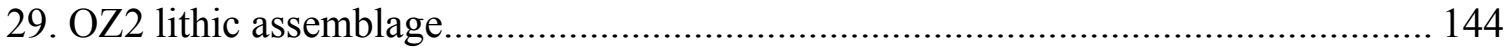

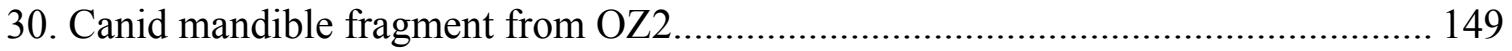

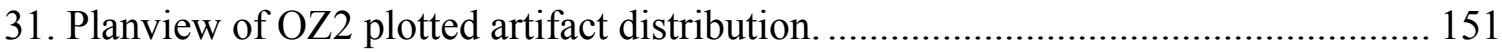

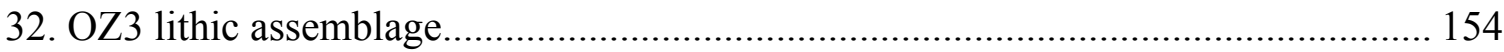

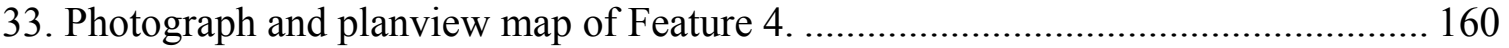

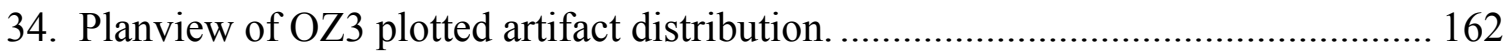

35. OZ4 lithic assemblage and upper component and surface finds.............................. 164

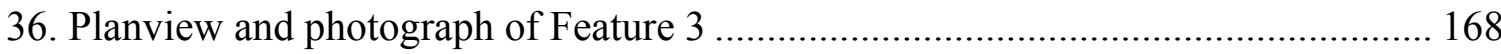

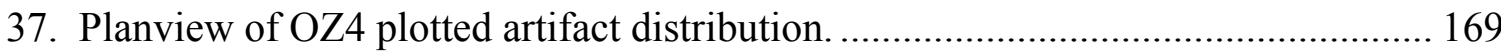

38. Units 6 and 9 debitage (a) and faunal (bone) counts and weights (b)....................... 173

39. Adjusted residuals of the distribution of reduction flake types............................... 176

40. Average lengths of reduction categories of flakes from Occupation Zones............. 177

41. Icehouse site fauna size percentage distribution for OZ1-3 ................................... 180

42. Soil magnetic susceptibility data with faunal size by Occupation Zone. ................. 181

43. Lengths of reduction categories of flakes from the Icehouse and Armstrong sites. . 189

44. Adjusted residuals of the distribution of select fauna from four Early Archaic sites.

45. The Early Archaic components at 41HY161 compared to Central Texas pollen records, bison abundance, and a Central Texas prehistoric population index. 


\author{
ABSTRACT \\ ARCHAEOLOGICAL INVESTIGATIONS AT THE ICE HOUSE SITE, 41HY161 \\ A REVALUATION OF EARLY ARCHAIC TECHNOLOGY, \\ SUBSISTENCE AND SETTLEMENT ALONG THE \\ BALCONES ESCARPMENT \\ AND CENTRAL TEXAS
}

On behalf of the Texas State University-San Marcos, the Center for Archaeological Studies (CAS) conducted data recovery excavations at the Icehouse site, a State Archeological Landmark (SAL), 41HY161, from May to September 2004. The excavations were a partial mitigation for the installation of flood control structures on Sessom Creek on property owned by the Texas State University-San Marcos. Investigative trenching discovered potentially significant cultural deposits within the proposed project area and the mitigation excavations were targeted to within the area of direct impact. As a state agency as defined by Section 61.003, Texas Education Code, Texas State University-San Marcos is required under the Chapter 13 Section 191.002 of the Antiquities Code of Texas to protect and preserve archeological and historical sites on and under properties under its control. Investigations were conducted under Texas Antiquities Permit No. 3438 with Dr. C. Britt Bousman, then Director of CAS, serving as Principal Investigator.

An excavation block 3-x-4 meters was excavated $260 \mathrm{~cm}$ below current grade. This was the area and depth of impact from the construction project. Machinery was used to remove the upper $180 \mathrm{~cm}$ of modern overburden, and then hand excavations continued to the terminal depth. Approximately 5.2 cubic meters were excavated from eight 1-x-1 meter units in undisturbed prehistoric deposits. A significant result of the excavations was the discovery of a series of Early Archaic occupations dating from approximately 7700-6500 B.P. This period is poorly understood and lacks a chronometric basis, in part because of the difficulty in finding preserved deposits. Using soil magnetic susceptibility, artifact distribution and radiocarbon dates, three occupation zones (OZs) were detected in the Early Archaic age strata. A fourth OZ contained 
Late Archaic material. Only Gower or Gower-like projectile points, a form that has been rarely dated and usually is recovered from mixed deposits, were recovered from the Early Archaic deposits. A small faunal assemblage was also recovered, and was used to obtain the radiocarbon dates for the site.

Through the thousand years of Early Archaic occupations, the faunal assemblage and lithic assemblage reflect a shift in hunting emphasis from large game, such as bison and deer in OZ1 to small game such as hare and rabbit by the later OZ3. The intensified use of smaller game is examined in the context of optimal foraging theory and comparisons are made to local and regional Early Archaic components. During OZ1 and OZ2, the Icehouse site functioned as a hunting camp, where projectile points were refitted and new lithic supplies were procured, possibly before forays into chert- poor regions to the east of the site. By the later OZ3, a decrease in overall mobility may have led to decreased ranges, and depleted local stocks of big game , thereby intensifying hunting pressure on smaller resources such as rabbits, rodents and birds. Throughout the occupation of the Icehouse site, there is little variation in the type and size of the lithic materials being worked. The lithic assemblage appears to vary in function along with the use of the site, rather than manufacturing technique or technology. 


\section{CHAPTER 1 INTRODUCTION}

The project area is located on the campus of Texas State University-San Marcos near the confluence of the San Marcos River and a seasonal stream, Sessom Creek (Figures 1 and 2). The project area is also adjacent to the original San Marcos Fish Hatchery, and the construction of fish ponds in the early $20^{\text {th }}$ century impacted the underlying archaeological deposits to varying degrees. As part of a plan to control flooding, the university proposed the installation of two flood control structures. Both of these structures were located within the boundaries of State Archeological Landmark (SAL) 41HY161, the Icehouse site, a prehistoric archeological site. Only one of the structures would impact potentially significant cultural material, and in partial mitigation from the impact, the Center for Archaeological Studies conducted data recovery excavations within the footprint of the proposed structure to the proposed depth of impact. The investigations at the Icehouse site began in May of 2004 and ended in September 2004 under Texas Antiquity Permit No. 3438. The construction project was allowed to proceed following the completion of the archaeological fieldwork.

The excavations were conducted on a berm separating Sessom Creek from the fish pond complex (Figure 3). The investigations noted four Occupation Zones (OZ), three were Early Archaic in age, while the fourth was mixed with Early and Late Archaic material. The site is significant because the Early Archaic period has few sites with reliable dates on stratigraphically intact deposits, and only one style of projectile point was recovered-Gower. These are split stemmed points distributed throughout Central Texas and especially close to the Balcones Escarpment.

With projectile points as a constant, the lithic assemblage was compared between Occupation Zones (OZ) and with their faunal assemblages. In the earlier OZ1, ca. 7700 B.P. the faunal assemblage and lithic tool assemblage suggests the site was used to process big game and to refit points and lithic supplies, possibly after returning from chert-poor regions. Large game such as bison and deer account 80 percent of the faunal assemblage, while in OZ3, ca. 6650 B.P., the faunal assemblage is 20 percent large game and 80 percent small game. There is a similar decline in projectile points and other tools associated with processing big game animals.

When compared to local and regional Early Archaic components, the Icehouse site functioned as a small hunting camp for small groups of mobile hunter/gatherers who had an adaptable lithic technology suited to a variety of hunting strategies. The Icehouse site is situated at the boundary between biotic regions with a variety of plant and animal resources, reliable water and an abundance of chert resources. From this location, large game such as bison and antelope would have been available at varying periods on the prairies 
FIGURE 1. REDACTED

Figure 1. Location of the Icehouse site, 41HY161.

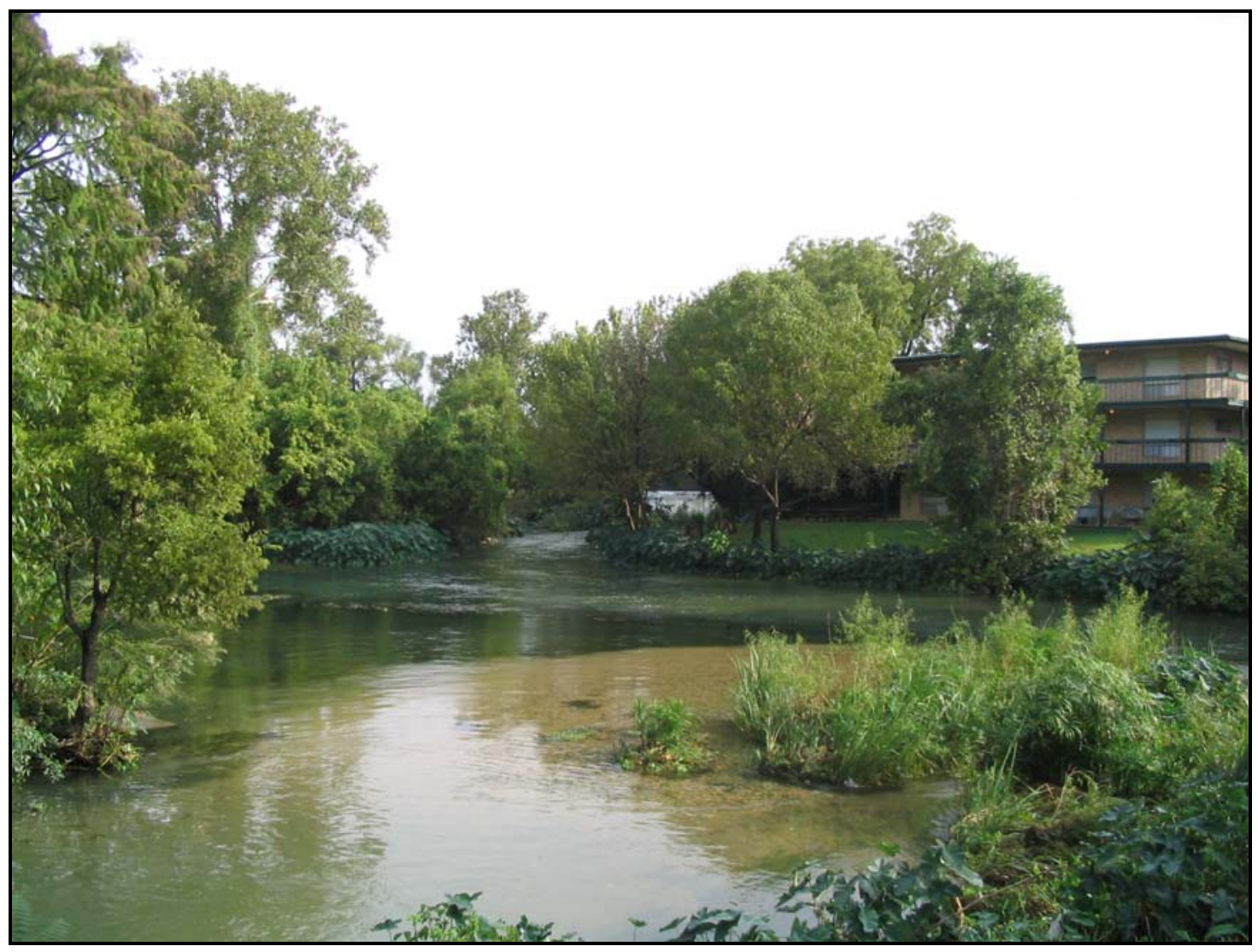

Figure 2. Confluence of Sessom Creek and the San Marcos River looking upstream towards Spring Lake Dam. 


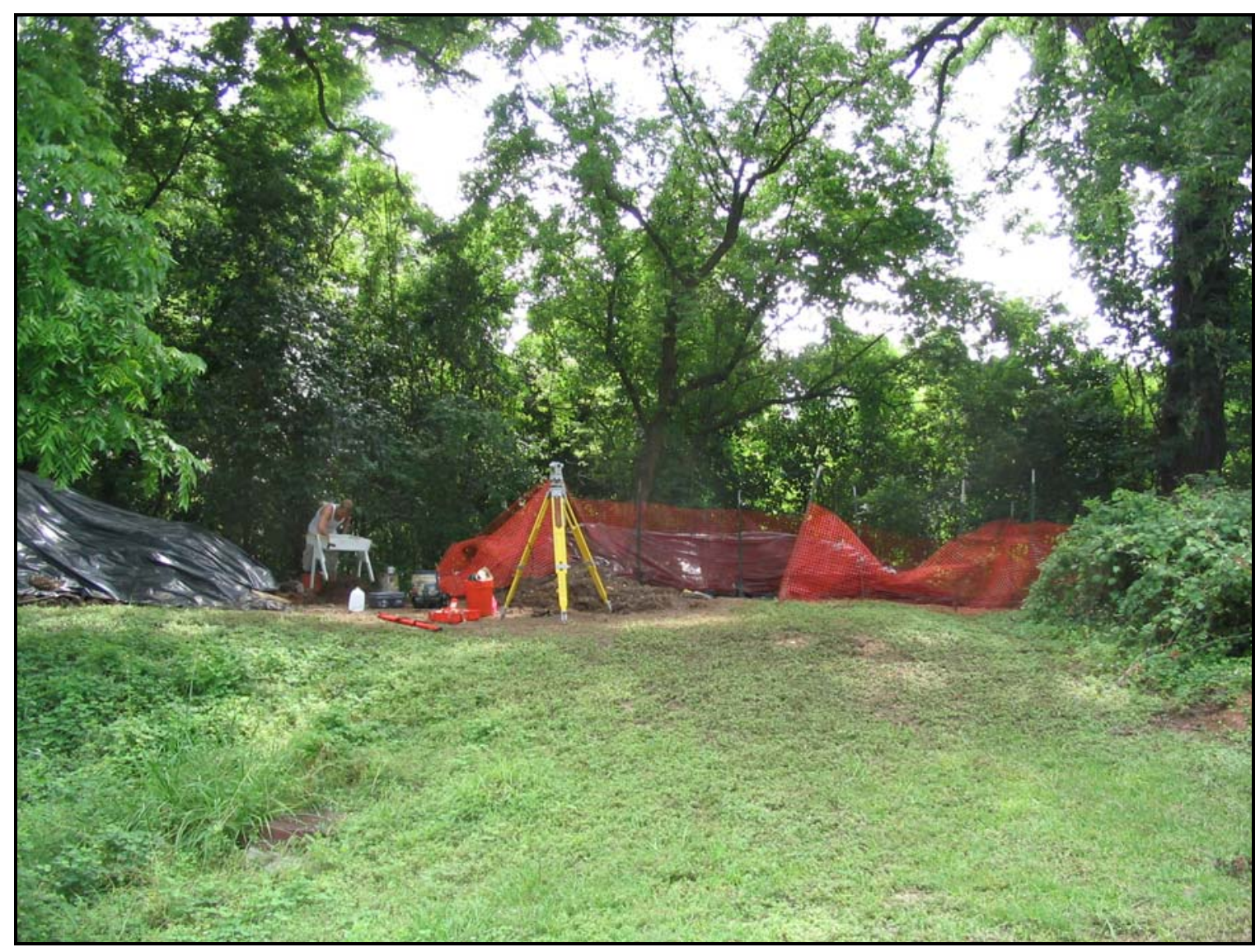

Figure 3. Photograph of the excavations at the Icehouse site 41HY161, looking north.

east of the site. Within the canyon lands along the eastern edge of the Balcones Escarpment and along the riparian corridors of streams would have been deer, nuts, and plants such as Camassia sp. that could be harvested for their bulbs. By the later Early Archaic OZ3, the decline in locally available large game may have been the result of increasing population pressures and climate changes that depleted local resources, making local small game an increasingly necessary and important resource.

The split-stemmed points in use during the Early Archaic may have developed from the Late Paleoindian points already found in the region. Split-stemmed points show increasing variation in form through the Early Archaic, even within geographic populations. This variation suggests that regionalization was increasing as the previously wide-ranging standardization in projectile point forms decreased.

There are eight chapters to this report. Chapter 1 is the Introduction. Chapter 2 is the physical environs of the Icehouse site, during the present and past. Chapter 3 discusses previous local archaeological research and the Early Archaic components in Central Texas and associated projectile point forms, and provides a chronology of the Early Archaic. Chapter 4 lays out the theoretical issues and models with which to examine the Icehouse 
site data through time at the site, and in comparison to regional Early Archaic components. Chapter 5 is the excavation and analytical methodology. Chapter 6 is the results of the geomorphological analyses and the identification of occupation zones. Chapter 7 presents the results of the excavations by Occupation Zone (OZ) and includes the lithic and faunal assemblages, starting with OZ1, the oldest. Chapter 8 is the interpretations and comparisons section where the OZs are compared to each other and then the site is compared to local Early
Archaic assemblages, and then Early Archaic assemblages throughout Central Texas. Appendix A presents the results from the Accelerator Mass Spectrometry (AMS) dating of faunal bone by Beta Analytic, Inc. Appendix B is the faunal analyses provided by Barbara Meissner. Appendix $\mathrm{C}$ contains expanded descriptions of the lithic tool assemblage. Appendix D is digital data of the artifact measurements including the lithic debitage that is too large for tabular paper format. 


\section{CHAPTER 2}

\section{REGIONAL ENVIRONMENTAL SETTING-PRESENT AND PAST CLIMATES OF THE BLACKLAND PRAIRIE AND BALCONES ESCARPMENT}

\section{Physiography}

Hays County lies within two major physiographic regions, the Edwards Plateau and the Coastal Plains (Figure 4). Four-fifths of the county is within the Edwards Plateau, and the remaining fifth, the eastern portion of the county, is within the Blackland Prairie, which forms the western edge of the Coastal Plain. Separating the Edwards plateau and the Blackland Prairie is the Balcones Escarpment (Birket 1984). The Edwards Plateau is an outcrop of the Texas Cretaceous rock system of approximately 93,320 square kilometers (Riskind and Diamond 1986).

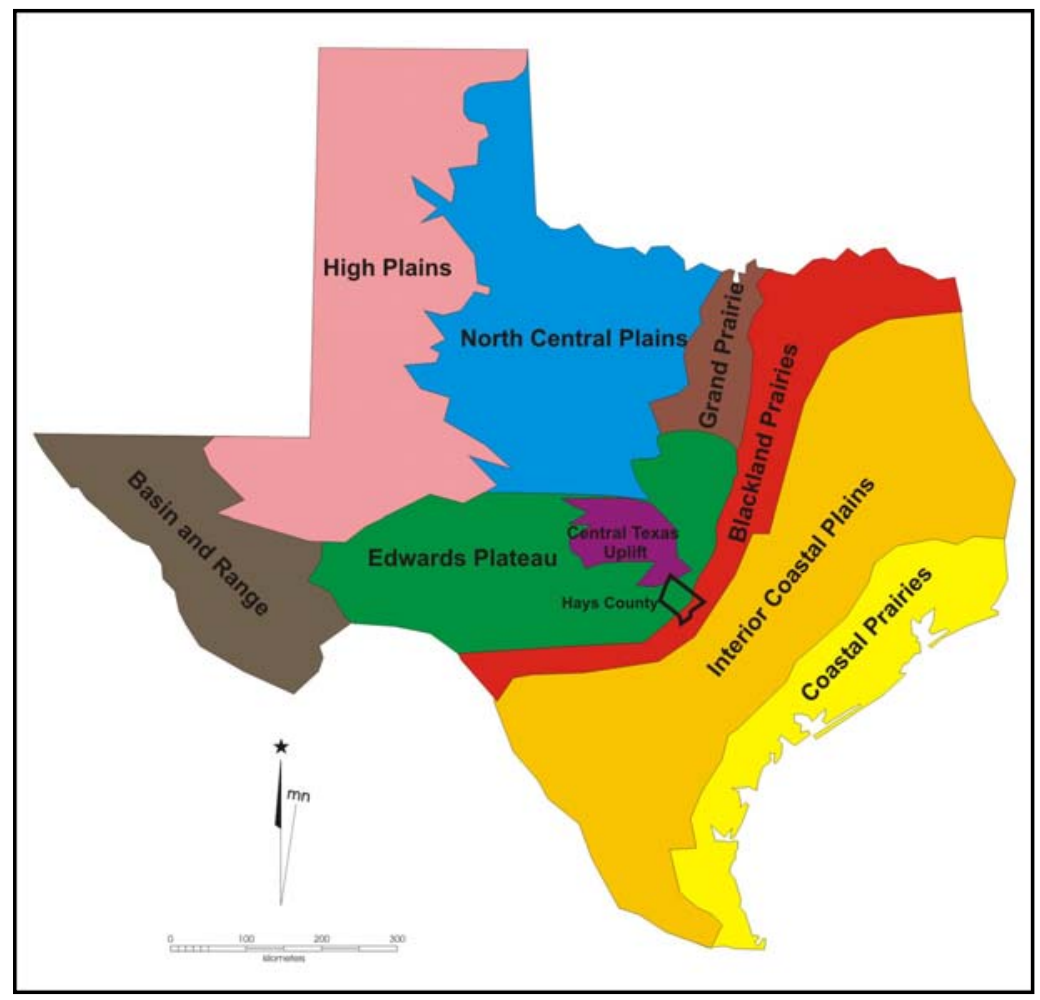

Figure 4. Natural regions of Texas and location of Hays County. Adapted from Texas Parks and Wildlife GIS Library. 


\section{The Edwards Plateau and Balcones Escarpment}

The Balcones Escarpment forms the division between the Blackland Prairie to the east and the Edwards Plateau to the west. The Balcones Escarpment is the dominant expression of the Balcones Fault Zone and is an extension of a discontinuity that originates in the Ouachita Mountains in southwest Oklahoma and extends though Texas to the Rio Grande. It is marked by a low eroded and dissected escarpment beginning east of the Pecos River near Del Rio, extending east to San Antonio, and there turning north to the Brazos River near Waco (Abbot and Woodruff 1986). The upthrusting that created the escarpment occurred during the Eocene. Along the fault lines on the western side, Lower Cretaceous limestones have been up thrust against the Upper Cretaceous limestones to the east. The western side is the stable interior formation, while the eastern

side is still subsiding Gulf Coast Basin (Abbot and Woodruff 1986). The Balcones Fault. The western side is the stable lines represent the surface of a deeply buried moving hinged section between the Interior and Gulf Basin. To the east of the Balcones Escarpment, much of the Cretaceous system is buried under more recent Tertiary deposits of the Gulf Coastal Plains.

The Edwards Plateau is north and west of the Balcones fault system. The Edwards Plateau contains numerous distinct ecological and environmental sub-regions and is a southern extension of the Great Plains (Riskind and Diamond 1986). Elevation of the Edwards Plateau increases from the south and east to the northwest. The southeastern and southern edges of the Plateau are deeply dissected through erosion that has created the Balcones Canyonlands, ostensibly part of the Edwards Plateau that is also referred to as the "Hill Country". Surface erosion is hastened by steep gradient drainages that have cut through limestone, dolomite, shale 
and marl layers of varying resistance. The numerous faults along the southeast boundary and selective dissolution of limestone layers have created a karstic recharge zone, where surface water enters underground aquifer systems and discharges as springs and seeps (Kastnig 1986; Riskind and Diamond 1986). In addition to defining the regional hydrology, several distinctive plant communities are found within the Balcones Canyonlands and defined by their topographic settings that are stream sides, floodplains, and steep slopes.

To the north and northeast of the Edwards Plateau, erosion has removed Cretaceous deposits, exposing the underlying rocks (Adkins 1990). The southeast corner is demarcated by the Llano uplift, from which Lower Cretaceous rocks have eroded exposing the underlying preCambrian and Paleozoic formations. North of the Plateau is the Pennsylvania-Permian Basin that extends to the Red River and into Oklahoma. The Callahan divide is a northern erosional remnant that marks the extent of Cretaceous deposits. The southern edge of the Llano Estacado contain Lower Cretaceous rocks, which are absent along the Canadian River (Adkins 1990). The Texas Cretaceous is part of the same system found in the Rocky Mountains and Northern Mexico.

\section{The Blackland Prairie}

The Blackland Prairie covers approximately 47,860 square kilometers within Texas (Riskind and Collins 1975; U.S. Department of Agriculture and Natural Resources Conservation Service 2003). This prairie is a funnel shaped region widest in the north near the Red River and tapering down to the south at the Nueces River. In Central Texas it forms a narrow band paralleling the Balcones Escarpment. The Blackland Prairie Region is tall grass prairie that is a

southern extension of the True Prairie of the Midwest and merges with the Coastal Prairies. Two further sub-regions of the Blackland Prairie Region are the Blackland Prairie proper and the 
Grand Prairie (Lyndon B. Johnson School of Public Affairs 1978). The Blackland Prairie subregion is a true tall grass prairie, while the Grand Prairie is a mixed grass prairie that developed over shallower soils. The Grand Prairie is located along the northern and western edge of the Blackland Prairie. Other authors do not discriminate between the divisions of the Blackland Prairie (Diamond and Smeins 1985) but all further references here refer to the region Blackland Prairie.

\section{Geology}

Overall, Cretaceous geological deposits cover 28 percent of the state, or 194,250 square kilometers. Originally, almost the whole state was covered by this system. The system was formed after the Jurassic, when inland seas retreated and much of Texas was dry land. Western North America was bordered by three advancing seas, the Pacific, Arctic and Gulf or Coloradian seas. During the Cretaceous, seas advanced from the south and east, and the record of the advance of these seas forms the Cretaceous system in Texas. During the Eagle Ford period, the Gulf sea reached Colorado and united with the south end of the Arctic sea, which continued into the Austin stage when the maximum extent of the advance occurred in the Western Interior (Adkins 1990). In Texas, the maximum thickness of the Cretaceous deposits is 15,500 feet, although no single sections of these deposits remain. The Cretaceous was the last time that seas covered large portions of the continental interior; during succeeding periods tertiary seas were along narrow strips of the continental margins.

The Blackland Prairie overlays five parallel geologic units: the Central Texas Upper Cretaceous Eagle Ford, Austin Chalk, Taylor, Navarro and Midway Group and systems. Several of these units extend to the Ouachita Mountains (Collins, et al. 1975). The chalky limestones, marls, and shales are the source for the heavy, calcareous, dark brown and black clays for which 
the region is named. East of the Blackland Prairie, the Coastal Plains formed on later Tertiary deposits (Adkins 1990; Birket 1984).

Pecan Gap Chalk formations underlay the project area and outcrop immediately east of the site. North of the project area, within 800 meters, on the Balcones Escarpment, the Edwards Limestone is overlaid in order of deposition by: Del Rio Clay and Georgetown Formation (marl), Eagle Ford Group (clay and thin siltstones) and Buda Formation (Limestone), Austin Chalk, and Pecan Gap Chalk. At this location in the Balcones Fault zone, the older deposits to the west have been up thrust above the younger Pecan Gap Chalk to the east (Abbot and Woodruff 1986). The location of the Old Main Building at Texas State University-San Marcos is a massive, monolithic, uplift fault block (Grimshaw and Woodruff 1986). Overlying the bedrock in the vicinity of the site are Quaternary gravel sequences in the San Marcos River valley (Barnes 1974). These gravels contain abundant siliceous chert nodules, some of which are suitable for lithic tool manufacturing. In addition to these gravels, chert nodules that have eroded from the local limestone deposits are also available in small tributary streambeds and as re-deposited gravels within alluvium and exposed as surface gravels on terraces in more upland settings.

\section{Soils}

The diversity of lithologic and topographic expression of the Texas Cretaceous is accounted for by the initial formation of the Cretaceous deposits, erosion, and by weathering to form soils (Adkins 1990). The $99^{\text {th }}$ meridian, when extended northwards, roughly divides the soils of the continental United States into two major groups. The western sub-humid soils are pedocals, where calcium carbonate content can exceed the concentration of the underlying geologic parent formation. The eastern humid soils are pedalfers where horizons in mature soil development contain calcium carbonate in concentration below the parent material. The Upper 
and Lower Cretaceous have different soil series. The Blackland Prairie Upper Cretaceous are Houston-Wilson soils, while the Edwards Plateau Lower Cretaceous are Denton-Valera-Ector Groups (Adkins 1990; Batte 1984; Birket 1984). Typically on the Edwards Plateau, soil development is thinner than to the east in the Blackland Prairie.

Soils on the Edwards Plateau are varied because of the differences in substrate, and topography. In the uplands, the soils have typically developed in situ over basal limestone and chalks and shaly clay. Deeper upland soils on flats and in valleys are usually Mollisols and shallower soils on slopes are Inceptisols. Clayey Vertisols are also found throughout the Plateau (Riskind and Diamond 1986). Mollisols have a dark colored, organically rich, thick, mineralized surface horizon that overlies a mineral material. Mollisols favor a grass vegetation cover. Inceptisols are mineralized soils in which minerals besides silica and carbonates have been removed from the solum, but not have become concentrated. Generally, these are well watered soils, providing moisture for more than half of the year or 90 consecutive days (Soil Science Academy of America 2005).

The soil in the San Marcos River floodplain at 41HY161 is classified as Tinn clay (Tn) (Batte 1984). Tinn clay is part of the Heiden-Houston Black soil unit. Tinn clays are found in the in flood plains of small streams along the Blackland Prairie and range in area from 10 to 200 acres. Tinn soils are frequently flooded, which results in a pronounced shrink and swell effect on the clays from repeated cycles of wetting and drying. When dry and with surface cracking, water enters quickly. The rooting depth is deep because of the ability to retain high moisture content. The soil is dense and sticky when wet and cloddy and hard when dry. The soil supports riparian plants species that provide habitat for wildlife (Riskind and Diamond 1986). 
Tinn soils are classified as fine grain, motmorillonitic (calcareous), thermic Vertic Haplaquolls (Batte 1984). Haplaquolls (Hapla is a prefix meaning simple) occur along narrow drainages in the region. They are Mollisols that have had some minerals removed or altered, do not have a duripan, nitric, calcic, or an agrillic horizon, but still retain some carbonates. Haplaquolls are frequently inundated and in some instances, they can be characteristic of wetland soils. Changes in the solum occur because of repeated inundation. The soil formed in warm subhumid conditions (thermic) and exhibits moderate to high shrink swell characteristics that include surface cracking when the soil is dry (vertic).

\section{Rainfall and Hydrology}

Rainfall in Central Texas is divided into thee regions, humid, subhumid, and semi-arid (Adkins 1990; Carr 1967). The humid region extends westward to the approximately the $99^{\text {th }}$ meridian where annual rainfall is approximately 25 inches, and the sub-humid region west of the $99^{\text {th }}$ meridian to just east of and parallel to the Pecos River where rainfall averages between 15 and 25 inches annually. West of this line is the semi-arid region. Modern San Marcos rainfall averages 33.75 inches annually (Cecil and Greene 2006)

The numerous fractures and fault lines create a major recharge zone from ground water run off that in turn is released from the numerous springs along the Escarpment margins. Ground water has a more immediate effect upon the outcrops of limestone, which has created the incised topography along the margins of the Balcones Escarpment (Riskind and Diamond 1986; Sellards, et al. 1990; Woodruff and Abbot 1986). In addition to modifying surface topography, water has created a cavernous aquifer system. The Edwards Aquifer is an artesian aquifer, formed in the karstic limestone of the Edwards Plateau (Kastnig 1986). The Edwards Aquifer 
parallels the Balcones Fault line for approximately $400 \mathrm{~km}$, from Val Verde County east to Bexar County and then north to Bell County (Woodruff and Abbot 1986). Along the southern margin of the Plateau, the Nueces, San Antonio, and Guadalupe river systems cut through the Edwards Plateau and the Balcones Escarpment. The Edwards Aquifer is recharged from the catchments basins of these drainage and the drainages are also major discharge points. Recharge of the aquifer occurs in the semi arid western portion of the Plateau, while discharge occurs in the semi-humid eastern margin of the Plateau. Later faulting along the Balcones during the Miocene Epoch caused diverted streams to carve the extensive underground galleries that became conduits for storing and transporting groundwater. The development of surface drainages and the aquifer system are intricately connected. The aquifer system transfers water from one stream system to another system through springs that emerge along the Balcones Fault zone at the edge of the Balcones Aquifer.

The Balcones Fault zone also influences the stream regimes. Upstream, drainages are in wide alluvial valleys, between which are remnant plateau interfluves. In the fault zone drainages they are deeply incised with little alluvial build up and change direction following fault lines. Remnant terraces of alluvial gravels occur at these juncture high above the current landscape (Woodruff and Abbot 1986) that suggest earlier river systems that followed different channels. The Nueces River experiences a reduction in flow output as it crosses the Balcones Fault line as water is diverted through the aquifer eastward northward, while the Guadalupe River actually increases in flow at the Balcones Fault zone due to an increased gradient.

The project area is within the Guadalupe River drainage system. The largest spring system near the project area is the San Marcos Springs, and the spring system is the second largest group in Texas and the source of the San Marcos River (Ogden, et al. 1986). There are 
approximately 200 springs that issue from bottom of Spring Lake (Brune 2002), an historic impoundment created in 1849 by Edward Burleson (Bousman, et al. 2003). The Ice House Site (41HY161) is located near the confluence of the San Marcos River and Sessom Creek. Sessom Creek is a small intermittent tributary of the San Marcos River. The confluence of the Blanco and San Marcos Rivers is approximately 4,500 meters southeast of the project area, and the San Marcos River joins the Guadalupe River near the city of Gonzales.

\section{Climate}

The climate has had a large effect on the development of the drainage systems, landforms and soils. As an agent for landscape modification, rainfall has an effect as both groundwater runoff and within the aquifer systems. In turn, the climate is modified the insolation, sunlight reaching the surface, considering the region is subtropical by its latitiude, by the Pacific Ocean, and by the Gulf of Mexico, since prevailing wind patterns are from the south and southwest, bringing moisture inland (Bomar 1985; Caran and Baker 1986; Larkin and Bomar 1983). The regional climatic division of Hays County straddles the regimes of the two principal physiographic regions, the Edwards Plateau and the Gulf Coastal Plains following the approximate boundary between humid and subhumid rainfall regimes (Adkins 1990; Larkin and Bomar 1983). The project area is along the border of the South Central and Edwards Plateau climatic divisions for Texas (Bomar 1985; Carr 1967; Larkin and Bomar 1983). The 34 inch and 32 inch isohyets (annual precipitation amount lines) intrude onto the Edwards Plateau at this location, bringing more moisture than would be expected based upon the general east to west drying trend (Carr 1967).

Variation in Texas weather is the result of the movements and interactions between five types of air masses: the maritime polar, continental polar, continental arctic, maritime tropical, 
and continental tropical (Bomar 1985; Carr 1967). Extremes in weather, from temperature to rainfall, usually occur during the spring and fall. From May through July, prevailing southerly winds have brought large amounts of Gulf Coast water vapor into the Texas interior. This moisture encounters the westerly cold air low pressure troughs of continental air masses that create conditions for precipitation and for severe weather to develop (Slade 1986). During September, dry, cold, northern and westerly winds intersect the warmer southern prevailing Gulf Coast winds, as well as intrusions from moisture laden hurricanes, some from the Pacific Ocean.

The physiography of the Balcones Escarpment contributes to rainfall and extreme episodes of precipitation, making the Balcones Escarpment the most flood prone region in Texas, with the potential for extremely-high precipitation rates during brief rain storms (Caran and Baker 1986; Slade 1986). The Balcones Escarpment has an orographic effect, with a change in elevation of up to 1,000 feet over a short distance of a few miles (Bomar 1985; Carr 1967). Warm, moisture laden air from the coast follows the gently sloping Coastal Plains until it encounters the abrupt Balcones Escarpment that forces the air to rise further and cool, thereby encouraging moisture to condense and fall as rain. Average rainfall totals decrease from east to west across the Edwards Plateau, from an average of 34 inches at the eastern edge of the Edwards Plateau along the Balcones Escarpment to approximately 14 inches along the western edge of the Edwards Plateau (Larkin and Bomar 1983). Modern rainfall averages for the San Marcos area is 34.3 inches, based upon data from 1951-1980. By climactic region, the South Central region averaged 34 inches and the Edwards Plateau averaged 23.5 inches (Bomar 1985). In the eastern Edwards Plateau, the majority of rainfall is in the spring and autumn, while in the western plateau, it is in the summer (Mace and Angle 2004). 
Within the climatic regions surrounding the project area, seasons are characterized by hot summers and mild winters (Batte 1984; Bomar 1985; Carr 1967). Summer temperatures reach in the 90s and low 100s degrees Fahrenheit. Daytime temperature variation across most of the climatic regions in Texas is less pronounced during the summer months, as is day to day variation. The average earliest freeze date is November $30^{\text {th }}$ and as early as November $11^{\text {th }}$. The last freeze of the spring averages around March $10^{\text {th }}$ and can be as late as March $26^{\text {th }}$. The average high temperature for San Marcos is 79.3 degrees. January is the coldest month with an average high temperature of 60.8 degrees, while August is the hottest month with an average temperature of 95.5 degrees Fahrenheit (Bomar 1985). For comparison, in San Angelo, on the Edwards Plateau, the yearly average is 78.4 degrees Fahrenheit. The January average is 58.7 degrees Fahrenheit, while July is the warmest month at 96.5 degrees. The average rainfall in San Angelo is 18.2 inches (Bomar 1985). The median number of frost free days in the San Marcos area (five years in 10) is 264 days, and ranges from 238 days to 290 days (Batte 1984).

Flora

Diamond, et al. (1987) divide Texas into eleven natural regions which they further divide into sub-regions (Figure 5). The project area is located at the eastern edge of the Edwards Plateau and westward edge of the Blackland Prairie. Modern and historic impacts to the Edwards Plateau and to the Blackland Prairie have substantially altered the vegetation composition of both regions (Riskind and Diamond 1986). Remnant populations of these regions still remain, providing an insight into the prehistoric plant communities (Diamond and Smeins 1985; Fowler and Dunlap 1986; Smeins and Diamond 1983). 


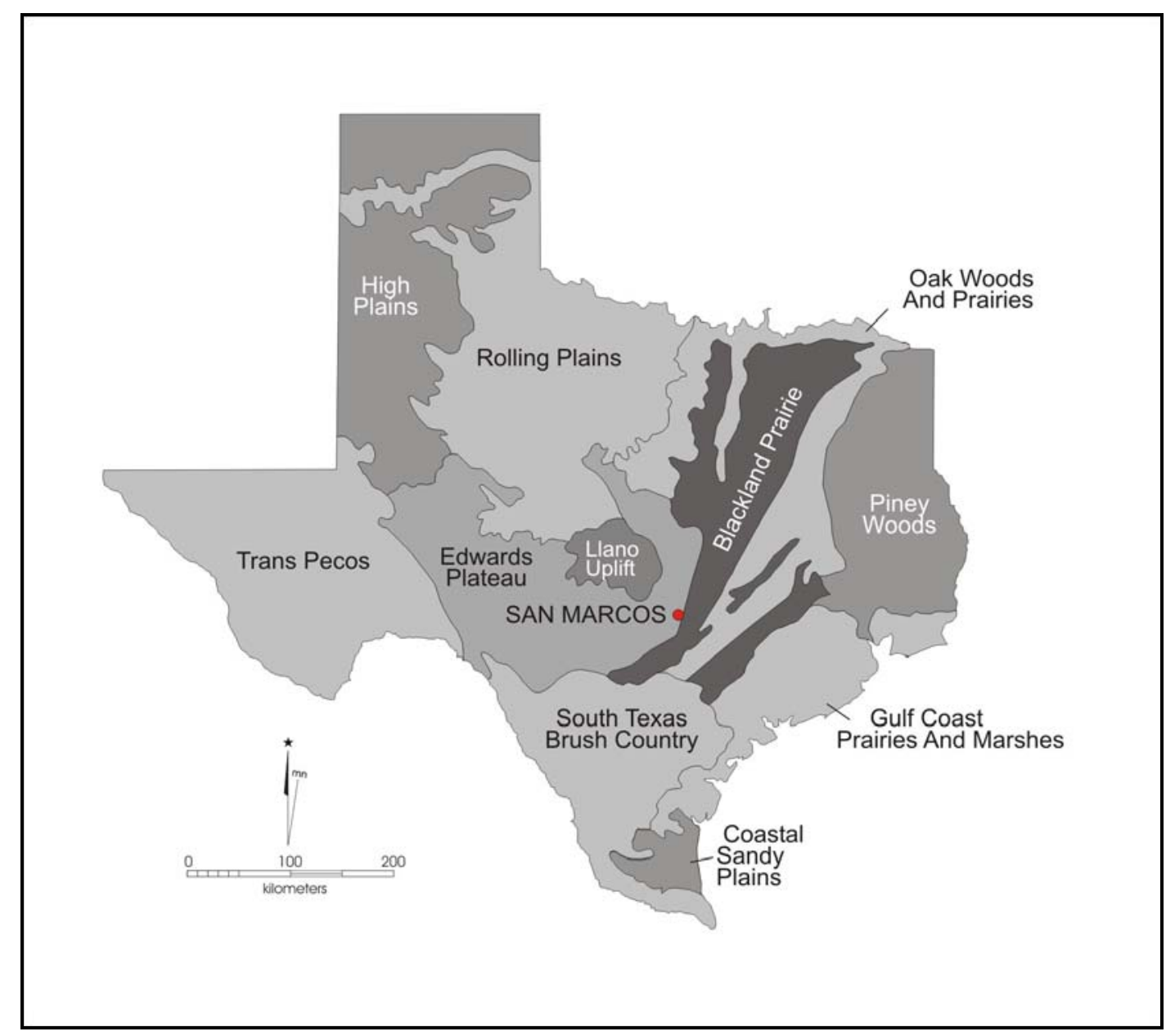

Figure 5. Texas vegetation sub-regions. Adapted from Diamond et al. 1987.

Blackland Prairie. The Blackland Prairie vegetation community is associated with a humid climate based upon soil moisture retention and rainfall and even in upland settings the Prairies resembles a lowland grassland (Collins, et al. 1975). The prehistoric maintenance of the Blackland Prairie depended upon disturbances such as wildfire, small mammals, insects, and herbivorous grazers by helping suppress shrub and tree growth, promoting species diversity, and maintaining equilibrium of the various species (Collins 1987; Gibson 1989; Kaiser 1998). Originally the Blackland Prairie was relatively open grasslands with clusters of shrubs and trees and riparian tree and shrub vegetation along the banks of dissecting streams. 
It is estimated that less than one percent of the Blackland Prairie remains $(43,000$ hectares), and most only as hay meadows (Bousman personal communication, 2008), remnant patches isolated by modern croplands and development (Riskind and Collins 1975). This amount is probably optimistically high, since the largest identifiable patch remaining is 810 hectare in Lamar County in northeast Texas. No significant tracts remain between the Colorado and San Antonio Rivers in the vicinity of the project area. This description represents the early historic condition of the Blackland Prairie, which was already in serious decline by 1900 (Dyksterhuis 1946; Strong 1938). The results of overgrazing and farming destroyed much of the original prairie, allowing invasive species such as honey mesquite (Prosopis glandulosa), sugar hackberry (Celtis laevigata), honey locust (Gleditsia triancanthos), Johnson grass (Sorghum halepense) and the Post oak Savannah to encroach.

The grasslands are composed of seven grassland plant associations (Collins, et al. 1975; Texas Parks and Wildlife Department 2005). The three plant associations closest to the project area from west to east as defined by Diamond and Smeins (1985) are the Little bluestem-Big bluestem-Indiangrass (Schizachyrium-Andropogon-Sorghastrum) association, the Little bluestem-Indiangrass-Big bluestem (Schizachyrium-Sorghastrum-Andropogon) association, and the Little bluestem-Indiangrass (Schizachyrium-Sorhastrum) association.

The riparian tree and shrub communities within the Blackland Prairie are Post Oak Woods, Forest, Grassland Mosaic, and Oak-Elm-Hackberry Parks/Woods (Riskind and Diamond 1986). The Post Oak communities are found along the sandier soils and were originally mottes or groves of Post oak (Quercus stellata) and blackjack oak (Q. marilandica). Eastern red cedar (Juniperus virginiana), mesquite (Prosopis glandulosa), yaupon (Ilex vomitoria), poison oak (Toxicodendron toxicarium), hawthorn (Crataegus sp.), black hickory (Carya texana), and cedar 
elm (Ulmus crassifolia) are some of the other overstory species found along the periphery of the Post Oak Savannah and Blackland Prairie (Frye, et al. 1984; Texas Parks and Wildlife Department 2005).

The Oak-Elm-Hackberry Parks/Woods are along the larger stream drainages such as the San Marcos and Guadalupe Rivers and contain pecan (Carya illinoinensis), American sycamore (Platanus occidentalis), sugar hackberry (Celtis laevigata), American elm (Ulmus americana), eastern cottonwood (Populis deltoids), and boxelder (Acer negundo), among other woody stemmed plants (Frye, et al. 1984; Kutac and Caran 1994). Bald Cypress is frequent along rivers south of the Colorado, while Bastard oak occurs from the Colorado north to the Brazos (Riskind and Diamond 1986).

The Edwards Plateau. The Edwards Plateau Region has been divided into three natural vegetation sub-regions because of its varied physiography: Live Oak-Mesquite Savannah, Balcones Canyonlands, and Lampasas Cut Plain (Frye, et al. 1984; Lyndon B. Johnson School of Public Affairs 1978). The Balcones Canyonlands is deeply incised and is generally the most mesic. It is characterized by forest and woodland species on slopes and bottomlands. The Lampasas Cut Plain has a flat to rolling topography and contains more grasslands with scattered junipers. The Live-Oak Mesquite Savannah is in the central and western Plateau and consists of open grasslands with trees in better watered areas as clumps or mottes (Riskind and Diamond 1986).

The Freeman Ranch is approximately eight kilometers west of the project and the edge of the Balcones Escarpment. Greater diversity in overstory species has also been noted north of the project area near Austin and along the edge of the Balcones Escarpment (Riskind and Diamond 1986). A study of the Freeman Ranch in Hays County inventoried the vegetation and identified 
five woody plant communities: Live Oak Savannah, Live Oak Woodland, Mesquite Savannah, Riparian Woodland, Juniper-Oak Forest (Baccus, et al. 2000). The study identified only six overstory species: live oak (Quercus virginiana), cedar elm (Ulmus crassifolia), hackberry (Celtis sp.), Ashe juniper (Juniperus ashei), honey mesquite (Prosopis glandulosa), and along riparian areas, Spanish oak (Quercus buckleyi). Understory was dominated by greenbrier (Smilax sp.) and Texas persimmon (Diospyros texana) in all areas except the Juniper-Oak forest, where understory included grasslands in open areas and prickly pear cactus as the dominant woody species. Along riparian habitats, north facing bluffs supported greater plant diversity because of greater available moisture (Baccus, et al. 2000).

\section{Fauna}

The use of natural or ecoregions is also applied to the distribution of fauna. The use of biotic provinces as proposed by Blair (1950) utilizes faunal distributions and it has been updated and further refined by Davis and Schmidly (Schmidly 2004). In Figure 6, both Blair's Biotic Provinces and Davis and Schmidly's faunal regions are displayed. They reduce the number of regions in Texas to four: the Trans-Pecos, Plains Country, East Texas, and the Rio Grande Plains (Davis and Schmidly 1997). The Blackland Prairie 


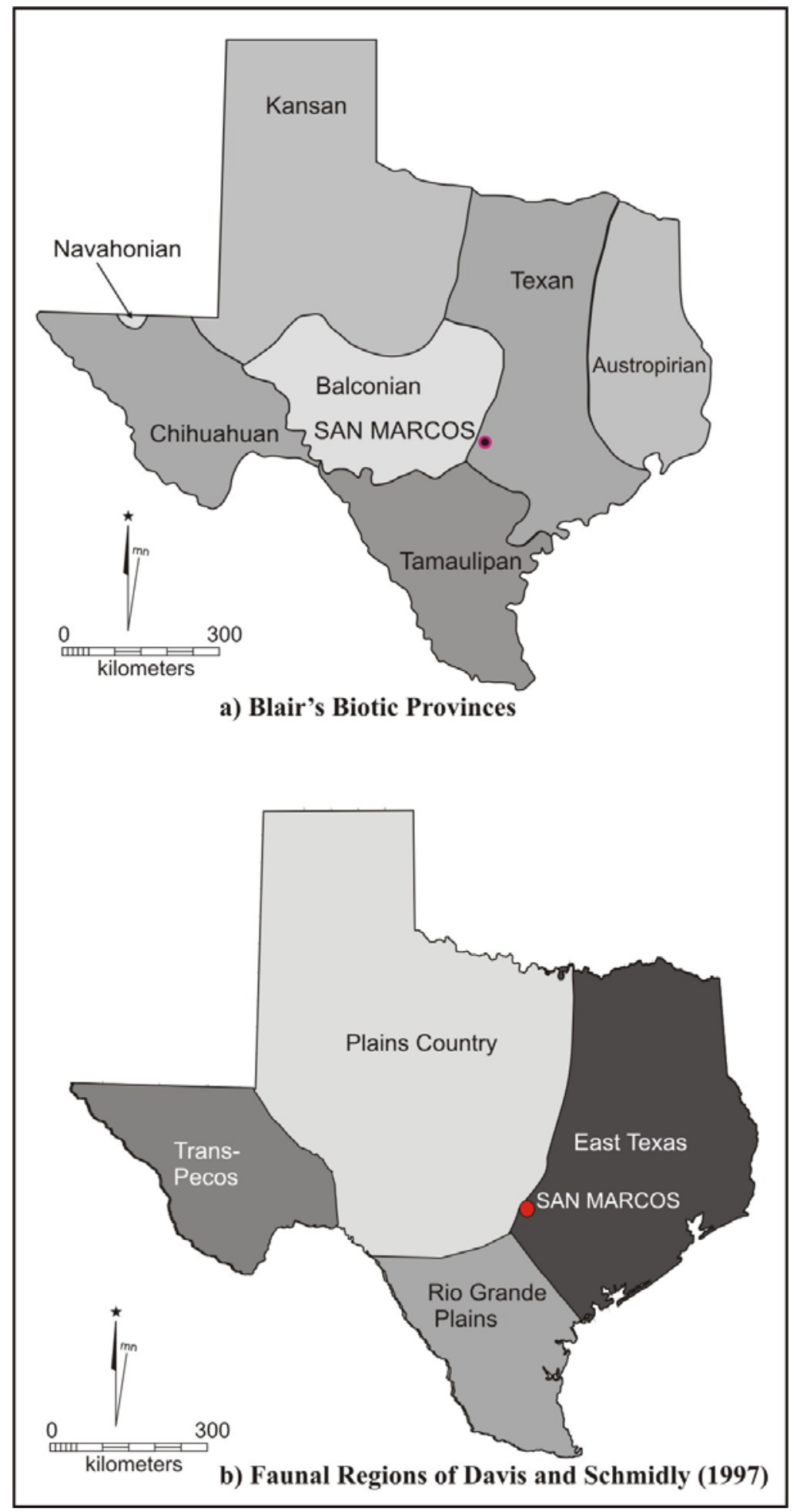

Figure 6. Biotic and Faunal Regions of Texas according to a) Blair (1950) and b) Davis and Schmidly (1997). 
is included in the East Texas region, and the Edwards Plateau is within the Plains Country. The Balcones Escarpment separates the Plains from the Rio Grande Plains and

East Texas. There are 141 species of native terrestrial mammals. The Rodentia species form the most numerous groups (68 species). Chiroptera or bats follow with (32 species), and Carnivora (28 species), and Artiodactyla (14 species) fill out the list.

There are five distinct patterns to the distribution of mammals in Texas: species that are or were endemic to the whole state; species found within a particular region; western species in the Trans-Pecos and Plains Country; western species in the Trans-Pecos, Plains, and South Plains; and eastern species east of the $100^{\text {th }}$ meridian. Species do occur outside of their designated boundaries, which makes the Balcones Escarpment region potentially rich and diverse in mammal species.

Schmidly (2004) lists twenty-five species that are or were found throughout the State. Larger species include bison (Bos bison), black bear (Ursus americanus), white-tailed deer (Odocoileus virginianus), mountain lion (Felis concolor), bobcat (Lynx rufus), coyote (Canis latrans), common gray fox (Urocyon cinereoargenteus), American beaver (Castor canadensis), common raccoon (Procyon lotor) and Virginia opossum (Didelphis virginiana). Smaller mammals include ringtail (Bassariscus astutus), long-tailed weasel (Mustela frenata), striped skunk (Mephitis mephitis), eastern cottontail (Sylvilagus floridanus), black-tailed jackrabbit (Lepus californicus), hispid cotton rat (Sigmodon hispidus), five species of bat, and four species of mice. Rodents are the most numerous species and account for the majority of regionally specific species.

Larger mammals that range or ranged in the Trans-Pecos are the wapiti or elk (Cervus elaphus) and mountain sheep (Ovis canadensis). There are no larger mammals (greater than five 
kilograms) confined to the plains region, the largest species that was extirpated is the blackfooted ferret (Mustela nigripes). The largest mammal occurring principally in the Rio Grande Plains is the ocelot (Felis paradelis), and smaller members of the feline family the margay (Felis wiedii) and jaguarondi (Felis yagouaroundi). In East Texas, the largest mammal is the river otter (Lutra canadensis). Along the western edge of the Edwards Plateau, the Plains Region and Trans-Pecos, were mule deer (Odocoileus hemionus), grizzly bear (Ursus arctos), kit fox (Vulpes velox) and porcupine (Erethizon dorsatum). In western Texas and the Rio Grande Plains, the gray wolf (Canis lupus), American badger (Taxidea taxus), collared peccary (Tayassu tajacu), and pronghorn (Antilocapra americana) were the largest mammals within the region, but also found were common hog-nosed skunks (Conepatus mesoleucus). The habitat range of all of these mammals was much wider before European settlement, and was not restricted until the close of the nineteenth century.

East of the $100^{\text {th }}$ meridian, the red wolf (Canis rufus), jaguar (Panthera onca) and common muskrat (Ondatra zibethicus) are the largest mammals. These mammals represent the largest mammals by mass in Texas. Smaller mammals, under two kilograms in mass, include four species of skunk, three species of squirrel, the black-tailed prairie dog, and four species of pocket gopher.

The diverse vegetation and environment along the Balcones Escarpment, with close proximity to both upland Edwards Plateau and the Blackland Prairie, has resulted in several examples of species paripatricy (adjacent or bordering ranges), sympatry (same geographic range) and allopatry (distinct separate ranges) (Neck 1986). Although Neck uses $n=128$ as the total terrestrial species for Texas, as based upon The Mammals of Texas (Davis 1974), the most recent publication of the Mammals of Texas (Schmidly 2004) lists 141 native species of 
mammals. Neck's analysis shows that approximately half of the mammal species occur along the Balcones Escarpment, and approximately half of these species (34) are bounded within the escarpment. Of these species, 53 percent occur only west of the escarpment, 35 percent are east of the escarpment, while 35 percent are found only along the line. Endemic species include a number of aquatic species that are found only within the spring fed streams along the escarpment such as freshwaters mussels False spike (Quincuncina mitchelli), Texas fatmucket (Lampsilis bracteata), Texas pimpleback (Quadrula petrina), and Golden orb (Quadrula aurea). These species are dependent upon flowing water and are not found in ponding areas or in temporary drainages.

In their analysis of the birds found in South Central Texas, Kutac and Caran (1994) describe a region that incorporates the south eastern edge of the Balcones Escarpment, the southern Blackland Prairie, and the eastern portion of the Edwards Plateau. As a spatial unit, the South Central Region is useful for describing the immediate environment and the resources available to inhabitants of the project area. The checklists were tabulated on a county by county basis for the counties within the defined area and illustrate the abundant and diverse animal resources in such a region. Kutac (1994) lists 349 species of birds regularly associated with the region; Toomey and Caran (1994) list eighty-two species of mammals; and Hamton (1994) lists forty-one amphibians and ninety-four reptiles. Caran and Hubbs (1994) note 130 species of fishes, that includes both historic and extinct taxa. Overall, the majority of mammals are small, from the orders of rodentia and chiroptera (bats). The overwhelming majority of the fish species are small as well.

\section{Past Climates of the Balcones Escarpment}


Paleoecology, the study of fossil organisms and the interpretation of these data depends in large degree on the principle of uniformitarianism, where identified fossil organisms are comparable to modern species and have similar environmental requirements (Roberts 1991). Paleoclimate reconstruction in Texas has centered upon geomorphic analysis, pollen and macrobotanical analysis, faunal analysis, and stable isotopic analysis.

The Last Glacial Maximum (LGM) occurred from 16,925 to 19,330 B.P. Glaciers reached their greatest extent, covering northern Europe and North America under ice up to four kilometers thick. Average temperatures were almost 20 degrees Celsius cooler and ocean levels were almost 120 meters lower world wide (Peltier 2005; Roberts 1991). The period between the Glacial Maximum at 18,000 B.P. ago and the end of the last glacial period at 10, 000 B.P. is marked by significant changes in the earth's climate, and subsequently, vegetation (Strong and Hills 2005), Vegetation and animal communities existed for which there are no modern analogues (Jackson, et al. 2000; Jackson and Williams 2004; Strong and Hills 2005). The Pleistocene climate change was not a gradual and uniform process, but occurred at different rates and intensity in different locations. An examination of glacial core samples from Greenland and the Antarctic suggest that extreme changes in climate could occur within a brief time period on the order of decades to centuries. By approximately 10,000 B.P., the shift from the Pleistocene to the post glacial warm period known as the Holocene occurred (Alley, et al. 2003; Kovanen and Easterbrook 2002; Roberts 1991).

The process of deglaciation took from eight to ten thousand years, and was punctuated with periods of glacial advance. Glacial retreat was hastened by increasing atmospheric aridity and insolation. The melting ice changed ocean and air current patterns that hindered the growth of glaciers until the period known as the Younger Dryas when glaciers returned for a period of 
approximately 1000 years from 11,000-10,000 B.P. After the end of the Younger Dryas the rapidly warming climate marked the beginning of the Holocene (Kovanen and Easterbrook 2002; Newby, et al. 2005).

The reconstruction of past climates is a complex process that is usually derived from numerous indirect and few direct sources of evidence (Caran 1998; Jackson and Williams 2004). Sources of evidence of past climates include pollen samples, soil chemical and grain size signatures from stratigraphic samples, geomorphology, faunal and flora samples, stable isotope analysis, and orbital analysis (Anderson, et al. 1988). The Cooperative Holocene Mapping Project (COHMAP) (Anderson, et al. 1988) examined oxygen isotope samples from ocean floor core samples and ice cores from Greenland to confirm that there was a periodicity to glacial periods. The observed cyclical patterning to the ice ages is the result of varying insolation from orbital patterns.

The uncertainty and sometimes conflicting climate reconstructions arises from biases present in both the data sets and in the interpretations. Frequently the available evidence has already been subjected to effects that may go undetected, and yet influence the interpretation. Caran (1998) categorizes the evidence into four orders: from direct or first order extrapolation through second, third and fourth orders of indirect extrapolation. Examples of first order or direct proxies are fossil remains of climate specific species, soils such as oxisols that form in humid tropical environments and desert varnishes that develop in dry climates. An example of second order extrapolation is carbon stable isotope values that indicate the relative abundance of cool weather species suggesting cooler and or wetter climate. Third order would be the development of calcic soils as the result of eolian sediments suggesting reduced vegetative ground cover as an indication of increasing xeric conditions. A fourth order example is the lack of certain diatoms 
that are dependent upon nutrient rich environment. The greater the order or level of abstraction, the greater the opportunity is to make an error. Accordingly, developing an accurate model of a paleoclimate requires an awareness of the problems that can arise with interpreting the data.

The underlying goal of paleoclimatic or paleoenvironmental reconstruction archaeologically is correlating changes in physical environment with cultural history, and that marked changes in the past environments are reflected in the archaeological record (Newby, et al. 2005). Ernst Antevs (1955) listed four steps for interpreting and dating what he termed the "geologic-climate", beginning with the analysis of geologic features, then the climatic interpretation of the features, the placement of a particular archaeological culture with a feature, and concluding with the uniting of climatic chronology with regional cultural chronology. Antevs estimated strata ages by association with known dates for particular phenomenon and from associated cultural deposits, since at the time of his research radiocarbon dating had not been developed. Currently, radiocarbon dating and other dating methods, combined with knowledge of stratigraphy, sedimentology, and post depositional effects, are used to assign ages to particular stratum (Butzer 1982; Waters 1992a).

Two recognized periods of climatic shifts, the Younger Dryas and the Altithermal, have been investigated for connections between the changing environment and the archaeological record (Balakrishnan, et al. 2005; Kovanen and Easterbrook 2002; Newby, et al. 2005; Shuman, et al. 2002). As previously mentioned, the Younger Dryas was a period of rapid glacial growth and advancement. From stable isotope analysis on land snails from the Folsom site in New Mexico, at approximately 10,500 B.P., the Southern High Plains was experiencing higher humidity and cooler temperatures (Balakrishnan, et al. 2005). The end of the Younger Dryas was an abrupt period of warming, and Newby et al. (2004) hypothesize that certain lithic technologies 
utilized by the Early Paleoindians such as fluted projectile points, were abandoned and that the disappearance of large fauna in the northeast United States was the reason for discontinuing the practice of fluting as regional climates became increasingly varied and subsistence patterns changed. On the Southern High Plains, large fauna, particularly bison, persisted as did the fluted Folsom points.

The Altithermal. In the American Southwest, Antevs proposed the term Altithermal in 1948 as a period in the Middle Holocene of increased temperature and aridity between 7500 to 4000 B.P. (Antevs 1955). Using varve samples from lakes and geomorphic analysis of stream channels to correlate geological events to post glacial climate regimes, Antev assumed that Europe and North America had similar climatic histories, in part based upon parallelisms in temperature fluctuations between the two continents over the last two hundred years. This correlation was thought to exist from the Pleistocene through the Holocene. Temperature was assumed to be the most significant agent for climate change. Variations in temperature in western North America would therefore be reflected in numerous proxy indicators, where a drop in temperature suggested a more mesic environment while an increase in temperature suggested a more xeric environment.

Recent analyses have demonstrated that the Holocene climate was highly variable regionally (Dean, et al. 2002; Goman and Leigh 2004; Meltzer 1999), and that the Altithermal was expressed differently between regions. Meltzer (1999) suggests that in addition to temperature increases the Middle Holocene experienced periods of increased aridity. This aridity was expressed along a north to south gradient of reduced moisture. The reduced moisture would impact both surface water features and the underlying aquifer levels, reducing the moisture 
available for animals. The Altithermal is thought to have spread the distribution of warm weather short grasses that utilized the $\mathrm{C} 4$ photosynthetic pathways.

During the middle of the Altithermal, an episode of cooler, more mesic, conditions from ca. 6000 B.P. to 5000 B.P. saw an increase in bison in Central Texas and artifacts associated with specialized bison hunting that also occur in Oklahoma, which Collins and others view as a southward intrusion of specialized plains bison hunters (Collins 1995). The actual effects from the Altithermal are debated by Johnson (1994), who did not see a significant shift in the environment at this time, however Bousman (1998) using pollen records from Central Texas discusses dramatic changes in this period.

Stable Isotopes. Paleoenvironmental studies using stable isotopes of carbon and oxygen are used to approximate the vegetation composition. Among higher plants, photosynthesis has developed into three main metabolic groupings, C3,C4 and CAM, based upon how carbon dioxide is metabolized within the plant (Ehleringer, et al. 2000; Ehleringer and Monson 1993; Osmond 1987). The photosynthetic pathways all have paleoenvironmental implications, since there are general associations between temperature, rainfall, growing season and daily light (Paruelo and Lauenroth 1996). C4 plants are usually warmer weather species that can tolerate lower levels of carbon dioxide and moisture and higher temperatures than C3 species. CAM have their own metabolic process and utilize both $\mathrm{C} 3$ and $\mathrm{C} 4$ pathways (Ehleringer and Monson 1993).

Isotopic analysis using stable carbon takes advantage of a bias in the $\mathrm{C} 3$ photosynthesis. The ratio of ${ }^{13} \mathrm{C} /{ }^{12} \mathrm{C}$ is compared against a standard. Deviation from the standard is given in parts per thousand (per mil, \%o), and in the case of most vegetation, this value is negative. C3 plants contain less ${ }^{13} \mathrm{C}$ and are more negative than $\mathrm{C} 4$ plants when compared to the standard. Average 
modern $\mathrm{C} 3$ carbon isotope ratio values (expressed as $\delta^{13} \mathrm{C}$, change in ${ }^{13} \mathrm{C}$ ) from mixed grassland prairies are $-26.7 \%$, while $\mathrm{C} 4$ families averaged $-12.9 \%$ (Ode, et al. 1980). The typical isotopic values of $\mathrm{C} 3$ plants range between -22 to $-35 \% \delta^{13} \mathrm{C}$, and $\mathrm{C} 4$ plants from -9 to $-16 \% \delta^{13} \mathrm{C}$. In North America, trees and most shrubs are C3 plants. CAM plants exhibit a value between $\mathrm{C} 3$ and C4 plants, depending upon temperature and available moisture. CAM plants are closer to C4 plants when using nocturnal respiration and under arid conditions (most CAM plants in Texas), while in periods of high moisture, CAM plants are similar to $\mathrm{C} 3$ plants.

The $\mathrm{C} 4$ photosynthesis is best adapted to grasslands with a warm growing season with summer rains, and grasslands in the tropics and subtropics are currently composed of over 90 percent C4 grasses (Archer 1984). C4 shrubs are more likely to be in arid environments. In semi arid environments, $\mathrm{C} 3$ plants dominate where there is a cool, rainy winter season, while $\mathrm{C} 4$ grasses dominate where there is a hot summer growing season (Paruelo and Lauenroth 1996). C4 plants are water efficient, and use less water to fix $\mathrm{CO} 2$ than do $\mathrm{C} 3$ plants, and utilize nitrogen more efficiently, which allows $\mathrm{C} 4$ plants to utilize nitrogen poor soils. Worldwide, C4 plants were originally low altitude plants that needed high levels of daily sunlight, the trade off for their photosynthetic metabolism.

The photosynthetic composition of grasslands in North America is dependent upon summer temperature and seasonal rainfall patterns. On a regional scale, C3 grasses favor lower temperatures and winter rainfall. $\mathrm{C} 4$ grasses dominate the southern United States, where there are higher temperatures and summer rainfall (Paruelo and Lauenroth 1996). On a local scale, topography that creates gradients of moisture, temperature, and light can create preferential C3 and C4 habitat (Archer 1984). 
Nordt et al. (1994) examined stable carbon isotope samples from three drainages at Fort Hood in Central Texas, from the same drainages analyzed by Blum et al. (1994) for geomorphology. Samples were collected from the terraces and alluvial sequence defined by Blum et al. (1994). The ratio of C3 to C4 plants was used to infer temperature and moisture in relation to modern communities. From a current base line of 65 to 70 percent $\mathrm{C} 4$ grasses, deviations from this community were categorized as cooler and wetter, warmer and drier, and when percentages were similar, transitional (Nordt, et al. 1994). Transition periods correlate with periods of channel erosion, and which is thought to be the result of increasing temperatures and decreasing moisture.

Along the Medina River in South Central Texas, a similar relationship between stable carbon isotopes was noted (Nordt, et al. 2002). Nordt et al. (2002) correlate major changes in C4 plant production to the major meltwater pulses at the end of the Pleistocene. The influx of glacial meltwaters into the Gulf of Mexico lowered surface water temperatures and decreased surface temperatures in Texas. After each pulse, C4 plant production dropped precipitously, signifying a drop in temperature. Both the Younger Dryas and the Altithermal periods appear in the $\mathrm{C} 4$ record, although the Younger Dryas is expressed as a warming period with an increase in C4 plant production rather than the cold period as it was in the Northwest. The start of the Holocene was a warming trend during which $\mathrm{C} 4$ production increased. An abrupt large cooling period occurred 8000 to 7000 B.P., a period that included the largest of the meltwater releases at 7700 B.P (Clarke, et al. 2004); however, the C4 signature indicates a two brief declines at 7000 B.P. and 6500 B.P. C4 values increase during the middle of the Altithermal between 6000 and 4500 B.P. indicating warmer and drier conditions. At 4500 B.P. C4 declines abruptly before increasing to the Late Holocene and present levels. 


\section{Pollen}

The effects from these glacial pulses vary regionally within the United States. Part of this is the preservation of proxy records and the interpretation of these records and part of it is the unknown effects of climate and the interpretation. The effect of the freshwater pulses on the climate of the continental interior has been studied from numerous locations (Yu and Wright 2001). During the Younger Dryas, paradoxically, warmer and drier conditions appeared in the Southern Great Plains, where Holliday (Holliday 2000) documented evidence of eolian dunes. The warmer air was the result of a shift in the continental wind patterns. Yu and Wright (2001) attribute the interior warming conditions to the influx of moist, warm, Caribbean air and the suppression of the Arctic air masses by the bulk of the Laurentide Ice Sheet. The continental interior between the Great Lakes and the Rocky Mountains may have experienced milder winters in comparison to today, and cooler summers. This is reflected in the non-analogous pollen assemblages in Missouri and Michigan around 13,500 B.P. that indicate forests of mixed spruce and deciduous composition: cooler summers allowed for the expansion of spruce southwards, while warmer winters preserved the native deciduous species.

In Central Texas, Bousman (1998) reexamined pollen data from Boriack and Weakly bogs. The Boriack Bog contains pollen date to approximately 16,500 B.P. while Weakly Bog documents the last 3,000 years. A deposition rate for the bog sediment has been constructed from radiocarbon assays, which was used to calculate the age of intervening strata. By comparing the percentage of arboreal to grass pollen through time, distinctive patterns emerged reinforcing paleoenvironmental findings from other regions, namely that during the terminal Pleistocene, there were vegetative communities for which there are no modern analogues. Arboreal pollen 
frequencies were used to calculate the percentage of arboreal cover, and whether the area was a forest, woodland, or grassland.

A rise in arboreal pollen is interpreted to indicate cooler and moister climate conditions and increased arboreal cover at the expense of grasslands. When the pollen assemblages were compared between the Pleistocene and the Holocene, a pattern emerged: in the Pleistocene there were oak and pine parklands, regions of thinly treed grasslands. This is in contrast to the Holocene assemblages that demonstrated no correlation between arboreal and grass pollen percentages. The arboreal pollen was also compared with the glacial meltwater record of the Mississippi and in particular to large outflows at approximately 12,000 B.P. and 9500 B.P (Bousman 1998a). The regional effect from these pulses was to alter the Gulf Coast climate, which in turn may have been agent that caused a corresponding drop in arboreal pollen percentages immediately following. The Younger Dryas is thought to have created drought-like conditions in the Southwest, based upon paleoenvironmental and archaeological indicators.

In Figure 7, arboreal pollen counts are used to show relative overstory cover. During the Early Archaic, from 8000 to 6000 B.P. there is a decrease in canopy cover and an increase in grasslands which indicates a warming, drying trend.

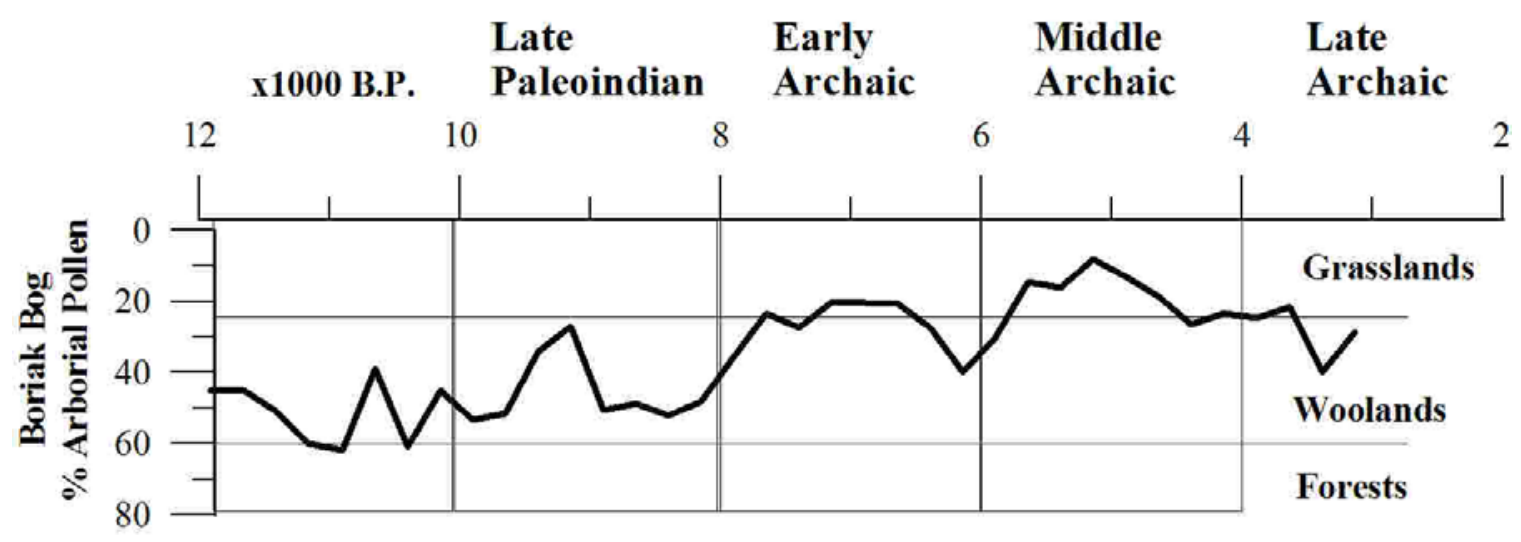

Figure 7. Change through time in arboreal pollen percentages from Boriak Bog, Central Texas with data from Bousman (1998a). 


\section{Geomorphology}

The response of fluvial networks to the environment is a source of paleoenvironmental data and an indicator of site preservation. Streams can be divided into four broad categories based upon their channel shape: straight, braided, meandering, and anastomosing (Reineck and Singh 1980; Waters 1992b). These categories can change along the course of a stream and reflect the strength of the current and its ability to carry sediments, the volume of water flowing and the gradient of the stream. Streams may begin as braided at their headwaters and become meandering as it loses energy downstream.

Straight rivers are comparatively rare, with the other categories being the overwhelmingly dominant types (Reineck and Singh 1980). Braided rivers have broad channels and consist of a complex of channels that diverge and rejoin, creating center islands, and gravel bars and sand bars. Braided streams form in areas with steep slopes with plentiful coarse sediments. The movement of the coarse alluvium frequently constricts channels creating meanders. Braided rivers have highly variable flow rates with low flows punctuated by flood episodes. Flooding creates new channels and erodes bars and islands. Braided rivers accrete both vertically and laterally. Islands and banks can be stabilized by vegetation which slow or prevent erosion. Reineck and Singh (1980) view braided streams as a category of meandering streams. Meandering rivers are contained in a single channel. They occur in areas of relatively low gradients with banks that are resistant to erosion and the fine grained sediments they transport rarely exceed their banks (Waters 1992b). Periodic flooding spreads deposits laterally across floodplains, although repeated flood episodes create a vertical sedimentary profile in addition to lateral movement. Erosion occurs with the channel along outside bends while accretion occurs in 
the form of point bars on the inside meanders. Meandering rivers can avulse, establishing a new channel across the lowest portion of floodplains. As the channel becomes filled with sediments, chutes from the main channel form, increasing the sinuosity of the river. These chutes in turn can be isolated from the main channel and form oxbow lakes. Chutes can be abandoned and reused multiple times as the flow changes. Archaeological deposits are most likely to be preserved in floodplains of meandering rivers when they are buried under successive low energy alluvial deposits.

Anastomizing rivers are networks of channels flowing around bars and islands. They differ from braided rivers in that the channels are narrow and incised and the islands are usually vegetated and stable (Waters 1992b). The floodplain contains backswamps and filled cutoff meander channels. They are usually located where there is a low gradient and are subsiding, conditions that occur in coastal settings.

Terraces are alluvial landforms in river valleys and form horizontal surfaces between the channels and the valley walls. The terraces form as the result of the lowering of the channel. The channel side is called the riser while the horizontal surface is the tread. Terraces are above the active flood plain and are inundated infrequently. Terraces are classified as either depositional or strath (erosional) depending on how they were formed and both types can occur within the same river valley (Waters 1992b).

Depositional terraces occur when alluvial deposits accumulate both vertically and laterally. The river channel incises or downcuts through the fill and below the previous floodplain, the surface of which becomes a terrace tread. Repeated cycles of deposition and erosion create a series of stepped terraces, with the upper terraces being the oldest. The terrace surface and underlying deposits are genetically related. The erosional terrace occurs where the 
tread surface is an older formation formed by lateral movement of the channel. The underlying material is not related to the formation of the surface since no deposition was involved and the tread represents an erosional surface. Archaeological sites may be found on terrace surfaces or within terrace fills. The age of the terrace can determine the approximate age of the occupation, and the chronological order of occupations between terraces.

In addition to terraces, alluvial fan deposits are another common landform. They are composed of poorly sorted coarse-to-fine sediments, and are located at the base of abrupt topographic breaks such as escarpments where stream channels grade into a more gentle gradient (Reineck and Singh 1980; Waters 1992b). Alluvial fans are frequently associated braided rivers in mountainous regions and form where there are heavy seasonal rainfalls and intermittent stream flow. The composition of the fan is dictated by the available sediment supply and the environment. Fans accumulate from flash floods, streams of sufficient strength to transport the debris rock, and stream flooding, and there is a preferential methods of formation linked to climatic and geographic regions (Reineck and Singh 1980). In humid regions, stream processes are the dominant agent, and the deposits are finer-grained and better-sorted as a result of the increased stream flow. In arid and semi arid regions, fans form from large scale wasting of local sources of lithic detritus and are more poorly-sorted as a result (Waters 1992b).

The shape of a stream section (the channel or segment), the bedding structure of alluvial strata, evidence of soil formation and pedogenesis, the composition of the strata by particle size and chemical properties, are all indicators of local and regional paleoclimate. Lee Nordt examined eight streams on Fort Hood, Texas for the purpose of devising a prediction model for detecting prehistoric and historic sites (Nordt 1992). The study identified a series of shared stratigraphic units common to the seven smaller upland drainages and a unique sequence along 
the larger Leon River. Shifts in the paleoenvironment were thought to be the principal component behind the geomorphic record. Periods of erosion, aggradation, and soil formation create different physical characteristics that appear in the geomorphic record which are used as proxies for the past climate. Soil formation occurs during periods of stability, when erosion and aggradation are in equilibrium. Episodes of erosion can remove previous soils but leave lower horizons intact (Butzer 1982). Periods of erosion are inferred to indicate decreased vegetative cover and possibly periods of excessive flooding or weather extremes. Periods of aggradation or deposition suggest more mesic conditions with possible upstream erosion to provide the alluvial material.

The five common alluviums in the Fort Hood area are: the Jackson and Georgetown alluviums, the Fort Hood Alluvium, the West Range Alluvium, and the Ford Alluvium (Nordt 1992). Three terraces were used for the upper streams, the T0, T1, and T2. The Jackson Alluvium formed the T2, the Georgetown, Fort Hood and Ford West formed the T1, and the most recent, the Ford Alluvium formed the $\mathrm{T} 0$. The ages of the stratum were determined through radiometric dating, and preference was given to actual charcoal samples. In some instances, bulk humate samples were used which creates problems for radiometric dating, since the age that is actually measured is a composite from all the organic carbon in the sample.

The Jackson Alluvium was dated to before 15,000 B.P. The Georgetown Alluvium contained the Bk horizon of a remnant soil, the Royalty paleosol that is estimated to have formed between 8000 and 9000 B.P. A charcoal date from archaeological deposits was approximately 8260 B.P. which suggests that the alluvium bulk humate dates may be as much as 1700 years older than the actual events. The Fort Hood Alluvium dates between 4800 and 8000 B.P. The West Range Alluvium was divided into two members, and deposition occurred from 
approximately 4300 B.P. to 600 A.D. The Ford Alluvium was deposited from 400 to 800 years ago. The periodic disconformities occurring around 8000 B.P., 4800 to 4300 B.P and 400 B.P. are episodes of erosion.

Strata in the Georgetown Alluvium were deposited in channels that were meandering and aggrading under low energy outfills. This suggests that rainfall patterns were different than today's, with wetter and cooler conditions (Blum, et al. 1994; Nordt, et al. 1994). Landscape stability was no longer than 800 years for the development of the Royalty Paleosol. The Fort Hood Alluvium contained no paleosols and was built through vertical accretion that limited soil formation. The larger streams were still meandering, with increased evidence of flooding, while the smaller streams were meandering and braided, which suggests periodic extreme flood events. The West Range Alluvium also does not contain identifiable paleosols. The bed load in all streams changed between 4800 B.P. and 4300 B.P. with fine grained alluvium being replaced with coarse grained and more poorly-sorted alluvium. During this time, erosion occurred in the larger stream channels, in some instances removing the early Archaic and Early Middle Archaic record. The Ford Alluvium contained evidence of large flooding episodes in the form of coarse bedded deposits, and which is characteristic of violent flash floods.

The response of Central Texas drainages along the eastern edge of the Edward's Plateau were used to construct a regional model of Quaternary climatic and environmental change (Blum, et al. 1994). Two Pleistocene terraces were identified from along the Pedernales and the upper Colorado rivers and these terraces are found on most of the other major drainages within the Edwards Plateau. The oldest is tentatively dated to 33,000 \pm 1620 B.P. based upon a single radiocarbon date and pedocalcic development. The younger terrace has a minimum age of $14,300+/-1190$ B.P. and is estimated to have been deposited between 20,000 and 14,000 years 
ago. After the formation of the younger terrace, major streams were incised into the bedrock by approximately 14,000 B.P. until 11,000 B.P. They identified three main periods of alluvial filling, an early to mid-Holocene fill from 11,000 to 5000 B.P., a late Holocene unit from 5000 to 1000 B.P. and the modern floodplain and channel from 800 B.P. to the present.

Blum, et al. (1994) synthesize the regional pollen, faunal and fluvial data to characterize the paleoclimate through time and the impact on fluvial systems. According to their analysis, the Late Pleistocene environment had deep soils and abundant grassland vegetation. Flood runoff was less severe than modern levels, flooding occurred within the stream channels, and streams did not transport large amounts of sediments. Upper tributaries supplied the fill for lower valley fills.

During the end of the Pleistocene, from 14,000 to 11,000 B.P. temperature seasonality increased, moisture decreased, and grasslands were well established on uplands (Blum, et al. 1994). Upland surfaces were stabilized under vegetative cover dominated by grasses and the source of alluvium was from the upper reaches of smaller tributary channels. The lack of alluvium in runoff allowed the channels to incise into the bedrock.

By the end of the Pleistocene and the Early Holocene, weather patterns shifted to a spring and summer rainfall pattern of heavy rainfalls. These rainfalls hastened the removal of upland sediments and removed developed soils on Pleistocene terraces. The Middle to Late Holocene was a period of low floodplain aggradation and large scale intensive flooding appears to be infrequent. By the Late Holocene, climate was characterized as dry, from 5000 to 2500 B.P. and shifting to mesic conditions from 2500 to 1000 B.P. The dry conditions from 5000 to 2500 B.P. are inferred from region wide patterns of channel abandonment and decreased flows and 
sediment transport. From 2500 to 1000 B.P. is a period of increased flooding by moderate to large floods. After 1000 B.P. drier conditions returned.

The conclusion of Blum et al. (1994) is that regional river and stream histories are conditioned by the regional environment. Different physiological regions may be affected by large scale climatic changes, but the response to these changes is determined by the physical environment. River valleys within the Edwards reflect responses to the same climatic changes while the valleys developed their own geomorphic structure. The valleys do share a common origin and similar physical setting and therefore have responded in a similar manner.

Nordt (2004) investigated the same drainage system that Blum et al. (1994) and Nordt et al. (1994) had sampled. He concluded that drainages even in the same system responded to climatic change differently and that smaller drainages may be more sensitive to environmental conditions. When Nordt compared the alluvial stratigraphy of the Fort Hood Brazos River watershed to other paleoenvironment data using pollen, stable carbon isotope, and sedimentary analysis, events were not always reflected in both Brazos River and Cowhouse Creek. Subtle variations in sediment texture and disconformities identified periods of erosion, which indicated that the geomorphology interpretation was supported by the other proxy environmental data.

Geomorphic investigations were conducted by Prewitt and Associates in preparation of development at the Aquarena Springs River Center (Goelz 1999). A total of thirty cores were excavated, revealing up to nine meters of alluvium. Two stratigraphic units were identified, Unit 1 and Unit 2. Unit 1 was from 8.7 meters to 5.5 meters below surface. A radiocarbon assay from a bulk humate sample collected in Unit 1 was dated to 11,470 +/-100 B.P. A bulk humate sample radiocarbon assay from a Unit 2 paleosol was $2660+/-50$ B.P. 
Ringstaff (2000) examined the landform evolution and site preservation at site 41HY165 for his Master's thesis, and utilized the data from Goelz (1999) and the excavation records compiled from the 1996, 1997, and 1998 Texas State University archaeological field schools. Three stratigraphic units were identified, Unit IA is Late Paleoindian and Early Archaic in age from 9500 B.P. to 6500 B.P. based upon projectile point types; Unit II is Late Archaic and Unit III contains Late Archaic through historic material. Notably absent is a Middle Archaic and late Early Archaic component dating ca. 4700 to 6400 B.P. Ringstaff attributes the missing unit to a prolonged period of erosion where there was little sedimentation to bury Middle Archaic occupations which became eroded instead.

Nordt (in prep) has conducted the most recent and extensive geomorphic analysis within the vicinity of the project area. Nordt's investigation of Spring Lake, the San Marcos River and Sink Creek is the first systematic geomorphic analysis of the Sink Creek alluvial deposits. The cores were excavated in conjunction with archaeological testing by the Texas State University in 2001 (Bousman and Nickels in prep). Analyzing samples from nineteen cores, Nordt detected five stratigraphic units, A through E. Unit A is the oldest unit and is a gravel lens from 2 to 2.5 meters thick that rests on the bedrock channel. Marsh deposits occur in some of the cores and two radiocarbon dates on plant materials indicate marsh formation occurred by $9585+/-40$ B.P. Unit B varies between cores and also indicates the presence of a marsh from depths of approximately $650 \mathrm{~cm}$ to $760 \mathrm{~cm}$ below datum. A date of $7365+/-40$ B.P. represents the end of deposition of Unit B. Unit C is a period of channel activity and channel gravels, although marsh deposits still occur, they are difficult to interpret. By 5975 +/-40 B.P. marsh deposition ceased. Unit D occurs in all cores and blankets the earlier deposits with a clayey stratum. Unit D exhibits evidence of pedogenesis, suggesting long term surface stability beginning after 5900 B.P. and 
continued to 3300 B.P or later. The surface was relatively stable, based upon the level of carbonate development. Unit E, the most recent unit, occurs in some cores as a narrow channel deposit.

The landscape evolution at the upper reaches of the San Marcos River begins with the infilling of the channel from 15,000 to 11,000 B.P (Nordt in prep.). A period of marsh deposition continued to 9500 B.P. after which channel entrenchment from 9585 to 7365 B.P. Aggradation resumed after 7365 B.P. and the marsh deposits returned. From 7365 B.P. to 5900 B.P. episodes of channel deposition and marsh formation alternated. After 5900 A.D. the fluvial regime changes drastically. Fine grained deposition closed some springs and water flow declined rapidly. The stream assumed an anastomizing channel shape, and deposition continued until 3300 B.P when downcutting resumed and created the narrow, modern Sink Creek floodplain. After 9500 B.P., the floodplain becomes unstable when downcutting occurs (Nordt in prep). The floodplain was not stabilized until 7400 B.P. From 7400 B.P. to 5900 B.P. the channel became sinuous and when flooding occurred and fine grained sediments were deposited. Sedimentation with fine grained alluvium continued until 3300 B.P., when sedimentation slowed and soil formation began. Sedimentation rates had generally been high enough to bury preceding deposits before pedogenesis could occur. The lack of paleosols was interpreted by Ringstaff (2000) to be the result of erosion; however, rapid deposition may have prevented soil formation.

\section{Summary of the Icehouse Environment}

The Icehouse site is situated in a complex and dynamic environment that offers a wide variety of resources, from water and chippable stone, and flora and fauna to its residents. Located along the edge of several physiographic regions, where vegetation and biotic regions intersect and overlap the residents where able to exploit the Blackland Prairies and Coastal Plains to the 
east, and the Canyonlands and Edwards Plateau immediately to the west. The streams along the Balcones Escarpment would act as a refugium for people, animals, and plants during periods of climatic change. Across Central Texas, the paleoenvironmental indicators offer sometimes conflicting interpretations of the Holocene climate (Collins 1995; Nordt 1992). During the Early Archaic, from ca. 8000 B.P. through 6600 B.P., there was a gradual cooling trend in Central Texas. Whether this was a substantially drier period is unknown, since some of the data, such as Nordt's 1992 study on Fort Hood showed alternating episodes of increasing and decreasing moisture during this period. 


\section{CHAPTER 3 CULTURAL HISTORY OF CENTRAL TEXAS}

\section{Previous Investigations in the Upper San Marcos River Basin}

Formal excavations at the Icehouse site and neighboring sites began in the late 1970's with Shiner's investigations at the Icehouse site (41HY161), and at the Terrace Site (41HY147) were evaluations of Spring Lake archaeology and the methodology of conducting underwater excavations. Figure 8 shows the location of these local sites. The investigations recovered Paleoindian and Archaic dart points, and the remains of extinct megafauna such as mastodon, mammoth, and bison. Based upon these investigations and artifact collections from sites at other large springs along the Balcones Escarpment, Shiner formulated the hypothesis that Paleoindian peoples along the Balcones Escarpment were semi-sedentary and congregated and settled around the springs (Shiner 1983). This position was refuted by Johnson and Holliday (Johnson and Holliday 1983), who viewed the Spring Lake assemblage as neither unique nor reflecting sedentism. They noted that larger Paleoindian artifact assemblages in the High Plains were not reflective of sedentary lifeways and it was unlikely that the Spring Lake remains were either. Johnson and Holliday were also critical of the Pleistocene faunal remains from Shiner's investigations which are primarily teeth, and therefore may only represent a few individual animals, again not necessarily reflecting a sedentary occupation. Johnson and Holliday offered an alternative interpretation; that the primary resource being procured was high quality, flakable chert from river cobbles and upland surface deposits. 
FIGURE 8. REDACTED

Figure 8. Location and relationship of the Icehouse site (41HY161) to local sites.

After Shiner's underwater excavations at 41HY161, there were numerous archaeological investigations at different areas of the site. These investigations were undertaken because of inadvertent discovery and for regulatory compliance for construction projects. The inadvertent discovery occurred in 1982 when the remains of two individuals at two separate locations were encountered during the excavation of irrigation lines and routine maintenance at the fishery ponds (Garber and Glassman 1992). Burial 1 contained insufficient remains to create an 
osteological profile, while Burial 2 was an adult woman, between 5 feet four inches and 5 feet six and a half inches in height. Further research on the remains was not conducted. The presence of mixed temporally diagnostic materials makes assigning a particular age to the burials problematic. Figure 9 is a photograph of the pond that contained the remains of Burial 1 looking northwest. The Icehouse site is located approximately 50 meters straight ahead.

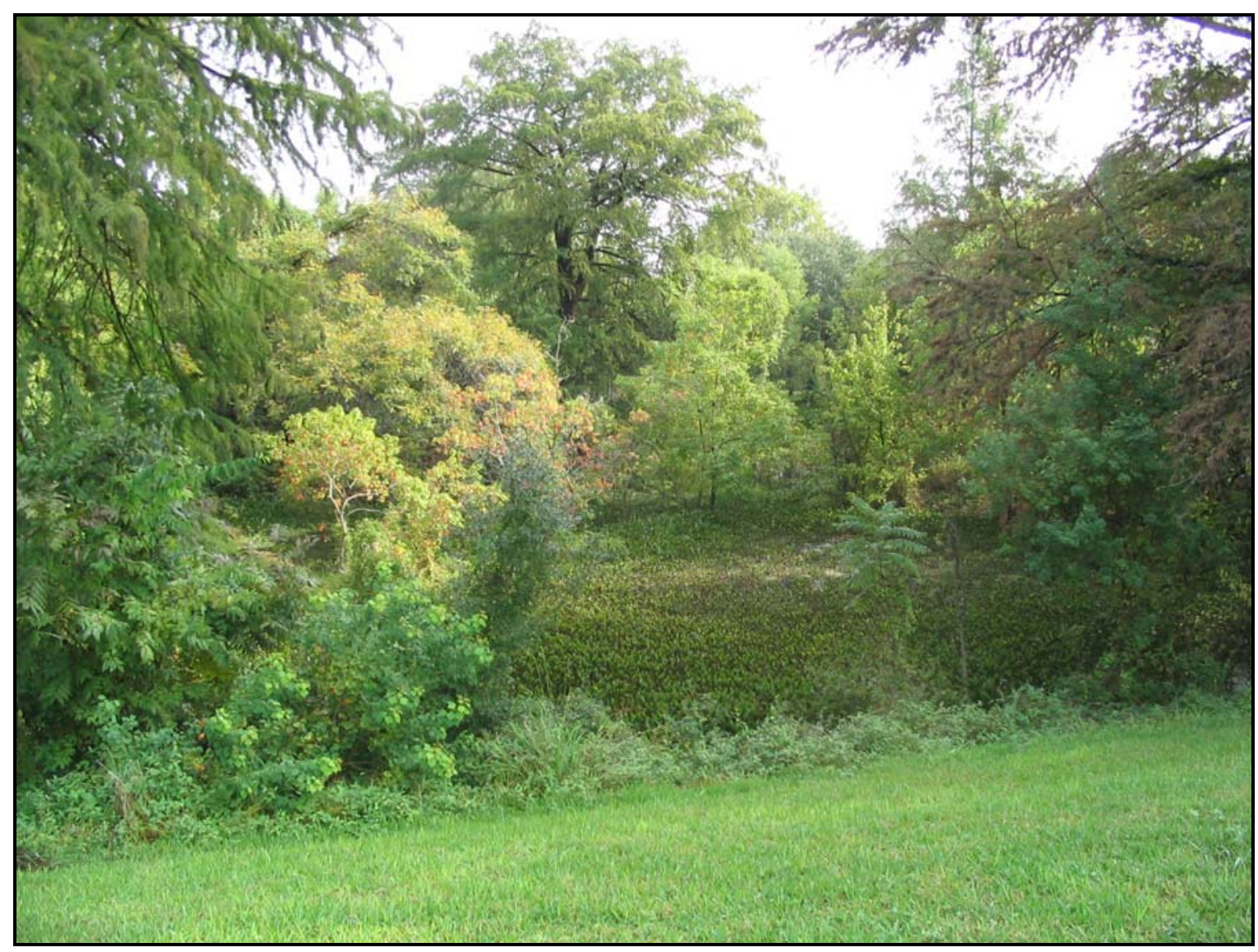

Figure 9. Fishpond where prehistoric burial was previously excavated.

The first Texas State archaeological field school was conducted at 41HY160 in the summer of 1982 (Garber, et al. 1983). The field school excavated 34 square meters up to $2.4 \mathrm{~m}$ below the ground surface. Fifty-three identifiable projectile points were recovered and these indicate that the site was occupied from the Late Paleoindian period through to the late Prehistoric. Over 35,000 pieces of lithic debitage, 473 flaked stone tools, 3 bone tools, and the 
remains of antelope, deer, and bison were recovered. Several features, including hearths and possible structure postmolds, were recorded.

The 1983 Texas State field school investigated 41HY160 and 41HY37, a multicomponent site 400 meters north of 41HY160 (Garber and Orloff 1984). 41HY37 contains abundant chert sources and may have been a primary source of raw material for tool making at 41HY160. The subsurface investigations were nine square meters in area, and were excavated to a maximum depth of $40 \mathrm{~cm}$ below the surface. Diagnostic projectile points include Pedernales and Edgewood, indicating the site was utilized during the Late Archaic period. Additional investigations at 41HY37 were conducted for the field school in 2000 on the historic remains of the Burleson homestead and a late Prehistoric component (Bousman, et al. 2003).

The field school excavations at 41HY165 in 1996, 1997 and 1998, were used by Ringstaff (2000) for a Master's thesis. The excavation data was limited to the upper strata as identified by Goelz (1999). Ringstaff identified three stratigraphic units, with Unit I being the deepest and oldest. The depth of the analysis was limited to a maximum depth of $260 \mathrm{~cm}$ below surface. Ringstaff's stratigraphic units were dated from a radiocarbon assay of 2300 +/-40 B.P. and from conservative estimates of the age of diagnostic projectile points. Unit IA is an early Holocene Bw-Bwk horizon, the A horizon thought to have been removed through erosion. Early Archaic and Late Paleoindian projectile points were used to date the strata. An estimated age for Unit IA is 6500 B.P. to 9500 B.P. Unit II, from 45 to $110 \mathrm{~cm}$ represents the Late Archaic from 1800 B.P. to 4600 B.P. based upon the carbon assay and temporally diagnostic projectile points. Unit III from the surface to $45 \mathrm{~cm}$ below surface contained Historic, Late Prehistoric and Late Archaic materials. The Late Prehistoric was determined by the presence of arrow points. Most significant is the lack of a Middle Archaic unit from 4700 B.P. to 6400 B.P. An unconformity 
between Units Ia and Unit II infers that there were spatial differences in erosion and that the northern areas of the site may have been subjected to mid-Holocene flash flooding.

The field school excavations results from the 1996 and 1997 at 41HY165, were also used for a preliminary faunal analysis by Gieske (1998). Her analysis identified changes in bison concentrations through time, with the greatest concentration occurring during the Middle Archaic. Deer-sized remains were the most common bone material and were found in every time period. Only low numbers of rabbit and fish were recovered despite the suitable local habitat, although this may be the result of taphonomic effects, rather than a reflection of subsistence patterning. Significant among the faunal remains were a bird bone bead, a shaped bone awl and a single shark tooth.

In 1997 and 1998, the Center for Archaeological Research (CAR) at University of TexasSan Antonio conducted archaeological testing at 41HY161 in 1997 at the parking lot for Joe's Crabshack, and in 1998 for a waterline. The 1997 excavations consisted of two backhoe trenches and eleven shovel tests which revealed severe disturbances from previous construction projects. Because of the disturbed nature of the deposits, the project was allowed to proceed (Ford and Lyle 1998).

In 1998 investigations, CAR excavated twenty-six shovel tests, two backhoe trenches, and three 1-x-1 meter test units, along a proposed waterline route. The units were placed in what were thought to be undisturbed areas of the site (Lyle, et al. 2000). Late Archaic, Early Archaic and Late Paleoindian dart points were recovered from the test units, as well as bifaces, unifaces, and 1310 pieces of unmodified lithic debris. Test Unit 1 (TU 1) contained three of the projectile points, with a Williams point, a Late Archaic point found directly above an Early Archaic Martindale point and the fragment of a likely Angostura point. A radiocarbon assay from a 
paleosol in Test Unit 1 that contained the Angostura point fragment was only 1060+/-70 B.P. in age. The authors concluded that the sample was contaminated with modern carbon since the soil profile exhibited carbonate development consistent with an Early Archaic or late Paleoindian age. The juxtaposition of Late Archaic in contact or immediately above Early Archaic deposits again suggests that the Middle Archaic materials have been eroded or mechanically removed by some process.

Excavations at 41HY160 were resumed in January 2001 for testing at the Texas River Center Project (Bousman and Nickels in prep). This incorporated the geomorphology study of Nordt (Nordt in prep) and the excavation of six one-by-one meter units. The excavations recovered a Middle Archaic Nolan component at the deepest levels at $170 \mathrm{~cm}$ below surface. The upper levels contained Late Archaic and Late Prehistoric components. The geomorphology testing indicates that cultural deposits extended to almost eight meters below surface.

Recent investigations at 41HY160 were conducted in 2006 for a Texas State University field school. Aery (2007) used the results of these investigations and previous field schools in 2001, 2002 and 2003 for her Master's thesis on the organization of lithic technology in the Central Texas Archaic. The deepest deposits included Early Archaic diagnostic projectile points such as Gower, Early Split-stem and Martindale at a depth below 135-140 cm. Excavations were terminated at $150 \mathrm{~cm}$ and therefore the depth of the Early Archaic deposits is unknown. The main period represented are Middle Archaic in age and is found in deposits approximately $60 \mathrm{~cm}$ in thickness. The transition between the Middle and Early archaic deposits occurs in a B2 horizon. There is some evidence of disturbance, with the inclusion of a Late Archaic point in Middle Archaic deposits. The Early Archaic assemblage includes Early Triangular as Early 
Archaic diagnostics and Andice as Middle Archaic, whereas in Collins' Central Texas Chronology (2004: Figure 3.9a), both styles are Middle Archaic.

Aery (2007) examined the amount of resharpening of dart points as a measure of tool maintenance and shows that resharpening decreased from the beginning of the Middle Archaic through the end of the Middle Archaic and the Late Archaic. Higher levels of resharpening are thought to correspond with a more forager-type mobility. A single radiocarbon date of $3550 \pm 45$ B.P. (SR-6101) was calibrated to 3833 B.P. was from Unit 6, between 70 and $80 \mathrm{~cm}$ depth and dates the end of the Middle Archaic deposits.

The Paleoindian and Early Archaic Transition

The use of subsistence and technology models in Texas archaeology has been hampered by the few comparable records, frequently poor preservation of organic materials, inequities in regions where archaeological work has occurred, and a general lack of stratigraphic integrity. Cultural and projectile point chronology in Central Texas (Figure 10), a region as defined by Prewitt (1981) is generally defined by two models, Johnson and Goode (1994) and Collins $(1995,2004)$. Both are attempts to refine the 


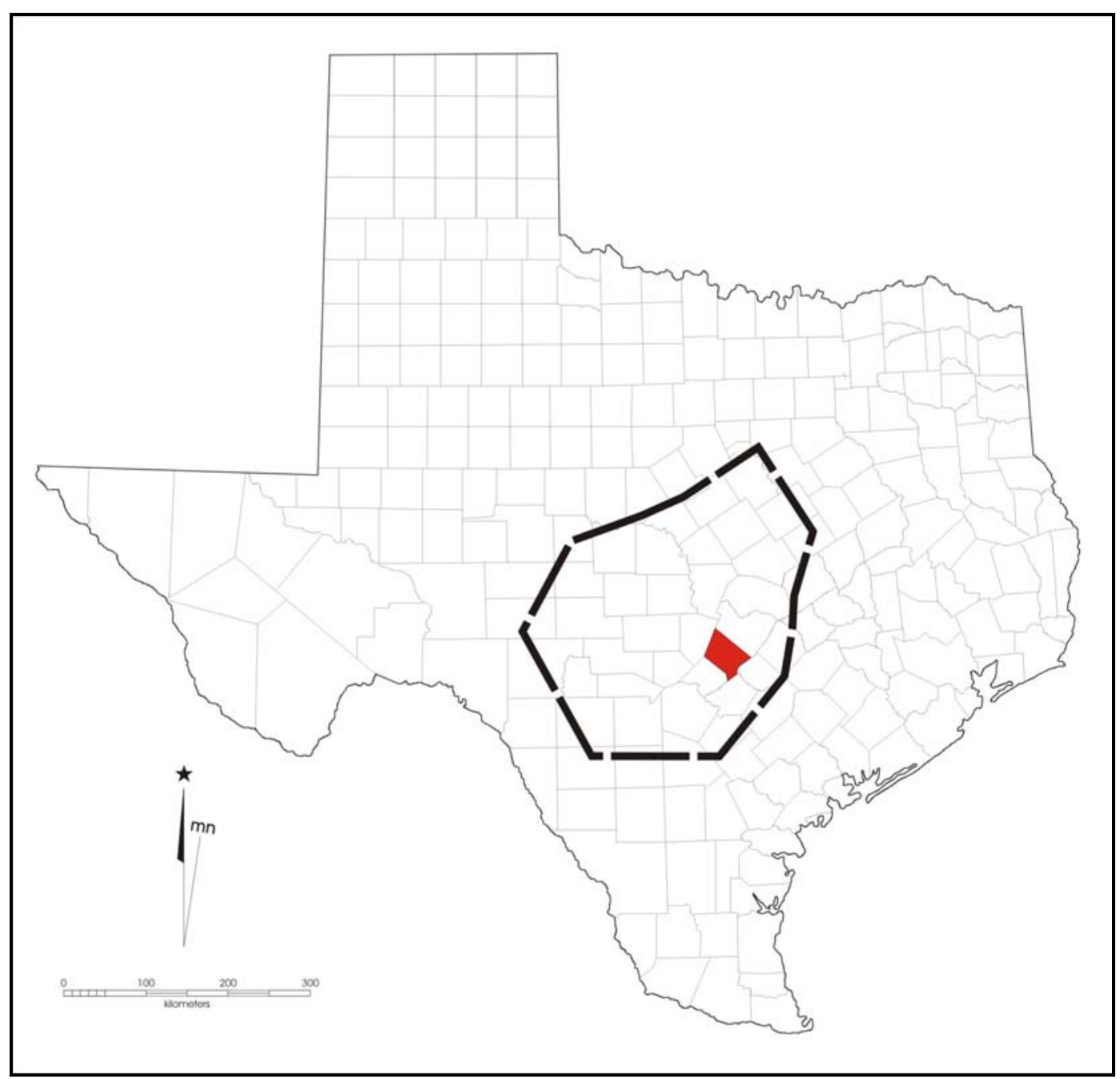

Figure 10. Central Texas Archaeological Region according to Prewitt (1981).

chronology of Prewitt (1981, 1984), which itself attempted to redefine Weir (1976) and Jelks (1962). Collins is in agreement with most of the chronological ordering with Johnson and Goode (1994), although there are differences in the number of subdivisions in the Archaic and the Late Prehistoric. Johnson and Goode, and Collins integrate paleoclimatic evidence using pollen, geomorphological, and faunal studies. Changes between periods, from Paleoindian to Archaic to the Prehistoric, should reflect distinctive changes in cultural practices and behavior in response to environmental pressure (Ford and Willey 1941; Phillips and Willey 1953). According to Collins (Collins 1995, 1998, 2004), in Central Texas the demarcation between the Late 
Paleoindian and Early Archaic is the shift to greater plant processing. This is followed by an increasingly diverse material culture. Figure 11 is a chronology for Central Texas adapted from Collins 2004: Figure 3.9a. The location of select archaeological sites in Central Texas with Early Archaic components is shown in Figure 12.

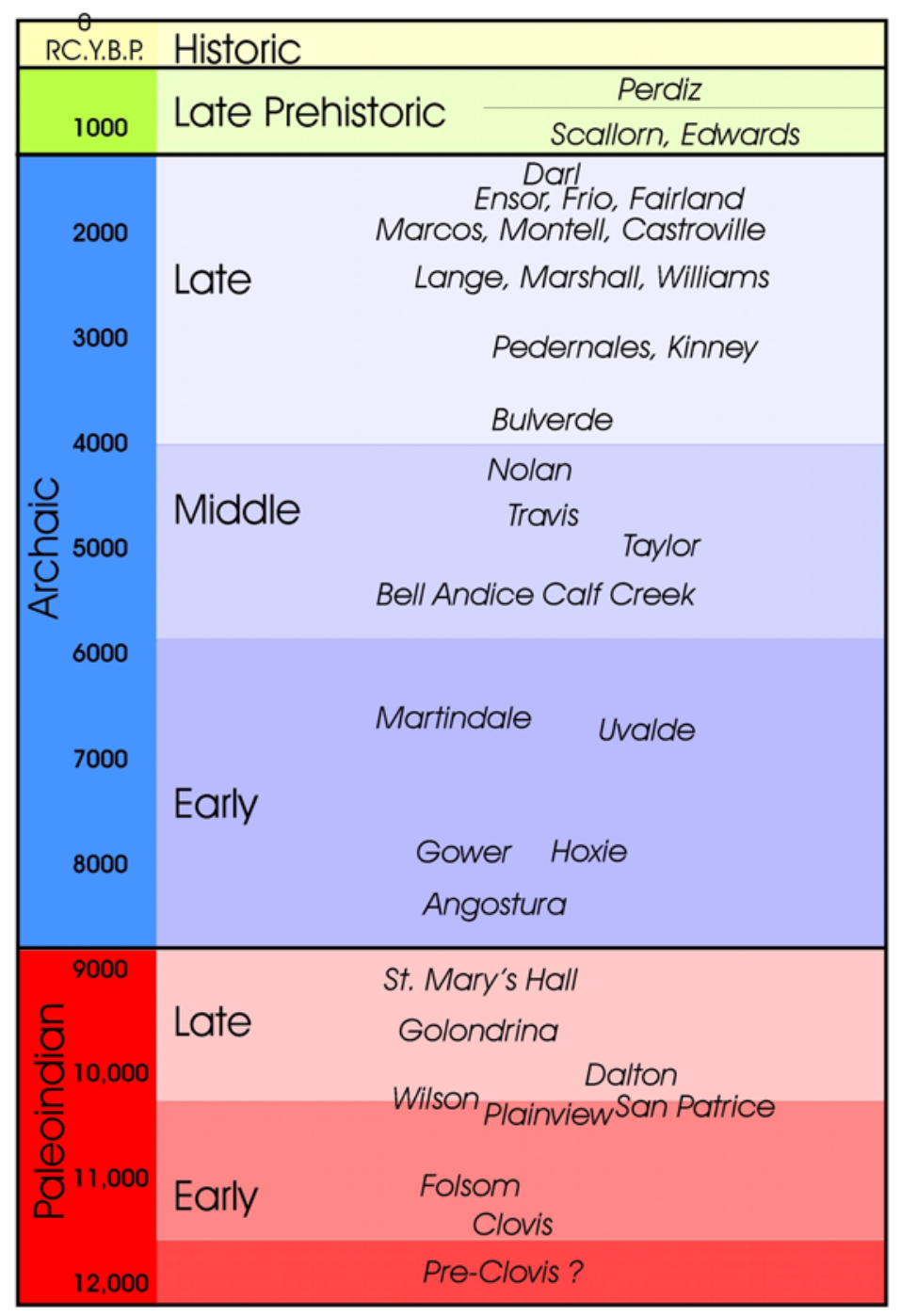

Figure 11. Cultural Chronology for Central Texas based on Collins (2004: Figure 9.3a). 


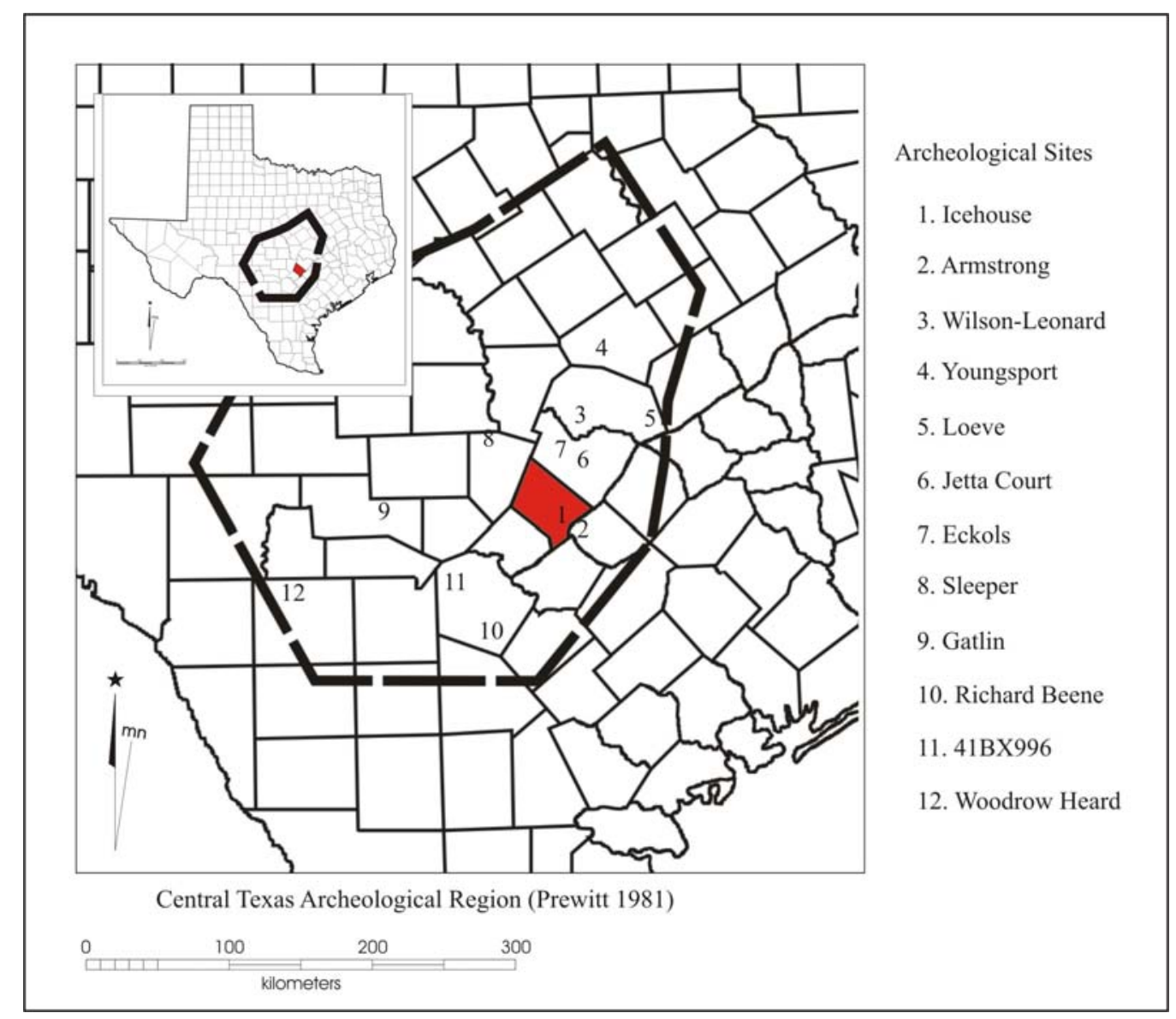

Figure 12. Selected Central Texas Early Archaic Sites.

In Eastern North America the transition from Paleoindian to Archaic was not a sharp boundary and is viewed by Meltzer and Smith (1986) as a continuum of foraging behavior with increasing diversification through time. The notion of Paleoindians as big game hunter specialists has been challenged from numerous sources from different regions of North America (Bousman, et al. 2002; Cannon and Meltzer 2004; Grayson and Meltzer 2002; Johnson 1987; Kuehn 1998; Tankersley 1998). Others (Ellis, et al. 1998) have argued that the archaeological record is insufficient to discount the big-game hunter hypothesis. Periods and regions of prey specialization are likely to have occurred, such as mammoth processing at Lubbock Lake and specialized Folsom bison hunting on the Southern High Plains, but even these sites contain a variety of taxa (Amick 1994, 1996; Johnson 1987). 
In the Great Lakes Region and Upper Midwest a generalized forager strategy in the Paleoindian period continues into the Archaic. Lithic tool diversity increases, lanceolate and notched points co-occur, and fire cracked rock appears in the assemblages, as do adzes (Kuehn 1998). This is similar to the Paleoindian-Archaic transition occupations in Central Texas such as at Wilson-Leonard, the Armstrong Site, and the more southerly Richard Beene. At WilsonLeonard, early stemmed points include Wilson, Berclair, San Patrice, and Big Sandy, with Wilson being the best defined and dated. The co-occurrence of lanceolate Golondrina, Angostura, and Thrall, with split-stemmed Hoxie and Gower points is problematic as to whether they do co-occur or are commingled because of site formation processes. There are essentially two periods for defining the start of the Early Archaic based upon projectile point typology, approximately 10,000 B.P. to 9500 B.P. or between 8500 B.P. and 8000 B.P.

The Wilson point is an Early Archaic form that appears in Central Texas around 10,000 B.P. in the Late Paleoindian period. Similar points in Texas are found primarily in the southern half of the state (Bousman 1998b). If the criteria for the Early Archaic are the use of stemmed points, a diverse subsistence base, a variety of lithic tools, and the practice of burial rituals, then the Wilson component qualifies as an Archaic occupation. Wilson points occur 500 years before similar looking forms from Eastern North America such as Palmer-Kirk points. The Early Archaic in the Southeast begins at 10,000 B.P. with the start of the Holocene and ends with the start of the Altithermal at 8000 B.P (Anderson and Hanson 1988). Early Archaic projectile points include both Dalton and Dalton side-notched, Taylor-Bohlen side-notched, and Palmer-Kirk corner-notched. Technological analyses revealed that accompanying tools included tools for processing plant and animal. Following the Wilson component (after 9530 B.P.), Bousman (1998b; Bousman, et al. 2002) extends the Late Paleoindian period at Wilson-Leonard to 
approximately 8000 B.P., and includes the lanceolate Angostura and Thrall points, based upon the age of Unit II from 9500 B.P. to 8000 B.P.

Although lanceolate points such as Angostura and Thrall are viewed as a remnant Paleoindian technology, and Collins (1995) and Collins et al. (1998) place them in the Early Archaic because they perceive a clear break in subsistence patterns from the Late Paleoindian period. The change in subsistence, namely the use of earth ovens to bake geophytes, is Collin's predominant criterion for defining the beginning of the Archaic in Central Texas. Collins et al. (1998) use 8800 B.P. as the beginning of the Archaic in Central Texas. The start date of 8800 B.P. for the Archaic marks the appearance of large plant processing features at several sites in Central Texas such as Richard Beene (Thoms 2005), and 41BX996 (Black, et al. 1998). At Wilson-Leonard, this date is derived from the age of the contact between Stratum II and Stratum IIIa and the oldest radiocarbon assay indicating use of a large burned rock basin (Stafford 1998). The oldest radiocarbon age from Feature 245, a large burned rock basin, in Unit IIIa is 8420 +/200 B.P. (CAMS-10206), while an average of three ages from sample CH-1311 $(8870+/-70)$ from the upper portion of Stratum II provided a maximum age (Collins, et al. 1998; Stafford 1998). The sample CAMS-10206 is one of three assays from Feature 245. Stafford (1998) counts two earlier dates of $8130+/-60$ B.P. (CAMS-10197) and $8110+/-70$ B.P. (CAMS-10194) as separate events or one event because there is no overlap at one sigma between them and CAMS10206.

Early Archaic dates from Richard Beene that are similar in age to Wilson-Leonard are from Feature 106 (Beta 80687; 8640 +/-60 B.P.) and a charcoal sample from Block T in a nonfeature context (Beta 47527 8805+/-75 B.P.) (Mason 2003; Thoms 1993; Thoms, et al. 1996). At the Loeve site in Williamson County, Feature 59 from Stratum III-1 dates to 8500 +/- 130 B.P. ( 
Tx-1675) (Prewitt 1981) and is overlapped with Feature 66. Feature 59 is a large basin hearth with burned limestone almost two meters in length and Feature 66 is 1.5 meters in length. Two Angostura-like projectile points were recovered from the same stratum; however, a range of other dates obtained from other Feature 59 samples and features in the same stratum range from $6810+/-300$ B.P. $($ Tx-802) to $9650+/-910$ B.P. (Tx-3405) in age.

At 41BX996 a radiocarbon assay on a charcoal sample from Stratum 26 was dated to 8550 +/-50 B.P. (Beta 80064). Stratum 26 was a large accumulation of burned rock measuring three meters in length and 80 centimeters in width. A second radiocarbon date of $8620+/-90$ B.P. (Beta 80065) was obtained from S32, a one meter by two meter area of burned rock and sediment. No projectile points were recovered in association with these features, although a single bifacial drill appears to be a reworked Angostura point (Black, et al. 1998).

Lanceolate and split-stemmed points are frequently found together in Central Texas and some researchers argue that they are contemporaneous (Collins, et al. 1998; Schroeder 2002); however, this may be the result of site formation processes rather than temporal affiliation. Whether these stemmed points evolved from the lanceolate shaped points such as Angostura is not known, although there are similarities in the manufacturing technology and in regional occurrence (Goode 2002; Kerr and Dial 1998). The increasing variety of points beginning in the Early Archaic has numerous implications: 1) they are distinct types representative of different cultural groups; 2) they are variations of a type along a design or style continuum that represents a single group or is shared between by one or more groups; or 3) they represent stages in the life history of a range of similar projectile points.

The Early Archaic Location of Split-Stemmed points 
The eastern edge of the Edwards Plateau and the Balcones Canyonlands and the margins of the Blackland Prairie have been recognized as containing the greatest concentration of Early Archaic Sites, particularly those identified by split-stemmed points such as Gower and Hoxie and other split-stemmed variants (Johnson 1991; McKinney 1981; Prewitt 1995; Story 1985). Although the region has also been one of the most investigated, the temporal placing of these points has been problematic because of the lack of isolatable and identifiable components and suitable preservation. The type sites for Gower, the Youngsport site (Shafer 1963), and Hoxie, the Loeve and Loeve-Fox and Tombstone Bluff sites (Prewitt 1981). All of the sites are in Williamson County; Youngsport is along the Lampasas River and Loeve, Loeve-Fox and Tombstone Bluff sites are along the San Gabriel River. There are no radiocarbon dates from Youngsport and no radiocarbon dates on comparable Early Archaic deposits from Loeve, LoeveFox and Tombstone Bluff. All of these sites were disturbed by site formation processes that were not initially recognized.

Three sites containing stratified deposits with radiocarbon dates associated with cultural activity from the Early Archaic period in Central Texas are the Wilson-Leonard site in Williamson County, the Richard Beene site in Bexar County and the Armstrong site in Caldwell County. Arguably, Richard Beene is claimed to contain the more discrete stratigraphy, however Wilson-Leonard has the greatest number of radiocarbon dates from charcoal. Other sites that contain large numbers of split-stemmed points are the Varga site (Quigg, et al. 2007) in Edwards County and the Woodrow Heard site (Decker, et al. 2000). The Early Archaic Component at the Woodrow Heard site appears to have a discrete Early Archaic component, while the Early Archaic component at the Varga site appears to be compressed and mixed. The Varga site splitstemmed points included Baker, Bandy, Martindale, and Gower. At the Woodrow Heard site 
(Decker, et al. 2000), the split stem med points included Baker, and Uvalde, with Martindale being the most numerous.

The most detailed morphological study conducted on Early Split Stemmed points was by Kerr and Dial (1998). Split stemmed points include Hoxie, Gower, Uvalde, Jetta, Baker, Bandy, and the more distinctive Martindale. Rather than clarifying the confusion surrounding the numerous names for these points, they noted similarities between groups, creating hybrid identifications such as Hoxie/Gower and Gower/Uvalde. The Baker point is viewed as a Pecos region variant as is Early Corner notched and perhaps Uvalde. The types are defined primarily on stem characteristics because of the extensive modifications done to the blades. Bases are generally expanding, with Hoxie points being slightly contracting. The contracting stem of the Hoxie point is similar in design to Angostura points.

The Early Archaic at Wilson-Leonard is divided into three grouping of projectile points. In chronological order as best defined they are lanceolate and early split- stemmed, early splitstemmed such as Gower and Jetta, followed by and Martindale-Uvalde and other split-stemmed points with little or no edge grinding. Collins et al. (1998) view edge smoothing and grinding on stems as a remnant Paleoindian trait.

Following the last of the Central Texas lanceolate point forms Thrall and Angostura, the split-stemmed point is a significant change in form or style with greater regional diversity then the previous forms. During the beginning of the Early Archaic, split stemmed points have been noted throughout the Central and High Plains, from North Texas (Prikryl 1990) to Wyoming (Frison 1978), and do these points represent a change in technology such as method of hafting and in some instances, style? Did they develop from indigenous styles and technology already 
present in Central Texas? The tradition of lanceolate points with indented bases includes Golondrina, St. Mary's Hall, and variants of Angostura, including Thrall.

Gower. Gower points were provisionally named at the Youngsport site in Bell County (Shafer 1963). The Youngsport Site is located at the eastern edge of the Balcones Canyonlands along a spring fed creek near its confluence with the Lampasas River. Shafer's excavations from 1960-1962 recovered projectile points that were all dart points and included Late Archaic Ensor, Montell, Marcos, Castroville, Williams, and Bulverde dart points, Middle Archaic Travis and Nolan points, and an Early Archaic Wells point. The fourteen Gower and Gower-like points appear in the deepest stratum, Stratum 8, from which a Clear Fork gouge was also recovered. The point and its variants are said to resemble poorly made Pedernales points. The defining characteristics are a crudely indented base, usually by the removal of a single flake from one side, parallel sides along the stem, although variants may have slightly expanding bases, and weak shoulders. The blade is generally triangular and slightly convex. Only one of the specimens appears to have ground edges (Shafer 1963 figure 7j). Overall thickness ranges from $5 \mathrm{~mm}$ to 10 $\mathrm{mm}$. The length and the shape and profile of the blade are the result of reworking.

A similar assemblage was collected from the Granite Beach site in Llano County (Crawford 1965). The Granite Beach Site is located in Lake Buchanan, created by damming the Colorado River. The site is near a spring fed tributary. A total of 51 burned rock scatter features were recorded on the surface and this density of features has been noted at other Early Archaic Central Texas sites, notably around present day San Antonio and Bexar County, at Richard Beene (Thoms 2005) and along upper Leon Creek (Tennis 1996). The fourteen specimens had varying degrees of basal concavity and several of the specimens were lightly ground along their stems. There is a similarity in the Granite Beach site assemblage among the overall shape of the 
blade on the complete specimens, particularly the angle of the lateral margins. They appear to have been discarded when the overall length decreased and changed the angle of the point. Figure $4 \mathrm{~g}$ (Crawford 1965) is a variant similar in base stem appearance to Hoxie/Gower variants at Wilson Leonard (Kerr and Dial 1998). The surface context of the site does not permit any chronological refinement for Gower points. The points vary in size and depth of basal concavity, and differ by stem sides, which are either straight sided or slightly expanding. The lateral edges of the blades were beveled on twelve of the fourteen specimens. The overall high number of projectile points, many of them extensively re-sharpened or broken, versus other lithic flake tools suggest that refurbishing and refit of hunting tools may be the principle activity at the site. No direct association between the dart points and the features could be determined, or with which group of dart points they were affiliated.

One of the largest assemblages of Gower points from a single site was from the Gatlin site, 41KR621, in Kerr County, where 34 specimens were recovered from Early Archaic and mixed Early and Middle Archaic components, with dates from 6600-6100 B.P. and 6100-4500 B.P. (Oksanen, et al. 2007)

Hoxie. Hoxie points were named by Prewitt (1981) during excavations at the Loeve-Fox, Loeve, and Tombstone Bluff sites. Hoxie points and Uvalde points were found on the surface. The points were assigned to Prewitt's Circleville Phase, Archaic Stage. The artifact assemblage was substantially different than the Loeve Site, in that the Tombstone Bluff site is described by Prewitt as a specialized hunting and lithic workshop in contrast to the Loeve Site which appears to be a campsite were numerous activities occurred requiring the use of hot rock features and unlined hearths. Similarities between Hoxie and Gower points have been noted by Kerr and Dial (1998) with the Wilson Leonard assemblage and in their statistical analysis of lanceolate and 
bifurcate stem projectile points. At the Armstrong Site, Goode (2002) noticed similar traits between Angostura and Hoxie and Hoxie and Gower. In addition he noted the continuum of other tool types from the Late Paleoindian assemblage and the Early Archaic. Thoms (1993) views the different bifurcate base Early Archaic projectile points as stages in use life. At Wilson Leonard they were found in both Late Paleoindian/Early Archaic and Early Archaic strata. This is similar to the Armstrong site, where the Hoxie appearing in Late Paleoindian and Archaic strata.

Jetta. Jetta Court in Travis County contained two Gower-like specimens, (Wesolowsky, et al. 1976). These were from the Zone A, the deepest zone with the Lower Midden deposits. The points have expanding stems and the shoulders are well rounded; however, the base of specimen Figure $11 \mathrm{f}$ is more of a Martindale type base indentation. Specimen 11e is an atypical Gower, lacking the removal of a single flake, and would likely be classified as an Expanding Stem point. An unidentified point from Jetta Court is illustrated in Wesolowsky, et al. (1976, Figure 15 e). This point has a deeply indented base and a slightly expanding stem. The base indentation most closely resembles the "Jetta" type point. The Jetta is one of two point styles that were distinctly different when cluster and discriminant function analysis were performed by Kerr and Dial (1998) on a sample of split-stemmed points, the Jetta were noticeably larger than the other points.

Uvalde. A Uvalde point was described by Suhm, Krieger, and Jelks (Suhm and Jelks 1962) as having an expanding stem with a U-shaped basal concavity like a Pedernales point. The point is viewed as a minor Central Texas point similar to Martindale and Frio. Although Frio are considerably younger, Collins (1995) and Decker et al. (2002) note the similarities between the types, and Decker et al. (2002) view Martindale and Uvalde as coeval, placing them together in 
Early Archaic III (6500 B.P.-4500 B.P. ). Collins (1995) placed Martindale-Uvalde at the end of the Early Archaic in his Central Texas synthesis. Martindale have a characteristic notched base that creates re-curved basal ears. Uvalde points have a deeply notched U shaper base and rounded basal ears that accentuate the narrowed distal stem. Kerr and Dial (1998) note lateral edge grinding of stems on some specimens, while Decker et al. (2000) do not include ground edges in their classification. Uvalde is seen as a regional variation, like Baker and Bandy points, which are more common along the Lower Pecos, and are part of a group of similar points with indented and expanding bases (Kerr and Dial 1998).

The projectile point assemblage from the Sleeper site (41BL65) in Blanco County (Johnson 1991) was almost exclusively Uvalde points, although as other researchers have noted (Decker et al. 2000), they could be classified as Gower points. The Sleeper site is significant because of its extensive feature assemblage of what Johnson terms baking pits, and a large number of ground stone implements, including manos and metates. Like most of these Early Archaic sites, the Sleeper site was not dated, and therefore the span of the occupations is unknown. From the extent of the features and processing tools when compared to the other Early Archaic sites, the Sleeper site is likely a rare specialized site.

Martindale. Martindale and varieties such as Bandy are the terminal points for the Early Archaic, although in South Texas, Early Triangular is included with the Early Archaic (Hester 1995, 2004). The end of the Early Archaic occurs with the appearance of Calf Creek, Bell and Andice points and unstemmed points such as Early Triangular (Collins 2004; Johnson and Goode 1994). Part of the discrepancy between South and Central Texas is that there is no significant break in subsistence practices with the appearance of unstemmed points (Hester 1995). Collins (2004:Fig 3.9a) uses an approximate date of 6,000 B.P. for the end of the Early 
Archaic, based on the appearance of Bell and Andice points and the increased numbers of bison to the region. However, although the date of 6,000 B.P. is widely used, there are no radiocarbon dates from the Landslide site, used as a representative site by Collins (2004). The date of Bell like points from the Texas coast are more likely 6,000 cal B.P., using the results from Ricklis (2004: Table 5.1) at 41NU221 Results from the Gatlin site 41KR621 in Kerr County suggests that Martindale points may have persisted until ca. 5200 B.P. (Houk, et al. 2007). Overall there appears to have been a climatic change towards the end of the Early Archaic that briefly attracted larger quantities of bison to Central Texas.

\section{The End of the Early Archaic}

Although, by convention, a date of 6,000 B.P. is used or the end of the Early Archaic, the end of the Early Archaic is more poorly dated than the beginning. Several point types associated with the Early Archaic in Central Texas, such as Martindale points may have persisted into what has been termed the Middle Archaic. The Early Archaic point types such as Martindale and Bandy were found in sufficient numbers and in relative context at the Gatlin site to suggest extending the Early Archaic by at least several hundred years or more to perhaps 5,500 to 5,200 B.P. Certain trends in extending the Early Archaic such as Decker et al. (2000) proposed extension to 4,500 B.P. is not radically different. However, because this end period is still underdocumented for radiocarbon dates in association with projectile points the end date for the Early Archaic varies regionally cannot be firmly established. By convention, and following Collins (2004) the date of the Early and Middle Archaic transition is set to 6,000 B.P. This date is used as a guide with the awareness that the actual date occurred at least several hundred years later. None of the preserved and relatively intact Early Archaic deposits at the Icehouse site are known to have been deposited at the terminal age of the Early Archaic. 


\section{CHAPTER 4 RESEARCH DESIGN AND GOALS}

The research goals for the investigations at the Icehouse site include the organization of technology, residential mobility and subsistence of the Early Archaic inhabitants. Organization of technology is a system of artifacts, behavior and culture applied to the physical world (i.e., Andrefsky 1998; Kelly 1995; Odell 2001; Shott 1989). Residential mobility incorporates the organization and composition of social groups and their movements through the landscape.

Subsistence includes the acquisition and processing of food resources and associated strategies. While these research areas appear to be independent avenues of research, all are linked in varying degrees, and there is much debate over how these spheres interact whether or not one is dominant, or if all significant factors. How a group moves across the landscape and what kinds of resources (including foods) are available can influence how technology is organized (e.g. Bettinger and Baumhoff 1982; Binford 1978, 1980, 2001).

By the Early and Middle Holocene transition in Texas, the apparent development of territories is expressed by spatial and temporal distribution of artifacts and projectile points in particular (Prewitt 1995). Whether makers of a particular style or range of projectile points represent a distinct ethnic group is unknown; however, the regional development of particular stone working traditions does suggest that some form of group identity is contained in the design of projectile points. 
Models of Residential Mobility, Subsistence, and Organization of Technology

The Icehouse site is situated in the ecotone between the Interior and Coastal Plains and along side an abundant source of permanent water. The inhabitants at the site had access to the resources of the Edwards Plateau such as chert, available as surface deposits and in stream channels, white tail deer and smaller game animals, cactus tuna, sotol, mast crops from pecan trees along the larger waterways, and other wild plants such as berries and grasses. At other sites on the Edwards Plateau such as the Sleeper Site (41BC65) in Blanco County, the presence of ground stone tools suggest that plant processing was becoming increasingly important during the Early Archaic (Johnson 1991). The nearby Blackland Prairies also contained game such as bison (at varying times), antelope, white tail deer, migratory birds, small mammals, and plant resources such as Camassia sp. In both regions aquatic resources such as fish, turtles, and fresh water mussels were available. The immediate area around the Icehouse site contained another raw material used by Early Archaic peoples, wood. Stone tool assemblages containing a variety of bifacial and unifacial tools with use-wear consistent with woodworking have been recovered from other sites such as Wilson-Leonard and Armstrong.

A pattern emerges from examining the projectile point distribution data of the two splitstemmed point styles, Hoxie and Gower (Prewitt 1995). According to Collins (1995) Hoxie points are older than Gower points, and Prewitt's data indicates Hoxie are identified throughout the Central Texas Region and concentrations trend towards eastern portions of the region and to the northeast along the edge of the Balcones Escarpment. Gower points are found throughout Central Texas; however, they are also found in the southern and western portions of the region. These points are found together in deposits at several Central Texas sites including WilsonLeonard and the Armstrong Site, suggesting they may have become coeval. The increasing 
diversity in projectile points has been used as an indicator for the development of territories, with the assumption that projectile points represent a particular cultural group in the continental southeast (Anderson and Hanson 1988), the Great Basin (Bettinger and Baumhoff 1982), Central Texas (Johnson 1991; Prewitt 1995) and the Kalahari in Southern Africa (Wiessner 1983).

Models of Residential Mobility. An archaeological site is a static record of a dynamic system that results from the complex interaction between behavioral and natural factors (Binford 1980; Schiffer 1983). For Binford, this is part of Middle Range Theory, the explanation of the static record to the behavioral processes that created the record. If the distribution of sites across a landscape and the patterning of artifacts within a site are to be interpreted for their behavioral and cultural significance, then a model of site creation has to be developed. Binford argues that the best model is within the ethnographic record and that only by observing patterns of site use can any link be made to interpreting the archaeological record. By analyzing the settlement practices and methods of acquiring resources of historical and modern hunter gatherer groups, Binford (1980) created two main categories, Foragers and Collectors. The greatest determining factor as to whether groups are organized as Foragers or Collectors is the regional environment. Binford uses a formula to calculate a value, Effective Temperature, for a given region. Effective Temperature is an environmental measure of the length of the growing season, seasonality, and differences in annual temperature fluctuations. The highest ET values are generally along the equatorial regions, while lower ET values occur in increasingly temperate regions. Seasonality is at its greatest between the polar and equatorial extremes (Binford 1980; 2001). Foragers are most frequent in environments where there is relative uniformity in climate and homogenous concentrations of resources or patches are distributed across the landscape. Collectors tend to be 
found in environments with greater seasonal differences and with greater disparity in the distribution and concentration of resources (Binford 1980, 2001).

Foragers gather food daily, hunt on an encounter basis, and rarely create surplus. Residential moves occur when the local resources are exhausted. Group size fluctuates based upon the available resources in a given patch and seasonally groups may disperse or congregate based upon resource availability. Binford (1980) identifies two types of sites that the Forager creates predominantly, the residential base site and the "location" site. The residential base is from where foraging groups emerge and return. At these sites all activities related to habitation occur such as food preparation, cooking, sleeping, tool manufacture and maintenance. The length of time a habitation site is used is determined by the size of the group and the distribution of resource patches in the landscape. Sites may be repeatedly occupied if they are associated with a stable resource such as a permanent water source (i.e. tethered nomadism).

Collectors are organized around the acquisition of "specific resources through specially organized task groups" (Binford 1980). The locations of base camps are frequently situated to exploit a particular resource. The heterogeneous distribution of critical resources necessitates the formation of task groups to procure essential resources. The task groups' movements are targeted to specific resources, which are ultimately returned to residential base camp. In addition to base camps and location sites, Collectors create field camps, station and caches. The field camp is the base for specialized task groups away from the residential camps, the station is where a resource is procured and processed, and the cache is where surplus resources are stored for further use. The size and complexity of these sites is dependent on the types of resources being procured and the size of the Collector party. The amount of resources processed is 
intended for a larger number of people than the immediate party and large scale or bulk processing may occur at the sites.

In the Great Basin region, Bettinger and Baumhoff (1982) use the terms Travelers and Processors that are approximately analogous to Forager and Collectors. The difference between their scheme and Binford's is their emphasis on group variation between subsistence patterns and how time is allocated to particular activities. Bettinger and Baumhoff examine the replacement of the Prenumic inhabitants of the Great Basin by the Numic speakers. The Prenumic were identified as Travelers and the Numic as Processors. Travelers targeted relatively high ranked resources, both animal and plant, expending their energy moving to exploit them. Processors utilized both high and lower ranked animal and plant resources, investing more time and energy in exploiting lower ranked localized resources through such methods as bulk processing. In a given environment, as resources become depleted, Processors have an advantage over Travelers since they already are accustomed to utilizing lower rank resources. Travelers are in areas with low population densities with sources of big game animals and plants. In areas with increasing population, when access to higher ranked resources becomes restricted, Processors become the predominant subsistence model, either through adaptation by the Travelers or replacement by Processors moving into new territory.

The Prenumic Travelers are compared by Bettinger and Baumhoff (1982) with the Early and Middle Archaic of the East and Midwest which are characterized by the procurement of large animals, sometimes acquired over great distances, the use of higher rank plant foods and the neglect towards small plant resources. In Central Texas, by their definition, Early Archaic groups appear to be increasingly Processor based, which continues into the Middle Archaic. The appearance of Calf Creek and specialized bison hunting during the Middle Archaic were 
episodes that favored Traveler strategies. In general, through time groups should move towards a Processor subsistence strategy as mobility decreases.

Robert Kelly's (1995) analysis of the !Kung San foraging lifestyle identified the mode of production as being "a system of subsistence based upon the hunting of wild game and the gathering of wild plant foods as well as the procuring of fish and shellfish. The foraging mode of production is dependent upon nature, and the forager groups operate within the parameters defined by the natural environment. Kelly defined five characteristic features of their modes of production; mobility to acquire sufficient foods, group size is set by the environment, groups must be flexible to adjust to seasonal variation in resources, high mobility limits the retention of material wealth, and access to resources is governed by elaborate rules between various groups (Kelly 1995). The family or household is the basic unit of production with labor divided between men, women, and children.

The technology of hunter gatherer groups should therefore reflect the characteristic features of hunter gatherer groups. Kelly's study (1995) revealed that the !Kung San consumed most food resources within 48 hours. Encampments were frequently moved to the location of large kills. Limited overnight forays are included in Binford's Forager model. Other San groups have been known to cure food for transport back to base camps, as documented by Laurence Bartram in the Eastern Kalahari (Bartram 1993). The site debris created by both types of activities should be distinctive. More bone elements should be at the kill sites and fewer elements at base camps when cured meat is returned. This also has implications for skeletal and food utility indices (Binford 1978b; Marean and Cleghorn 2003; Metcalfe and Jones 1988).

Binford acknowledges that using the ethnographic record to interpret the archaeological record is not a straight correlation (Binford 1978a), and that most group subsistence practices are 
along a continuum between foraging and collecting strategies. Complicating a purely functionalist interpretation of prehistoric behavior are cultural conditioning and group history, where groups are not necessarily acting as the most efficient or optimal hunter gatherers (Binford 2001).

Ian Hodder (1992) in particular disputes much of the cultural-environmental modeling or determinism of Binford and Schiffer, that environmental change is the driving adaptive force of cultural change. His criticism with processualism and functionalism and materialism is that they use an apriori argument and that the ethnographic record dictates the material archaeological record. Hodder argues that the interpretation of the archaeological record involves reconstructing prehistoric ideas and thought to explain adaptive responses. Ethnographic data demonstrates that symbolic and cultural ideologies have a significant impact upon the cultural record in daily life for example in how space was used, which artifacts were used for particular tasks, and the division of labor. Groups and individuals can utilize beliefs and interact with symbols differently and that variations may occur because of contextual differences due to environment and outside social influences (Hodder 1992). By using the contemporary symbols and ideologies the archaeological can be interpreted as opposed to predicted. The archaeological record is created by the manifestation of cultural concepts in social and ecological actions that is particular to a given context. Hodder (1992:29) uses the term "contextual archaeology" to describe the process of organizing symbolic and structural principals into "coherent sets and integrated into social and ecological strategies"

According to Hodder (1992), the symbolic and material context is always in flux, and is influenced by the historical context and it is the historical context influences how a particular group responds to social and environmental conditions. And although Hodder assails the 
processualist methods of ethnographic analogy, his contextual method replies upon a similar belief in ethnographic models, that symbolic meanings and insights can be projected into the past.

It is assumed that the inhabitants at the Icehouse Site were highly mobile people. Historical accounts indicate that during the summer and fall, the nearby San Marcos Springs were frequented by bison hunting groups whose permanent settlements were outside of Central Texas (Foster 1995). To determine the subsistence practices of the Icehouse site people, several models will be used to examine the lithic and faunal assemblages.

Bettinger and Baumhoff (1982), and Kelly (1995) envision environmental factors as the greatest determinant in subsistence practices. Their models incorporate aspects of Optimal Foraging Theory. In Optimal Foraging Theory, there are three main components: choice, units of energy, and limitations (Kaplan and Hill 1992). The forager makes choices such as diet breadth, patch choice, when to leave a patch, and movement between patches to maximize caloric intake during a given time period. Diet breadth is the number of food types consumed while patches are areas containing a resource or resources. Each variable can be further subdivided into various factors, such as risk aversion and proneness as a part of diet breadth. Optimal Foraging was originally used for ecological and environmental models (MacArthur and Pianka 1966; Pyke 1984; Smith 1978). Aspects of Optimal Foraging Theory can be used to address hunter gather subsistence and behavior and as a result, technology, mobility, and aspects of culture such as gender roles (Jochim 1988).

Bettinger has noted that Binford has criticized the idea of a cross-cultural consistent approach to foraging, and has suggested that subsistence practices are largely the result of cultural practices (Bettinger 1987, 1978b). Bettinger (1987) also noted that many of the middle 
range theorists, especially Binford use optimal foraging in their own analyses, such as Binford's ranking of butchering elements by their caloric return, and how it is related to Nunamiut group mobility, hunting success, and site formation (Binford 1978a). Binford does examine diverse cultural groups with the intent of creating standardized formulas and models in Constructing Frames of Reference (2001), where he incorporates Optimal Foraging Theory into numerous questions and hypotheses.

Subsistence: Diet Breadth and Patch Choice Models. The Diet Breadth and Patch Choice models were developed to test the hypothesis that feeding patterns of predatory animals can be explained as an evolutionary adaptation (Pyke, et al. 1977; Smith and Winterhalder 1992; Smith 1978). MacArthur and Pianka (1966) incorporated population biology and economics to examine the optimal foraging strategy of animals, where the greatest caloric intake is achieved in the least amount of time and caloric expenditure. In Diet Breadth models, the variables are time expended searching, time spent in pursuit and the number of species of prey. As additional resources are added to the diet of a consumer, the amount of time required to find a preferred food is lowered. As foods are added to the diet, they are increasingly lower in overall caloric return and higher in pursuit time. Foods are added to the diet until the energy costs, as reflected in pursuit time, exceeds their return (MacArthur and Pianka 1966; Stenseth 1981; Winterhalder 1983). When a forager encounters a resource that is slightly lower ranked than the one being sought, the forager is faced with a choice. The abundance of a resource has no bearing whether it is included in the diet, which is dependent on the availability of higher resources. Resources are not removed from the diet as abundance decreases.

In a Patch Choice model MacArthur and Pianka (1966) examine foraging returns within a homogenous environment where resources are distributed in equal abundance and they examine 
patchy environments, or habitats, where resources are unequally distributed within and between patches. The patches contain a variety of resources, with each patch similar to a food species in the Diet Breadth model. The pursuit time is the travel time to another patch. Patches contain varying amounts of energy which takes varying times to extract and are added to the foraging itinerary as resource availability fluctuates. In a landscape, the more intensive use of closer patches, those with the least travel time, suggests diminishing resources. In the diagram (Figure 13), delta $\mathrm{T}$ is the change in travel time to hunting areas and delta $\mathrm{H}$ is the change in time spent hunting for each area that is added. The optimal travel and time spent hunting is 3 , marked by the arrow. In this instance three hunting areas are the optimal, with the lowest travel time spent getting to these areas and the least hunting time expended.

A Central Place Foraging model includes diet, patch choice, foraging within patches, and travel from patches and a central location as inseparable factors (Pyke 1984). Central Place Foraging is incorporated into both Binford's and Bettinger and Baumhoff subsistence models (Bettinger 1991; Bettinger and Baumhoff 1982; Binford 1980). Patches vary in quality and distance from a central location such as a camp. 


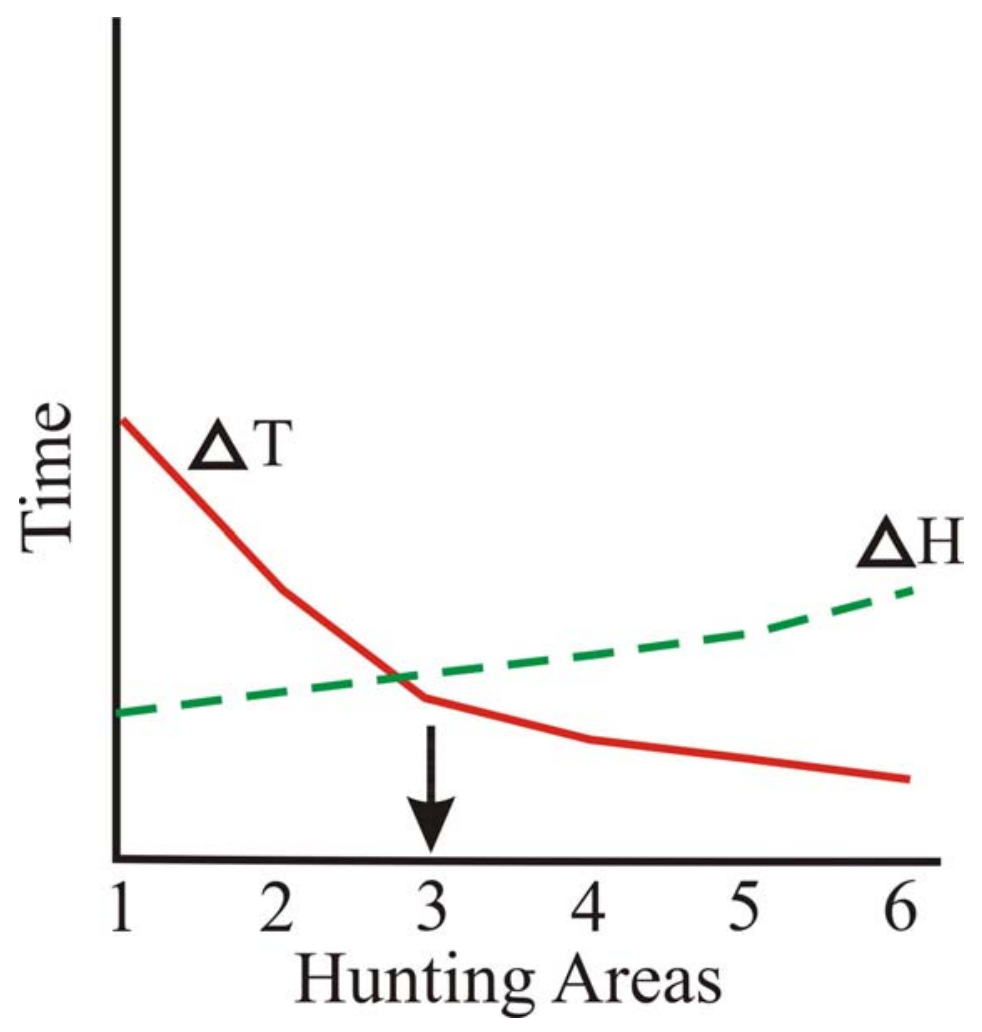

Figure 13. Optimal foraging travel time to hunting areas and time spent hunting. Adapted from MacArthur and Pianka 1966: Figure 2.

Because of these variables, the time expended at a patch and the amount of resources collected varies between patches. As more time is spent within a patch, the rate of return decreases. Closer patches should be exploited for a wider diversity of food sources with a wide range in the size of prey. The greater the distance traveled to a particular patch, the more likely a group will ignore resources with a lower energy yield, and the greater the likelihood that there is some level of specialization (Bettinger 1991; Pyke 1984). Overall, as the distance to a patch increases, the more time is spent at the patch and more resources extracted. One significant factor of Central Place Theory that is difficult to quantify is the allocation of time to exploit patches. This implies that the group has selected patches because of expected resources, and that there is the knowledge that resource patches are renewable over a particular time period (Pyke 1984). 
Stiner and Munro (2002) examine diet breadth increases during the Paleolithic in the Mediterranean Basin in the context of Flannery's Broad Spectrum Revolution hypothesis, that the Pleistocene/Holocene transition was the impetus for expanding diet diversity. Besides climate change, populations were increasing and population imbalances in certain regions spurred the development of agriculture. Stiner and Munro concluded that the transition to broad subsistence, particularly the emphasis on small mammal procurement began much earlier, from 50 to 40 thousand B.P. Dividing prey species into categories of size and speed, they noted an inverse correlation between small, fast, game and preferred larger game species. When large game was unavailable, small fast game such as hares was procured. When the primary prey was routinely procured, slow, small game such as turtles and tortoises were captured. Slow moving prey such as tortoises and certain mollusks mature slowly and can be depleted more quickly within a region. Fast moving prey such as hares has a quick reproduction rate. The systematic collection of slow moving species has a diminution effect, as larger specimens are routinely harvested, the size of the species decreases locally. Dependence on slow moving game and larger specimens implies low population densities. The increased exploitation of lower ranked quick small animals and decreases in the higher ranked slow animals suggests population increase and increasing density.

Using the approach of Stiner and Munro (2002), the Icehouse faunal assemblage is compared to other regional sites to examine diet breadth, mobility and inferences of social structure, during the transition from the Paleoindian through the Early Archaic periods. To compare the results of the faunal analysis, lithic analysis will also address issues of mobility and potentially diet breadth. 
There are numerous problems with applying an Optimal Foraging model to the Central Texas Early Archaic record, such as a poorly preserved archaeological and climatic record, and time resolution. Other problems involve epistemology, and the meanings of mobility, sedentary, and expedient, territory and range. If components contain a specific cultural identity and subsistence information, do subsistence practices change between components, and do they reflect cultural practices? Research domains that may be contained within, or derived from, the faunal assemblage include: the size and types of animals and quantities present, evidence of processing, butchering, or optimal foraging decisions such as the preferential or ranked selection for transporting portions of prey species (Begler and Keatinge 1979; Binford 1978, 1984; Kelly 1995; Marean and Cleghorn 2003; Metcalf and Jones 1988; Schmitt and Lupo 1995; Stewart and Stahl 1977).

Subsistence: Faunal Assemblages and Taphonomy. The occurrence of certain species in the faunal assemblage is assumed to represent subsistence. If certain bone elements have been recovered, the presence and absence of certain elements may reflect culturally driven selective gathering and processing that resulted in the composition of the faunal assemblage. As Lyman (1994), Metcalfe and Barlowe (1992), Schiffer (1983), Schmitt and Lupo (1995) among others realized, reconstructing behavior from the faunal assemblage is problematic because an assemblage is a complex creation of natural and cultural processes that in many instances are indistinguishable from one another.

Lyman (1994) summarizes the objective of taphonomy as the study of the differences and similarities between fossils and organisms, and between a fossil record and the prehistoric fauna from which it derived. Taphonomy, as originally described by Efremov (in Lyman 1994), is the transformation of animal remains from the biosphere to the lithosphere, where biological 
and geological phenomena become interlaced. Diagrams of châine de operation illustrating taphonomic history and analysis are compared by Lyman, stages common to most models include; the living community, modification at death, the death assemblage, modification shortly after death, accumulation of bone, modifications before and during site burial, geomorphological effects, excavation procedures and analytical procedures. Preceding the moment of death, natural and cultural factors and decisions shape the composition of the assemblage. What fauna was available at the time determined the selection of prey species. These species, along with intrusive species, added to the record through natural causes create the site population. Factors not controlled by the archaeologist include the cultural practices responsible for bone population, bone loss through disposal, and natural effects that result in the preserved assemblage. Taphonomic processes are both historical and cumulative.

The initial creation of the faunal assemblage contains the maximum amount of cultural behavioral information (i.e., Binford 1978). The taphonomic history model of Hesse and Wapnish (Lyman 1994) has five sample realms beginning with ancient behavior, physical consequences, finds, sample, and report, which demonstrates the modification of cultural information from the past to the present. Significant in the model is the loss of cultural information between stages that becomes obscured by natural effects. In most models, the archaeologist controls several realms such as determining the locations of excavations, field procedures, analytical procedures, and ultimately publication of the results. The initial behavioral information contained in the assemblage becomes a small subset of data during the final analysis. Determining the effects of natural phenomena is therefore critical for determining to what degree the final composition of the assemblage represents cultural patterning. 
In an attempt to reconstruct and quantify subsistence from the archaeological record, the use of mathematical models of site formation and attrition and cultural effects of optimal foraging are used. Binford's (1978a, 1984) site formation experiments among the Nunamiut, and analysis of the Klasies River faunal assemblage, demonstrated the utility and application of his methodology as factors in calculating optimal foraging theories and the difference between human and natural faunal assemblages. The actualistic approach, as proposed by Binford, assumes some invariance in cultural practices through time. Uniformitarianism assumes that effects of physical forces have been constant through time. Adopting actualism allows inferences to be made about human behavior from the archaeological because of studies of human behavior in the present, observable, world (Binford 2001; Lyman 1994, 2003; Marean and Cleghorn 2003). Prior to post-depositional effects and immediately after discard, numerous taphonomic agents can affect the preservation of the faunal record. Numerous models depicting the trajectory of an artifact entering the archaeological record have been devised. Walters (1985) documents the discard of bone refuse at a campsite in the southern Northern Territory of Australia by Alyawarre and Anmatjerre speakers. Over a 200 day period, Walters recorded all of the discarded bone from several different taxa. From camp maintenance and scavenging from birds and dogs in particular, only about 3 percent of the discarded bone was recovered. Heavier, larger bones from larger animals were more likely to be recovered in an archaeological context.

Klein and Cruz-Uribe (1984) examined the faunal remains from two components at Boomplaas Cave A and found there was a difference in elemental abundance as related to taxon size; significantly, larger bovid were represented by fewer elements than smaller bovid. The authors attributed this to the "schlepp effect" that smaller animals were probably returned intact 
to the cave for processing, while only certain elements were returned from the larger animals, reflecting a high utility strategy.

Klein and Cruz-Uribe's (1984) faunal analyses in Paleolithic cave sites in France and Spain, documents changes in faunal species abundance as a likely indicator of environmental change, rather than a change in hunter-gatherer behavior. Reindeer abundance at the sites corresponded to changes in climate that expanded the range of the reindeer into the vicinity of the sites. If there were no recognizable changes in the environment, then changes in the abundance of taxa most likely represent behavioral change or preferences that may supersede optimal foraging. For either determination, a thorough understanding of site context is essential to make inferences about prehistoric behavior which includes information about the inhabitants and environmental information and the depositional regime.

Klein and Cruze-Uribe (1984) present three scenarios and the expected faunal element compositions based upon: species abundance and changes in environment, species abundance and cultural change, and species abundance between human behavior and carnivore behavior. Using two separate Paleolithic assemblages from Southern Europe and South Africa, they note that when climatic conditions fluctuated during certain periods, corresponding faunal assembles reflected this change in the type and availability of certain species. For demonstrating behavioral differences due to culture, they compared Middle Stone Age (MSA) and Later Stone Age (LSA) from Klassies and Nelson Bay. The greater diversity of prey, including dangerous prey, in the Nelson Bay assemblage suggests that LSA peoples, using superior technologies (bow and arrow, nets, toggle harpoons) and practices, were able to adapt to and exploit more efficiently their environment. For assemblages created by carnivores, observed differences with archaeological sites include a cranial/post cranial ratio that increases with smaller prey species and cranial bones 
tend to be from juveniles, while adults are overrepresented in the post cranial elements, with a corresponding lack of cranial fragments. Small, hard bones such as sesamoids, carpals and tarsals are rare, yet super-represented on archaeological sites. Age composition is attritional in carnivore sites, while in archaeological assemblages, age profiles may represent mass kills or the capture of a family unit.

Expected Archaeological Signatures. Site use, approximate duration, and intensity may be estimated from a site's faunal assemblage. Small groups in rich environments would select the slow moving turtles and tortoises, and these would be depleted quickly. The use of technology such as nets would increase the potential success for hunting fast prey, as small mammals, especially rodents and lagomorphs. Local procurement of high rank prey suggests there is a low population density (Pyke, et al. 1977; Stiner and Munro 2002; Stiner, et al. 2000). In mammal populations, small rodents $(<1000 \mathrm{~g})$ are the most susceptible to changes in temperature, moisture, and topography (Badgley and Fox 2000). The Balcones Escarpment is along a species gradient where the number of mammals increases from 60 to over 80 over a short distance moving from east to west. Rodent species density increases from east to west and reaches the highest density in the driest and warmest environments (Owen 1990). The variability in topography along the edge of the Balcones Escarpment provides a range of habitat niches over a short distance.

The use of geophytes has been documented from Angostura components from the Wilson Leonard site. Plants such as Camassia sp. prefer wet soil conditions as found along Blackland Prairies riparian zones. Similar large-sized cooking features were at Loeve site and at 41BX996 (Black, et al. 1998). A significant finding from Wilson Leonard and from the Armstrong sites is the presence of geophyte fragments in smaller features (Collins, et al. 1998; Schroeder 2002; 
Schroeder and Oksanen 2002). These features are too small to have been used for the initial conversion of inulin into edible and digestible carbohydrates, and therefore, it is likely they are reheating elements. The association of small features and geophyte bulbs indicates the use of preprocessed or portable foods. The small size of the features limits there ability to process large quantities of food at one time, suggesting that they supplied small groups or individuals.

The use of technology increases diet breadth by allowing a greater number of resources to be exploited. Technology allows formerly lower ranked resources to be selected by lowering handling times. As overall search time is decreased, the hunter gatherer group is more selecting of resources.

Organization of Technology: Design, Style and Types. The lithic assemblage is the primary data for modeling the behavior of the site's occupants. As a data set, the lithic assemblage represents a dynamic process, where materials were acquired, tools manufactured and utilized, refurbished, lost, discarded and recycled (Andrefsky 1998; Kelly 1988a; Shott 1989). These activities have implications for technological organization and subsistence, and possibly artistic expression. How these effects are expressed in the real world create different signatures in the archaeological record (Carr and Bradbury 2001; Odell 2001).

All of the tools were created by chipping stone and no ground tools were recovered during the excavations. The assemblage is divided into two categories, stone tools and the unaltered debris from manufacture, debitage. The stone tools are further organized into standard morphological categories that include projectile points and hafted bifaces, bifaces, flake tools, utilized flakes, and cores (Andrefsky Jr. 1998; Kelly 1988a; Odell 2004). Artifacts were further organized within categories based upon technological traits and further morphological characteristics. 
The purpose of the debitage analysis is to determine what types of tools were being manufactured and to what extent, by what processes were stone tools produced, and the source and type of material was being utilized at the site (Dibble 1997; Odell 2000, 2004). Flakes were initially categorized as to how they were produced such as hard hammer or soft hammer (billet) percussion and pressure flaking. The size of flakes and the ratios between flake types are indicators of the production methods. Other attributes such as the presence of cortex suggest the source of raw material, whether from stream beds or upland deposits.

Tools can indicate site function, although this can be complicated by the fact tools recovered from the site may not have been used at the site. In addition to possible site function, tool types have been used as indicators for mobility or sedentism (Kelly 1988a; Kuhn 1994; Parry and Kelly 1987). Tools broken during manufacture and the debitage from tool manufacturing were examined for diagnostic traits. The choice of manufacturing techniques are determined by several factors that include raw material type and availability and the intended tool form (Dibble 1997; Hayden 1989).

A larger scale issue such as regional identity is examined through the typology of the projectile points. Certain tool forms, particularly projectile points, can act as a social identity in addition to their technological function (Bentley and Maschner 2001; Krieger 1944; Wiessner 1983; Wobst 1977), although caution has been expressed for the concept of style superseding technological requirements and change through the use life of an artifact (Flenniken and Raymond 1986; Shott 1989).

The organizational and subsistence practices of the inhabitants may account for the composition of the assemblage (Binford 1980). Along the hunter-gather continuum, there are different needs and emphasis based upon resource availability and distribution across the 
landscape (Bleed 1986). Forager campsites are expected to contain elements of generalized daily tasks and foraging tools would be classed as "maintainable". The more generalized the subsistence strategy, the more ready tools have to perform numerous tasks and/or be quickly employed. Collector sites should contain some "reliable" tools in addition to maintainable tools. Maintainable tools are designed to be employed and repaired quickly and may perform numerous tasks. A reliable tool is specifically designed for efficiency for a single task or narrow range of tasks. They are bulkier than maintainable tools and likely to be composite tools, made from many parts which may come from different sources. These parts are easily replaced if damaged so that there is less chance of a catastrophic failure. These tools require a greater initial investment in manufacturing time and periodic maintenance (Bleed 1986). As described by Bleed, the Forager toolkit should contain curated tools and the use of expedient tools in equipment refurbishing. Within the Collector tool kit, tools are reworked or discarded more frequently and tools may be cached close to a particular resource area. Just as Forager Collector hunter gatherer mobility and subsistence strategies are a continuum and not dichotomous, a combination of maintainable and reliable tools would be utilized by most groups along the continuum.

Tool design can therefore be viewed as an adaptive response to optimize efficiency in a particular environment economic decision and an attempt to minimize risk and maximize returns (Bettinger and Baumhoff 1982; Bousman 1993; Torrence 1989). Reduction of risk includes the prevention of loss, the transfer of loss, caching and storage by individuals, and resource pooling. Each risk reduction strategy has both technological and broader social organizational implications (Torrence 1989; Wiessner 1982). 
Prevention of loss as proposed by Wiessner (1982: 172-173) includes rituals to ensure the success of a hunt, the allocation of territory, and manipulating the environment through proscribed burns. As population density increases, boundaries may be defended and territories may become further defined. The transfer of loss can be mitigated from the sharing of surpluses to less fortunate groups or individuals through ceremonies, or expropriating other territory or surpluses. Intrasite patterning that reflects sharing can include communal houses and open areas where resources are openly displayed. The distribution of faunal remains may reflect sharing and preferential treatment, and that the distribution of meat is formalized and ritualized process. In these instances, butchering techniques would become increasingly formalized. In other instances, as Wiessner notes, butchering is highly variable depending on numerous immediate factors. Wiessner proposes that societies with formal patterns of sharing exhibit more regular butchering practices, while household groups would have greater variability in butchering patterns, and consumption and storage decisions based upon immediate needs and long term planning. The caching of resources for later use is an internal method of reducing risk, while the pooling or sharing of risk combines social connections, where daily risk is spread amongst the population within groups to exchanges with other groups. The mutual sharing and exchange create and reinforce social bonds, and may be an expression of status for individuals and groups. Risk and risk mitigation can operate within an immediate or short term time scale or over a longer period and Wiessner concentrates on the archaeological patterning resulting from short term and immediate risk reduction strategies and not the actual tool types or assemblages.

Tool design can have a mitigative effect on risk and Torrence (1989) proposes that reliability is a response to the severity of risk, while maintainability is the timing of risk. Design is also a tradeoff or a balance between long and short term risk. Short term risk favors encounter 
type foraging and maintainable systems, while long term risk favors a more collector strategy, where logistical moves revolve around mapping onto particular resources. Risk is also an assessment of predictability and two components of predictability are constancy, the year round availability of a resource in a particular location and contingency, the seasonal or varying availability of a resource in a particular location.

The use of narrow breadth specialized tools is characteristic of a reliable tool strategy. The need for a reliable tool system arises when the consequences of failure are significant (Bleed 1986; Bousman 1993). A task that must be performed repeatedly under time constraints is one justification for developing specific tools. Tomka (2001) notes that specific types of hafted bifacial knives appear in the archaeological record with highly mobile groups associated with bison hunting. The use of the hafted biface knives as opposed to expedient flake tools suggest that they were used for strenuous and repetitive work. Odell (1994) views hafting as a response to increasing sedentism as the result of population pressures that decreased the range of groups and reduced access to lithic sources. In response to reduced territories, logistical mobility strategies would increase, the consequences of failure would increase, and therefore the use of reliable systems would increase.

Typology. The organization of archaeological materials arose out of the antiquarians in the early nineteenth century. The classification of materials based upon use, material and form correlated to temporal periods was first published by C.J. Thomsen in 1836. Thomsen's organization of the Three Age System of Stone, Bronze and Iron Ages was to establish typological thinking, the application of ethnographic analogy, and the application of a progressional history to chronological ordering (Rodden 1981). Bo Gräslund argues that Thomsen's division into three major categories was not arbitrary (Gräslund 1981). According to 
J.J.A. Worsaae, who worked as Thomsen's assistant, Thomsen had extensive knowledge of the archaeological context from which to base his structure and accompanied the three divisions with detailed accounts of associated artifacts, placing more emphasis on the systematic recording of material context. The National Museum in Copenhagen contained the largest regional collection of artifacts which allowed Thomsen the opportunity to formulate a chronological synthesis. Unlike the later works of Warsaae and Niilson, Thomsen's system does not address technological, economic, or artistic developments, but uses artifacts to illustrate chronology. His system of classification was the first detailed, scholarly, chronological archaeological history (Gräslund 1981). Thomsen and Worsaae were in the tradition of "essentialists", a movement beginning with Aristotle and influencing the natural sciences, where "types" occur in nature to be discovered (Rodden 1981).

The original purpose of archaeological typologies was to categorize and organize collections of artifacts. In 1903, the Swedish archaeologist Oscar Montelius published Die Methode (Klejn 1982), outlying his typological method for artifacts. His intent was to supplement stratigraphy by showing an evolutionary path between artifacts using his "Swedish Method" of seriation. Specific artifacts were recorded with regard to their geographical location and similarities between object forms were thought to indicate contemporaneity. The method was not intended to address all kinds of artifacts but was intended for classes of artifacts that could be categorized into specific types. His approach placed a preferential reliance on typology and was concerned with determining types and the similarities and differences of form. Both stratigraphy and combinations of assemblages were indirectly relevant to his method. For Montelius, the critical goal of his method was to document or demonstrate an evolutionary pathway for a particular artifact from one form to another. 
Since the development of earliest archaeological typologies it was assumed that artifacts were both a repository of historical information and collectively charted material and cultural evolution. The analogy to the physical science of geology and emerging paleontology imbued artifacts with traits, as if describing a plant or a fossil (Adams and Adams 1991; Bisson 2000; Gräslund 1981; Klejn 1982; Sackett 1981). Although the artifacts were cultural proxies, a whole culture was created for the artifacts: the main importance of the artifacts was to illustrate chronologies, with no real attempt to investigate human behavior. Inherent to archaeological interpretation is the creation of a culture history, ascribing behavior to the archaeological record, and assuming that the record accurately portrays the data (Sackett 1981). Understanding the creation and origins of a typology is essential, since both typing and sorting of artifacts incorporates what are essentially numerous arbitrary decisions during the creation process (Adams and Adams 1991).

The creation of types involves the selection of defining criteria, usually morphological traits, one of which can be "style", and though both type and style are used extensively, they are frequently not defined. Types can incorporate a diverse range of traits including both functional and stylistic variation (Adams and Adams 1991). Artifacts can be examined stylistically, in which instance a style typology can be created. Types can be composed of whatever criteria are thought necessary to create divisions within a grouping. In some instances, perceived cultural and style differences have actually been morphologic changes through the use-life of the artifact (Bisson 2000; Rolland and Dibble 1990).

Typologies were originally assembled by function and a particular form of an artifact was assumed to be correlated to its use. When creating typologies, style was the dominant criterion, or it was ignored or not recognized as style by archaeologists. A style-containing trait implied 
that the message or intent of the style preceded the creation of the object, and that the artifact was a vehicle to transmit the style physically and cognitively. As with other types, stylistic derived types existed because of circular analysis if style became separated completely from function (Wobst 1977). Stylistic analysis could also become self referencing, being able to detect style, but unable to determine its behavioral content. Certain behaviors may be undetectable in the archaeological record, which calls for speculation and with style, this is only a particular trait of the artifact (Wobst 1977).

In "The Typological Concept", Krieger (1944) intended to rescue the use of archaeological typologies from the abuse of over use and poorly expressed definitions. The creation of typologies should, as their basis, address human behavior. If the typologies cannot interpret of reconstruct human behavior, assumptions based upon the typologies are probably incorrect and fictitious. Groupings of artifacts had been used to create "culture complexes" and demonstrate "culture change" geographically and temporally. These groupings were referred to as "types", the medium for comparisons and analysis in archaeology. Clarifying the definition of type was Krieger attempt to bring some form of standardization.

For Krieger (1944), a type should represent a cultural practice, much as the ethnologist defines a "culture trait". Like the culture trait, an archaeological type should convey a recognized pattern of behavior that is transmitted between individuals, and through the study of styles, a genetic path similar to a phylogenic tree can be followed to the origin of the particular style, or in the case of a culture trait, the origin of the practice. The archaeological type is an organizational tool used for creating groups of materials that have a recognizable historical context and illustrate a particular behavior. 
The analogy to the natural sciences and biology in particular, were viewed as an analogy only, while in France the origins and history of "type" were indelibly linked to paleontology. The comparison of archaeological artifacts with fossils had a detrimental effect upon creating a useful systematic archaeological typology (Sackett 1981). Culture history was approached as paleontology in that natural and archaeological strata were directly correlated, and that defined cultural contexts, like paleontological complexes were invariant. Overall, archaeologist underestimated both the complexity of the stratigraphy and of the assemblages to such a degree that they missed subtle variations in the cultural record and artifacts not part of a recognized or expected complex were discarded in the field.

Eventually the archaeological record was shaped to conform to the theoretical record. The natural model assumed that archaeological assemblages were created at a particular time by a specific people. When there was a combination of assemblages, especially those with contemporaneous association, but functionally different, they where not part of the model. The idea that a culture could pursue multiple tasks at the same time and that these tasks could vary considerably at the same site, was not in accordance to the organic model they had created. Investigations had concentrated on demonstrating the linear progression and phylogeny of artifacts and cultures that produced them. Changes in material culture were then directly associated with their contemporaneous climate, and that there were correlated to these changes.

Denis Peyrony’s work with the Upper Paleolithic in Perigord, France, was advanced and sophisticated for the 1930's (Sackett 1981). However, his typologies followed an organic model in that types were waiting to be discovered. Variations in assemblages or mixed artifact assemblages were ascribed to different races of people rather than different site use or different industries practiced by one particular group. The strict fossil/phyla approach began to change in 
the 1930's and by 1950 new advances in methodology, theory, and research strategies, initiated in large degree by François Bordes', introduced new paradigms for stratigraphic and typological analysis (Sackett 1981). Binford and Binford (1966) note that Bordes claims to be able to distinguish the seasonality of an assemblage based on lithic tool morphology and counts. Bordes is also credited with establishing standards of documentation and comparison, allowing supposedly objective criteria to compare Mousterian assemblages. Because of the slow rate of change within the Middle Paleolithic lithic artifact forms, Bordes used quantitative analysis of artifact frequencies for comparisons between assemblages. Bordes thought that the composition of the assemblage appeared more likely to reveal behaviorally related patterning then traditional methods of classification to typologies (Bisson 2000).

The Binford's (1966) analysis of variations in composition of assemblages proposed that the variations were the actual result of cultural activity, that they were directly related to particular activities. Bordes' original system did, however, create the initial framework of the French Paleolithic and its emphasis on deliberate and careful empirical study, created the environment for the new approaches. The base unit of Bordes' typology was the artifact, upon which assemblages were constructed. Typological errors in determining types would therefore alter the composition of an assemblage. A major problem with Bordes' typology was confusing classification with interpretation (Bisson 2000). The examination of stone tool morphology is affected by numerous variables, according to Bisson:

Raw material, function, and reduction history are related in such a complex way that the morphology of tools in a component, howsoever it may be analyzed, will not in itself reveal the behaviors that created that particular archaeological record (2000:42). 
The composition of a type must account for the range of individual variation in materials, while separating itself from other styles. The typology should be reproducible with other analysts. Krieger (1944) critiqued the current and past practice of typology in three categories: detailed descriptions of individual artifacts, visually determined typologies used to reduce repetitive description and based upon personal assumptions, and classification systems for large geographic areas. Krieger acknowledges that these methods have their use; however, none are true typological systems. A type must have a particular historical significance, and the determining criteria cannot be rigid, since types are discovered through analysis of a particular material collection. Through the thorough examination of a material assemblage, a series of characteristics will coalesce into a specific type.

Accordingly for Krieger (1944), the type should distinguish between tradition and ideal behavior and actual enactments, since duplicating the ideal form is limited by the skill, effectiveness, and intent of the craftsman. Individual variations that are not encompassed with the range of the style are regarded as background noise and are of no historic significance, and only through transmission and repetition does a style exist. The division into types must be based upon real historical or archaeological factors rather than the analyst's ideas or desire to label or categorize all artifacts. The type should allow the archaeologist to use groups that have the demonstrated ability to reflect historical meaning of behavior processes.

Overall, typologies should not be rigid constructs (Krieger 1944). Problems arise through the selection of criteria; the favoring of one measurement over another and the preordering of artifacts chronologically should be avoided. The separation between groupings may be artificial because minor variations in criteria for imposed categories. Specimens may satisfy the morphological criteria, but belong to another distinctive cultural group. Variation within a group 
can change depending on the number of attributes that are selected to define the typologies. The use of a classificatory system implies a genetic link vertically, where associations to the main heading attribute appears stronger than to the other subgroupings.

The intent of the classification system was to create a standardized methodology rather than standard typologies. Previous research describes methods of typology, utilizing a mixture of morphology and geography, but provides no explicit information as to how the types were derived. Krieger (1944) critiques these as being more concerned with orderliness, and how the act of classification automatically creates types. The underlying premise of these methods is that that there is a universal key to human workmanship that opens the way to interpreting prehistoric culture and behaviors. To counter these problems classification systems or trait lists for cultural relationships should be abandoned for analytical use. In addition, the methodology used for ceramics should be extended to other materials, artifact types should be fully illustrated, and the use of "type" should be suspect unless a full methodology is presented.

Life-use and re-sharpening experiments where conducted by Flenniken and Raymond (1986) during which they manufactured 30 Elko Corner-notched projectile points. The points were used for simulated hunting and damaged and broken specimens were repaired. Fragments large enough to be re-hafted were reworked in the same original style. Damage to the points was frequently at the medial and proximal ends rather then the expected distal ends and the act of resharpening changed the "type" of some of the specimens by altering both base characteristics and the blade, with the base exhibiting damage more frequently than the proximal end. In some instances, the basal barbs were completely removed resulting in a constricting stem (Flenniken and Raymond 1986). This is in contrast to other use experimenters, who noted that the proximal end was damaged after almost every use, while the base was not damaged 57 percent of the time 
(Odell and Cowan 1986). The reworking removed some points as types by making them "untyped", while others (33 percent) were changed into the appearance of types separated by several thousand years chronologically.

Based on previous research and the preliminary results from the investigations at the Icehouse site, a series of research questions were devised to guide the analysis and attempt to address noted gaps in the archaeological data record:

What type of residential mobility is inferred for the inhabitants of the Icehouse site?

Is there a change through time?

How is the lithic technology organized?

What changes occur in the lithic assemblage through time?

How is the faunal assemblage and subsistence information related to lithic technology and mobility?

How are the environmental conditions and climate of the Early Archaic related to mobility and organization of technology?

How valid is the Gower type?

How does the artifact assemblage at the Icehouse site compare to region wide assemblages?

How does the faunal assemblage compare to other regional sites? 


\section{CHAPTER 5 METHODOLOGY}

\section{Data Recovery Excavation Mapping, Unit Designations and Sampling}

The construction of the Sessom Creek Diversion Project was going to impact State Archeological Landmark site 41HY161 and Texas State University contracted with the Center for Archeological Studies (CAS) to conduct data recovery excavations. Three backhoe trenches were excavated within the footprint of two flood control structures. Structure 1 was located near the corner of Aquarena Springs Drive and Sessoms Road where Backhoe Trench 1 was excavated. Figure 14 shows the installed flood control structure. Cultural material noted from the trench was disturbed from previous construction activities and no intact deposits were identified. The second structure was located west of Structure 1 and along Sessom Creek. Backhoe Trench 3 identified potentially intact deposits beginning at a depth of approximately 180-190 cm below grade.

To investigate the buried deposits, a block 4 meters by 3 meters that incorporated Backhoe Trench 3 was excavated by backhoe to a depth of approximately $180 \mathrm{~cm}$ below surface (98.02 m). At a depth of $180 \mathrm{cmbs}$ there was a marked disturbance in the soil, running from the south of the block to the north end Figure (15). The area of disturbance was approximately four square meters and appeared to be a previous mechanically excavated trench of unknown age that connected Sessom Creek to the fishponds. 


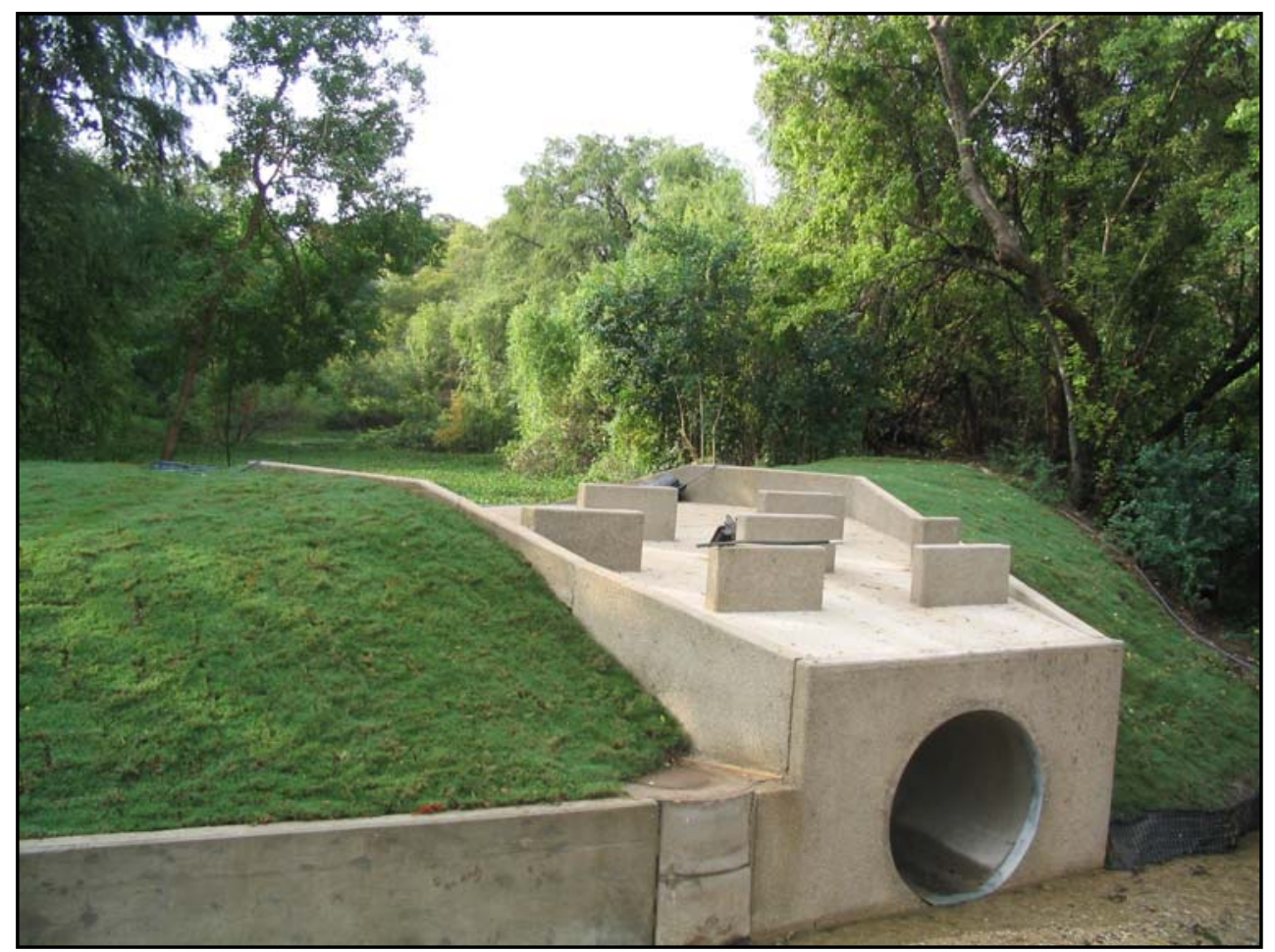

Figure 14. Installed flood control structure near Sessom Drive.

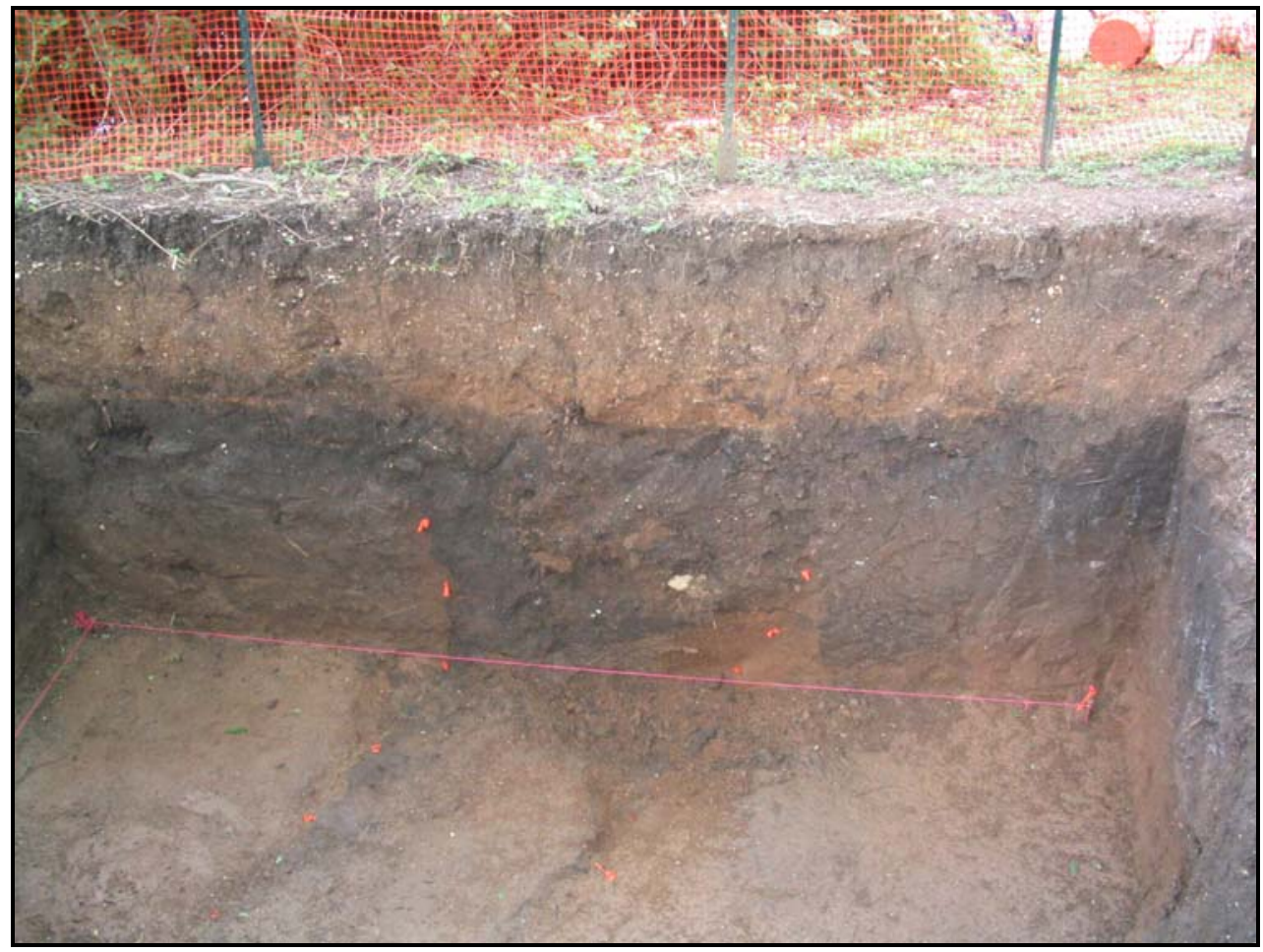

Figure 15. South wall and floor of excavation block showing modern disturbance. 
A datum of $100 \mathrm{~m}$ elevation was established at the base of a pecan tree adjacent to the block. The edge of the block closest to Sink Creek was termed the North End. A Leitz NO10C theodolite was used to establish the north base line and the west and east base lines. The block was leveled by hand using shovels to a starting elevation of approximately $97.90-97.93 \mathrm{~m}$ in the eastern half of the block and $97.80-97.85 \mathrm{~m}$ in the western half of the block. Survey tapes were used to establish the meter increments for the 4 meter by 3 meter grid. An arbitrary North 1000 meters and East 1000 meters was established at the southwest corner of the block. After the block was established a Sokkia SET600 digital total station and SDR33 data recorder was used to record the grid.

Within the block at the northeast corner a single 1 meter square, designated Unit 1, was excavated beginning at $190 \mathrm{cmbs}(97.92 \mathrm{~m})$ and ending at a depth of $260 \mathrm{cmbs}(97.22)$ to assess both the trench disturbance and the potentially intact deposits. Results from the test unit indicated that the depth of the modern disturbance continued to the estimated depth of impact and that artifacts from the intact deposits included faunal and lithic materials.

The initial excavation plan proposed that all 12 square meters would be hand excavated. The revised excavation plan called for controlled hand excavations in eight square meters of the block, including the initial assessment unit, because of the ditch feature. The excavation of the remaining seven square meters was divided into eight 1-x-1 meter excavation units. The units were divided into eastern and western divisions, with the trench anomaly as the dividing line. Eastern Units were 1, 4, and 7; western Units were 2, 3, 5, 6, and 9 (Figure 16). 


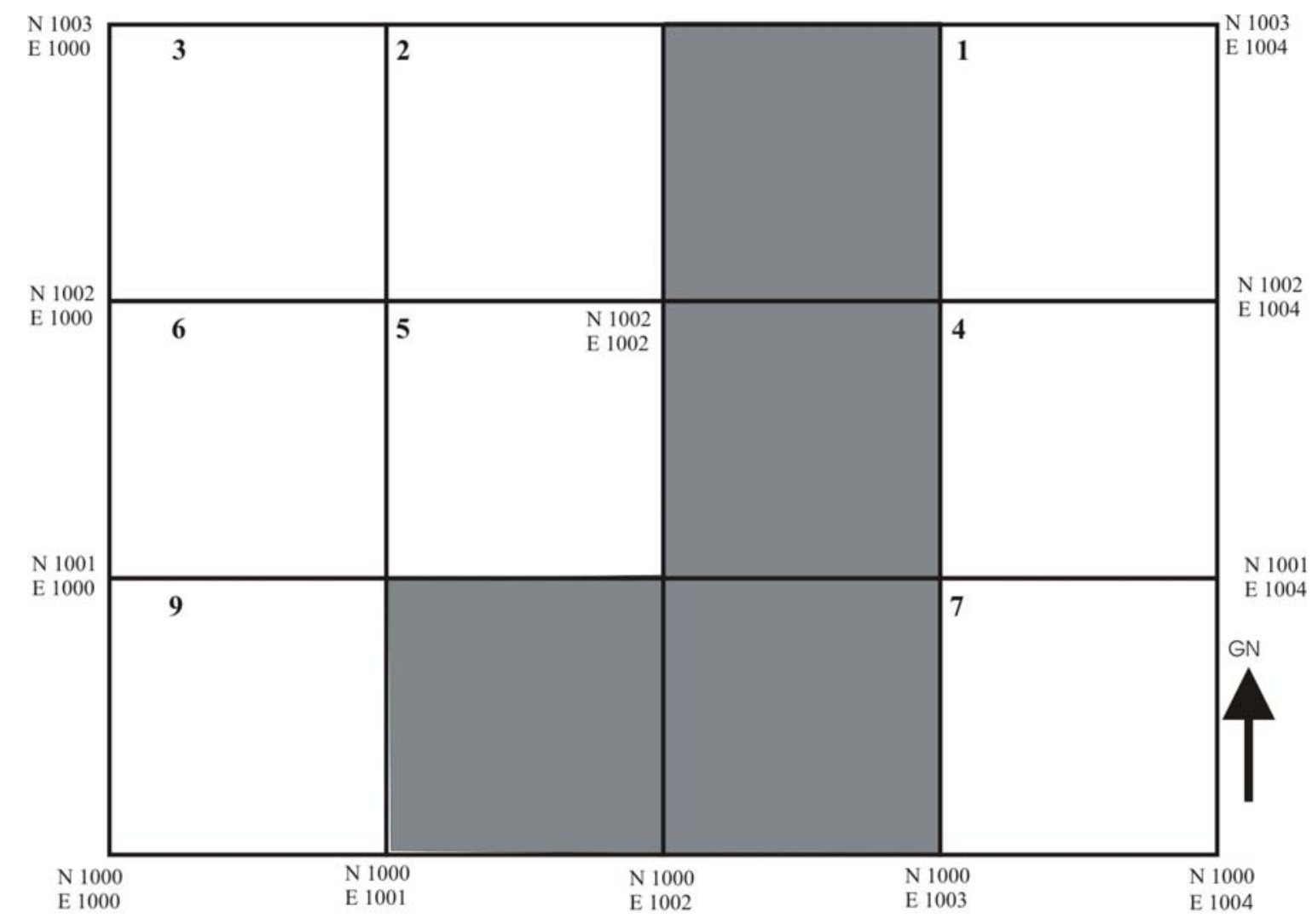

Figure 16. Schematic planview of Excavation Units.

Eastern units began at a depth of approximately $190 \mathrm{cmbs}(97.92)$ and ended at a depth of approximately $260 \mathrm{cmbs}(97.22)$. The western units began at $200 \mathrm{cmbs}(97.82)$ and ended at 270 cmbs $(97.12 \mathrm{~m})$. The intent of the excavation was to sample approximately $70 \mathrm{~cm}$ of what were potentially intact deposits. The final depth of individual units was determined by the starting depth of the block and the project depth of approximately $260 \mathrm{~cm}$ below existing grade, and the rising water table. Figure 17 is a schematic of the profile of the excavation units and levels. An estimated 5.2 cubic meters of archeological deposits were excavated by hand. 

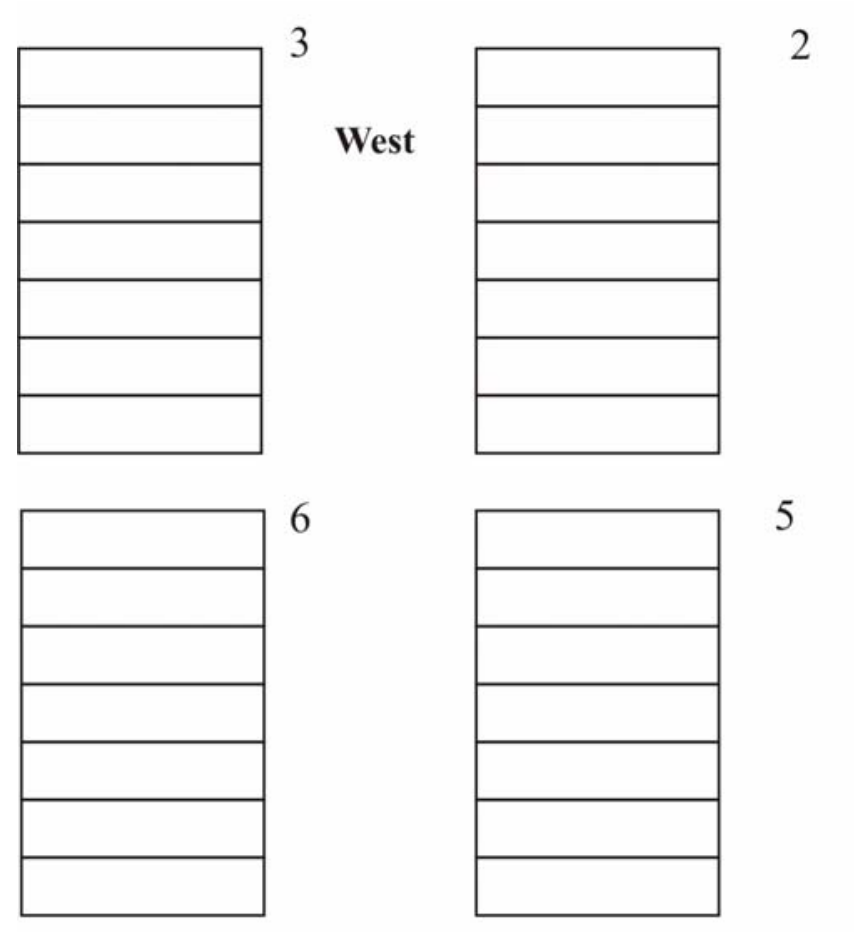

5

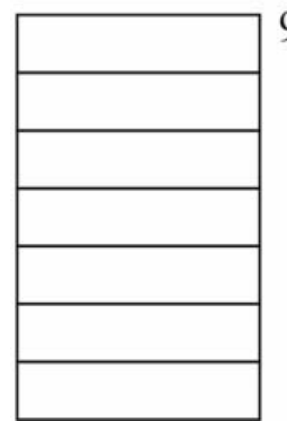

9

Units 2,3,5,6,9

1 98.xx-98.72 m

2 98.72-98.62

3 98.62-98.52

4 98.52-98.42

5 r $98.42-98.32$

$\begin{array}{ll}6 & 98.32-98.22\end{array}$

$\begin{array}{ll}7 & 98.22-98.12\end{array}$

Units $1,4,7$

1 98.xx-98.82 m

2 $298.82-98.72$

3 98.72-98.62

4 98.62-98.52

$\begin{array}{ll}5 & 98.52-98.42\end{array}$

$\begin{array}{ll}6 & 98.42-98.32\end{array}$

$\begin{array}{ll}7 & 98.32-98.22\end{array}$

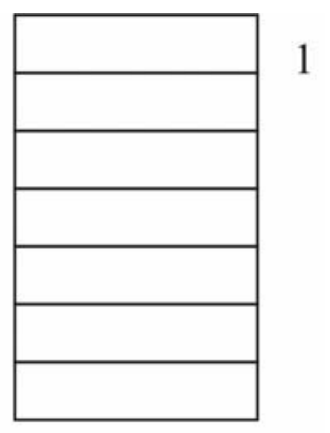

4

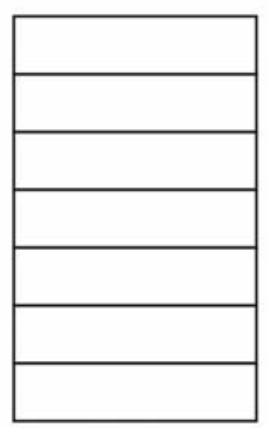

7

\section{Figure 17. Schematic profile of Excavation Units.}

For daily use the Leitz theodolite was used to establish elevation for the excavation. During hand excavation, unit elevations were recorded using line levels attached to a known corner datum elevation. These were termed subdatums, and their elevation was recorded on the excavation forms. Elevations in the field notes were recorded as depth below datum. The elevation of each datum point was recorded in a master log, as were any change in the datum location. The elevation of each datum was checked at the start of each field day and compared with the previously recorded elevation. Depths on the excavation forms were converted to 
elevations in an Excel spreadsheet. At the conclusion of the excavation, the Sokkia SET-6 Total Station was used to record final elevations of the excavation.

Excavation was conducted using trowels and hand tools. All material excavated from non-feature context was dry screened through $6 \mathrm{~mm}$ hardware cloth. The location of artifacts was recorded using hand tapes for the northing and easting and elevation with the string line. The location was plotted on CAS excavation forms. Artifacts were identified by sequential lettering for each new unit and level on the planview form. Artifacts that were identified in the field as possible tools and faunal remains were collected as individual specimens, and retained their field identification. Artifacts were numbered according to Unit, Level and letter designation. For example, specimen “D” from Unit 9, Level 6, was labeled 41HY161 9-6D.

Features were identified as unusual accumulations of cultural material such as burned rock or anomalous patterning in the soil matrix. Features were recorded on the standard unit elevation forms. Additional maps showing planview and section views were also produced. The form recorded the type of feature, any associated materials, soil texture and color, and the type and location of any special sample locations. Each feature was bisected and each half was excavated separately to examine the profile. The fill from each feature was screened separately from the unit and level fill. Photographs were taken of each feature. Special studies analysis samples included radiocarbon AMS dating, micro and macrofloral samples, archeomagnetic, magnetic soil susceptibility, faunal, and soil textural sampling.

Laboratory Methods. Samples were prepared according to the type of sample and according to the requirements of a particular analyst. All field samples were assigned a sample number and all sent samples were listed in a shipping log. 
Radiocarbon. The site contained no identifiable carbon samples from a defined provenience. All radiocarbon dates were obtained from collagen extracted from samples of fauna bone. All samples were processed and assayed by Beta Analytic. The fauna samples used for dating were selected based upon their stratigraphic association within an analytical unit and three dimensional provenience, the size and condition of the fragment-large enough to contain adequate collagen and neither excessively weathered nor burned. Each sample was selected from suitably sized fragments of a specimen. Each sample was air dried before shipping and weighed and packaged in aluminum foil and polyethylene with an enclosed tag identifying the specimen sample number. The sample identification number incorporated the site trinomial, unit, and level.

Soil Magnetic Susceptibility. Magnetic susceptibility is a measure of the concentration of magnetic minerals within a soil (Crowther 2003; Hanesch and Scholger 2005; Magiera, et al. 2006; Singer, et al. 1996). Major applications for magnetic susceptibility studies are paleoclimatology modeling, paleoenvironment and pollution modeling, and archaeology. The magnetic enhancement of soils is used as a proxy indicator for long term patterns of rainfall and drought such as the 2.5 million year record of the Chinese Loess Plateau, and a 500,000 year record in southern Illinois (Grimley, et al. 2003; Maher and Thompson 1995). Magnetic susceptibility values can indicate the presence of buried paleosols and anthropogenic activity, contributing to the geomorphic interpretation used to identify archaeological site formation processes (Batt and Dockrill 1998; Crowther 2003; Macphail, et al. 2004; Marwick 2005; Peters, et al. 2001; Peters and Thompson 1999).

The presence of magnetic materials and their level of intensity have numerous sources that include the original base material for the soil, the addition of magnetic particles from natural 
deposition from wind blown loess and ash, pedogenic processes that include both biogenic and inorganic chemical transformations, and anthropogenic enhancement (Crowther 2003; Hanesch and Scholger 2005; Maher and Thompson 1995; Peters and Thompson 1999; Singer, et al. 1996). Modern pollution from air discharges can introduce elevated magnetic levels to topsoil and exposed surfaces, and magnetic susceptibility has been used to map the extent of the pollution (Hanesch and Scholger 2005; Magiera, et al. 2006; Royall 2001).

Studies from the Chinese Loess Plateau have demonstrated that natural increases in magnetic susceptibility are the likely result of pedogenic effects, namely the formation of ultrafine ferrimagnetic grains during stable periods of soil formation (Crockford and Willett 2001; Harvey, et al. 2003; Kemp and Derbyshire 1998; Liu, et al. 2001; Maher, et al. 2002). Iron minerals have different levels of magnetic intensity: the ferromagnetic iron oxides of magnetite and maghemite have a much higher susceptibility, approximately 1000 times greater, than hematite and geothite (Maher and Thompson 1995). Particle size also has an effect on susceptibility, with ultrafine particles having up to 10 times the susceptibility than larger particles of the same material. Small grains have a greater surface area to mass ratio and are more chemically reactive and susceptible to magnetic alignment and alteration. Maher and Thompson (1995) found that weathered loess and paleosols had 2-5 times the magnetic susceptibility of relatively less-weathered loess.

The magnetic susceptibility of a soil is enhanced from pedogenic effects from inorganic precipitation that is aided by iron-reducing bacteria (Maher and Thompson 1995; Maher, et al. 2003). The bacteria are most active during periods of wetness. Organic matter in the soils is decomposed by the bacteria which use iron oxides for their metabolism; in turn, they release positive iron ions which then oxidize as fine grained maghemite precipitate during drier 
conditions. The size of the magnetite particles is conditioned by rate of oxidation, $\mathrm{pH}$, and resident iron content. If drying does not occur, and the soils are in a reduced environment, then magnetic oxides do not form in the same high concentrations as found in the drier, oxidized environment. According to Maher and Thompson (1995), the greatest enhancement occurs in wetter environments with greater numbers of wet and drying cycles in the upper soil A horizon. Susceptibility continues until equilibrium occurs between oxidation and reduction in the soil. This is conditioned upon there being no additional ferromagnetic sources such as ash from fires, being added to the stabilized soil. They also assume that soil formation rates and the creation of an organic A horizon is a quick process, occurring in less than 100 years, a rate that has been questioned (Kemp and Derbyshire 1998).

A comparison between the Chinese Loess Plateau and Alaskan loess demonstrates the effect of temperature and precipitation on the pedogenic development of magnetic susceptibility in loess deposits (Liu, et al. 2001). In Alaskan loess, susceptibility was negatively correlated with pedogenic development. The high rate of precipitation and the poor drainage of the Alaskan loess results in a predominantly reducing state in the soil where magnetite and maghemite are converted to griegite, which has a much lower magnetic susceptibility. The development of pedogenic high value ferromagnetic minerals is controlled to a large extent by both precipitation and drainage, where low levels of precipitation and high levels of evaporation create ferrimagnetic minerals, while high levels of moisture and low rates of evaporation reduce and destroy ferrimagnetic minerals (Hanesch and Scholger 2005; Liu, et al. 2001).

The highest concentration of ferrigmagnetic minerals is created in the A horizon. Analyses of soil columns from modern A horizons demonstrate that the highest values are within the upper $10 \mathrm{~cm}$ and then rapidly decrease. However, deposits that formed over a magnetic 
lithogenic base, in which case, the values increase with depth (Magiera, et al. 2006). Erosion of the A horizon can concentrate magnetic susceptibility in the remaining B horizon, while plowing can create a homogenous zone of susceptibility extending to $70 \mathrm{~cm}$ or more. Generally magnetic susceptibility decreases in depth below an A horizon. However, Maher and Thompson (1995) use modern soil profiles from temperate and warm climate zones to show that a strong magnetic signature is translocated to the $\mathrm{B}$ horizon during pedogenesis. The average increase in the $\mathrm{B}$ horizon was approximately $28 \times 10^{-8} \mathrm{~m}^{3} \mathrm{~kg}^{-1}$. The estimated increase due to natural pedogenic activity is estimated at $400 \times 10^{-8} \mathrm{~m}^{3} \mathrm{~kg}^{-1}$ (Maher and Thompson 1995; Peters and Thompson 1999) The decrease down profile may be the result of dissolution, where iron is removed by leaching (Crockford and Willett 2001).

Susceptibility enhancement resulting from fire can decrease through time, especially when formed in alluvial deposits. It is thought that maghematite and other iron oxides formed in the coatings on particle surfaces (Crockford and Willett 2001). These particles can be unstable and as they disaggregate, the inner less magnetic material dilutes the magnetic strength of the deposits. The effect of dilution would be contingent on the overall size and temperature of the fire and the duration, with larger, hotter, longer burning fires creating the strongest magnetic influence, and therefore more resistant to dilution. In absence of evidence of other sources of magnetic enhancement such as iron based lithology or pedogenic activity, fire, especially anthropogenic fire may be the source of enhancement (Weston 2002). Two sources of magnetic enhancement from fire are the heating and burning of the topsoil and the introduction of ash and burned organic matter. Peters and Thompson (1999) noted that susceptibility values had been increased by a factor of 200 over the initial values when they examined Norse occupation sediments on Orkney Island. Their investigations of suspected hearth deposits found elevated 
values of 1400 to $2000 \times 10^{-8} \mathrm{~m}^{3} \mathrm{~kg}^{-1}$. These elevated values suggest that there is an alteration in the existing sediments and soil that increases susceptibility, and that additional ferrimagnetic material is being added by cultural activity.

Soil Magnetic Susceptibility Sampling Methods and Analysis. A soil column was collected from the east wall of the excavation block in Unit 4. The column extended from the surface to the floor of Level 7, a depth of $265 \mathrm{~cm}$, and samples were collected at $5 \mathrm{~cm}$ increments. Because the upper soil deposits were disturbed from previous construction, the analyzed samples were from $185 \mathrm{~cm}$ to $260 \mathrm{~cm}$ below surface. This corresponds to elevations of 97.97 to $97.22 \mathrm{~m}$.

Samples were placed in $6 \mathrm{~cm} 3$ plastic containers and were analyzed with a Bartington MS2 Magnetic Susceptibility meter and a dual frequency detector operating at a low frequency (LF) of $0.465 \mathrm{kHz}$ and high frequency (HF) of $4.65 \mathrm{kHz}$. Samples were analyzed by mass and data was collected directly from the MS2 into Multisus $2^{\complement}$ software on a Dell Latitude notebook computer. Samples were measured to the nearest 0.1 gram and each sample was measured three times for both LF and HF. A mean from the three readings for each frequency was used to calculate the magnetic susceptibility.

If only one frequency measurement is made, the low frequency is usually selected because of its greater sensitivity. The MS2B dual frequency detector induces an oscillating magnetic field at either of the two frequencies. In the presence of the sample, oscillations in the field are digitized and compared to a reading from the empty detector to compute the value of magnetic susceptibility (Bartington Instruments LTD 2003). The units used to express magnetic susceptibility are dimensionless, are calculated for either mass for volume. This study used mass because it is eliminates sampling error based on improper filling of the containers. The samples 
were recorded in S.I. units where MS is expressed as MS $\times 10^{-8} \mathrm{~m}^{3} \mathrm{~kg}^{-1}$ for both low and high frequency measurements. These results are used to derive the coefficient of frequency dependence, $\mathrm{XFD} \%=100 \times((\mathrm{Xlf}-\mathrm{Xhf}) / \mathrm{Xlf})$.

\section{Lithic Technology Categories and Definitions}

Bifaces. Bifaces are stone objects that have been extensively worked from two parallel, opposing sides or faces, that form an edge where they converge and circumscribe the artifact (Andrefsky Jr. 1998; Kelly 1988a). Biface production is frequently viewed as a series of production stages in the trajectory from raw material to finished tool shape. Four or five stages are usually defined, and these stages can occur uninterrupted or over a short period of time, or incrementally with distinct time breaks between stages. The difference between four and five stages is usually regarding the final form of the biface or the initial raw material form. During any stage, bifaces can be transported to different locales and further reduced (Kelly 1988a; Whittaker 1994).

The following are the five idealized stages used by Whittaker (1994:200-203). Stage 0 is the initial flake blank or cobble. Stage 1 is the edged blank, where the blank is trimmed creating a bifacial edge using hard or soft hammer percussion or a combination of the two, and portions of cortex or the original flake surface can remain. Stage 2 is the preform, where the edged blank is further thinned, removing the original material surfaces and the edge becomes less sinuous in profile with a lenticular cross section. Reduction occurs using a large billet and the preform may be used as a tool. Stage 3 is the refined biface, the biface is thinner, has a flatter cross section and has edge angle of 25 to 40 degrees. Flakes become increasingly smaller, as smaller percussive tools are used. The finished tool, Stage 4, may be minimally shaped beyond a Stage 3 biface or it may have a complicated shape, and hafting elements may be added. Finishing techniques 
include billet percussion and pressure flaking that further refine the edge and remove traces of platform preparation. Each of these stages produces characteristic debitage and a debitage assemblage is usually a mixture of various percussor types during different stages of biface production (Bradbury and Carr 1999).

Defining stages is further complicated when they are used as tools, since stages apply to the production of bifaces only. Bifaces may break from use or during manufacture. They may be discarded at this point, or refurbished, or recycled into another form, such as a broken point shaped into a perforator. Kelly proposes three roles for the production of bifaces: as a core for creating flake edges, creating longer-use tools since bifacial edges can be resharpened and maintained, and it embodies a style or traditional object or shape (Kelly 1988a). Generally, biface tools are more likely to be curated and categorized as formal tools since they represent a greater investment in time. Projectile points and hafted biface tools represent a final stage or formal finished product.

Measurements and characteristics recorded for bifaces include metric measurements of length, width, thickness, weight, stage of completeness, edge angle, evidence of reworking and hafting, breakage patterns and macro-use wear, material, cortex and treatment such as heating and burning.

Projectile points were recorded using the artifact quantification coding form devised by Elton Prewitt. The form records metric data and mass and quantifies general observations regarding hafting stem treatment, barb break patterning, refurbishment, shoulder, base shape, tip breakage. Additional traits that were recorded were material type and color, and flake patterning. 
Flake Tools. Flake tools are manufactured from a flake blank and usually retain an identifiable ventral or dorsal surface, striking platform, or distal end that is characteristic of a flake. Flake tools are divided into non-formal and formal categories (Odell 2004). Non-formal flake tools are minimally altered from the initial flake blank and modifications lack a standard configuration or location. Formal flake tools have a standard recognized morphology such as a scraper or burin and may have extensive surface modification, usually to the dorsal side. Formal flake tools such as scrapers could be extensively resharpened and curated much the same as bifacial tools. In some instances, if all original flake characteristics have been removed it may be difficult to distinguish a flake tool from another form such as a core or cobble tool. Flake tools are divided by the location of the retouch or modification into unimarginal and bimarginal retouch and combination tools that have multiple characteristics. Unifacial retouch occurs on a single face, while bimarginal retouch is a bifacial edge. Because the bifacial edge is usually limited in length and confined to the flake margin, the tool is not considered a true biface (Andrefsky 1998). Non-formal flake tools are further divided by edge modification, edge angle, and flake morphology in to such categories as steep-edged notched flake and edge trimmed. Included with flake tools are resharpening spalls that are diagnostic of certain types of formal flake tools such as scrapers. They indicate that those tools were present and were being refurbished on site. Burins are another category of flake tool and are a formalized type.

Cores. Cores are objects from which flakes have been detached (Andrefsky 1998) and core tools are created from non-bifacial cores. Besides being a source of flakes for possible tools, both exhausted cores and new cores may be used as a tool, which was usually based upon the availability of additional lithic resources. Tasks for core tools include chopping, wedging and hammering. The major categories of cores are unidirectional and multidirectional. 
Unidirectional cores have flakes detached from a single surface and in the same direction, while multidirectional cores have flakes detached from numerous directions. Unidirectional cores are thought to be a more formalized version, since there was greater control over detaching flakes of a consistent size.

Debitage Analysis. The debitage was searched for any tools and tool fragments and all edges were examined for traces of modification and macro use wear. All of the debitage from the site was examined. The debitage was assigned to the production categories based upon a set of criteria from Johnson and Goode (1995), Goode (2002), Whittaker (1994), and Andrefsky (1999). The lithics were initially sorted into one of nine categories based upon the methods used to produce them and their completeness. The categories are 1) hardhammer complete, 2) hardhammer fragment, 3) softhammer complete, 4) biface thinning flake complete (really a subset of 3), 5) softhammer and biface thinning flake fragment, 6) indeterminate complete, 7) indeterminate fragment, 8) flake fragment, 9) shatter, and 10) burin spall.

Hardhammer are produced by impact with a hard percussor such as a hammerstone of tough limestone or quartzite. Because of the force of the impact the detached flakes generally have a pronounced bulb of percussion on the dorsal face, a small area of crushing near the point of impact at the platform and on the bulb of percussion there may be eraillieur scars or fissures (Cotterell and Kamminga 1987). The platform may contain cortex and be modified through abrading or trimming and is usually simpler than a softhammer platform. The ratio of platform width to thickness should be closer to 1 than softhammer flakes since the platform is a point and less linear. They are usually larger and thicker flakes and serve as blanks from other tools. Typical hardhammer flakes are more likely produced when a core is reduced, although they may 
occur throughout biface manufacturing. In this analysis they are used as an indicator of core reduction.

Softhammer flakes are produced using a resilient hammer such as antler or wood. When compared to hardhammer flakes, the platform is usually more linear, the point of impact less distinctive, and the bulb of percussion is either absent or diffuse, and further from the point of impact. When a soft hammer flake is detached from a core or biface, a thin burr or lip is formed that is perpendicular to the dorsal face. This lip can seen or felt with a finger tip. The platform has been prepared by abrasion and/or faceting to strengthen the edge, and direct the force of the blow by changing the angle between the tool edge and the hammer blow. The majority of the soft hammer flakes are assumed to be from biface reduction, which includes Category 4, Biface Thinning Flake. The platform of a biface thinning flake retains a portion of the bifacial edge. If too large a portion of the edge is removed, the biface may break. Biface flake are usually thinner and wider than hard hammer flakes and have a greater flake to edge ratio (Andrefsky 1998). The thin edges of biface flakes make them immediately useable as cutting tools.

Indeterminate flakes are generally smaller flakes that have platform characteristics of both hard hammer and soft hammer flakes. As flakes become smaller, hard hammer flakes can have a less pronounced bulb and may have a slight lip. Similarly, soft hammer flakes may have a more pronounced bulb and eraillieur scar. Within the indeterminate category, pressure flakes were included. These flakes had a small isolated platform with an average length of less than $15 \mathrm{~mm}$. A single platform type that resembles a punch technique was also included in the category. Indeterminate flakes are thought to represent late stage biface and tool production where small amounts of material are being removed prior to or during final shaping. 
Flake fragments lack a diagnostic proximal end. If the fragment was the distal end of a flake, the type of termination was noted. Flake fragments are created during lithic manufacturing and post depositionally by trampling from humans and animals. Even though the diagnostic proximal end is missing, on larger fragments the remaining characteristics may be diagnostic, although in this study, only flakes with platforms were categorized to technology type.

Shatter was debris that did not have recognizable flake traits, and were usually blocky fragments. Chert fragments burned in a fire can generate shatter when material is detached by heat and the fragment itself can become a piece of shatter. Shatter may be created during hard hammer reduction. Since shatter can be generated numerous ways, many of them natural, it is not used to calculate flake to tool ratios.

Burin spalls, while debitage, are analyzed with burins. These represent deliberate resharpening or rejuvenation attempts on a unifacial tool where the flake is removed perpendicular to the tool edge or bit. The cross section of these flakes is triangular.

The measurements from the flakes were collected with a Mitutoyo Digimatic caliper model 500-171-20 with digital output through Wedgelink data collection software into an Excel spreadsheet. Measurements were to the nearest $0.01 \mathrm{~mm}$. Mass was measured with an Ohaus Portable Plus 300 x 0.1 gram scale to the nearest $0.1 \mathrm{~g}$.

The measurements were: length, measured perpendicular to the platform, thickness at mid-point, maximum width, platform thickness, platform width, and mass.

Six category codes were used to describe the platform:

1) Intact platforms are single faceted or flat platforms.

2) Abraded platforms had been prepared by using a stone or other abrasive to dull and strengthen the dorsal edge of the platform, isolate a portion of the platform, or change the angle of the 
platform by creating a beveled surface. Included in the category are platforms with small step fractures along the proximal dorsal edge. These fractures can be caused by either abrasion or by hard hammer trimming of the platform edge. The intent is similar to abrading a platform, to strengthen a platform, change the angle, and isolate a point for the platform. Step fractured platform edges are more common with hard hammer percussion. Abrading can detach small flakes that would escape recovery from $1 / 4$-inch screen mesh.

3) Faceted platforms have more than one surface and can be created through abrasion or from trimming. The resulting facets create a complex striking surface that is most common with soft hammer biface flakes than hard hammer core reduction (Andrefsky 1998; Carr and Bradbury 2001). Like abraded platforms, faceting can be used to control edge angle and isolate a particular platform section.

4) Crushed platforms retain a diagnostic portion of the original striking platform, but a portion has collapsed and been removed. Crushed platforms are usually the result of hard hammer percussion.

9) Pressure flake platforms are small isolated platforms that are found on indeterminate flakes. The platforms are thin, less than $2 \mathrm{~mm}$, and can have a slight lip or be slightly crushed. Pressure flakes are detached using some form of narrow tool such as the tip of an antler tine which is pressed against the opposite face from the desired removal. The slight lip on the platform is from the bending force applied to the platform. Pressure flakes are from late and final stage tool manufacturing, and also from re-sharpening and refurbishing.

10) There is only a single example of a punch flake, where a narrow tip punch was pressed or struck parallel to the platform. Like pressure flakes, small punch flakes are from the final finishing stages. 
Dorsal flake scars were counted on a scale of 0 to 3 , with all numbers greater than 3 being assigned as 3. A count of " 0 " indicates that the dorsal side is covered in cortex. Dorsal scar counts can be used as an indicator of a stage of biface reduction, and the extent of core reduction. Low scar counts also occur as flakes become smaller at later stages of manufacturing and particularly indeterminate flakes.

When the platform of the flake is struck, a shock wave is propagated through the core. How the shock was travels and exists from the interior of the core creates particular breakage patterns. The variables that can influence the creation of certain types of terminations are knapper skill and raw material. The direction and force of a blow is the greatest determinant of termination type. Secondly, raw material: visible and hidden flaws can disrupt the intended path of the shock wave. Fracture types used a nominal scale from 0 to 6 . Terminations were recorded for complete flakes and proximal fragments and for dorsal sections of flake fragments. Breakage terminology follows Odell (2004), Cotterell and Kamminga (1987), and Whittaker (1994).

0) Feather terminations are gradual terminations that taper gently to the flake surface. This is the usual desired edge of a flake and the intent of the knapper.

1) Hinge terminations occur when the shock wave encounters an imperfection in the chert or the blow was misdirected resulting in a hinge-like scar with the barrel part of a hinge on the flake and a concave portion on the core.

2) Step fractures leave a right angle termination on the flake and a square flake scar on the core. They result insufficient force or from encountering fractures and bedding planes in the core. 3) The outrepasse or overshot flake removes a portion of the distal end of the core which could also be a biface. They occur when the distal end of the core is a perpendicular angle. In most instances this is an error, although Clovis flintknappers used it to thin bifaces (Collins 1999). 
4) Axial bipolar occurs when the distal end is resting on a hard surface or anvil as the flake is struck, creating two cones of impact, one at the proximal end and one at the distal end. When done deliberately, it allows smaller cores to be utilized since they do not need to be held freehand. Axial scars can occur when small cobble and pebbles are being split.

5) A snap or also called a bending fracture is likely a post depositional breakage. The scar left on the end is lipped or hinged. This occurs when stress is loaded on either side of an unsupported point. The fracture can be deliberate with the flake grasped between thumb and finger at two ends and snapped in two, or it could occur from trampling.

6) Excavation fractures were recorded when noted. They are identified by the freshness of a break and the presence of metal traces. Trampling and contact with tools was the main cause of breakage.

Cortex was recorded on a scale of 0 to 4 . Cortex is the outer, weathered surface of a core. The presence of cortical flakes suggests that cores and cortical blanks were being reduced at the site. The size of cortical flakes can indicate the size range of raw material being reduced. The color and texture of the cortex can be diagnostic of the source of the material, whether it is from river gravels, upland sources or directly from a bed. Cortex was coded as river cobble or upland source depending upon appearance. Both types of chert were available to the inhabitants of the Icehouse Site. The scale measured presence and absence and the location of the cortex. $0=$ no cortex present, $1=$ cortex at the distal end, $2=$ cortex at the proximal end and platform, $3=$ cortex covering the majority of the dorsal surface, and $4=$ cortex along a lateral margin. If cortex was found in more than one location, the area with the most coverage was used. A specimen with Category 3 cortex had greater than 50 percent coverage of cortex. 
The final category that was recorded was the presence or absence of burning. This was determined by fractures and discoloration of the specimen. Potlid scars, crazing, friable or glossy almost greasy texture, and a blackened or oxidized appearance were diagnostic characteristics of burning. In addition, burned chert does not fluoresce when exposed to ultra violet light and appears black, unlike the rest of the assemblage. The origin of burned flakes is likely from being discarded in a fire. As part of the camp environment they may become burned post-depositional. 


\section{CHAPTER 6 \\ DEPOSITIONAL CONTEXT}

\section{Site Formation Processes Results}

An examination of the east wall of the block documented nine soil zones, with Soil Zones 1 through 8 in the upper 180 to $190 \mathrm{~cm}$ identified as disturbed fill. The undisturbed Zone 9, beginning at $185-190 \mathrm{cmbs}$, is a Bt horizon which continues to at least $265 \mathrm{cmbs}$. Figure 19 is a photograph showing excavation Unit 1 excavated into Soil Zone 9, as well as the stratigraphy of the other soil zones in the excavation block. Controlled excavation was to begin at approximately $190 \mathrm{cmbs}$, at the approximate boundary of Zone 8 and Zone 9 . The depth below surface and descriptions of the soil zones are in Table 1. In addition to the disturbed upper fill, the remnants of what is likely a trench crosscuts the excavation block. As a result, units that were within the trench boundaries were not excavated. The trench is assumed to be a modern feature associated with water lines or drainage. During the initial removal of overburden, several cast iron pipes were noted, including one pipe estimated to be $20 \mathrm{~cm}$ in diameter.

During the excavations, there was no systematic recording of gravel content in the sediments. An examination of the walls of the excavation block detected no laminae or sedimentary breaks. The majority of artifacts were found in a flat orientation and evidence of stream tumbling such as heavy battering along edges and faces of artifacts were absent. Gravel, when noted, appeared diffused and along with fine-grained 


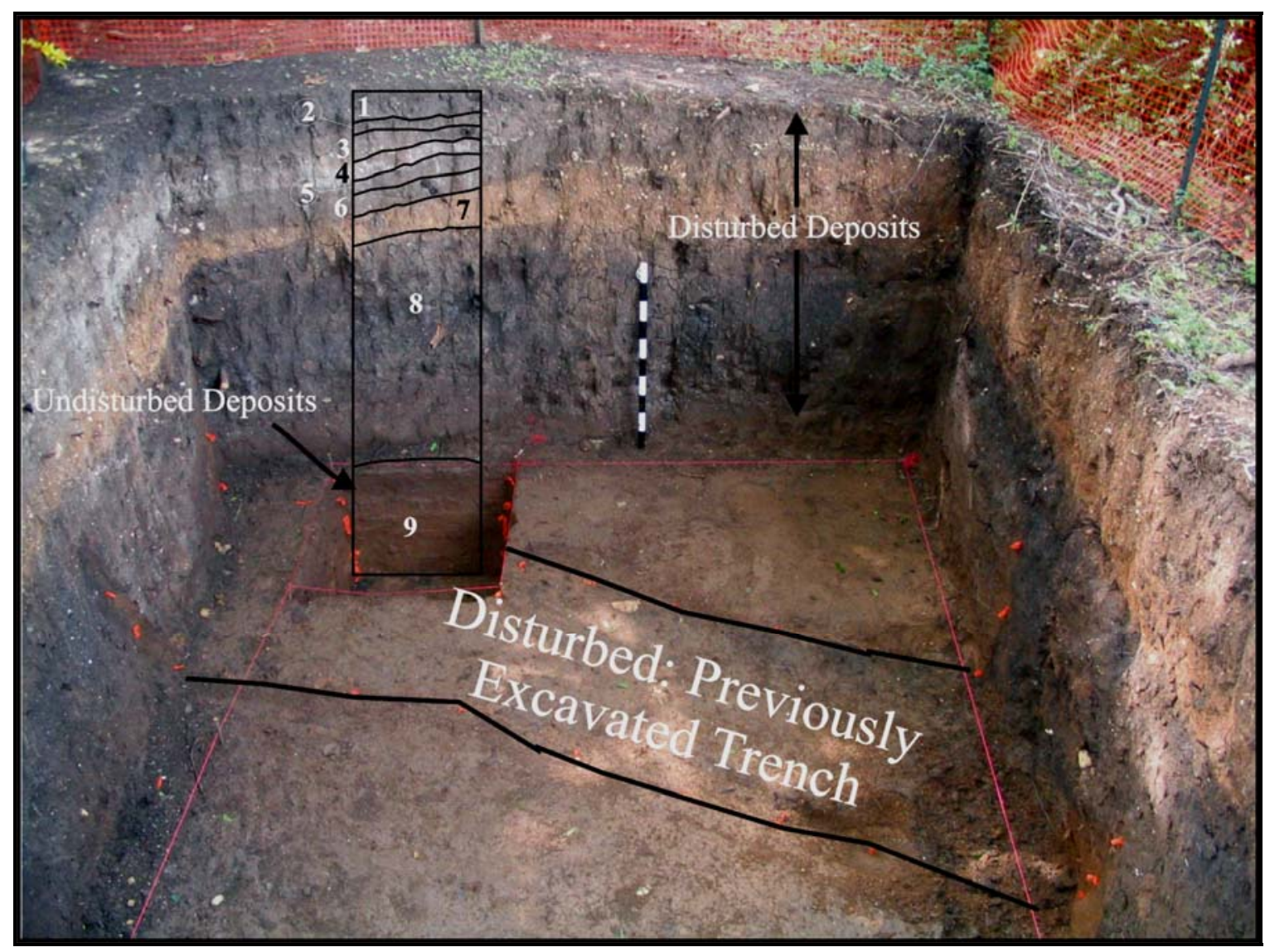

Figure 18. Schematic of east wall of excavation block showing soil zones.

characteristics of the soil matrix suggest the terrace developed in a slowly aggrading environment.

Soil Magnetic Susceptibility Results. The frequency dependence (XFD\%) is of particular importance because it demonstrates the presence of fine grained magnetite and maghematite associated with pedogenic development of a soil surface (Harvey, et al. 2003; Jordanova, et al. 2001). The LF readings indicate the presence of ultra fine grained magnetite and other ferrimagnetic minerals. The results were compared with the vertical and horizontal artifact distribution and radiocarbon dates. There were no visual or textural indicators within Zone 9, and the profile appeared to be homogenous in color and structure.

Table 1. Soil zone descriptions from east wall of excavation block, by Britt Bousman. 


\begin{tabular}{|c|c|c|c|}
\hline Zone & Depth (B.S. cm) & Description & Soil Horizon \\
\hline 1 & $0-19$ & $\begin{array}{l}\text { Very dark gray (10YR 3/1) clay loam, friable, } \\
\text { granular structure, common rootlets, few roots, } \\
\text { common limestone pebbles sub-angular to } \\
\text { rounded, abrupt sloping lower boundary, clearly } \\
\text { disturbed }\end{array}$ & Ap1 \\
\hline 2 & $19-23$ & $\begin{array}{l}\text { Very dark grayish brown (10YR 3/2) clay loam, } \\
\text { friable, granular structure, common rootlets, } \\
\text { few roots, few limestone pebbles sub-angular to } \\
\text { rounded, abrupt sloping lower boundary, clearly } \\
\text { disturbed }\end{array}$ & Ap2 \\
\hline 3 & $23-32$ & $\begin{array}{l}\text { Dark gray (10YR 4/1) clay loam, friable, } \\
\text { granular structure, few rootlets, few roots, few } \\
\text { limestone pebbles sub-angular to rounded, } \\
\text { abrupt sloping lower boundary }\end{array}$ & Ap3 \\
\hline 4 & $32-39$ & $\begin{array}{l}\text { Yellowish brown (10YR 5/4) clay loam, friable, } \\
\text { crumb structure, common rounded limestone } \\
\text { pebbles, few rootlets, few roots, crushed snail } \\
\text { shell, abrupt sloping lower boundary, clearly } \\
\text { disturbed }\end{array}$ & Ap4 \\
\hline 5 & $39-48$ & $\begin{array}{l}\text { Gray (10YR 5/1) clay loam, friable, platy } \\
\text { structure (compacted), few sub-rounded } \\
\text { limestone pebbles, abrupt sloping lower } \\
\text { boundary, clearly disturbed }\end{array}$ & Ap5 \\
\hline 6 & $48-67$ & $\begin{array}{l}\text { Dark grayish brown (10YR 4/2), clay loam, } \\
\text { friable crumb, few gravels, few rootlets, abrupt } \\
\text { lower boundary, clearly disturbed }\end{array}$ & Ap6 \\
\hline 7 & $67-76$ & $\begin{array}{l}\text { Brown ( } 7.5 \text { YR 4/4) clay loam, friable, crumb } \\
\text { structure, common small sub-rounded limestone } \\
\text { pebbles, few snail shell both crushed and } \\
\text { complete, abrupt lower boundary }\end{array}$ & Ap7 \\
\hline 8 & $76-190$ & $\begin{array}{l}\text { Very dark gray (10YR 3/1) clay loam, friable, } \\
\text { crumb structure, few rootlets and roots, } \mathrm{CaCO}_{3} \\
\text { filaments on ped faces and root pairs, few } \\
\text { snails, clear smooth lower boundary }\end{array}$ & Ap8 \\
\hline 9 & $190-265$ & $\begin{array}{l}\text { Brown (5YR } 4 / 4 \text { and } 7.5 \text { YR 4/2) clay loam, } \\
\text { friable, crumb structure, few pebbles, lower } \\
\text { boundary not observed }\end{array}$ & $2 \mathrm{Bt}$ \\
\hline
\end{tabular}

The XFD\% (Change in frequency between high and low frequency readings), and LF

(Low frequency readings) are compared against the elevations of the radiocarbon assays and the

projectile points (Figure 19). From the results of the magnetic susceptibility and the projectile

points, one significant anomaly stands out, namely the transition between soil zones 8 and 9 . The

presence of a Late Archaic Pedernales point 


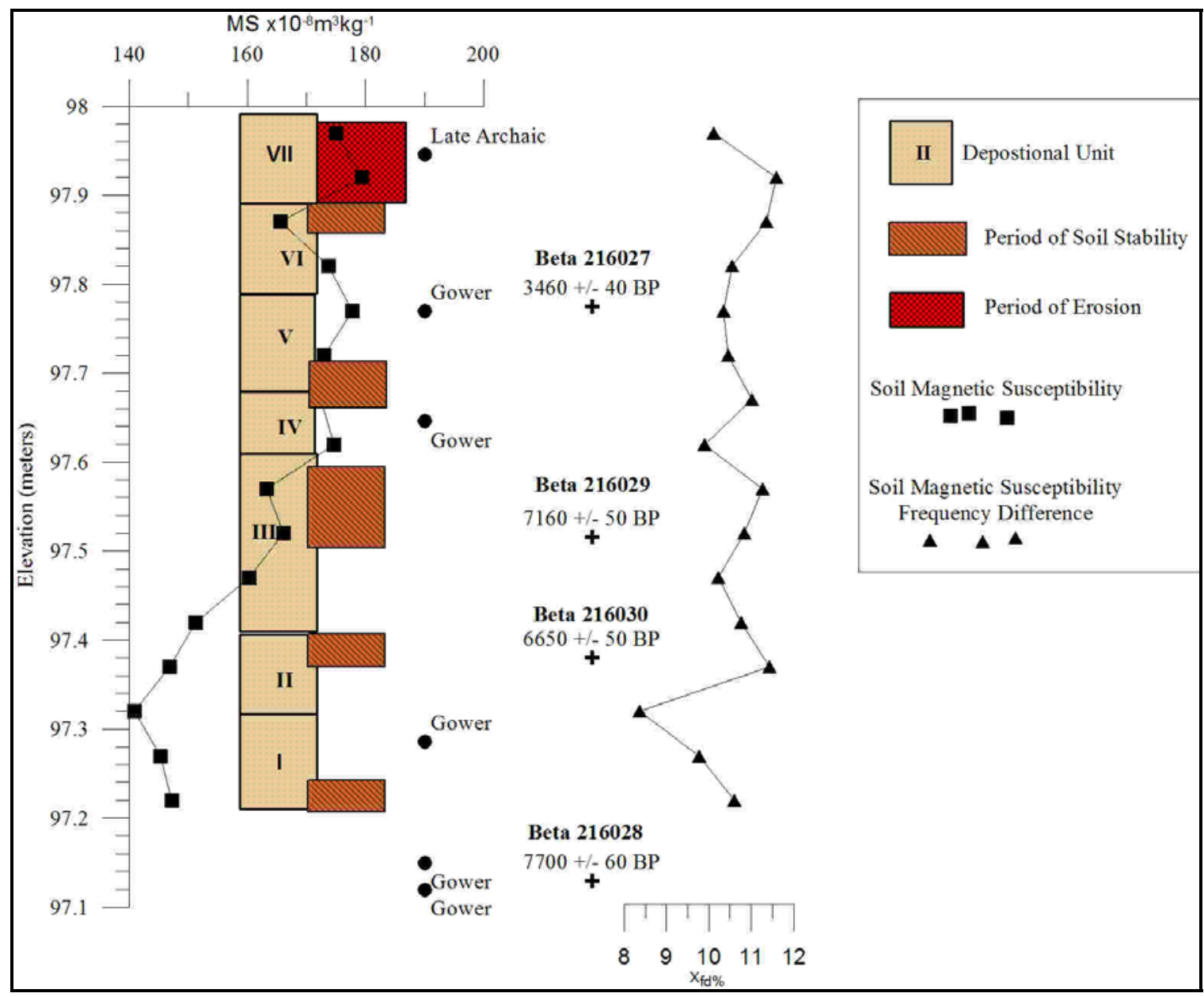

Figure 19. Schematic profile of soil magnetic susceptibility results, projectile point elevations and elevation of radiocarbon results.

overlaying Early Archaic Gower points suggests that the soils from the Middle Archaic from at least 5000 B.P. to 3500 B.P. is missing from the profile. This is demonstrated in the magnetic susceptibility results that show a truncated soil profile and a LF profile that is characteristic of long-term soil development beginning at $97.87 \mathrm{~m}$ elevation and going down in the profile. Prior to this event, alluviation was occurring, followed by brief periods of soil development. The resulting sediments accumulated to a thickness of approximately $70 \mathrm{~cm}$ from the bottom of the excavation block to the truncated soil. Based upon the radiocarbon dates, from Beta-216028 and 
Beta 216029 , approximately $40 \mathrm{~cm}$ of deposition occurred over approximately 540 radiocarbon years.

Results of Radiocarbon Assays.

The four Accelerator Mass Spectrometry (AMS) assays from the site were performed on samples of bone by Beta Analytic, with extracted collagen used as the dating medium. Table 2 shows the samples that are plotted by depth on Figure 19.

The bone samples were selected after the results of the soil susceptibility analysis to provide a date from stratigraphic breadth of the deposits. The date of $3460 \pm 40$ B.P. (Beta216027) demonstrates the potential for the uppermost levels to contain intermixed cultural materials with potentially a wide range of ages. OZ4 is closest to the contact between the truncated surfaces and therefore was more likely to contain an admixture of cultural material from a younger context. Part of this mixing is evident in the results from the AMS sample results where two of the dates (Beta-216029 and Beta-216030) are stratigraphically inverted. The overall rate of deposition is difficult to determine; however, a rough estimate from of $40 \mathrm{~cm}$ deposition over 540 years appears to be low, but is in fact relatively rapid, given the depositional context of other Early Archaic sites (Frederick 2007).

Table 2. Provenience of radiocarbon samples and resulting radiocarbon ages.

\begin{tabular}{|c|c|c|c|c|c|c|c|c|}
\hline Sample & Unit & Level & $\mathrm{N}$ & E & $\begin{array}{l}\text { Ele. } \\
\text { (m) }\end{array}$ & $13 \mathrm{C} / 12 \mathrm{C}$ & $\begin{array}{c}\text { Conventional } \\
\text { Radiocarbon } \\
\text { Age (B.P.) }\end{array}$ & $\pm 1 \sigma$ \\
\hline Beta 216027 & 2 & 1 & 1002.97 & 1001.25 & 97.775 & $-19.5 \%$ & 3460 & 40 \\
\hline Beta 216029 & 9 & 3 & 1000.40 & 1000.55 & 97.520 & $-19.1 \%$ & 7160 & 50 \\
\hline Beta 216030 & 9 & 5 & 1000.34 & 1000.62 & 97.380 & $-20.5 \%$ & 6650 & 50 \\
\hline Beta 216028 & 6 & 7 & 1001.50 & 1000.12 & 97.130 & $-19.8 \%$ & 7700 & 60 \\
\hline
\end{tabular}

The magnetic susceptibility results identified seven episodes of deposition averaging approximately $10 \mathrm{~cm}$ in thickness, and up to $20 \mathrm{~cm}$. These are shown in Figure 19 as boxes 
identified by Roman numeral and which are overlain on the soil magnetic susceptibility graph. Between episodes of deposition are periods of stability, identified by boxes filled with diagonal hash marks, where the magnetic signature was enhanced and this is likely the result of both pedogenic development and anthropomorphic activity. In addition to these shorter intervals of soil development is evidence of long-term soil profile development from $97.88 \mathrm{~m}$ to $97.32 \mathrm{~m}$ in the low frequency curve. The curve profile suggests there was a long-stable surface just above $97.88 \mathrm{~m}$. The above soil was eventually truncated and a later deposition occurred sometime after the Middle Archaic. This is shown by the cross hatching fill in the uppermost box on Figure 19. This soil was, in turn, removed during the construction of the fish hatchery ponds. 


\section{CHAPTER 7}

\section{ARCHAEOLOGICAL CONTEXT}

Based upon the magnetic susceptibility data and the distribution of artifacts, the excavated strata were divided into four analytical units- termed Occupation Zones (OZ). Mapped artifact elevations when projected against the north and west wall show vertical concentrations of artifacts (Figure 20), despite inconsistencies in the mapping of artifacts that makes an apparent higher density of debitage occurs in the upper levels. The vertical distribution of debitage and faunal remains are shown in Figure 21. Each of the zones is composed of a series of repeated occupations that accumulated artifacts within a period of deposition or surface stability. Zones are used rather than surfaces because of the difficulty of identifying and excavating an occupation surface, and whether intact surfaces could survive the numerous taphonomic forces, both natural and cultural. The zones are therefore a compromise analytical unit that is the result of excavation technique of using 10-cm arbitrary levels, and the movement of artifacts within the soil column. Each of the occupation zones is comprised of two $10 \mathrm{~cm}$ levels. The western units, those west of the trench anomaly, Units 2,3,5,6, and 9, were excavated to an elevation of $97.12 \mathrm{~m}$. In the eastern portion of the block, Units 1, 4 and 7 were excavated to an elevation of ca. $97.22 \mathrm{~m}$. As a result only level 7 from the eastern units are included in OZ1. The schematic Figure 22 is a representation of the units and levels associated with the Occupation Zones. 


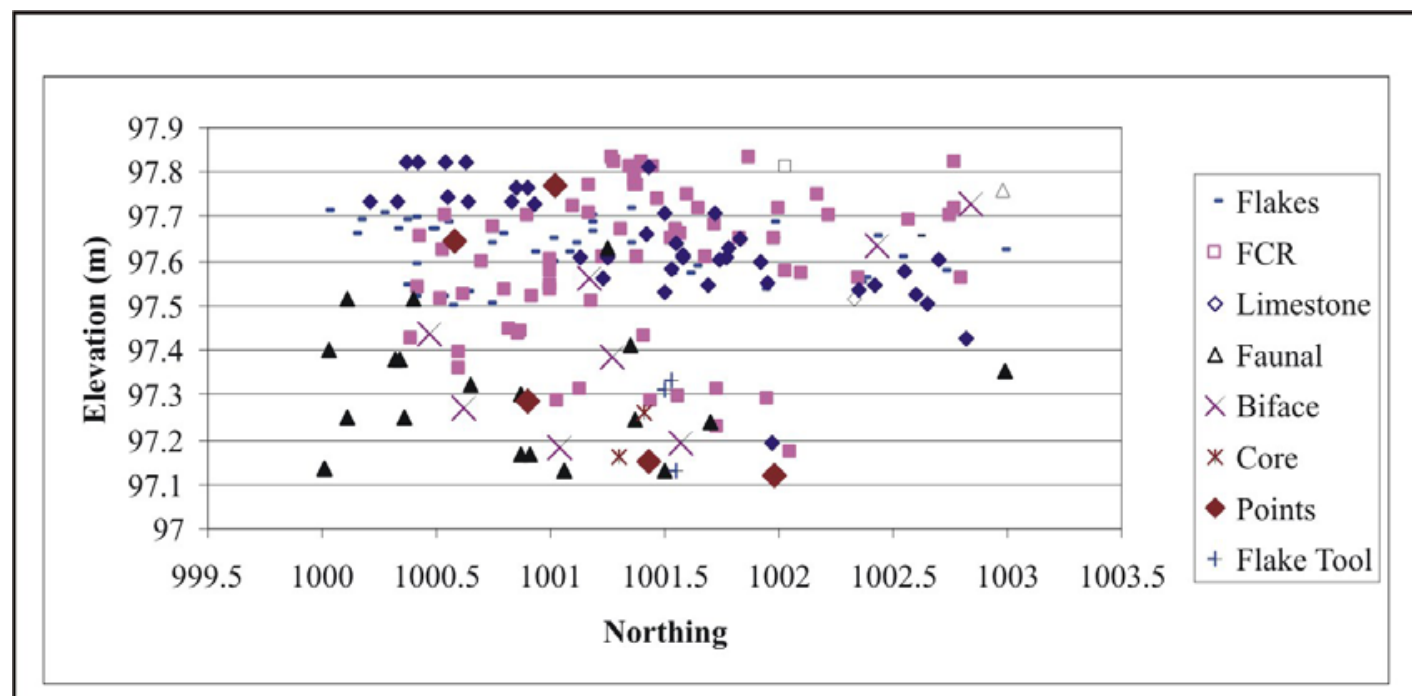

a) East wall of excavation block.

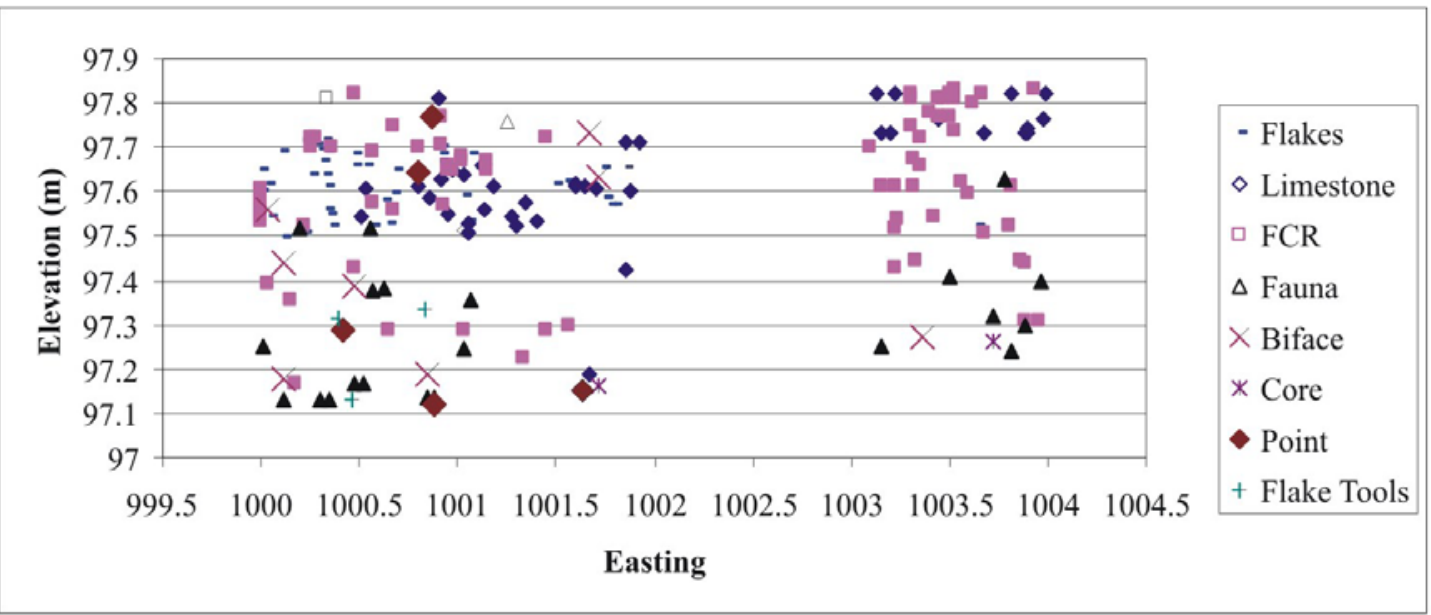

b) North wall of excavation block,

Figure 20. Mapped artifact schematics collapsed and projected on a) east and b) north wall profiles. 


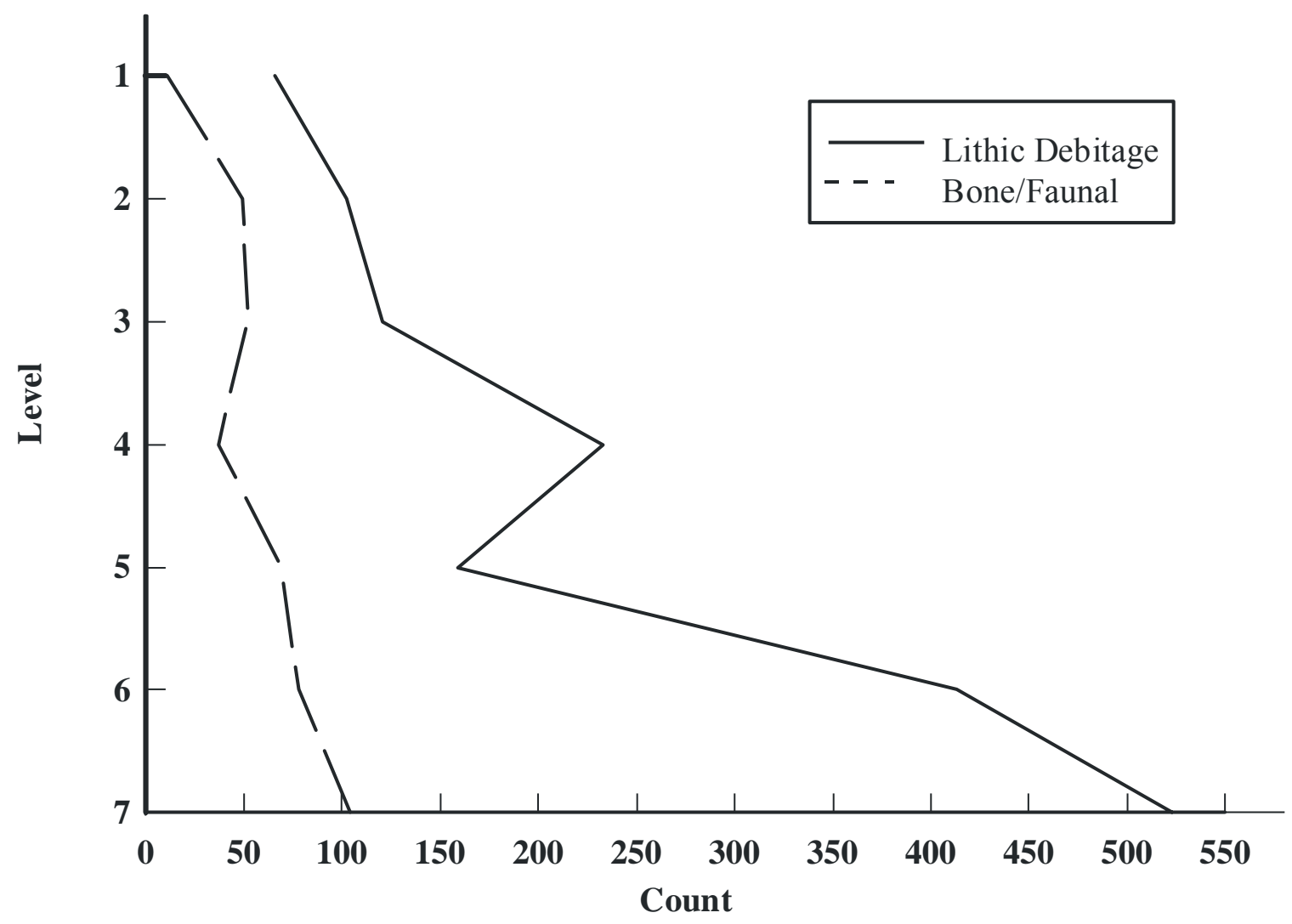

Figure 21. Debitage and bone (NISP) totals by excavation level.

The Occupation Zoness were designated by comparing artifact frequencies and depositional history of the site using the magnetic susceptibility data. As shown in Figure 23, the division of occupation zones with the magnetic susceptibility data, OZ1 corresponds to the deepest depositional unit and where both the LF and frequency dependence readings are at their lowest values. Also evident is that lithic debitage increases with depth, roughly doubling in frequency when using the debitage from the units with the highest debitage counts, Units 6 and 9 (Figure 24). 


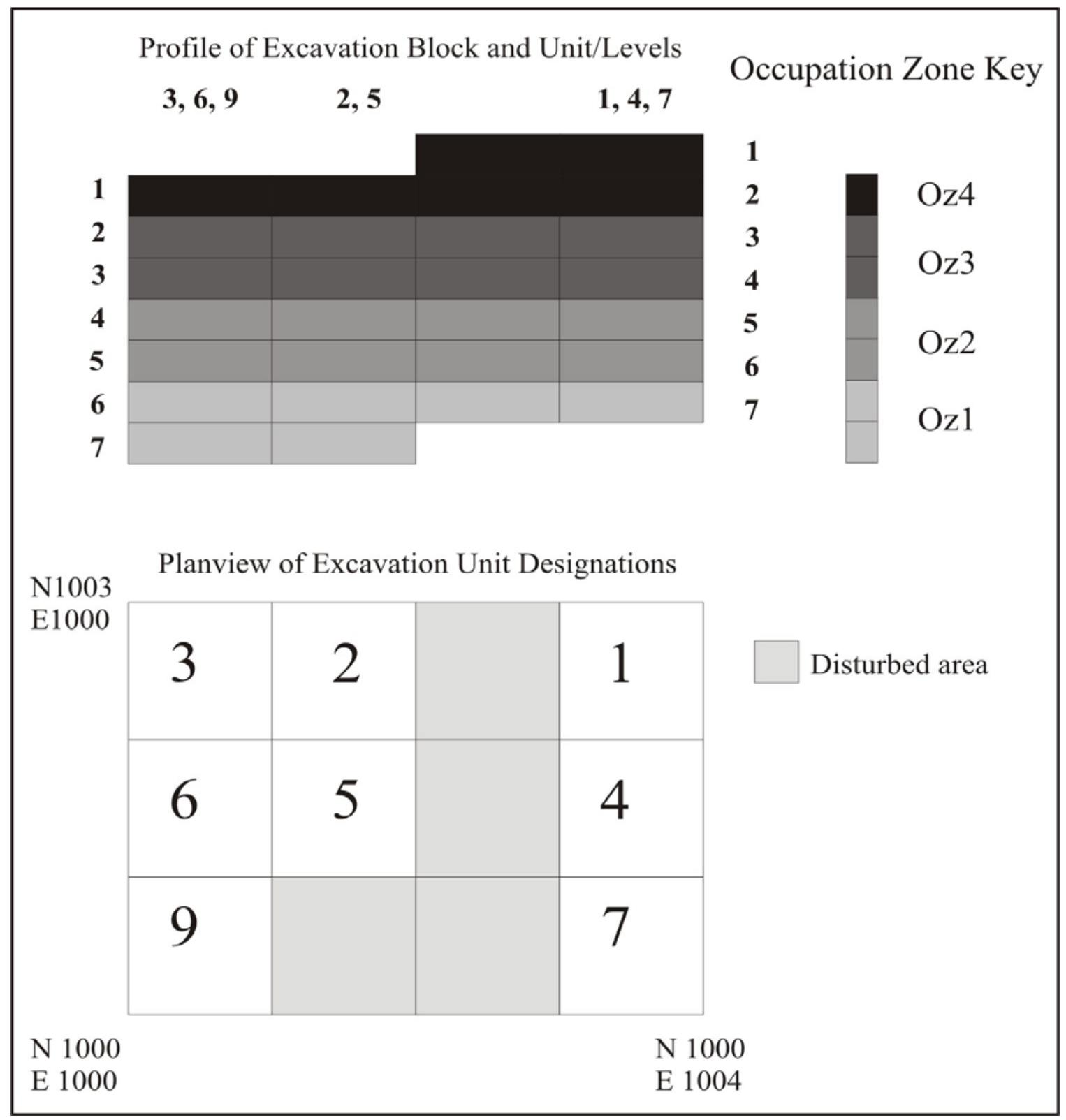

Figure 22. Schematic representation of Occupation Zones and unit designations.

\section{Occupation Zone 1}

Occupation Zone 1 is the deepest and oldest defined Occupation Zone of the data recovery excavation. The unit and levels comprising OZ1 are shown in Figure 22. Approximately $1.3 \mathrm{~m}^{3}$ of fill was excavated. The bottom elevation of the zone, $97.12 \mathrm{~m}$, was at the approximate water table of Sessom Creek and the San Marcos River. This is 


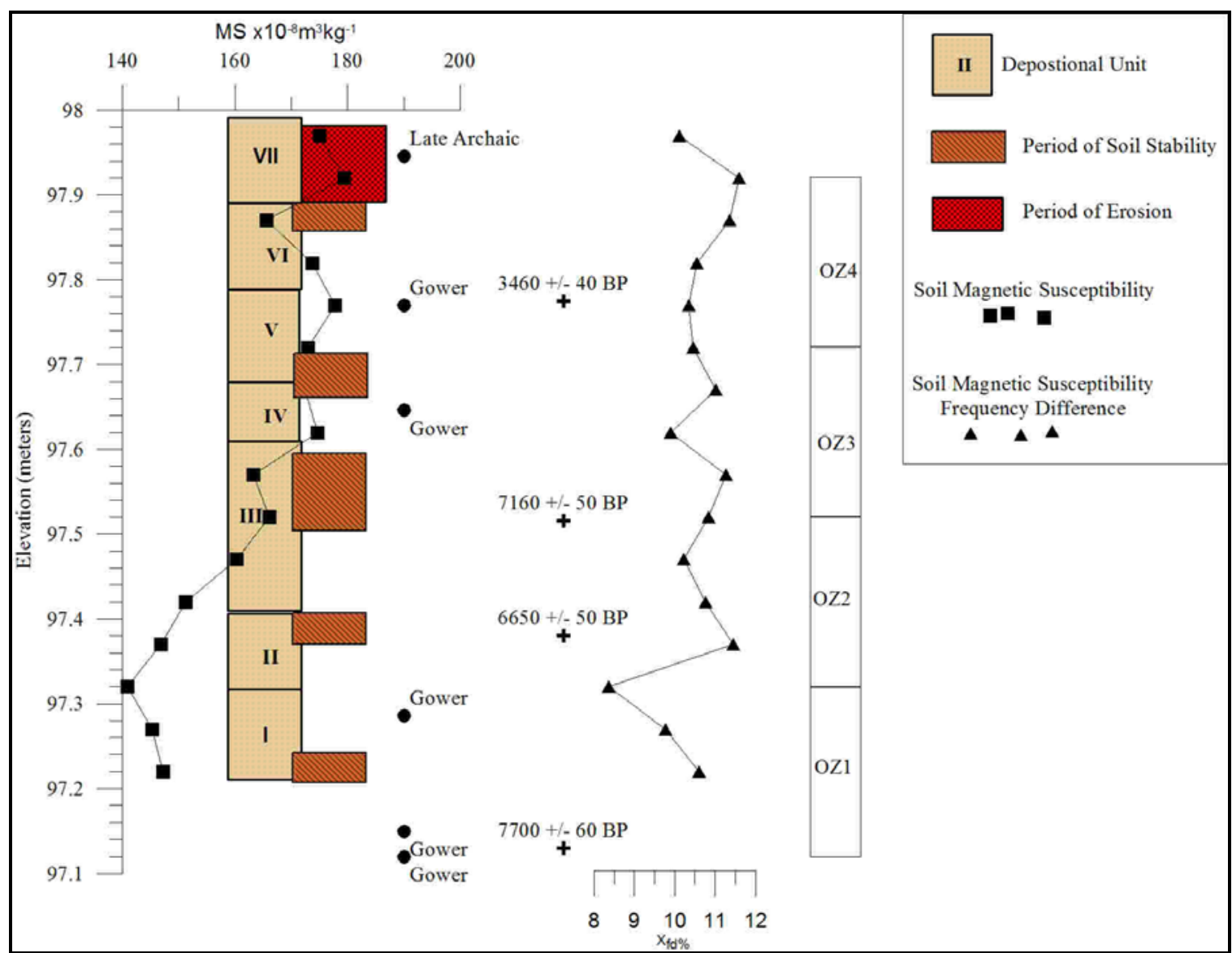

Figure 23. Schematic of Occupation Zone elevations with magnetic soil susceptibility, radiocarbon dates and projectile points.

evident by the crayfish burrowing into the excavation block (Figure 25) at the conclusion of the excavations. Crayfish can have a notable effect on site integrity because they can be significant agents of bioturbation (Pennak 1989).

The artifact assemblage consists of lithic tools and debris and faunal remains. All flotation and special samples that were collected for macrobotanical analysis contained no identifiable macrobotanical remains from any Occupation Zone. The lithic assemblage consists of three projectile points, five bifaces, four flake tools, one burin and one burin spall and two cores. The full descriptions of these artifacts are in Appendix C. 


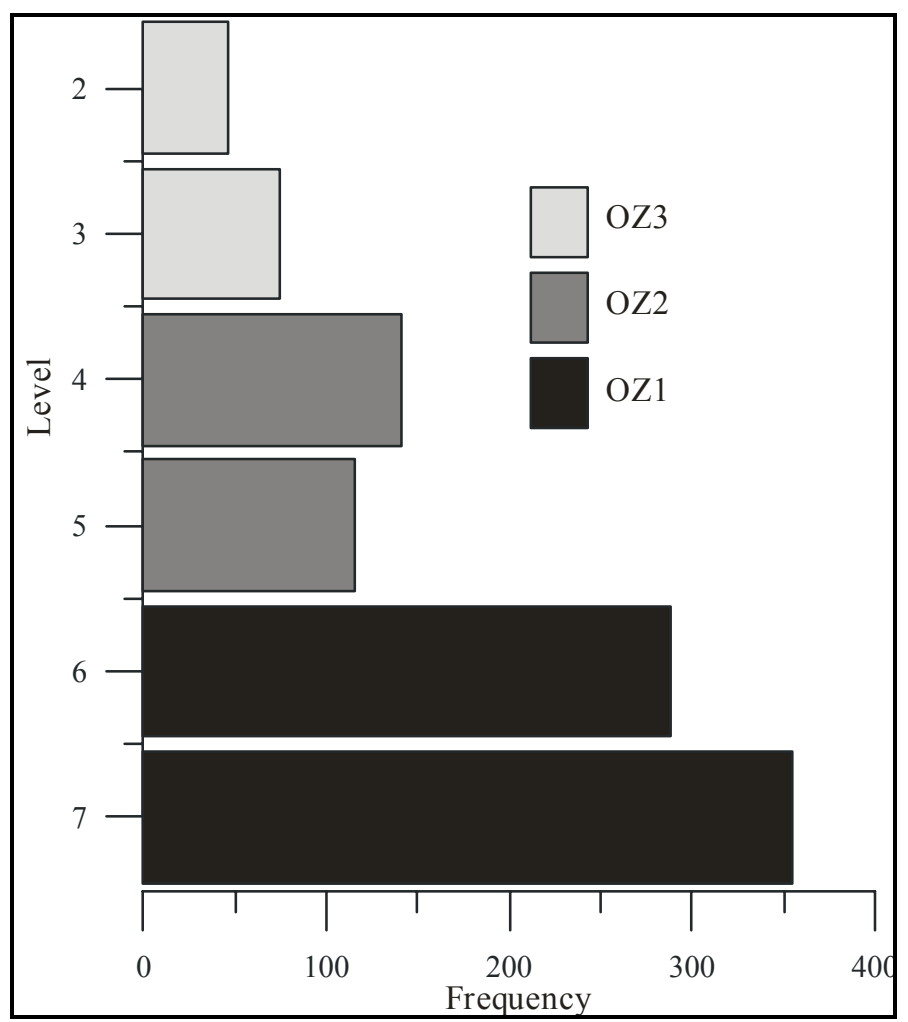

Figure 24. Debitage counts from Units 6 and 9.

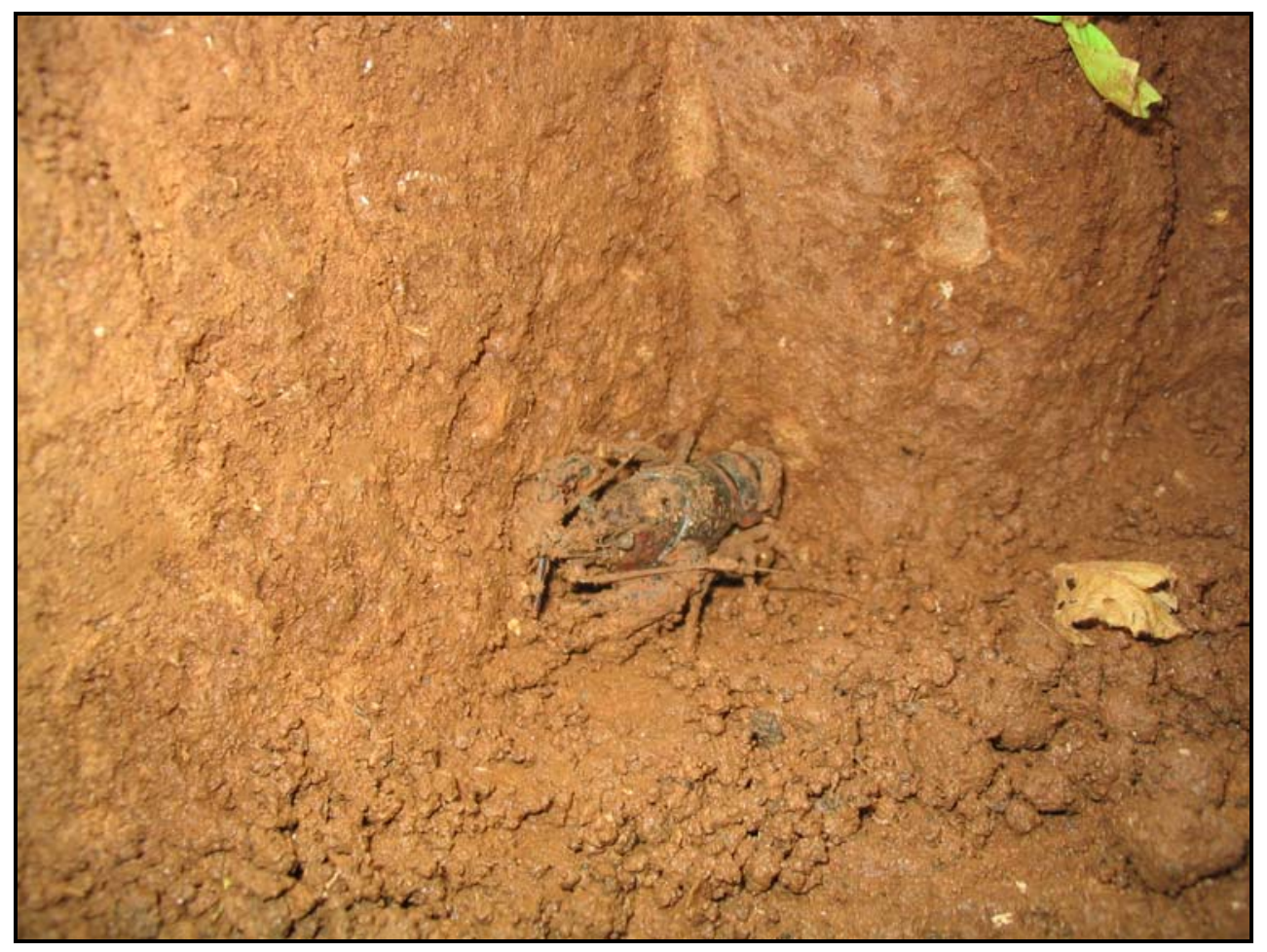

Figure 25. Crayfish burrowing into floor of excavation block at 97.12 m elevation. 
Table 3 shows the lithic tool categories and artifact identification number and the artifacts are shown in Figures 26 and 27. The single radiocarbon date on a fragment of large mammal bone (Beta-216028) is $7700 \pm 60$ B.P. This is from a sample from near the lowest excavated elevation and is the earliest date for the deposits. There is no precise end date for OZ1, mainly because of the reversal of dates between $\mathrm{OZ2}$ and OZ3, where the younger of the two dates is lower in elevation.

Table 3. OZ1 lithic assemblage.

\begin{tabular}{cccccccc}
\hline $\begin{array}{c}\text { Projectile } \\
\text { Points }\end{array}$ & Bifaces & $\begin{array}{c}\text { Flakes } \\
\text { Tools }\end{array}$ & Burins/Spalls & Cores & Other & Debitage \\
\hline 6-7X & $5-7 \mathrm{~B}$ & $9-6 \mathrm{~B}$ & $6-6 \mathrm{~A}$ & $4-7 \mathrm{~A}$ & - & 881 \\
& $9-6 \mathrm{~B}$ & $7-7 \mathrm{Y}$ & $6-6 \mathrm{C}$ & $6-6 \mathrm{X}$ & $5-7 \mathrm{P}$ & - & - \\
& $5-7 \mathrm{~A}$ & $9-7 \mathrm{~F}$ & $9-7 \mathrm{~A}$ & - & - & - & - \\
& - & $6-7 \mathrm{~N}$ & $5-7 \mathrm{o}$ & - & - & - & - \\
& - & $6-7 \mathrm{Y}$ & - & - & - & - & - \\
\hline Totals & $\mathbf{3}$ & $\mathbf{5}$ & $\mathbf{4}$ & $\mathbf{2}$ & $\mathbf{2}$ & $\mathbf{0}$ & $\mathbf{8 8 1}$ \\
\hline
\end{tabular}

Projectile Points. All of the projectile points are split stemmed points (see Figure 26). Specimen 6-7X is a basal fragment that resembles both a Gower and Hoxie, a type noted at WilsonLeonard (Dial, et al. 1998). It was broken during use, ending in a bending type fracture at the juncture of the stem and blade. The two more complete specimens, 9-6B and 5-7A, are Gower points and have been reworked and resharpened along the blade edges. Both of the specimens have proximal ends that terminate in combination impact and bending fractures, as would be expected from use as a projectile point. Both of the specimens were reduced in overall width because of the resharpening and specimen 9-6B has alternate beveling, where opposite edges and faces were retouched, creating a trapezoidal or parallelogram profile. This type of resharpening occurs while the tool remained hafted, since there was no apparent change in the profile of the base where hafting would be expected. Likewise, 5-7A, while not alternately beveled, was likely 


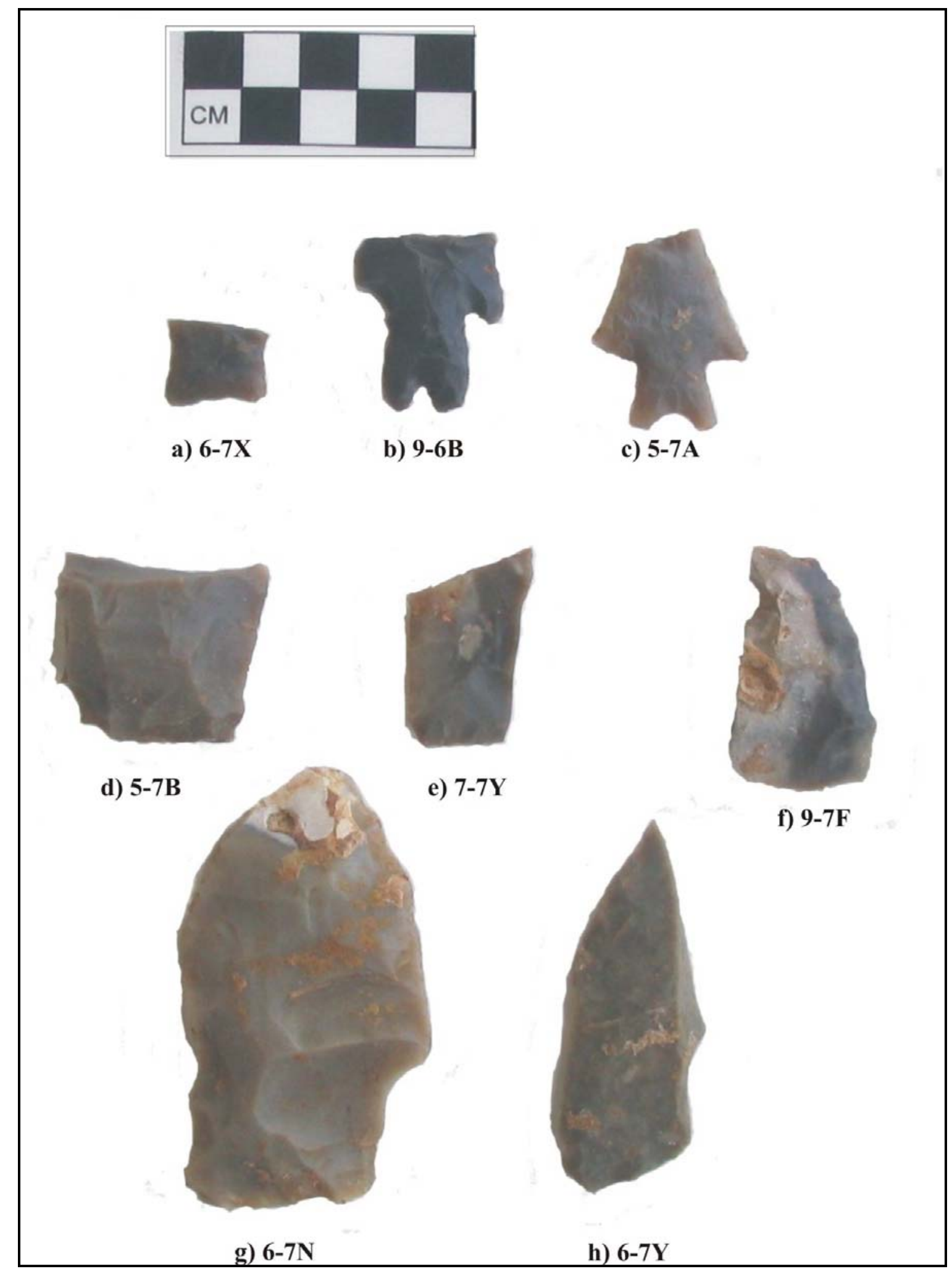

Figure 26. OZ1 Projectile points and bifaces. 


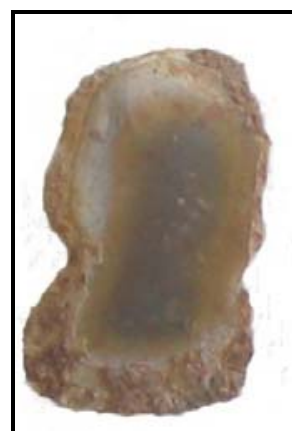

a) $9-6 \mathrm{C}$

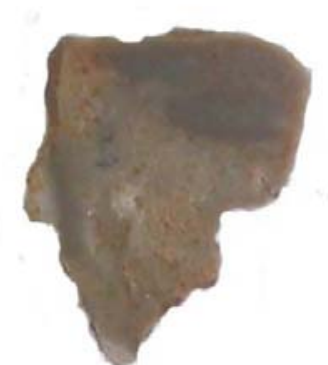

b) $6-6 \mathrm{C}$

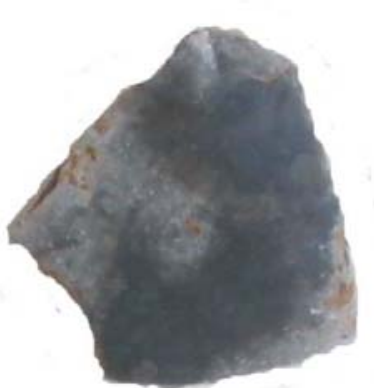

c) $9-7 \mathrm{~A}$

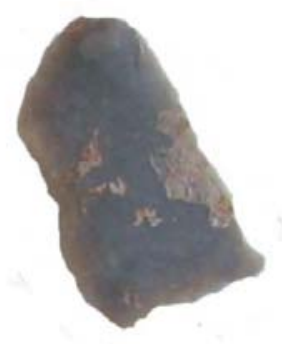

d) 5-7o

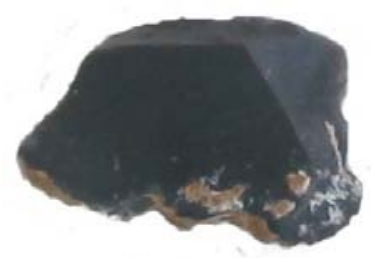

e) $4-7 A$

g) 6-6A
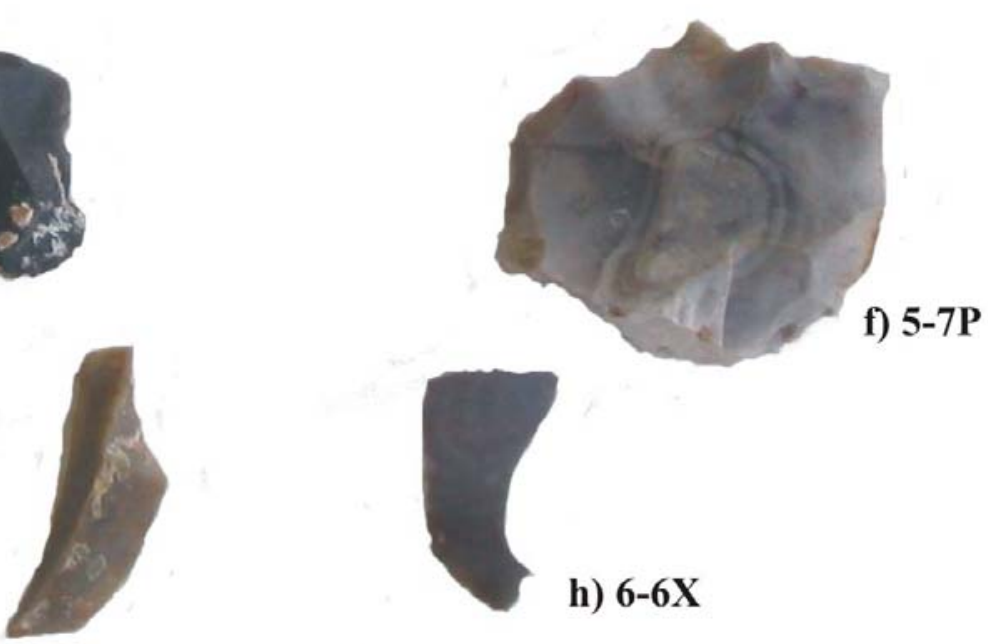

h) 6-6X

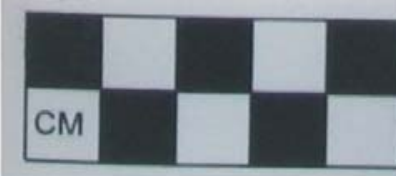

\section{Figure 27. OZ1 Flake tools, cores and burins and burin spalls.}

resharpened or repaired while still hafted. Repair continued on 9-6B until it became too short to be resharpened at the proximal end. These two projectile points were maintained and repaired when damaged and these specimens were then discarded when it was no longer necessary or possible to repair or recycle them for another function.

All of the specimens appear to have been broken while still hafted and therefore probably during use. The discard of the specimens probably occurred away from where they were broken, 
most likely the darts points were removed from the hafting element at a later period during an episode of tool maintenance.

Bifaces. The biface assemblage consists of five specimens, three are late stage or are finished bifaces, one is an early stage reduction and one is from a middle stage of reduction (see Figure 26). Two specimens were probably made on large hardhammer flakes (5-7B and 7-7Y). Specimen 5-7B retains part of a ventral surface while 7-7Y has a curved lateral profile similar to a flake profile. Specimen 9-7F is an edge fragment created from a plunging flake. The remaining parent biface (not recovered) would have likely failed and broken because of the amount of material removed. At least one of the specimens $(6-7 \mathrm{~N})$ is made from a large hardhammer flake that retains portions of the striking platform. One of the late stage specimens, 6-7Y was probably recycled from another bifacial tool, given its small size and minimal modification overlying larger previous flake scars. Specimens 7-7Y and 6-7Y may have been hafted based upon edge damage and location of the damage. Specimens 6-7N and 6-7Y were each partially thinned, and 6-7N was broken as a result of further attempts to thin the biface.

Burin edges created from some of the fractures do not appear to be utilized and therefore were not intentionally created as tools. Based upon the edge configuration of these bifaces, finished specimens and late stage bifaces appear to be cutting or slicing tools as opposed to gouges and drilling type tools.

All of these specimens are made from chert sources that appear in the debitage. Fossil inclusions in several of the specimens may have contributed to failure to further reduce the bifaces by creating unpredictable fracture planes. Small amounts of cortex on two of the specimens indicate the source material was from weathered upland cobbles. The raw chert source of the other specimens is probably a mixture of weathered surface exposed nodules, stream 
cobbles and bedded primary chert sources. This is based upon the locally available chert sources reflected in the debitage assemblage. The specimens have varying degrees of patination, which can roughly approximate exposure to ultraviolet radiation (sunlight) and therefore reflect how long specimens were exposed or were shallowly buried (Frederick, et al. 1994).

All of the specimens are relatively small, with several of the specimens made on flakes. When further thinning of the specimens was difficult due to variations in the raw material, the specimen was still salvaged and utilized as a tool. The presence of both early and late stage bifaces and salvaged and reworked tools indicates both maintenance and manufacturing occurred at the Icehouse site, and that there was an effort to maximize the lifespan of a biface before it was discarded. All of the specimens are either small or are fragments from small specimens. Over 95 percent of the debitage contained no cortex suggesting that primary reduction of bifaces was not a common lithic activity at the Icehouse site in OZ1.

Flake Tools. These tools consist of two morphological categories, steep-sided tools (96C, 6-6C) and thin tools (9-7A, 5-7o) (see Figure 27 a-d). All of the specimens have been minimally modified from the original flake blank. The thick steep-sided flakes appear to be multifunctional tools with several areas of use wear and different kinds of use wear. Notches and beaked tips suggest scraping and scoring, or perforating activities, while the edges of 6-6C (Figure 27b) may have been used for cutting or slicing. Both of the thick steep edged tools were made from large hard hammer flakes. They appear to be deliberately detached from portions of tabular cores such as the corner, in to create a triangular outline and steep sides.

The two thinner specimens were also used for a variety of tasks, possibly scraping thin cylindrical objects, possibly components for a projectile shaft, and scoring a material such as wood. Specimen 5-7o is the least modified and would classify as an edge damaged or utilized 
flake created through use. Overall, all of the flake tools could be classified as expedient flake tools as opposed to formal tools. Although in some instances, there appears to be a deliberate selection in raw material to make a desired flake shape, the resulting tool is minimally altered from its original form. These tools are likely generated at the site for the immediate tasks at hand.

Cores. There are two core specimens: 4-7A which is a blocky fragment from a multidirectional core and 5-7P is a discoidal shaped core that is crudely bifacial (see Figure 27 ef). Flake scars on the specimens indicate they where reduced using hardhammer percussion. The small flake scars suggest that both of the specimens were reduced to the point of exhaustion and were subsequently discarded. The remaining cortex on 5-7P is typical of weathered upland cobbles which are locally available.

Burins and Resharpening Spalls. Although the flake tool assemblage appears to be expedient and informal, there are two specimens, a resharpening spall (6-6A) that suggest that more formal flake tools were used at the Icehouse site but were not discarded or not recovered, and specimen 6-6x, a burin edged fragment (see Figure $27 \mathrm{~g}-\mathrm{h}$ ). The burin edge or point is created from a previously broken flake tool. This is more likely the result of salvaging an already broken flake tool rather than deliberately creating a tool to fracture, given that biface fragments with burin like points were available and not utilized, suggest that it was an opportunistic activity.

The spall represents an episode of resharpening or edge rejuvenation when the exhausted scraper edge is removed by a transverse blow perpendicular to the distal edge or bit of the flake tool. The removed flake resembles an orange segment and contains evidence of the last use of the flake tool. The original tool was most likely a complete formal scraper. Formal flake tools are 
more likely to be maintained and curated for future use. Because of this, it is unknown whether the specimen represents the actual use of a scraper at the site, or whether it was from a later episode of repair or refitting.

Debitage. There are 881 pieces of lithic debitage from OZ1, accounting for more than half of the total collected from the site. The debitage by reduction categories are displayed in Table 4. The flake fragments (FF) category has the most specimens, followed by indeterminate complete (IC). Generally this indicates a relatively high percentage of identifiable and relatively complete specimens, especially when compared to other Early Archaic assemblages such as the Sleeper site, where the majority of specimens were fragmentary (Johnson 1991). The high number of IC flakes suggest that late stage reduction occurred using both hardhammer and softhammer techniques. These flakes are typically small and have small platforms. Although not searched for specifically in the debitage analysis, IC flakes can be created from resharpening unifacial tools, using a soft billet or hammerstone. The number of dorsal scars on a flake can indicate how much prior reduction occurred. Small, numerous scars indicate a later stage reduction. When excluding shatter and flake fragments without platforms, 88.5 percent of the debitage has two or more dorsal flake scars, with the highest frequency among indeterminate flakes at 40.4 percent and hardhammer flakes at 32.7 percent. Softhammer (softhammer complete (SHC) and softhammer fragmentary (SHF)) and biface thinning flakes (BFT) account for 15.4 percent of flakes with multiple scars.

Table 4. Lithic debitage counts and percentages for OZ1.

\begin{tabular}{|c|c|c|c|c|c|c|c|c|c|c|c|}
\hline & $\mathrm{HHC}$ & HHF & $\mathrm{SHC}$ & BFT & SHF & IC & IF & $\mathrm{FF}$ & Shatter & $\begin{array}{c}\text { Burin } \\
\text { Spall } \\
\end{array}$ & Total \\
\hline$\%$ & 18.4 & 3.4 & 5.6 & 2.5 & 1.9 & 25.1 & 3.5 & 38.0 & 1.5 & 0.1 & 100.0 \\
\hline $\mathbf{n}$ & 162 & 30 & 49 & 22 & 17 & 221 & 31 & 335 & 13 & 1 & 881 \\
\hline
\end{tabular}


In addition to the high numbers of specimens in the IC category, the hardhammer complete (HHC) category is also unusual, especially when compared with hardhammer fragmentary (HHF). The majority of the hardhammer flakes are complete. Most of the complete flakes are smaller flakes, averaging $25.83 \mathrm{~mm}$ in length. These are smaller flakes detached from already prepared material and therefore are less likely to be fractured during reduction. Cortex occurs on 40 specimens, and on 21 of the HHC flakes. Only eight specimens have more than 50 percent cortex on the dorsal side. These flakes are larger than the average HHC flake, at $32.6 \mathrm{~mm}$ average length. The small size of the hardhammer flakes suggests that most resulted from cobble reduction, where most of the decortification occurred elsewhere. Most of these flakes are too small to have been intended blanks for flake tools although they may have been suitable for informal expedient tools.

The predominance of hardhammer flakes does not necessarily mean that flake production for flake tools was the intended result. Reducing bifaces from both cobbles and flake blanks can be accomplished with either technique or in combination (Whittaker 1994:126). The composition of the lithic debitage assemblage in OZ1 suggests that the primary lithic activities were the repair and maintenance of tools and the refitting or manufacture of bifaces.

Of the 881 pieces of debitage that were analyzed in OZ1, 72 of the pieces, or 8.2 percent, were burned to varying degrees. Most of the burned specimens $(n=44)$ are flake fragments, and burning could be attributed to further fragmentation. Burning is assumed to be post-depositional and related to activities such as discard and camp maintenance, where fragments may be accidentally incorporated into a fire. Overall, 9.6 percent of the total analyzed lithic debitage was burned, and therefore, OZ1 has slightly lower rate of burned debitage. 
Shattered flakes and shatter debris were also few in numbers. Shatter can be expected during core and biface preparation and initial reduction, and during actions such as bipolar reduction where a cobble is rested on an anvil as it is struck. Excessive shatter can be created by taphonomic forces such as exposure to high heat and trampling.

Abundant local raw material from stream bed loads and outcrops in both surface and bedded deposits were readily accessible to the occupants. The discarded tools such as the projectile points suggest that these were replaced at the site, which may have included making new projectile points.

Faunal Remains. There are 182 bone specimens from OZ1 weighing 92.36 grams (Table 5). The majority of the specimens ( $\mathrm{n}=177$ or 97.3 percent) are mammalian, with 3 specimens of birds, one fish scale, and one reptile (turtle). The fragmented bone made identification to genus taxon difficult and 131 specimens are classified as mammalian, 32 are large mammal, five very large mammal, and three small mammal. Mammalian genus identified include single specimens of Canis sp., Sylvilagus sp., Geomys sp. and Rodentia sp, two specimens of Artiodactyl sp. The sized mammal classes and the undifferentiated mammal specimens account for over 97 percent of the weight of the faunal assemblage. A single Lepisosteus sp. (gar) scale is not unexpected, given the proximity of the site to water. Seven elements were identified, a $1^{\text {st }}$ phalange from a Canis sp., a calcaneus from a Sylvilagus sp., a metapodial and molar fragment from artiodactyls, a maxilla from a gopher and a fish scale from a gar. The rest of the assemblage is too fragmentary.

\section{Table 5. Faunal bone assemblage from OZ1.}

\begin{tabular}{ccrc}
\hline Taxon & Element & Total & Weight $(\mathrm{g})$ \\
\hline Mammal--very large & - & 5 & 10.42 \\
Mammal-large & - & 32 & 43.1 \\
Mammal & - & 131 & 36.13 \\
Mammal-small & - & 3 & 0.22
\end{tabular}




\begin{tabular}{cccc} 
Canis sp. & $1^{\text {st }}$ phalange & 1 & 0.25 \\
Geomys sp. & Maxilla & 1 & 0.19 \\
Sylvilagus sp. & Calcaneus & 1 & 0.25 \\
Rodentia & - & 1 & 0.1 \\
Artiodactyl & Metapodial & 1 & 0.77 \\
& Molar & 1 & 0.24 \\
Testudines & Carapace & 1 & 0.25 \\
Aves & - & 3 & 0.37 \\
Lepisosteus sp. & Scale & 1 & 0.07 \\
\hline Totals & & 182 & 92.36 \\
\hline
\end{tabular}

The artiodactyl specimens are interesting in that it may be from a single animal, although no connection was established between the two elements. The sample of bone used to derive a radiocarbon date was selected from a fragment of large mammal, probably deer (Odocoileus virginianus). The specimen from Unit 6 Level 7 was one of several fragments. As noted in Appendix B, Meissner's examination of the faunal assemblage did not record evidence of burning, however, long bone fragments of deer and deer sized animals appear to have been split while still green, possibly to extract marrow.

An important aspect of the assemblage is the five fragments of very large mammal that are conservatively identified as bison-sized animal. These are likely bison remains, which are rare during this period of the Early Archaic at ca. 7700 B.P. The Icehouse site is ideally situated to make forays out onto the neighboring Blackland Prairies, which could be excellent bison habitat provided there were sufficient grasses. This is a period when bison were scarce or absent through much of Central Texas (Dillehay 1974).

Although the faunal assemblage is small, it demonstrates a variety of potential behavior; the presence of bison suggests group hunting on the adjacent Blackland Prairies, deer are found along the riparian corridor and along the Balcones Escarpment, while turtle and gar can be collected in the immediate vicinity of the site. Most of the remains are mammalian, and most are of these remains are from large mammals. The fragmented nature of the bone is attributed to 
taphonomic forces both natural such as sediment compaction and microbial activity, and cultural, such as splitting bone for marrow extraction. Combined with the lithic assemblage, it is reasonable to suppose that the Icehouse site was a hunting camp where a variety of game was processed and consumed.

Distribution of Artifacts. Every attempt was made to plot artifacts in place and on planviews during the excavations. Figure 28 is a schematic planview of all of the mapped artifacts from OZ1. Due to the dense clay soil, varying excavator experience and time constraints, artifacts were mapped and plotted unevenly. However, planviews of the plotted artifacts show some trends, especially the variation between Units 1, 4 and 7 on the east side of the trench and the units on the west side of the trench. Flake frequency is 


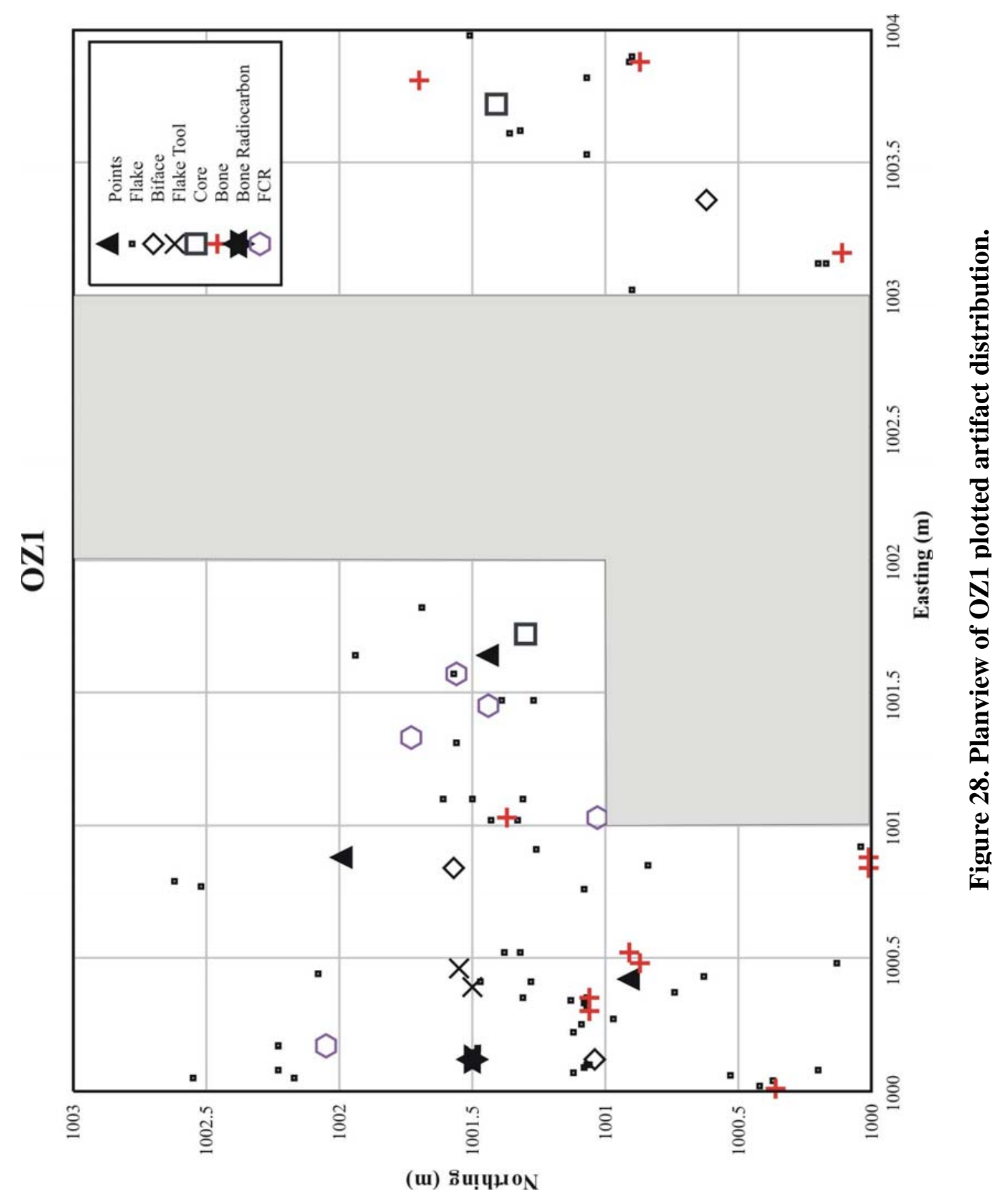


greater in the western units, especially Units 5, 6, and 9. In all Occupation Zones, the density of most artifact classes is significantly greater in the West section (units west of the trench), than in the East section (units east of the trench) of the excavation block in OZ1. That the artifact discrepancy occurs throughout the profile suggests that the effect may have a strong natural component, especially since the only class of artifacts that outnumbers the frequency to the west of the trench is burned rock. Although the majority of the artifacts are found west of the trench, they tend to be concentrated in Units 5, 6, and 9. In the debitage frequency counts, Units 1, 4 and 7 have counts similar to Units 2 and 3. This distribution appears to have a cultural construct, although these units are closest to Sessom Creek as Units 4 and 7 are closest to the San Marcos River. The presence of bison is inferred by fragments from a very large mammal, larger than a deer, and all of these fragments were recovered from Units 4 and 7 on the eastern side of the block. There are too few bone specimens to indicate that this was a butchering or processing are for at least one bison. No burned rock features were observed in OZ1, although burned rock was scattered and diffuse through the block, particularly at the western side. The few rocks argue against large processing features such as earthovens were constructed in the examined portion of the Icehouse site. The scattered burned rocks appear to be the remnants of small rock ringed or lined hearths.

\section{Occupation Zone 2}

Occupation Zone 2 is between elevations $97.32 \mathrm{~m}$ to $97.52 \mathrm{~m}$, levels 4 and 5 in excavation Units 2, 3, 5, 6 and 9 and levels 5 and 6 in excavation Units 1, 4, and 7. Portions of excavation Unit 1 contained part of the trench disturbance, and this material was collected separately because of its disturbed context. The estimated volume excavated is $1.6 \mathrm{~m}^{3}$. As in OZ1, the artifact assemblage consists of lithic tools and debris and faunal remains. No 
macrobotanical materials were recovered, and although burned or fire-cracked limestone was noted, no features were identified.

The magnetic susceptibility values at $97.32 \mathrm{~m}$ are the lowest recorded values from the site. This suggests a stratigraphic break and a period of rapid alluviation that deposited between 5 and $10 \mathrm{~cm}$ of sediments (Depositional Unit II in Figure 23). The rapid sedimentation decreased the formation of maghematite and also reduced the period in which there were stable surfaces. Stable surfaces can have elevated levels of magnetic susceptibility because of the repeated introduction of iron to the soil through burning and pedogenesis (Crockford and Willett 2001). The ending elevation of $97.52 \mathrm{~m}$ at the upper boundary of level 4 is where debitage frequency increases when compared to OZ2 above. The break is at approximately at the middle elevation of Depositional Unit III, and at the bottom of a period of stability after the formation of Depositional Unit III.

The artifacts assemblage consists of one projectile point, three bifaces, one flake tool, one burin and 400 pieces of debitage (Table 6). The lithic assemblage, without the debitage is displayed in Figure 29. There are 105 bone fragments and one of the most significant finds is a lower mandible fragment with teeth from a Canis sp. Characteristics of the mandible suggest that it may be a domesticated dog (Canis familiaris), although no definitive identification has been made at this date.

The AMS date of $6650 \pm 50$ B.P. is later than the date of $7160 \pm 60$ B.P. from OZ2. This suggests that there is some measure of disturbance in OZ2. The disturbance may be the vertical translocation of the bone fragment used for the AMS date. 
Table 6. OZ2 lithic assemblage.

\begin{tabular}{cccccccc}
\hline $\begin{array}{c}\text { Projectile } \\
\text { Points }\end{array}$ & Bifaces & $\begin{array}{c}\text { Flakes } \\
\text { Toools }\end{array}$ & Burins/Spalls & Cores & Other & Debitage \\
\hline $9-5 \mathrm{X}$ & $9-4 \mathrm{~B}$ & $6-5 \mathrm{~B}$ & $6-4 \mathrm{C}$ & - & - & 400 \\
& - & $3-5 \mathrm{~A}$ & - & - & - & - & - \\
\hline Totals & $\mathbf{1}$ & $6-5 \mathrm{~A}$ & - & - & - & - & - \\
\hline
\end{tabular}

Projectile Points. A single projectile point, 9-5X, (Figure 29 a) was recovered on the screens from $\mathrm{OZ2}$ and is a base fragment and partial stem from a Gower or Gower/Hoxie type similar to specimens recovered from Wilson-Leonard (Dial, et al. 1998). The specimen has the stem shape of a Gower point and the basal concavity similar to a Hoxie point. Such specimens illustrate the difficulty in identifying and assigning a specimen to a particular type when they share several traits along a continuum. The base was thinned unifacially creating an offset wedge, and the stem and base are ground, a trait found on Paleoindian and the older Early Archaic points. The breakage location suggests the point was broken while hafted. The material is a light tan colored chert that is fine grained and may be heat treated. The tan chert is noted locally, especially in river cobbles.

Bifaces. The sparse biface assemblage consists of two complete specimens and a distal fragment from what was likely a large later stage biface preform (see Figure $29 \mathrm{~b}$-d). Specimen 9-4B (Figure $29 \mathrm{~b}$ ), is the distal end of a large biface that was broken before final thinning occurred. The snap fracture suggests the specimen was broken during manufacturing. The specimen is evidence of biface production at the site using locally available chert.

Specimen 3-5A (Figure 29 c) was probably a complete and finished tool that was damaged and an attempt was made to rejuvenate the left margin. A series of flake 


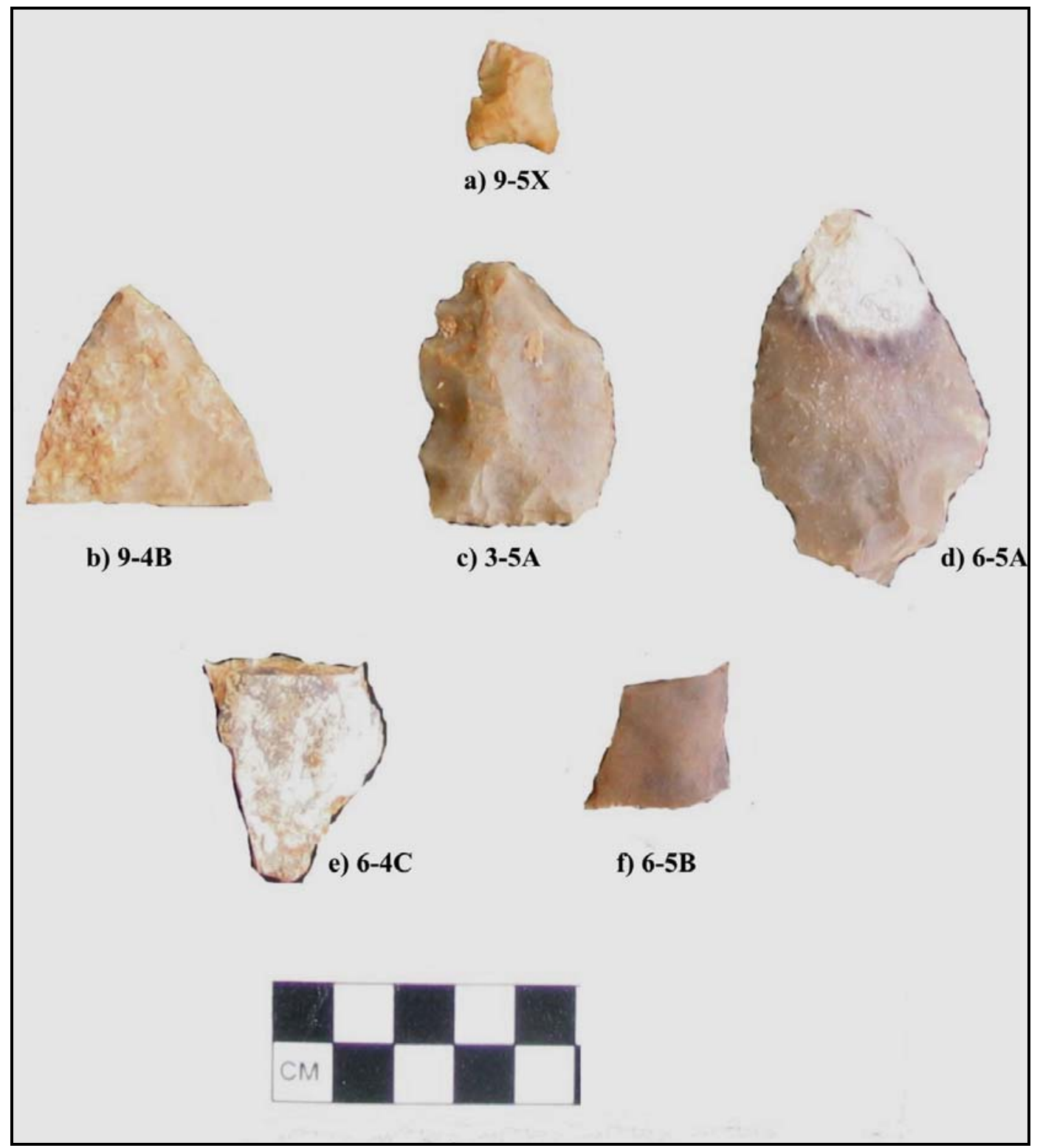

\section{Figure 29. OZ2 lithic assemblage.}

removals created a denticulate edge that may have been the intended modification. The base is thinned, possibly for hating purposes and the specimen resembles a hafted bifacial knife similar to specimens from the Early Archaic deposits at Wilson-Leonard (Dial and Collins 1998:551). The fine grain tan gray chert is found locally and throughout the assemblage.

Specimen 6-5A is made from a hardhammer flake, from which the bulb of percussion was removed. The proximal end was not further thinned, resulting in a wedge shaped profile. 
Attempts to further thin the specimen resulted in step hinges where thinning flakes failed to propagate. The specimen does have possible use wear along the lateral margins along $49 \mathrm{~mm}$ of the edge, and the distal end has an impact burin scar. The specimen is made from a fine grain tan gray chert that is found locally. The light color is a partly the result of patination and the original color is a light gray. The distal tip is considerably patinated almost white, which suggests that the specimen may have been partially buried, with the distal end exposed. The size of the flake is an indicator of the potential size of flake blanks used in tool production. The three biface specimens represent both manufacturing and repair/rejuvenation occurred during the occupations within OZ2.

Flake Tools. The solitary specimen (6-5B) is a sub-rectangular shaped medial flake fragment with small-1mm wide- flake scars along the left margin that do not extend past the breaks at the proximal or distal ends (see Figure 29). The slight concavity along the trimmed edge suggests it was used as a scraper. Both ends were snapped, in opposing directions possibly as a deliberate action to create the tool. There is no evidence of hafting and the specimen was likely held and used with light force. The material is fine grain tan gray chert and a small portion of cortex indicates the raw material was from a weathered upland or exposed cobble.

Burins and Burin Spalls. Specimen 6-4C (Figure 29 e) is the largest burin in the site assemblage and is made on the proximal fragment of a large hardhammer flake (see Figure 29). There are two burin edges and two burins that are along the left margin. The burins appear to be deliberately shaped, although the specimen is crazed from exposure to high heat, which obscures any use wear damage on the burins.

Debitage. There were 400 analyzed pieces of debitage from OZ2, and the reduction categories by frequency and percentage are displayed in Table 7. The percentage of flake 
fragments at 38.4 percent is almost identical to the percentage in OZ1. The distribution is similar to OZ1 with the main difference being there is a higher percentage of softhammer flakes in OZ2. Indeterminate complete flakes are second highest category at 22.5 percent, followed by complete hardhammer flakes. The percentage of debitage with two or more dorsal flake scars, excluding flake fragments and shatter is 89.3 percent, similar to the percentage in OZ1. Indeterminate flakes are 35 percent, hardhammer are 33.3 percent and softhammer are 21 percent of flakes having multiple dorsal scars. The greatest difference from OZ1 is the increase in softhammer flakes with multiple scarring.

Table 7. Lithic debitage counts and percentages for OZ2.

\begin{tabular}{ccccccccccc}
\hline & HHC & HHF & SHC & BFT & SHF & IC & IF & FF & SR & Total \\
\hline$\%$ & 18.0 & 5.5 & 9.3 & 1.0 & 2.8 & 22.5 & 1.8 & 38.3 & 1.0 & 100.0 \\
\hline $\mathbf{n}$ & $\mathbf{7 2}$ & $\mathbf{2 2}$ & $\mathbf{3 7}$ & $\mathbf{4}$ & $\mathbf{1 1}$ & $\mathbf{9 0}$ & $\mathbf{7}$ & $\mathbf{1 5 3}$ & $\mathbf{4}$ & $\mathbf{4 0 0}$ \\
\hline
\end{tabular}

Among the flakes with platforms, fragmentation remains low. The highest breakage rate is in the hardhammer flakes at 30.6 percent followed by softhammer and biface thinning flakes at 27.8 percent, while indeterminate flakes are 7.8 percent fragmented. This is also similar to OZ1, where indeterminate flakes have the lowest breakage rate. Again this is to a large part related to the smaller size of indeterminate flakes. The average length of a complete hardhammer flake is $20.97 \mathrm{~mm}$ and the length of a complete softhammer flake is $21.63 \mathrm{~mm}$ and $28.25 \mathrm{~mm}$ for biface thinning flakes. The average length of an indeterminate flake is $14.71 \mathrm{~mm}$.

Cortex occurs on 42 specimens, or 10.5 percent of the analyzed 400 specimens. Hardhammer flakes account for 21 of the specimens or 50 percent, followed by 10 flake fragments or 23.8 percent and indeterminate flakes at 8 specimens or 19.0 percent. The percentage of cortex on flakes is low, suggesting late stage reduction and manufacturing on flake blanks. 
Burning or exposure to high levels of heat was identified on 41 specimens, or 10.3 percent of the assemblage. Flake fragments account for 27 burned specimens, with the other categories accounting for no more than three specimens. The 10.5 percent is slightly greater than the 9.6 percent burned rate of the overall assemblage. Burning of debitage is likely post depositional and occurs when debitage is introduced or incorporated into hearths.

All of the observed chert used for tools and found in the debitage can be found locally. No exotic material such as obsidian was noted. It is reasonable to assume that locally available material was used for the manufacture of lithic artifacts at the Icehouse site. The composition of the assemblage suggests that late stage reduction and manufacturing and repair and recycling of tools were the main lithic activities in OZ2. The tools are characteristic of what would be expected in a highly mobile hunter's assemblage consisting of bifaces and hafted tools (i.e., Keeley 1982; Kuhn 1994).

Faunal Remains. The faunal remains from OZ2 consist of 105 specimens with a total weight of 54.91 grams. The majority of specimens are mammal, 101 of 105, or 96.2 percent. Aves sp. and Testudines sp. make up the other taxa. The most numerous fragments are from mammals and are too fragmented to estimate a general animal size. These 80 specimens account for 76 percent of the faunal assemblage. The faunal assemblage from OZ2 is displayed in Table 8 showing taxon when available, count (NISP), and weight.

Table 8. Faunal bone assemblage from OZ2.

\begin{tabular}{ccrc}
\hline Taxon & Element & Total & $\begin{array}{c}\text { Weight } \\
(\mathrm{g})\end{array}$ \\
\hline Mammal & - & 80 & 19.42 \\
Mammal-large & - & 12 & 18.53 \\
Mammal-small & - & 2 & 0.19 \\
Canis sp. & Mandible & 1 & 8.77 \\
Procyon lotor & 1st phalange & 1 & 0.16 \\
Artiodactyl sp. & Metapodial & 1 & 0.50 \\
Odocoileus virginianus & Deciduous molar & 1 & 3.11
\end{tabular}




\begin{tabular}{cccc} 
& Deciduous premolar & 2 & 2.75 \\
& Molar & 1 & 0.21 \\
Testudines & Carapace & 1 & 0.06 \\
Aves & - & 3 & 1.21 \\
\hline Totals & & $\mathbf{1 0 5}$ & $\mathbf{5 4 . 9 1}$ \\
\hline
\end{tabular}

No overt burning was noted on the specimens, but along with a high degree of fragmentation, there was pitting on fragment surfaces that can be caused by microbial activity while the bone is exposed and by passing through the human or canine digestion system. If this pitting and etching was caused though digestion, the presence of a canine mandible fragment raises numerous scenarios about camp scavenging and whether the mandible fragment is from Canis latrans, coyote, or Canis familiaris, a domesticated dog.

The mandible fragment (Figure 30) has evidence of severe arthritis at the condoyle, a condition that occurs in older animals. If the mandible was from a coyote, it is rare that it would have lived so long or with this condition. This suggests that the animal had help feeding for it to have lived with this condition. Dog burials are known at several Archaic sites, including three burials in Early Archaic deposits at the Koster site at ca. 8500 B.P. (Morey 2006; Morey and Wiant 1992), and dogs may have been in the Americas with the first settlers (Fiedel 2005). 


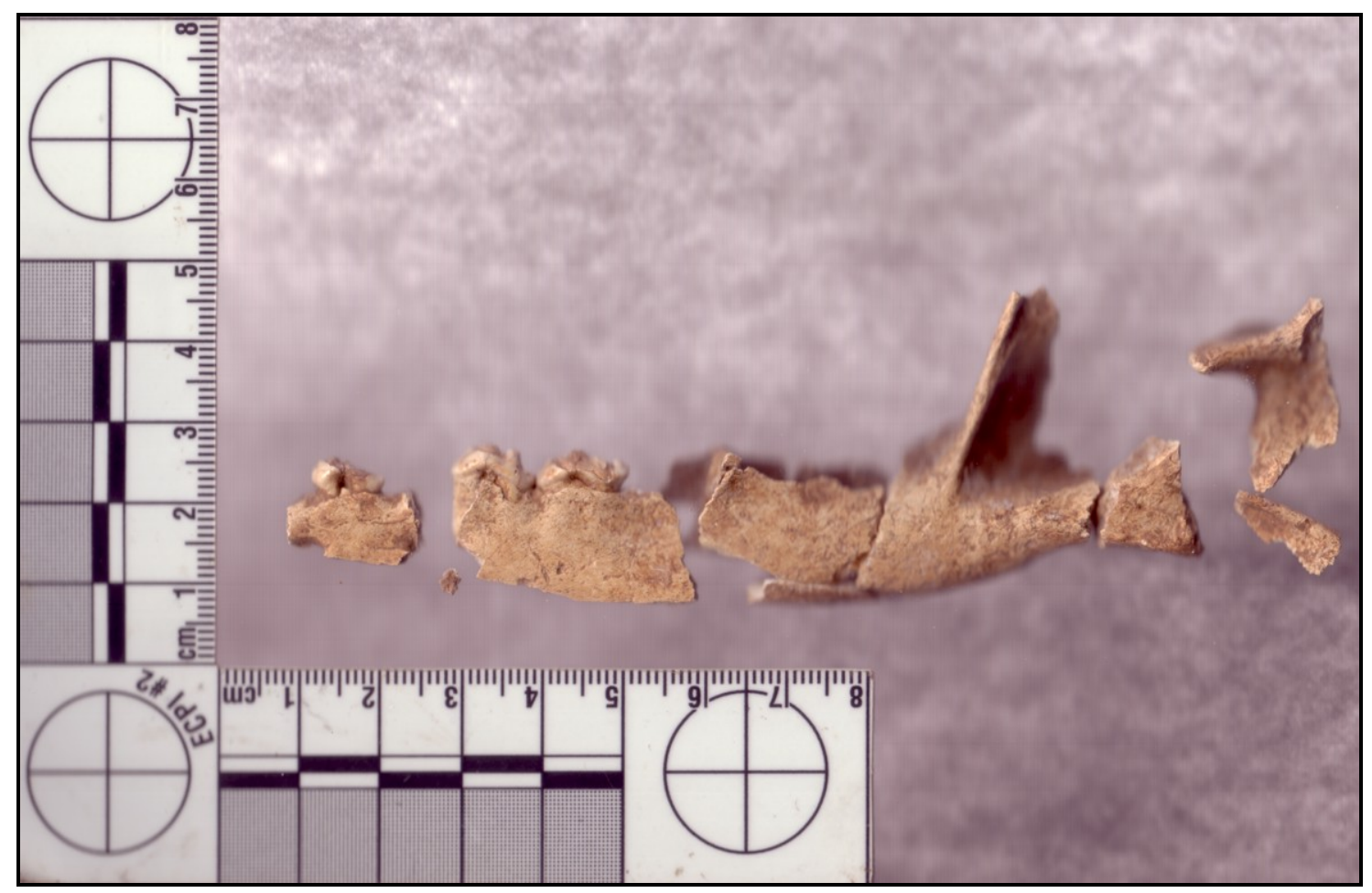

\section{Figure 30. Canid mandible fragment from OZ2.}

Dog burials are viewed as a particular Archaic practice in the continental southeast that decreases during the late prehistoric (Morey 2006). The specimen is incomplete and missing several indicators that would make identification on the basis of observed characteristics easier. Traits in jaw morphology that indicate domestication include shortening of the mandible and increased curvature and closer dentition to accommodate teeth in a shorter jaw (Morey and Wiant 1992). The specimen is missing several premolars and portions of the condoyle that would illustrate how dense the teeth were spaced and the overall curvature of the mandible. Canids have been a source of fur and hide, teeth for ornamentation and food (Novekosky and Popkin 2005). Canid remains are relatively scarce in Texas faunal assemblages, even at sites were there is a wide variety of prey species and a high degree of precision in the recovery techniques, such as the Wilson Leonard site north of the Icehouse site, where a complete column was waterscreened through fine mesh (Baker 1998; Balinsky 1998). 
The presence of both deer teeth and an artiodactyl metapodial suggest that whole animals were brought to the site, and that the distance from the kill was relatively short. Elements such as the femur contain the most meat and the most bone marrow, while the lower limbs contain little meat and are more difficult to extract marrow (Binford 1981; Madrigal and Capaldo 1999; Madrigal and Holt 2002). The elements brought to a site are conditioned by factors such as the food value of the elements, processing costs and time, the size of the animal and distance traveled. In addition, taphonomic forces can further alter a faunal assemblage by selectively destroying bone at varying rates (Marean and Cleghorn 2003; Monahan 1998).

The faunal assemblage contains a mixture of animals found in the riparian corridor, which includes turtle, bird, white-tailed deer, raccoon, and artiodactyl, most probably deer, although pronghorn antelope were processed at the Armstrong site (41CW54) located only a few kilometers from the Icehouse site. The Canis sp. jaw fragment may be from a domestic dog of advanced age. The mandible fragment was recovered at the north boundary of the excavation block and although no burial pit or concentration of bone was noted, because of its location a determination on the origins of the fragment is not possible.

Distribution of Artifacts. Figure 31 is a planview of plotted artifacts. Lithic tools are found to the west of the trench, as is most of the debitage, 89.5 percent or 359 of the 400 specimens. 330 specimens are found in just three Units, 5, 6 and 9, with 125 specimens in Units 6 and 131 specimens in Units 9 . Units 6 and 9 contain the most 


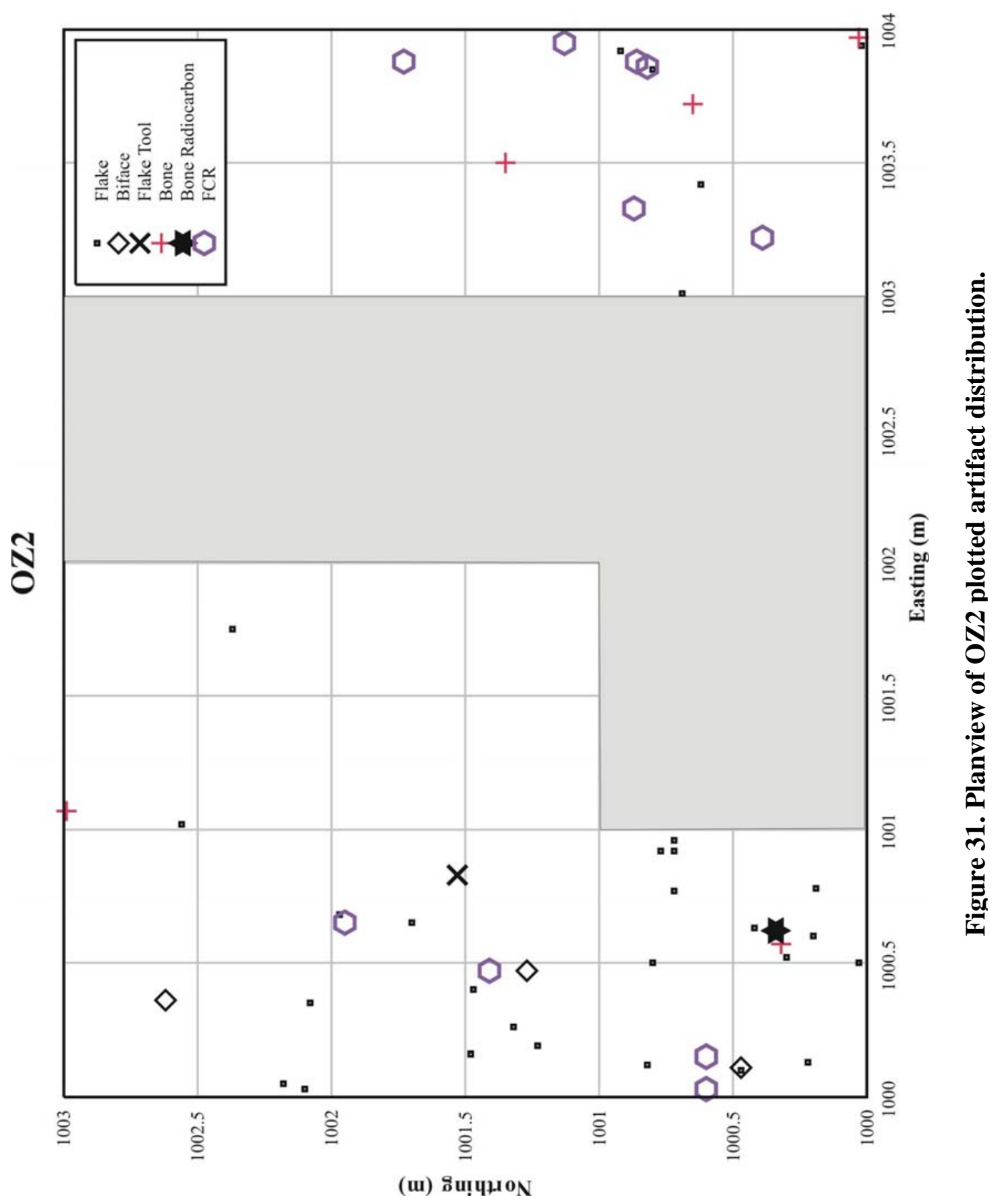


concentrated assemblage of lithic material, including two of the bifaces and a flake tool, and may be a knapping location which may extend westward into the unexcavated areas. Burned rock is unpatterned and diffuse and may be parts of disarticulated hearths that were constructed directly on the surface and not lining a pit or depression. Faunal material is more widely distributed, however Unit 9 had a total specimen weight of $18.07 \mathrm{~g}$. Unit 2 contained 17 specimens with a total weight of $11.78 \mathrm{~g}$. All of the deer teeth are from Unit 9, which also has the greatest variety of fauna in the OZ2 assemblage. The mixture of faunal material in Unit 9 suggests that it may have been a locale where animals were processed for food.

\section{Occupation Zone 3}

Occupation Zone 3 is between elevations $97.52 \mathrm{~m}$ and $97.72 \mathrm{~m}$, corresponding to levels 2 and 3 in Units 2, 3, 5, 6 and 9, and levels 3 and 4 in Units 1, 4, and 7. A portion of Unit 6 extended to elevation 97.74 but is included in OZ3. The estimated excavation volume is $1.61 \mathrm{~m}^{3}$. A small burned rock feature was recorded along the boundary of Units 5 and 6 , and the remainder of the assemblage consists of lithic tools and debris, and faunal bone and teeth and includes possible bone tools.

OZ3 is within three units of deposition, III, IV and V, and two periods of soil stability or anthropogenic enhancement (see Figure 23). Elevated quantities of unburned limestone and burned rock were noted in OZ3. After depositional Unit III was deposited there was a period of stability that was long enough for a period of soil formation that is demonstrated in both Low Frequency curve and Frequency Dependence values that show a decrease with slight peaks. These slight peaks can be caused through pedogenesis and anthropogenic activity as magnetic particles are translocated downwards. There is a slight peak in the HF magnetic susceptibility at $97.62 \mathrm{~m}$ with a reading of $174.7 \times 10-8^{\mathrm{m} 3} \mathrm{~kg}^{-1}$ S.I. units. This increase may be the result of 
increased burning in the level where Feature 4 was recorded. This is also where the Frequency Dependence $(\mathrm{xfd} \%$ ) value decreases, indicating a depositional break and alluviation of Deposition Unit IV (see Figure 23).

An AMS date of $7160 \pm 50$ (Beta-216029) was obtained from a bone fragment from Unit 9 level 3 at elevation $97.52 \mathrm{~m}$, the bottom elevation of OZ3. The artifact assemblage consists of one projectile point, two bifaces, one flake tool, and two cores and 202 pieces of debitage (Table 9). One small burned rock feature was recorded and 90 pieces of faunal bone representing a variety of animals were recovered. The lithic artifacts are displayed in Figure 32.

Projectile Points. The single projectile point is a Gower point $(9-2 \mathrm{~N})$ missing the distal end (Figure $32 \mathrm{a}$ ). The fracture is consistent with impact breakage patterning that also removed a portion of the left margin and both obverse and ventral faces. Prior to the extensive impact damage, the specimen was extensively resharpened while remaining hafted.

Table 9. OZ3 lithic assemblage.

\begin{tabular}{cccccccc}
\hline & $\begin{array}{c}\text { Projectile } \\
\text { Points }\end{array}$ & Bifaces & $\begin{array}{c}\text { Flakes } \\
\text { Tools }\end{array}$ & Burins/Spalls & Cores & Other & Debitage \\
\hline & $9-2 \mathrm{~N}$ & $2-2 \mathrm{~B}$ & $9-3 \mathrm{X}$ & - & $9-3 \mathrm{Y}$ & - & 202 \\
& - & $6-3 \mathrm{C}$ & - & - & $9-3 Z$ & - & - \\
\hline Totals & $\mathbf{1}$ & $\mathbf{2}$ & $\mathbf{1}$ & $\mathbf{0}$ & $\mathbf{2}$ & $\mathbf{0}$ & $\mathbf{2 0 2}$ \\
\hline
\end{tabular}

Resharpening created alternate beveling and reduced the width of the blade creating weak shoulders. The flaking patterning is random, and compared with the Wilson-Leonard assemblage, the basal concavity is shallower and the overall size of the specimen is smaller than average (Dial, et al. 1998:344). 


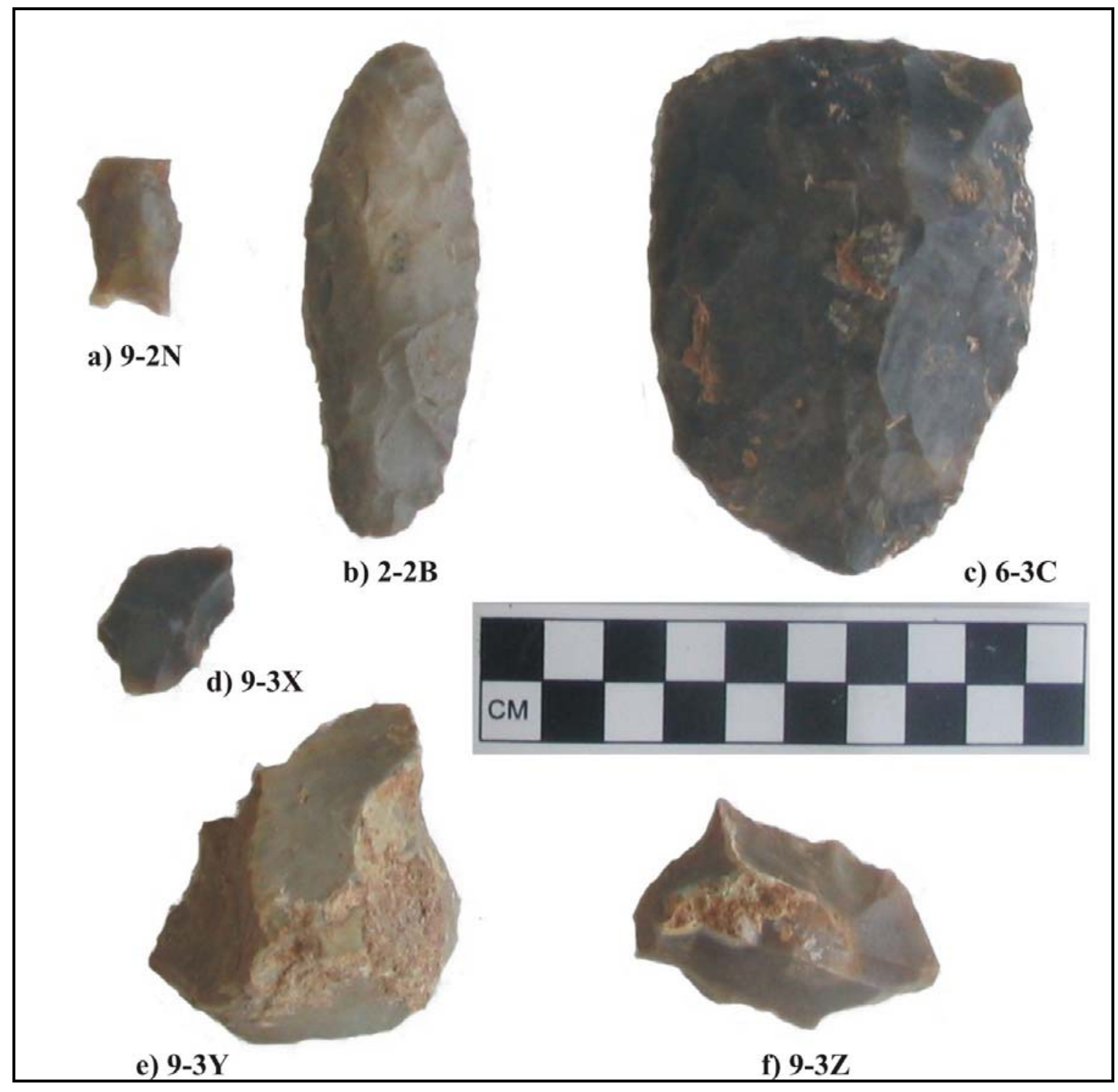

Figure 32. OZ3 lithic assemblage.

Bifaces. The two bifaces are complete specimens (Figure $32 \mathrm{~b}-\mathrm{c}$ ). Specimen 2-2B is a late Stage 4 biface that is bipointed. The specimen has a slight curvature in profile and a bulb of percussion is thinned, indicating that the specimen is made on a large hardhammer flake. Flaking is randomly patterned and there are several failed attempts to further thin the biface. It is possible that further thinning attempts were stopped as the specimen became too narrow to effectively thin further. Trimming was done using hardhammer percussion to prepare the edges. Edge damage may be from use wear as a cutting tool or abrasion and dulling for platform edge 
preparation for further thinning. The chert is fine grain tan gray colored with developing patination and traces of calcium carbonate adhesion. The chert is a locally available and observed material.

Specimen 6-3C is the largest biface in the assemblage and resembles a large bifacial gouge. Made from a large hardhammer flake using hardhammer reduction, the specimen does not appear to be used. Step fracturing around the margins developed during attempts to thin the specimen and numerous fossils $10 \mathrm{~mm}$ in diameter may have impeded attempts to effectively thin the specimen. Based upon the degree of manufacturing and reduction, the specimen is classified as a Stage 3 biface. Although it is possible that the specimen was used and the bit edge rejuvenated, there is no damage consistent with hafting such as of edge grinding. The fine grain grayish chert is available locally and appears to be a patinated specimen of tan gray chert.

Flake Tools. The single specimen, 9-3x, (Figure $32 \mathrm{~d}$ ) is a fragment from a trimmed flake, where the trimming is interrupted by the breakage. The remaining trimming is unifacial and extends for $18 \mathrm{~mm}$. The specimen appears to be a piece of shatter from a larger trimmed flake. From the fragment, it appears that modification is along an edge and that the edge was minimally modified.

Cores. Two small multidirectional cores were recovered (Figure $32 \mathrm{e}$, f). Both cores are small and exhausted, and are made from small pieces of gravels. One of the specimens, 9-3Z may have been used as a tool for scoring or engraving. This function appears after the specimen was used as a core. The material is a fine grain tan chert that is found in the local stream channels. Specimen 9-3Y is similar to specimens from the nearby Armstrong site with small flake scars going in multiple directions. The material is a fine to coarse grain tan chert. It is 
unknown what the detached flakes were intended for, or if the intent was to create the core or core tool.

Debitage. There are 202 pieces of debitage analyzed from OZ3. The reduction categories are in (Table 10). As in the other occupation zones, flake fragments are the dominant category, followed by complete indeterminate flakes and then hardhammer complete flakes. The OZ3 debitage assemblage differs from the previous OZ1 and OZ2 in that there is a higher percentage of hard hammer and indeterminate flakes and a decrease in flake fragments. The flakes having more than one dorsal scar is 97.9 percent when flake fragments and shatter is excluded. Indeterminate flakes accounted for 46.6 percent of the multiple dorsal scar flakes, hardhammer 40 percent and softhammer at 13.5 percent. Fragmentation was low in OZ3 with 23.0 percent of hardhammer flakes, 12.5 percent of softhammer flakes, and 10.7 percent of the indeterminate flakes. There is a slight increase in fragmentation of indeterminate flakes compared with earlier OZs; however, fragmentation of hardhammer and softhammer flakes is considerably lower. The average length of a hardhammer flake is $26.49 \mathrm{~mm}$; softhammer flake, $21.78 \mathrm{~mm}$, biface thinning flake, $30.60 \mathrm{~mm}$ and $14.80 \mathrm{~mm}$ for indeterminate flakes.

Table 10. Lithic debitage categories counts and percentages for OZ3.

\begin{tabular}{cccccccccccc}
\hline & & & & & & & & & & Burin \\
& HHC & HHF & SHC & BFT & SHF & IC & IF & FF & Shatter & Spall & Total \\
\hline$\%$ & 21.3 & 5 & 5.9 & 2 & 1 & 27.7 & 3 & 32.7 & 1.5 & 0.00 & 100.0 \\
\hline $\mathbf{n}$ & $\mathbf{4 3}$ & $\mathbf{1 0}$ & $\mathbf{1 2}$ & $\mathbf{4}$ & $\mathbf{2}$ & $\mathbf{5 6}$ & $\mathbf{6}$ & $\mathbf{6 6}$ & $\mathbf{3}$ & $\mathbf{2 0 2}$ & $\mathbf{2 0 2}$ \\
\hline
\end{tabular}

Cortex occurs on 11.9 percent of the debitage or 24 of the 202 specimens. Hardhammer flakes account for 66.7 percent of flakes with cortex $(n=16)$, fragments and shatter account for 20.8 percent $(\mathrm{n}=5)$ and there was a single indeterminate flake with cortex. As in the other OZs cortex is found on 10 to 11 percent of the debitage specimens. Hardhammer reduction is the dominant reduction form and it is likely that many of the indeterminate flakes are also 
hardhammer flakes. Biface reduction occurs on blanks were cortex has already been removed, while 37 percent of hardhammer flakes have some cortex. The debitage assemblage indicates that some earlier stage reduction using hardhammer reduction occurred at the site. The small size of these flakes does suggest that small sized raw material in the form of large flakes and small cobbles were being reduced rather than cortex covered cobbles.

Burning occurs on 24 of the specimens (11.8 percent), with fragments and accounting for 11 specimens, seven indeterminate specimens, four hardhammer specimens, and two shatter specimens. The percentage of burned debitage is a slight increase over the previous occupation zones, although the sample size is also smaller.

All of the chert is available locally from stream beds, lag deposits and outcropping nodules along the edge of the escarpment within 100 meters west of the site. The tool assemblage is indicative of a mobile hunter gathers that used the site to discard exhausted cores and projectile points. The two bifaces also appear to have been discarded, possibly because further thinning failed.

Faunal Remains. There are 90 specimens weighing a total of 40.75 grams from OZ3. The majority of the assemblage is mammalian, and includes white-tailed deer, jackrabbit and cottontail, squirrel, cotton rat, artiodactyl, rodent, and unidentified fragments from large and small mammals. Undifferentiated mammal fragments account for 59 specimens or 65.6 percent of the assemblage. There are five bird bone fragments and a single gar scale.

Table 11 shows the taxon, element, counts (Number of Identified Specimens Present, NISP) and weight of the OZ3 faunal assemblage. One specimen from Unit 9 Level 3 is a partially modified fragment that was sharpened into a tip. Taphonomic effects include 
fragmentation and etching of surfaces. There are cut marks on a large fragment from the same unit and level.

Table 11. Faunal bone assemblage from OZ3.

\begin{tabular}{ccrc}
\hline Taxon & Element & Total & $\begin{array}{c}\text { Weight } \\
(\mathrm{g})\end{array}$ \\
\hline Mammal--large & - & 4 & 7.16 \\
Mammal & - & 59 & 25.09 \\
Mammal--small & - & 6 & 1.20 \\
Lepus californicus & Calcaneus & 1 & 1.18 \\
& Humerus & 2 & 1.61 \\
& Incisor & 1 & 0.16 \\
Sylvilagus sp. & Calcaneus & 1 & 0.05 \\
& Metapodial & 2 & 0.18 \\
& - & 1 & 0.08 \\
Rodentia & Femur & 1 & 0.18 \\
& Incisor & 1 & 0.10 \\
Artiodactyl & Incisor & 1 & 0.35 \\
Odocoileus & & & \\
virginianus & 1st phalange & 1 & 1.38 \\
Sciurus sp. & Femur & 1 & 0.37 \\
Sigmodon hispidus & Humerus & 1 & 0.11 \\
& Mandible & 1 & 0.05 \\
Aves & - & 5 & 1.40 \\
Lepisosteus sp. & Scale & 1 & 0.10 \\
\hline Totals & & $\mathbf{9 0}$ & $\mathbf{4 0 . 7 5}$ \\
\hline
\end{tabular}

A lack of subaerial weathering of the bone surfaces indicates that the bone was buried rapidly or that the site had sufficient shade to protect the bone from long term surface exposure. The cut bone and bone tool fragment indicate that butchering or food preparation occurred at the site and many of the highly fragmented remains are the result of deliberate breaking and occurred when the bone was fresh. This could be from scavengers such as coyote, or from the deliberate crushing to extract marrow and or bone grease. The presence of both jackrabbits and cottontail suggest a variety of environments close to the site, with the jackrabbit favoring new growth in recently opened forest and the Blackland Prairie, and retreats to more open areas as canopy cover increases. The cottontail prefers areas that have been cleared or burned several 
years before to feed on the bark of samplings (Taylor and Lay 1944). The riparian corridor on the edge of the Blackland Prairies would offer suitable habitat for both species.

What is notable about the OZ3 faunal assemblage is the higher percentage of small faunal remains. Excluding the undifferentiated mammal, small animals account for 25 of the 31 specimens (80.7 percent), while large animals account for 6 of 25 specimens (19.4 percent). While it is probable that the fragmented bone may be from larger mammals, the OZ3 fauna assemblage shows a dichotomous prey size selection between the largest and smallest. Several types of hunting, from deer hunting with projectiles to hunting rodents and rabbits and birds with sticks or traps and fishing may have occurred at the site. Artiodactyl teeth and phalanges suggest a complete animal was brought to the site and the butchering cut marks on bone fragments also suggests that butchering occurred at the site. The procurement of small mammals along with large game in OZ3 is a reversal of the ratios encountered in OZ1 and OZ2 and indicates a growing reliance on smaller game.

Feature 4. Feature 4 is a small, diffuse grouping of five burned limestone clasts. Four of the clasts are in an area approximately $30 \mathrm{~cm}$ in diameter and the fifth rock is an outlier approximately $25 \mathrm{~cm}$ north of the main cluster. Figure 33 is a planview and photograph of Feature 4 that also shows sample locations. Archeomagnetic sampling was attempted but the clasts were unable to be drilled without fragmenting. Flotation from the two sample locations contained no macrobotanical remains, nor was there any difference 


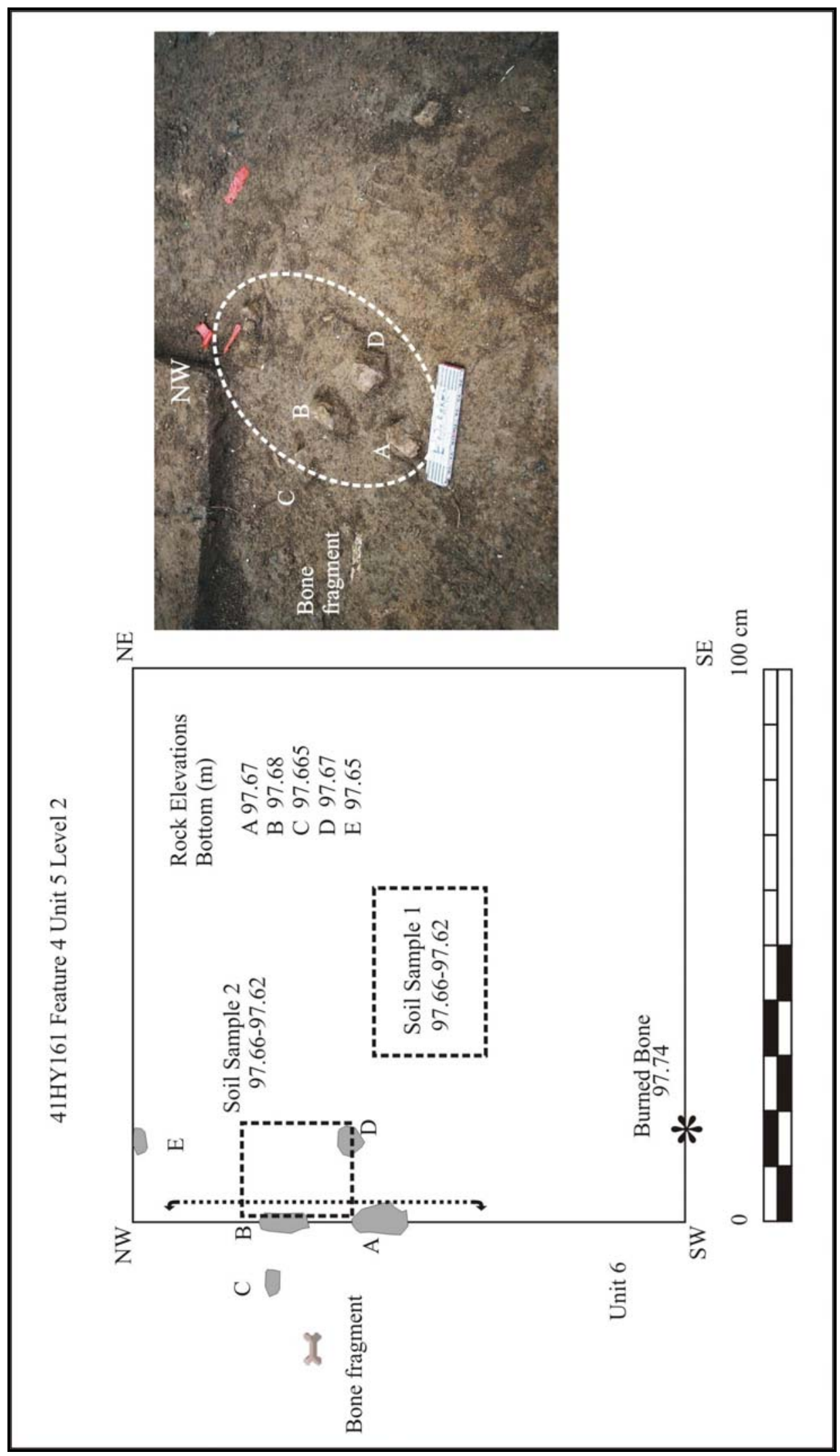

告 
in the surrounding matrix. The diffuse nature of the feature is similar to Late Paleoindian and Early Archaic features that incorporated only a few rocks in their construction. Feature $2 \mathrm{~T}$ at the nearby Armstrong site is such a diffuse feature (Schroeder 2002). Alternately, the rocks could be part of a larger disarticulated feature; although burned rock was diffuse throughout OZ3 and no definite localized concentrations were noted.

Distribution of Artifacts. Figure 34 is a planview of plotted artifacts from OZ3. The apparent clustering of burned rock in Unit 7 appears a cluster in planview only. When elevations are compared, the rocks are distributed through $20 \mathrm{~cm}$ of matrix. The burned rock likely represents the disturbed remains of small informal heating or cooking features built directly on the ground. Flintknapping and tool repair is concentrated in the west units, especially Units 6 and 9. The overall artifact density is low, and there is little association between burned material and Feature 4, suggesting it is not an intact feature, or that its small size limited the amount of material that it could burn. The mix of large and small game in the units indicates cooking and processing likely occurred in the same area, regardless of the size of the game.

\section{Occupation Zone 4}

This is the uppermost component excavated and a radiocarbon date of $3460 \pm 40$ B.P. indicates mixing with Late Archaic-age material. Prior to the block excavation, equipment stripping removed $170-180 \mathrm{~cm}$ of obviously disturbed overburden. During the hand excavating to the starting elevation, a large Pedernales point was recovered, for which a date of 3460 B.P. is entirely plausible. The radiocarbon date however, was from the same elevation as a Gower point, and therefore the bone is likely a more recent artifact that was incorporated into older material. As a result of this possible 


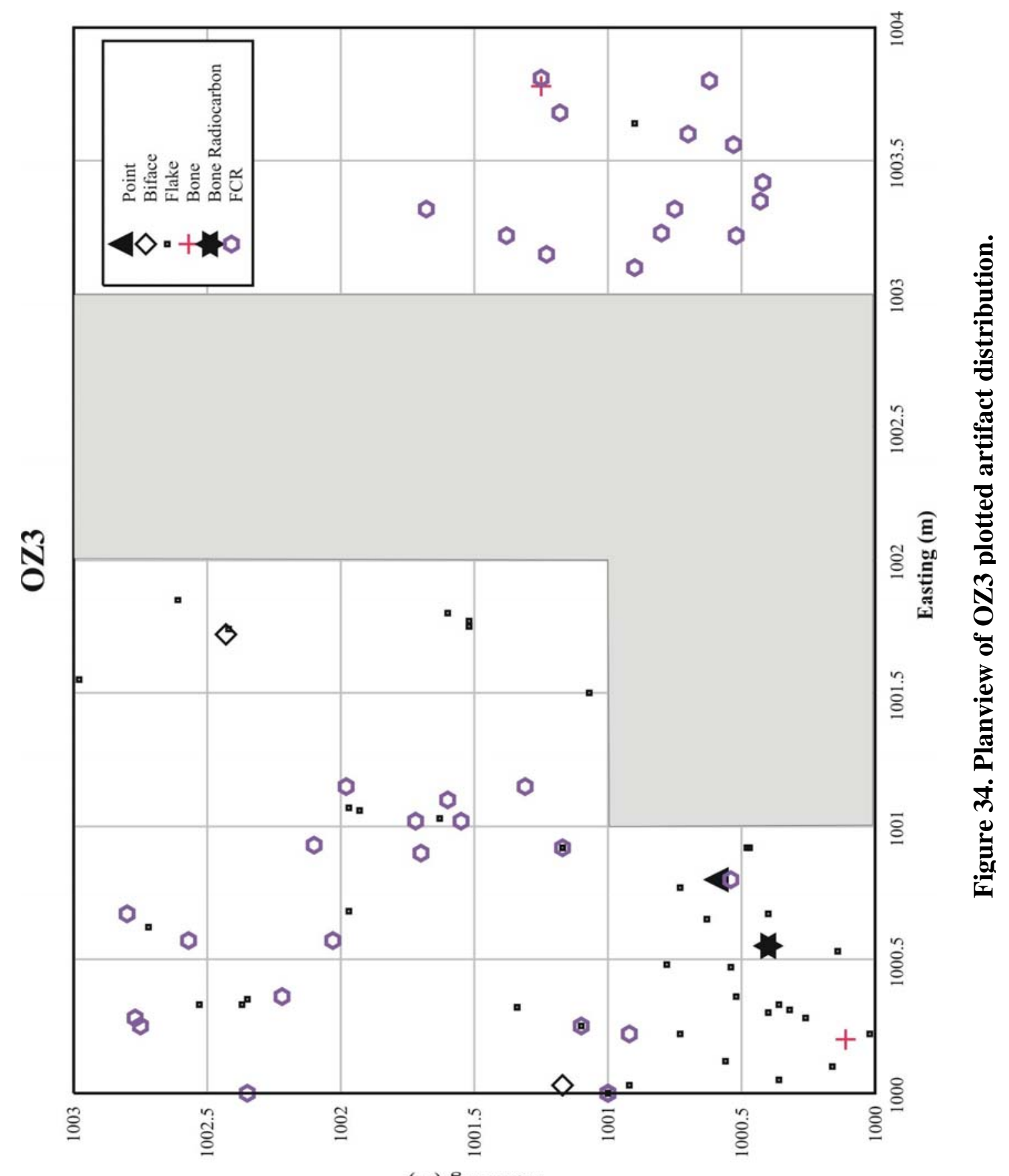

(u) ถึบเุน 
contamination, the first level of Units 2, 3, 5, 6 and 9 from elevations above $97.72 \mathrm{~m}$ were not included in the overall analysis. In Units 1, 4 and 7 this includes levels 1 and 2, which contained a burned rock feature, Feature 3. The volume of excavated material in OZ4 is approximately 1.1 $\mathrm{m}^{3}$. The Central Trench, Feature 1, impacted Units 1, 4, and 7, making artifact counts and associations from OZ4 difficult.

Based upon the magnetic susceptibility results, a stratigraphic break occurs just below $97.90 \mathrm{~m}$. This is a truncated surface that was eroded and stable surface. Alternating periods of erosion and deposition occurred through the Middle Archaic until the alluvial deposition VII (see Figure 23). The frequency dependent data from $97.98 \mathrm{~m}$ is characteristic of soil development that occurs from pedogenic dislocation of magnetic material in the soil, possibly as the A horizon develops into a B horizon below the surface.

The artifact assemblage consists of lithic tools and debris (Table 12) and faunal material and a burned rock feature. The lithic tools are a Gower point and a large core tool (Figure 35 cd). There are 74 pieces of debitage and 16 pieces of faunal bone.

Table 12. OZ4 lithic assemblage.

\begin{tabular}{cccccccc}
\hline $\begin{array}{c}\text { Projectile } \\
\text { Points }\end{array}$ & Bifaces & $\begin{array}{c}\text { Flakes } \\
\text { Tools }\end{array}$ & Burins/Spalls & Cores & Other & Debitage \\
\hline & & & & & & $2-1 \mathrm{~A}$ \\
& & & & & - & Core & tool \\
& 6-1A & - & - & - & - & - & - \\
& X1 & - & - & - & - & - & - \\
\hline Totals & X2 & - & - & - & $\mathbf{0}$ & $\mathbf{1}$ & $\mathbf{7 4}$ \\
\hline
\end{tabular}

Projectile Points. Specimen 6-1A is the stem of a point that resembles both a Gower and some Hoxie points, where the basal ears have been ground but the base has not. The distal fracture is where the hating element and blade meet, where a break would 


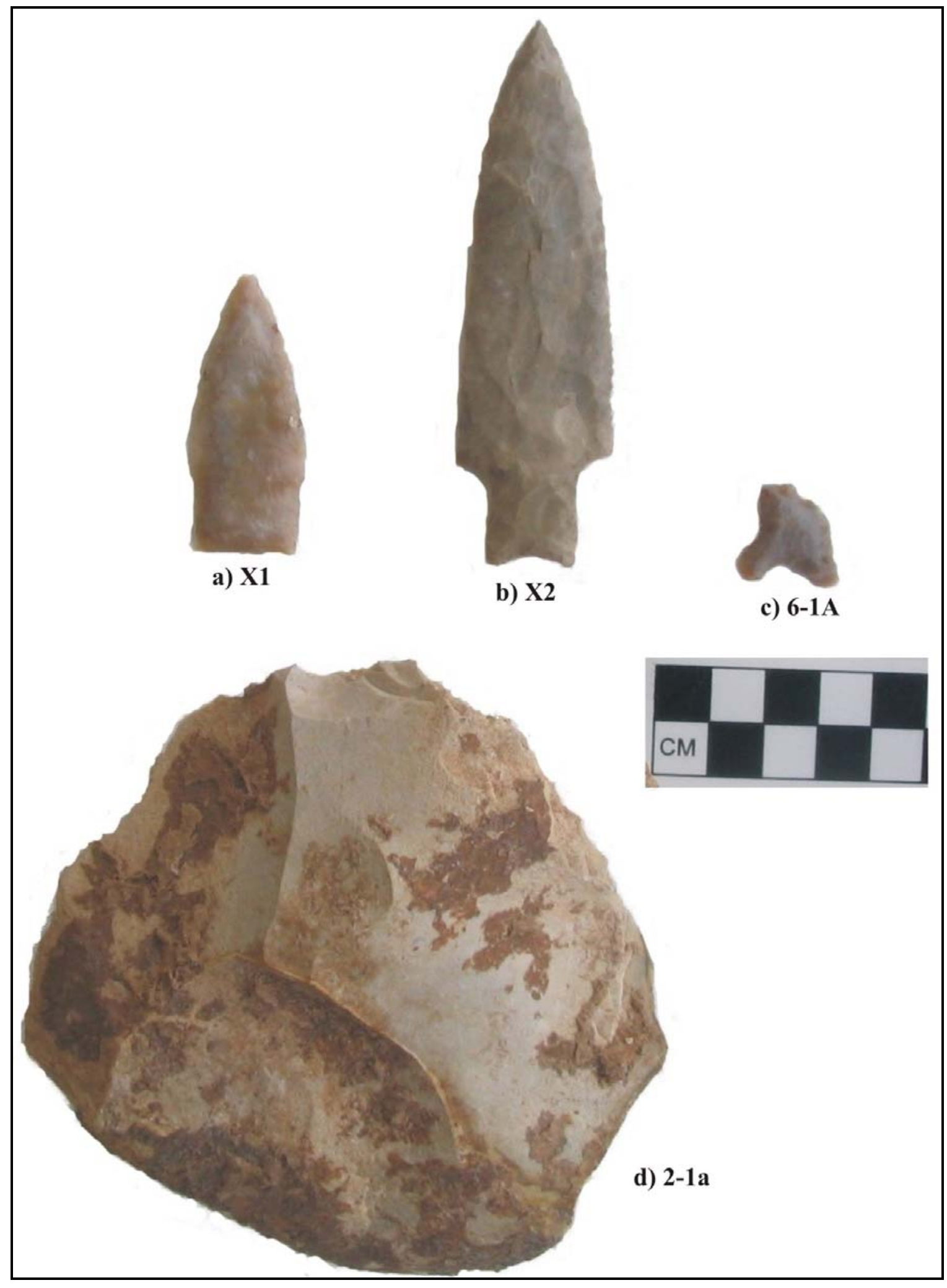

Figure 35. OZ4 lithic assemblage and upper component and surface finds. 
occur from use. The remaining base shows the range of basal modification and measurements that can occur in Gower and in Hoxie points. The chert is a tan gray fine grain chert that was heat treated. Similar raw chert is available locally and was noted in the debitage assemblage.

Core Tool. The large core tool, Specimen 2-1a, is a naturally backed cobble with bifacial flaking along one end. The tool was made by removing large hardhammer flakes that were 40 to $50 \mathrm{~mm}$ long and wide. The final edge angle is approximately 75 degrees. The bit edge was step fracturing consistent with chopping or battering (Keeley 1980; Vaughan 1985). The material is a weathered upland cobble of medium grain tan chert that was chosen for its toughness, given the availability of finer grain materials.

Debitage. There are 74 pieces of debitage and the reduction technologies are shown in Table 13. Flake fragments account for the highest category, while hardhammer flakes and indeterminate flakes are tied as the second numerous at 17 specimens each. There are only three softhammer flakes, indicating hardhammer reduction was the primary technique in OZ4. Overall, the assemblage is similar in percentages to the other occupation zones, and the differences are partly the result of a smaller sample size which can exaggerate small differences. All of the non-shatter and non-lake fragment debitage had two or more flake scars indicating late reduction. Cortex is found on 9.46 percent of the specimens, with the highest percentage on the hardhammer flakes. Burning occurs on 16.22 percent of the flakes with flake fragments having the most burned flakes. This overall percentage is double the rate of OZ2. No hardhammer of softhammer flakes were burned.

Table 13. Lithic debitage categories counts and percentages for OZ4.

\begin{tabular}{|c|c|c|c|c|c|c|c|c|c|c|c|}
\hline & $\mathrm{HHC}$ & $\mathrm{HHF}$ & $\mathrm{SHC}$ & BFT & SHF & $\mathrm{IC}$ & IF & $\mathrm{FF}$ & Shatter & $\begin{array}{l}\text { Burin } \\
\text { Spall }\end{array}$ & Total \\
\hline$\%$ & 23 & 2.7 & 1.4 & 1.4 & 1.4 & 23 & 5.4 & 35.1 & 6.8 & 0.00 & 100.00 \\
\hline
\end{tabular}




\begin{tabular}{llllllllllll}
\hline Count & 17 & 2 & 1 & 1 & 1 & 17 & 4 & 26 & 5 & 0 & 74 \\
\hline
\end{tabular}

The overall breakage rates are low; this can be a function of skill, raw material, and the types of artifacts being made and at what stage in manufacture, and the size of the artifacts being produced. The average length of a hardhammer flake is $26.10 \mathrm{~mm}$, a softhammer flake is 30.42 $\mathrm{mm}$, and indeterminate of $30.42 \mathrm{~mm}$. The debitage assemblage in OZ4 is small but does indicate a marked preference for hardhammer reduction. The large biface thinning flake may have been intended as a tool blank for further use and may have been brought to the site. The assemblage utilized locally available chert from upland and river cobble sources. The large bifacial tool may have been made as an expedient tool for the site an was cached for future use or discarded at the site. The lack of biface failures and flake tools suggests that lithic activities conducted at the Icehouse site were limited and the debitage could be from one or a series of short visits to the site.

The lack of tool diversity also suggests that a limited number of activities occurred at the site during the later OZ4 occupations, and that it was individuals or a small group that created the assemblage through repeat visits. This was not a part of the site were intensive lithic reduction activity occurred.

Faunal Remains. There are 16 specimens from OZ4 (Table 14). These include a fragment of probable bison, a turtle fragment, and leg bone fragment from a bird such as Prairie Attwater Chicken. Unidentified mammal is still the greatest category. The radiocarbon sample is from the very large specimen. If the bone is from a bison then it is associated with the Pedernales point in age. Because of the possible mixing in $\mathrm{OZ4}$, it is difficult to associate the remaining faunal remains to a particular period that is either Early Archaic or Late Archaic.

\section{Table 14. Faunal bone assemblage from OZ4.}




\begin{tabular}{cccc}
\hline Taxon & Element & Total & $\begin{array}{c}\text { Weight } \\
(\mathrm{g})\end{array}$ \\
\hline Mammal--very large & - & 1 & 3.23 \\
Mammal--large & - & 3 & 3.06 \\
Mammal & - & 9 & 1.76 \\
Mammal--small & - & 1 & 0.24 \\
Emydidae & Carapace & 1 & 0.84 \\
Galliformes & Tibiotarsus & 1 & 0.19 \\
\hline Totals & & 16 & 9.32 \\
\hline
\end{tabular}

Feature 3. Feature 3 is a stacked cluster of 16 burned rocks that includes outliers. Figure 36 shows the feature in planview and as a photograph as it is half-sectioned. The densest cluster is in an area of 50- by- $30 \mathrm{~cm}$ and stacked double thickness. Five of the rocks were drilled for archeomagnetic testing; however, no cores were extracted because of the fragile condition of the rock. No botanical remains were recovered from the soil samples. No change in the matrix was noted. The pile of burned rock may be a cleanout or dump from a container or pit feature.

Feature 1T from the Armstrong site and Feature 2 are similar clusters, where Feature 1T may be a dump pile, and Feature 2 is a shallow lined pit feature. Feature 3 has characteristics of either feature type. Although no date was affiliated with Feature 3, it has the appearance of other Early Archaic features. The small size of the feature indicates it was used by an individual or small group.

Distribution of Artifacts. Figure 37 shows the distribution of plotted artifacts in OZ4, including the cluster of burned rock in Feature 3. Debitage is concentrated in the southwest corner of Unit 9. Faunal remains occur throughout all the units except Units 6 and 9, which usually contain the highest density of artifacts. The sparse quantities 


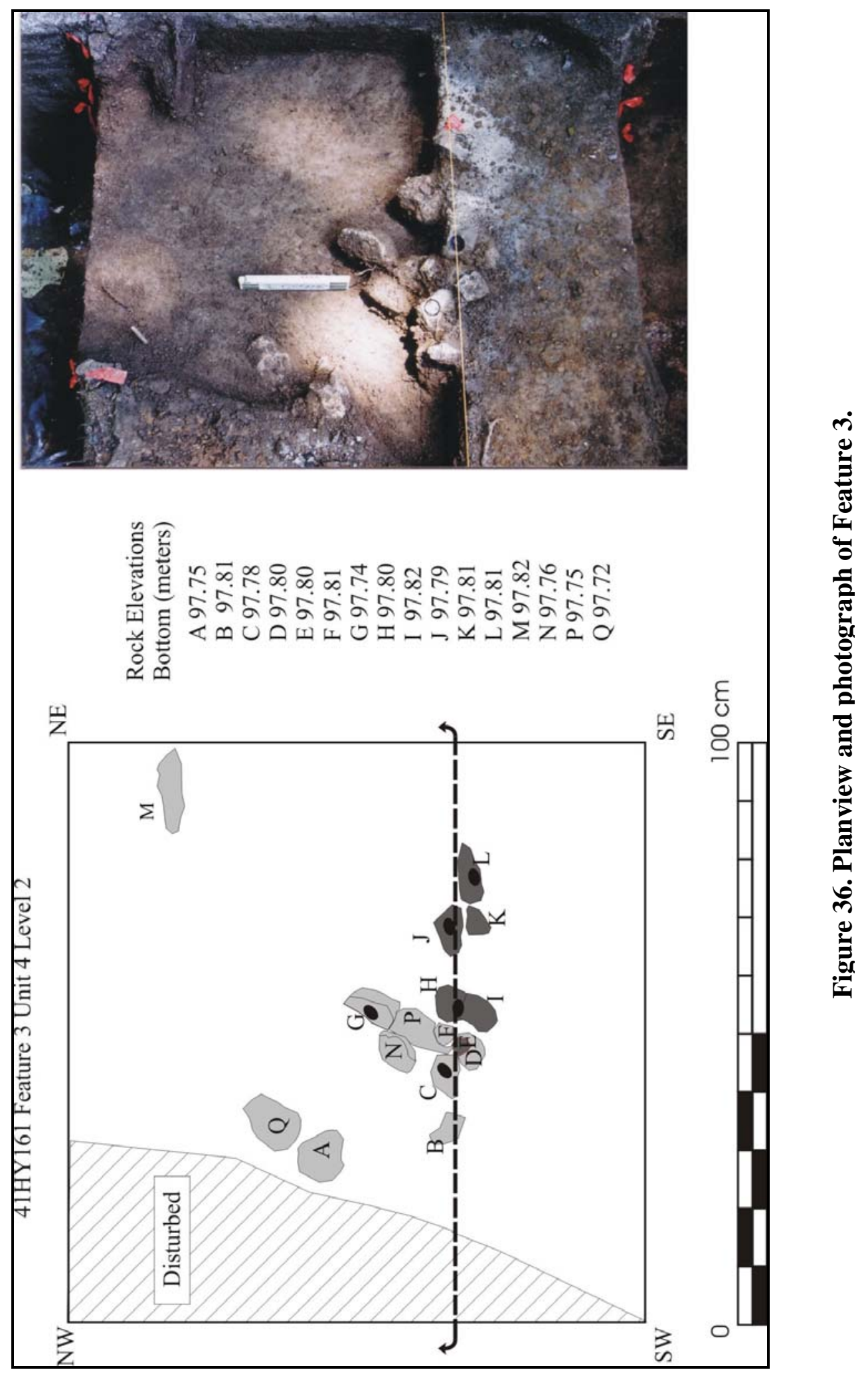




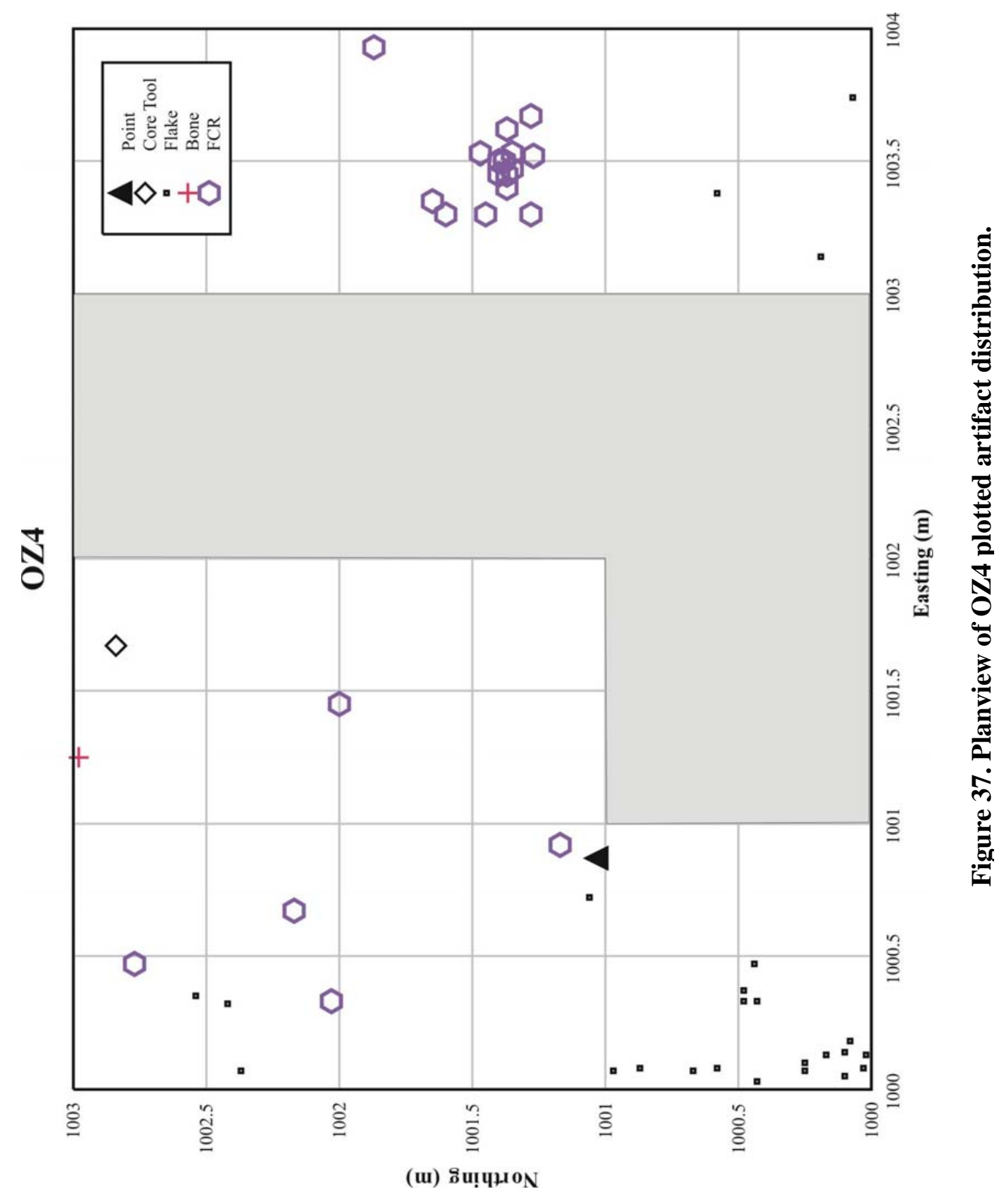


of artifacts suggest that this portion of the site was not utilized intensively; however, over what time frame the occupations occurred makes it difficult to assess how the site was utilized.

\section{Upper Component and Surface Artifacts}

Two diagnostic artifacts were recovered from contexts outside of the hand excavations (Figure $35 \mathrm{a}-\mathrm{b}$ ). Specimen X2 was encountered during the preparation of the excavation block after the initial machine excavations at the southwest corner at N1000 E1000 elevation 97.946 m. Originally thought to be an Early Archaic split stemmed point, because of its elevation within an erosional boundary and above a Late Archaic radiocarbon date of 3460 +/-40 B.P., it is most likely a Late Archaic Pedernales point.

This late Archaic designation was further reinforced with the resemblance of the specimen to Pedernales points recovered from the Gault site in Bell County, Texas (Prewitt 2005). 


\section{CHAPTER 8}

INTERPRETATIONS: CONTINUITY AND CHANGE AT THE ICEHOUSE SITE

\section{Comparisons between Components at the Icehouse Site}

The Icehouse site documents an estimated 1000 years of Early Archaic occupations in Central Texas, from ca. 7760 to 6600 B.P., an estimate based upon the radiocarbon dates and the known date range for Gower points. The site is significant because the only dart points encountered in the Early Archaic deposits were Gower points. Given the use of the same projectile points from $\mathrm{OZ1}$ through $\mathrm{OZ3}$, how other aspects of the organization of technology and subsistence practices changed or remained the same shows how the locale was used during a poorly documented part of the Archaic record.

An examination of the lithic and faunal assemblages illustrates both continuity and changes in the $\mathrm{OZ}$ assemblages. One obvious observation is the overwhelming use of locally available chert in the debitage and the tools assemblages. The sources of chert are abundant gravels from stream bed loads, eroded upland nodules still visible today on limestone escarpment above the Icehouse site, and weathered nodules on upland areas to the west of the site. East of the site on the margins of the Blackland Prairies, Willis formation gravels cover upland terraces and are also found in stream beds. These cherts are gray and tan, fine grained, and frequently heat treated. The most obvious trend of the site is the decrease in site use intensity through time. Measured by debitage and lithic tool 
totals, the densest periods of habitation occur in OZ1, followed by OZ2, and then OZ3. This trend may be partially accounted for by variations in sedimentation rates if there were decreased sedimentation rates during $\mathrm{OZ1}$ and $\mathrm{OZ2}$, resulting in concentrated lenses of artifacts. Examining Figure 23, there are varying Depositional Units as well as varying periods of surface stability, and short periods of deposition occur in both the deepest and uppermost Occupation Zones. The concentration of artifacts by depth is examined in excavation Units 6 and 9. Higher counts of debitage, as measures of debitage frequency with depth, the pattern of decreasing artifact frequency as elevation rises is evident in Figure 38a. Faunal NISP and weight follow a similar pattern but it is not as dramatic (Figure 38b).

A change in lithic technology, from the types of tools manufactured and the method of manufacture and choice of raw materials can be indicators of mobility (Binford 1978a, 1980) at varying scales from the individual and group to the larger band-size organization. The various taphonomic effects on the site deposits make the interpretation even more difficult since individual visits and actions become an agglomerate of behavior. Binford's (1978) analysis of the hunting site is at a fine scale of resolution over a short period of time where direct action is observed and measured.

The Collector and Forager dichotomy is recognized and intended as a continuum, where groups and individuals can operate at varying degrees depending on season and environment (Binford 1980). Higher residential mobility is equated with a predominantly Forager subsistence strategy. The foraging tool kit relies on a more flexible technology based upon bifaces that perform a variety of tasks and are easily maintained (Bousman 1993; Kelly 1988b, 1992; Parry and Kelly 1987; Torrence 1989). 


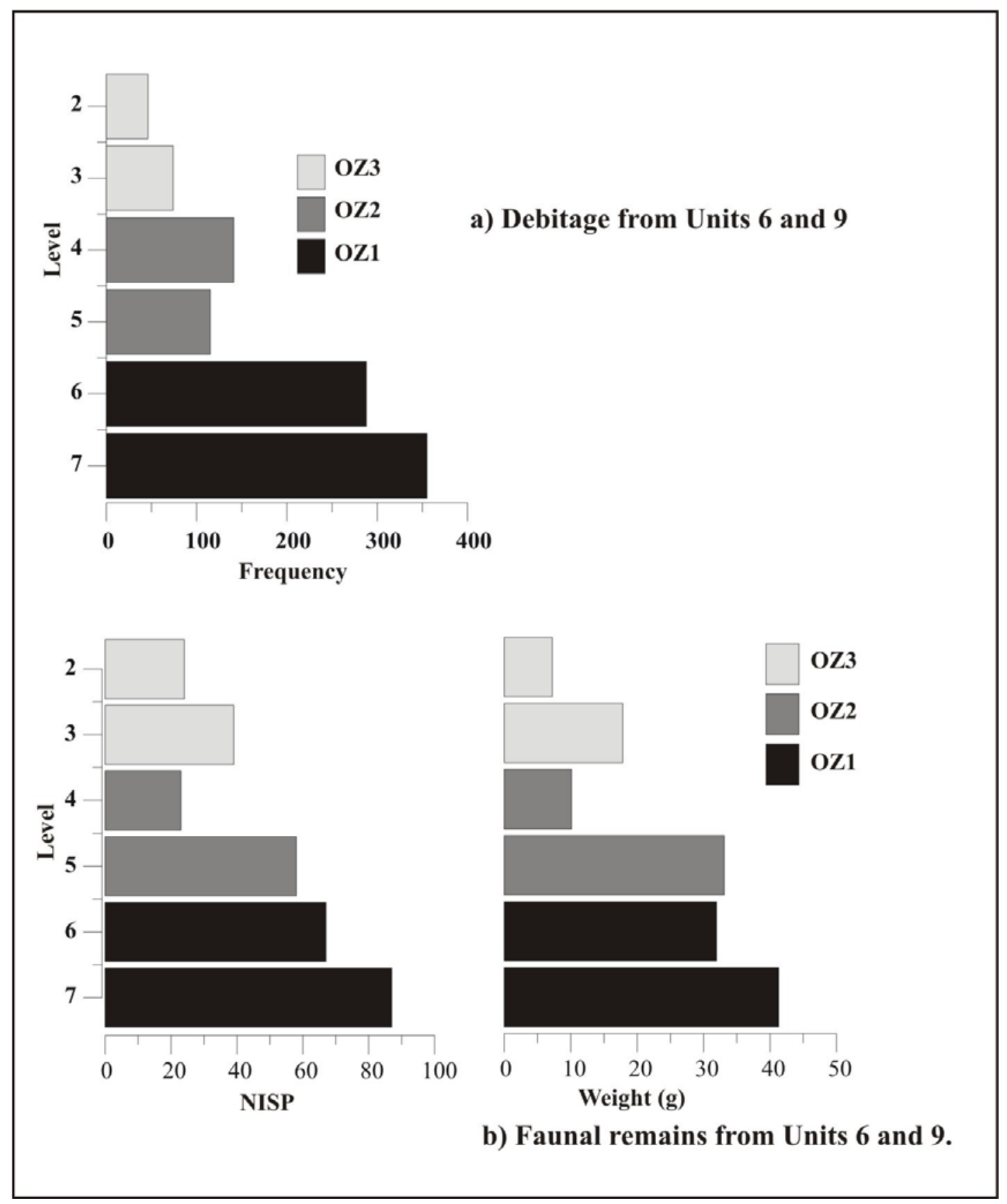

Figure 38. Units 6 and 9 debitage (a) and faunal (bone) counts and weights (b).

Variation in the types of tools being produced should be evident in both the tool assemblage and the lithic debitage. Three of the Gower points are from the oldest deposits of OZ3, while single Gower points were recovered from OZ2 and OZ3. Burins and burin spalls are found only in OZ1 and OZ2. A burin spall from OZ1 is evidence that formal flake tools were being maintained and possibly used at the site. The burin appears to be a scoring or engraving 
tool made from a broken retouched flake tool. The burin spall is an example of repair and rejuvenation, while the burin is evidence of tool recycling and the manufacture of tools made from other materials. Bifaces are intermediate and late stage fragments and complete tools and some specimens are made from large hardhammer flakes. These specimens were reduced at the Icehouse site; however, the initial reduction or blank creation occurred outside of the excavated areas and it is possible that the visitors to the site brought tool blanks with them for final reduction on the site. The greater diversity of tools in the OZ1 assemblage reflects a wider range of activities occurred at the site. To see if there is a change in the selection of raw material, such as the use of larger blanks or cobbles, and the method of reduction several indicators were examined. Table 15 shows the distribution in frequency of the major flake types from the Icehouse site such as hardhammer, soft hammer and biface thinning flakes (combined), and the smaller indeterminate flakes. These numbers include proximal fragments where characteristics are sufficient to make a determination about lithic reduction technique.

Table 15. Lithic reduction methods between OZs.

\begin{tabular}{crrcc}
\hline OZ & HH & SH & Indeterminate & Total \\
\hline OZ1 & 192 & 88 & 252 & $\mathbf{5 3 2}$ \\
OZ2 & 94 & 52 & 97 & $\mathbf{2 4 3}$ \\
OZ3 & 53 & 18 & 62 & $\mathbf{1 3 3}$ \\
\hline Totals & $\mathbf{3 3 9}$ & $\mathbf{1 5 8}$ & $\mathbf{4 1 1}$ & $\mathbf{9 0 8}$ \\
\hline
\end{tabular}

To compare technological variation between OZs, the results from Table 15 were analyzed as a contingency table to determine significant variation in a flake type category. A chisquare $\left(\mathrm{X}^{2}\right)$ analysis was performed as well as a comparison of adjusted residuals. Using a technique from Everitt (1977:46-48), the count from each cell is compared to the margin totals and overall total. The variance between the expected and actual frequencies is used to compute an adjusted residual in Z-score values, where a Z-score above 1.96 is above 95 percent. Z-scores above 1.96 are significant departures from the expected value where there is a less than 5 percent 
chance of a particular cell frequency occurring randomly. The adjusted residuals were calculated in Excel using a formula from Everitt (1977).

The chi-square result is $\mathrm{X}^{2}=6.27$, with $\alpha=.05, \mathrm{df}=4$ and $\mathrm{p}=.18$. The chi-square analysis finds little variation in flake type assemblages between Occupation Zones; however, the test can obscure variations between individual categories.

The result of the flake types by Occupation Zone using adjusted residuals is shown in Table 16 and illustrated in Figure 39. When comparing the overall assemblage by debitage reduction, the greatest variance occurs in indeterminate flakes and softhammer flakes, which also includes the biface thinning flakes which in this analysis are billet flakes detached from bifaces. OZ2 approaches a significant level of more than the expected amount of softhammer flakes and OZ3 has fewer than expected flakes. OZ2 has significantly fewer than expected indeterminate flakes. There appears to be a connection between softhammer flakes and indeterminate flakes-when there are more softhammer flakes there are fewer indeterminate flakes. The inverse is similar too, where there are fewer softhammer flakes in OZ3, and there is a slight increase in the indeterminate flakes, although neither value is significant. The variation is noted in the raw scores in Table 15, where indeterminate flakes outnumber the hardhammer flakes by 252 to 192 . This decreases significantly in OZ2 and OZ3. The higher numbers of indeterminate flakes in OZ1 suggest that late stage finishing was a major lithic activity at the Icehouse site during the earlier occupations which correlates to the frequency and variety of lithic tools in OZ1. Hardhammer flakes counts are not significant in any Occupation Zone, although there are slightly fewer in OZ1. 
Table 16. Debitage adjusted residuals from OZ1, OZ2 and OZ3.

\begin{tabular}{ccrr}
\hline OZ & HH & \multicolumn{1}{c}{ SH } & Indeterminate \\
\hline OZ1 & -0.92 & -0.81 & 1.51 \\
OZ2 & 0.51 & 1.92 & -1.96 \\
OZ3 & 0.65 & -1.27 & 0.34 \\
\hline
\end{tabular}

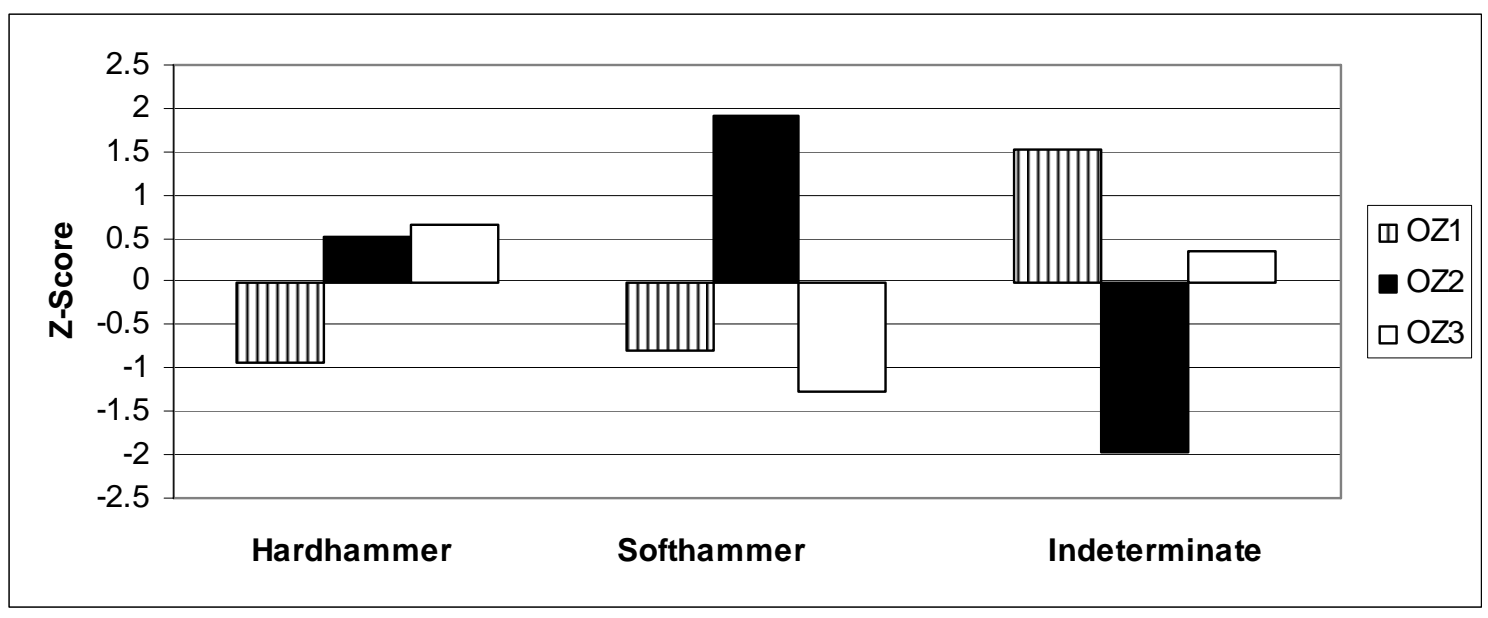

Figure 39. Adjusted residuals of the distribution of reduction flake types.

The size of complete flakes was examined from OZ1, OZ2 and OZ3. Length was compared for hardhammer, softhammer, and indeterminate flakes. As displayed in Figure 40, the greatest variation occurs in the hardhammer flakes, where the mean length of flakes in OZ3 are significantly shorter than OZ1 and OZ3 by almost $5 \mathrm{~mm}$. An Analysis of Variance (ANOVA) on the length of each flake category across occupation zones. This examines the variation between the means of each OZ and whether they are significantly different or fall within the expected distribution of length. The ANOVA was calculated using SPSS14 and Excel 2003. Post hoc tests to determine where the variation 


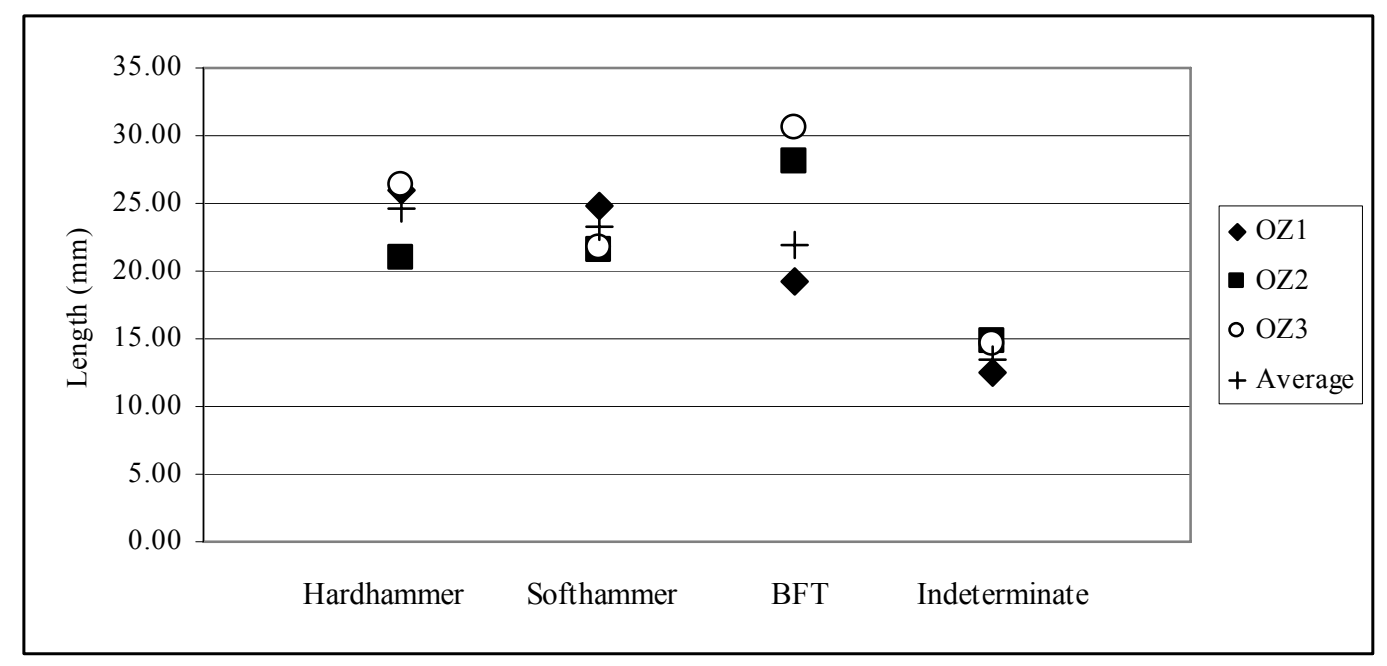

Figure 40. Average lengths of reduction categories of flakes from Occupation Zones.

occurred were also conducted. Only hardhammer flakes showed any significant variation between occupation zones. Biface thinning flakes (BFT) appear to show a large difference between $\mathrm{OZ1}$ and $\mathrm{OZ2}$ and OZ3; however, there were only four specimens from OZ2 and four from OZ3. When biface thinning flakes were combined with the softhammer flakes, there was no significant difference in the average length between occupation zones. The ANOVA result from hardhammer flakes is $\mathrm{F}=5.122 ; \mathrm{df}=2,274 ; \mathrm{p}<.05$. The source of variation is $\mathrm{OZ2}$, as suggested by Figure 40. The results of the softhammer flakes with biface thinning flakes included is $\mathrm{F}=.235 ; \mathrm{df}=2,125 ; \mathrm{p}>.05$

The reduced size of hardhammer flakes in OZ2 may correlate with the higher than expected frequency of softhammer flakes. No cores were recovered from OZ2 and the biface assemblage includes mid-to-late stage bifaces. The bifaces appear to be made on hardhammer flakes that may have been created elsewhere and brought to the site. The general similarity in the debitage measurements is indicative of the stages of tool manufacturing, the desired final product, and the size of the raw material and the type of raw material. The overall similarity in the length of the hardhammer flakes shows continuity in the manufacturing process that is 
adaptable to utilizing the same raw material and producing lithic tools are reduced in a similar manner despite the final tool form.

All of the multidirectional cores could be termed exhausted, because of their small size and lack of available platforms for further flake removals. Given the proximity to chert at the Icehouse site, there would be no need to reduce cores to this size, and therefore these cores were probably used offsite in a region lacking abundant chert resources, such as the Blackland Prairies and Coastal Plains to the east of the Balcones Escarpment (Banks 1990). At the Icehouse site, these cores were discarded as new lithic material was obtained. Resources to the east of the Icehouse site would have included bison at various times, and pronghorn antelope and Camassia sp. bulbs for example.

Faunal Remains. The faunal assemblage, although small and highly fragmented, is a significant contribution to the Early Archaic data base. Even though the remains were collected from $1 / 4$-inch screen, a wide variety of small taxa was recovered. Although fish and turtle remains were recovered, these were in relatively low numbers given the proximity of the site to water. The low counts can be a factor of the collection method that did not recover smaller fragments, taphonomic forces that destroyed or removed smaller bone from the assemblage, and the availability of the resources and the selection of these resources. According to the model of Stiner and Munro (2002) higher ranked prey, when abundant is hunted almost exclusively. Lower ranked food sources are ignored until a decline in the higher ranked resources as in optimal foraging theory. The increasing use of small game is thought to arise out of population pressures and decline in the abundance of larger game. The types of small game are also divided into quick game such as rabbits and birds and slow moving game such as tortoises and turtles. Slow moving prey would be quickly exhausted in the vicinity of a site, and these species may be 
slower to return. The added pressure on collecting them results in the diminution of the species as larger specimens are consistently selected (Stiner, et al. 2000). While the focus of hunting appears to be big game, there are ample examples of the significance of small game to the daily diet; indeed, small game may provide the bulk of day to day subsistence between successful hunts (Hockett and Haws 2002; Stiner and Munro 2002).

The faunal assemblage from the Icehouse site changes through time. In Table 17, the faunal assemblage is categorized according to sizes of small, medium, large and very large. Small animals include rodents, lagomorphs (rabbits and hares), birds, reptiles and fish. Medium sized animals include raccoon and coyote and dog. Large game is deer and pronghornsize animals, while very large game represents bison.

Table 17. Size categories of faunal remains (NISP) from OZ1, OZ2 and OZ3

\begin{tabular}{ccccc}
\hline OZ & very large & large & med & small \\
\hline OZ1 & 5 & 34 & 1 & 11 \\
OZ2 & 0 & 17 & 2 & 6 \\
OZ3 & 0 & 6 & 0 & 23 \\
\hline
\end{tabular}

Table 17 clearly shows the abundance of large game in OZ1 and OZ2 as compared with OZ3. By OZ3, the faunal remains are either large of small animal. In Figure 41, these results are graphed as percentage by OZ, which clearly shows the change from large game to small game: in OZ1 and 2, approximately 80 percent is large and very large game, while by OZ3, it is reversed, with small game accounting or 80 percent of the assemblage. The switch from large game may be reflected in the lithic assemblage, where the greater numbers of bifaces and flake tools associated with scraping and engraving are 


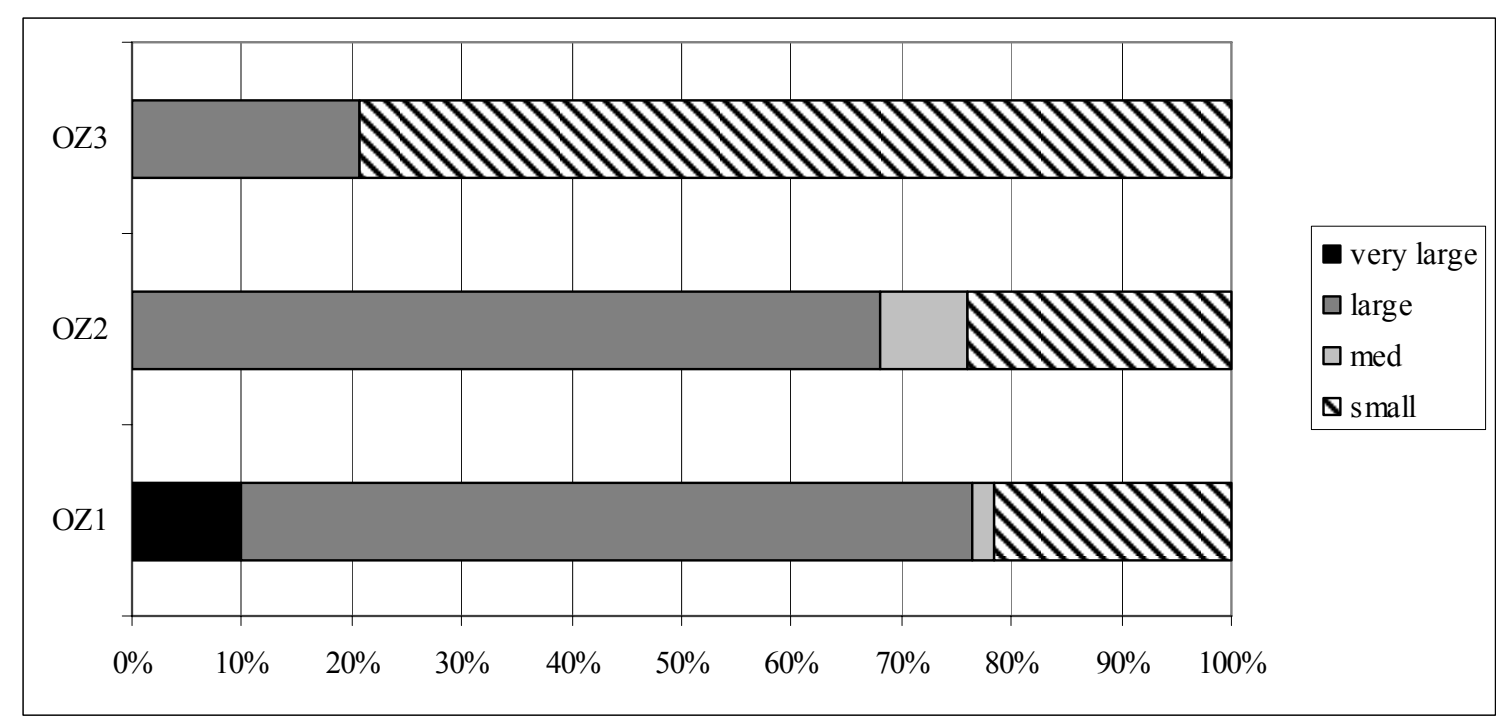

Figure 41. Icehouse site fauna size percentage distribution for OZ1-3.

from $\mathrm{OZ} 1$ and $\mathrm{OZ2}$. As site intensity decreases as measured by artifact frequency, the size of game also decreases, and that the lithic reduction activities in OZ1 and OZ2 are related to hunting and processing large game at or near the site. Although the debitage assemblage as measured as percentages of types is relatively constant through time, the tool assemblage varied when large game was present. Instead of broad technological changes through time, visitors to the site may have adapted their technology because of the local availability of game. Therefore, the expected faunal resources may have dictated the technology employed at the site. The animal assemblage is compared to the soil magnetic susceptibility data, projectile points and radiocarbon data in Figure 42, with the far right column shows the faunal assemblages by occupation zone. What is intriguing with the results, although the data set is small, is whether the decline in projectile points and scrapers in OZ3 is related to the faunal assemblage, where there was an increase in small game and a decrease in evidence of larger. 


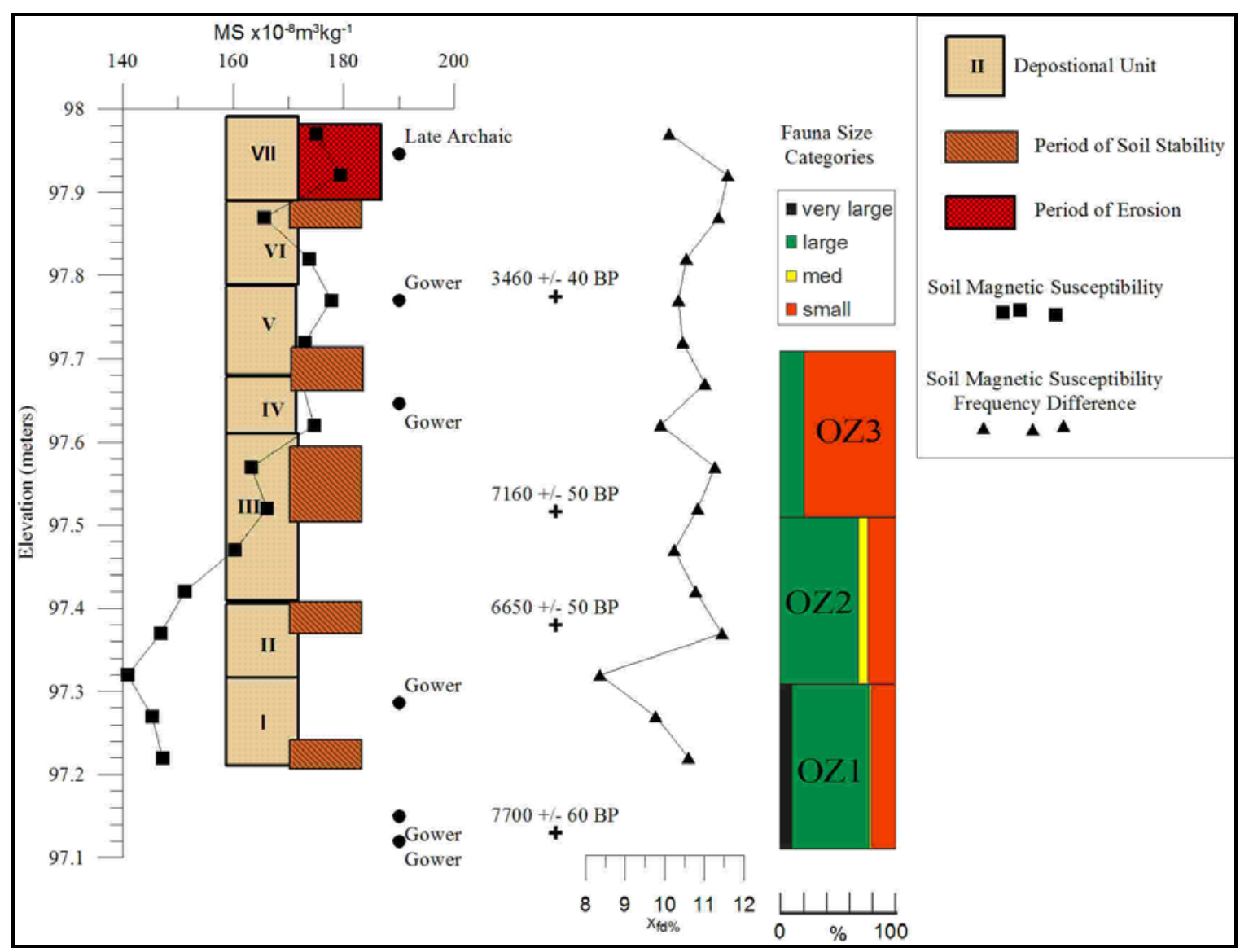

Figure 42. Soil magnetic susceptibility data with faunal size by Occupation Zone.

Comparisons between the Icehouse Site and Other Early Archaic Sites

An examination of Early Archaic components in recent literature shows how few sites have stratigraphic integrity and isolable components and how few have associated radiocarbon dates. Collins' (2004:Fig 3.9a) shows four sites having high integrity, while only two sites have radiocarbon dates and only one site has multiple assays. Intersite comparisons are therefore difficult to correlate. The Icehouse is compared to Early Archaic deposits in Central Texas sites that contain split stemmed points. These sites are Richard Beene (41BX831), the Armstrong site (41CW54), the Gatlin site (41KR621), the Eckols site (41TV528), Wilson-Leonard (41WM235), and the Sleeper site (41BC65). 
From Richard Beene, the assemblages of comparable age to the Icehouse Early Archaic occupations are Elm Creek from ca. 8300-7300 B.P. and Lower Medina 7000-6600 B.P. (Thoms 2005). No projectile points were recovered in the Elm Creek deposits, but early split-stemmed points classified as Baker and Uvalde points that are similar to Gower points were recovered in the Lower Medina Deposits (Dockall and Pevny 2005). Paleoenvironmental evidence suggests that the period from 8,000-7,000 B.P. was cooler and dryer than the preceding period.

Recent investigations at the Gatlin site included the recovery of 34 Gower points from two occupation zones, OZ1, dated between ca. 6600-6060 B.P. and OZ2, dated between 61004600 B.P. The significant date range for comparison to the Icehouse site is Gatlin-OZ1, where a single Gower point was recovered (Oksanen, et al. 2007). While the range of dates is broad in Gatlin-OZ2, the Gower points are the oldest type in the Gatlin-OZ2 assemblage and probably date between 6,100 and ca. 5,500 B.P. Despite the large numbers of radiocarbon dates, no conclusive end date for Gower and Gower-like points could be determined for the Gatlin site. Johnson's (1991) analysis of Early Archaic deposits at the Sleeper site also recovered Gower-like points only; however, there were no radiocarbon assays, making temporal refinement of the Early Archaic beyond the site difficult. The site contains the largest assemblage of ground stones from an Early Archaic context. Karbula's (2000) investigations of the Eckols site, along the banks of Barton Creek west of Austin, recovered split-stem points in Analytical Unit (A.U. 3) which is dated by radiocarbon on charcoal to ca. 6500 B.P. At the Armstrong site, near the Icehouse site, a Hoxie and Hoxie/Gower-like point were recovered from Occupation 3

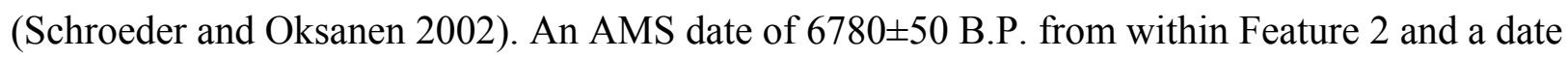
of $8490 \pm 40$ B.P. was obtained from Feature 1T, which brackets the known dates from the excavations at the Icehouse site. The context does suggest that there was a stable surface at the 
Armstrong site. At Wilson-Leonard, the Gower and Gower-like points were recovered the Early Archaic Unit IIIa and Unit IIIb deposits which range in age from 8700 B.P to as young as 4000 B.P. (Collins et al. 1998). This demonstrates the degree of mixing during this period, although some of Unit IIIa may be more tightly constrained between 8700 to 8000 B.P. The Early Archaic occupations at Wilson-Leonard were recovered from deposits varying in stratigraphic integrity, and as a result, the Early Archaic units were unable to refine the chronological scale to a period comparable in age of the Early Archaic occupations at the Icehouse site.

Projectile points, bifaces, flake tools and cores were tabulated for each component and are displayed in Table 18. These values were then compared in a contingency table (Table 19) using the procedure in Everitt (1977:46-48) from which the adjusted residuals were calculated. The resulting residuals, as Z-scores, show the variation of a tool category between the expected and observed values. Small observed or expected frequencies with values less than 5 can affect the calculation of the chi-square statistic and the calculation of the adjusted residuals; however the potential distortion of combining several categories is more problematic then low frequencies (Everitt B. S. 1977:40). Values exceeding \pm 1.96 indicate a significant difference between the observed and expected values. The chi-square statistic is 1134.6408 , and with $\mathrm{df}=24$ at $\alpha=0.01$, a value of $X^{2}=42.98$ is significant. The use of the adjusted residuals allows the identification of cells that are the most varied from the expected results.

Table 18. Early Archaic sites selected lithic artifact category totals.

\begin{tabular}{cccccc}
\hline Site & Points & Bifaces & Flake Tools & Cores & Totals \\
\hline 41HY161- Icehouse & 5 & 10 & 9 & 4 & 28 \\
41CW54- Armstrong- OZ4 & 3 & 17 & 32 & 4 & 56 \\
41KR621-Gatlin-OZ1 & 6 & 19 & 9 & 2 & 36 \\
41KR621-Gatlin-OZ2 & 88 & 144 & 116 & 63 & 411 \\
41BC65-Sleeper & 19 & 35 & 83 & 279 & 416 \\
41TV528-Eckols-AU3 & 14 & 22 & 0 & 3 & 39 \\
41WM235 Wilson- & & & & & 2005 \\
Leonard-Early & 356 & 755 & 807 & 87 &
\end{tabular}




\begin{tabular}{lrrrrr}
$\begin{array}{c}\text { 41BX831-Richard Beene- } \\
\text { Lower Medina }\end{array}$ & 11 & 23 & 41 & 19 & 94 \\
$\begin{array}{c}\text { 41BX831-Richard Beene- } \\
\text { Elm Creek }\end{array}$ & 0 & 2 & 4 & 5 & 11 \\
\hline Totals & $\mathbf{5 0 2}$ & $\mathbf{1 0 2 7}$ & $\mathbf{1 1 0 1}$ & $\mathbf{4 6 6}$ & $\mathbf{3 0 9 6}$ \\
\hline
\end{tabular}

Table 19. Adjusted residuals for comparative Early Archaic lithic categories.

\begin{tabular}{lcccc}
\hline \multicolumn{1}{c}{ Site } & Points & Bifaces & Flake & Tools \\
\hline 41HY161- Icehouse & 0.24 & 0.29 & -0.38 & -0.11 \\
41CW54- Armstrong- OZ4 & -2.24 & -0.45 & 3.4 & -1.67 \\
41KR621-Gatlin-OZ1 & 0.07 & 2.51 & -1.33 & -1.62 \\
41KR621-Gatlin-OZ2 & 3.06 & 0.86 & -3.33 & 0.17 \\
41BC65-Sleeper & -6.93 & -11.53 & -7.14 & 31.89 \\
41TV528-Eckols-AU3 & 3.35 & 3.1 & -4.67 & -1.29 \\
41WM235 Wilson-Leonard-Early & 3.15 & 7.18 & 7.38 & -22.6 \\
41BX831-Richard Beene-Lower Medina & -1.21 & -1.82 & 1.66 & 1.42 \\
41BX831-Richard Beene-Elm Creek & -1.14 & -1.06 & 0.06 & 2.82 \\
\hline
\end{tabular}

Highlighted cells are significant results

From the Icehouse site, there is no significant difference in any of the tool categories. The only other assemblage with no significant difference from the expected counts is the Lower Medina components at Richard Beene, although there is almost a significant difference in the number of bifaces. The variations between expected and observed counts at the Icehouse site are the least of any of the site assemblages, and is also the assemblage that is the most evenly distributed across categories. At the Armstrong site, 41CW54, there are fewer than expected points and an abundance of flake tools. In OZ1 at the Gatlin site, 41KR621, bifaces are more numerous and cores and flake tools are marginally fewer than expected. In OZ2 at the Gatlin site, there are more points than expected and fewer flake tools, while cores are within the expected range. The Sleeper site has an unexpectedly large number of cores, and consequently significantly fewer than expected tools in all other lithic categories. At the Eckols site, the AU3 deposits have much higher than expected quantities of points and bifaces and significantly fewer flake tools. The Early Archaic deposits at Wilson-Leonard have greater points, bifaces and flake tools than expected and fewer than expected cores. Richard Beene has a greater than expected 
number of cores in the Elm Creek deposits. When comparing tool categories this way, the Sleeper site and Richard Beene-Elm Creek are different than the other assemblages by having a greater than expected number of cores. The usefulness of the adjusted residuals in interpreting the lithic assemblages is that it shows both the extreme and more subtle variations in the composition of the assemblages. One interesting observation is in the adjusted residuals for cores, where sites with a negative adjusted residual are those sites associated with hunting and a high degree of mobility given that these sites have a higher number of bifaces relative to cores (i.e., Parry and Kelly 1987).

In addition to calculating the adjusted residuals, Boone's measure of Homogeneity and Brainerd-Robinson scores were calculated using the values in Table 18 with Keith Kintigh's program for Boone's Measure of Assemblage Heterogeneity (2006). Table 20 shows the results of the analysis sorted by Brainerd-Robinson score. The Icehouse site has the highest B-R score, out of a maximum score of 200 . The score is calculated using the percentage margin totals from each tool category and the total artifacts from each site. Higher scores more closely resemble the artifact distribution of all sites combined. Similar scores indicate proportionally similar distribution of artifact classes.

Table 20. Boone's measures of similarities and differences and Brainerd-Robinson scores between comparative Early Archaic components.

\begin{tabular}{crrrrr}
\hline Site & N & Boone's & Scaled & BR & Prob \\
& & H & Hs & & G>obs \\
\hline 41HY161-Icehouse & 28 & 0.002 & 2.07 & 191.6 & 0.978 \\
41KR621-Gatlin-OZ2 & 411 & 0.008 & 4.46 & 185.3 & 0.004 \\
41BX831-Richard Beene-Lower Medina & 94 & 0.019 & 6.97 & 173.6 & 0.082 \\
41WM235-Early Archaic & 2005 & 0.039 & 9.88 & 178.6 & 0 \\
41KR621-Gatlin-OZ1 & 36 & 0.06 & 12.21 & 159.9 & 0.058 \\
41CW54-Armstrong-OZ4 & 56 & 0.089 & 14.93 & 156.8 & 0.002
\end{tabular}




\begin{tabular}{crrrrr} 
41TV528-Eckols-AU3 & 39 & 0.161 & 20.08 & 114.2 & 0 \\
41BX831-Richard Beene-Elm Creek & 11 & 0.247 & 24.83 & 137.6 & 0.042 \\
41BC65-Sleeper & 416 & 0.409 & 31.97 & 96 & 0 \\
\hline
\end{tabular}

Boone's H score was originally used to measure the diversity of midden deposits (Boone 1987). In general as assemblages increase in size, diversity decreases. Applied to site assemblages, it is a measure of how evenly distributed the assemblage is among selected categories. A score close to zero indicates artifacts are more evenly spread and that the assemblage is heterogeneous, while a high $\mathrm{H}$ value indicates a homogeneous assemblage, where artifacts are concentrated in a few categories. Kintigh advocates the use of Hs, a transformation of the $\mathrm{H}$ score to percentage units (Kintigh 2006). With Hs, the higher the value, the less diversified the assemblage. The Williams corrected G statistic is a goodness of test fit for the Brainerd-Robinson test and measures the probability that the current B-R score or less would be obtained randomly. In the case of the Icehouse site, $41 \mathrm{HY} 161$, there is a 98 percent chance that a randomly selected sample would differ from the expected values. The high G statistic for the Icehouse site is partly a function of the small sample size, where a small change in artifact frequency has a larger effect on the distribution of artifact categories.

Sites that have closer B-R values are similar in their variance from the population of artifacts and artifact categories. When the sites are sorted according to Scaled Hs, the B-R scores remain the same except for Richard Beene-Lower Medina and Wilson Leonard-Early Archaic, and the Eckols site-AU3 and Richard Beene-Elm Creek.

Based upon these results and the categories of artifacts selected, the Icehouse site is most similar to the Gatlin site-OZ2. The nearby Armstrong site contains a higher than expected flake tool assemblage which increased the homogeneity of the site assemblage. The high Hs percentage of the Sleeper site, 41BC65 is because of its large assemblage of cores. Another 
measure not included was the groundstone assemblage, where the 108 specimens would further demonstrate that the Sleeper site is a special purpose site unlike any of the others. The largest assemblage is from the Wilson-Leonard site, which resembles a base camp. The smaller assemblages with less than 100 artifacts represent short term occupations by small groups. The lithic assemblage from the Icehouse site could be termed a generalist assemblage, adaptable to a variety of resources, rather than a specialized assemblage. The nearby Armstrong site, located out on the Blackland Prairie, in contrast has a greater number of flake tools than expected, and many of these tools are hide scrapers and shaping tools for hide working and possibly wood and bone. The small assemblage from the Icehouse site is dominated by projectile points and bifaces, and where lithic activities involved later stage finishing using hard and softhammer reduction, and hardhammer thinning of initial blanks. The lack of substantial amounts of feature material and the small size of a burned rock features and that tools were refurbished and recycled. Although the Icehouse lithic assemblage is relatively evenly distributed between lithic categories, the inferred tasks based on the tool assemblage suggests a limited range of activities occurred through the habitation of the site, and this limited range continued to decrease with time. The decrease in varied lithic assemblages may correspond to the shift to increasing small game utilization.

Comparison between the Icehouse and the Armstrong Sites. The debitage sample from the Armstrong sites was selected from Units 2, 4, 18 and 20, levels 10 and 11 using a random sample without replacement from OZ4. These 161 pieces of debitage were analyzed in the same method as the Icehouse site assemblage. The results of the analysis in Figure 43 show the similarity in the lengths of flakes in all categories except biface thinning flakes, where there were no comparative specimens. The percentages of identified flakes in Table 21 are also consistent 
between the two sites, with the Armstrong site indistinguishable from the Icehouse site. The Armstrong assemblage includes woodworking gouges and formal scrapers. Evidence of a scraper comes from OZ1 at the Icehouse site, while a gouge-like biface is from OZ3. The similar composition of the debitage assemblages and the similar size of flakes suggest that there was a standard size range of blanks being reduced and that tool production followed a similar reduction strategy that generated similar ratios of flake categories. Both sites had a similar amount of dorsal scars, with 86.4 percent of the Armstrong debitage having multiple scars (discounting shatter and flake fragments), is similar to the approximately 89 percent rates at the Icehouse site. The initial reduction of cobbles and large flake blanks occurred away from the excavations at the Armstrong site as they did at the Icehouse site. The differences in the lithic tool assemblages are not reflected in the debitage, which indicates that manufacturing techniques were common to the two sites, and that the same techniques were used to make a variety of tools, since the proportionality in the flake types is the same. 


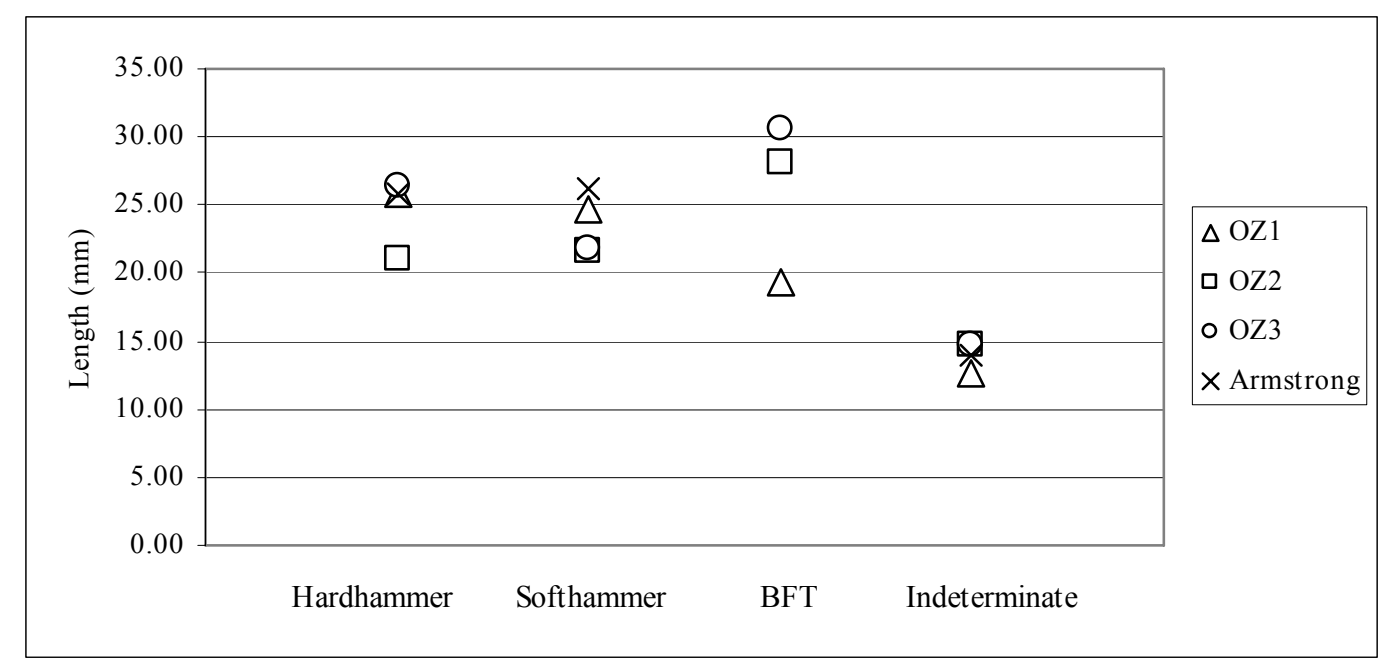

Figure 43. Lengths of reduction categories of flakes from the Icehouse and Armstrong sites.

Table 21. Debitage reduction methods from the Armstrong and Icehouse sites.

\begin{tabular}{lrrr}
\hline Component & HH & \multicolumn{1}{l}{ SH } & Indeterminate \\
\hline Armstrong & $39.8 \%$ & $16.5 \%$ & $43.7 \%$ \\
OZ1 & $36.1 \%$ & $16.5 \%$ & $47.4 \%$ \\
OZ2 & $38.7 \%$ & $21.4 \%$ & $39.9 \%$ \\
OZ3 & $39.9 \%$ & $13.5 \%$ & $46.6 \%$ \\
\hline
\end{tabular}

The debitage from the Armstrong site reflects all stages of the expected manufacturing process of the types of tools found at the site, which were of modest size for the most part (Goode 2002).

Differences in the Assemblage. Cortex is found on 17.4 percent of the Armstrong site debitage and occurs on 4.5 to 11.5 percent of the Icehouse assemblage. Likewise, 17.3 percent of the Armstrong debitage was burned while the Icehouse occupations were between 9.1 percent and 12 percent. The upper levels of the Armstrong site contained a diffuse layering of burned rock, and an abundance of burned clay and charcoal in the sediments (Schroeder and Oksanen 2002).

Comparison of the Icehouse Gower Points to the Gatlin Site Gower Points. An examination of the Gower points demonstrates that it is difficulty in identifying point styles by 
metric attributes alone, and how much variation can occur for a point type to be valid. A large assemblage of 34 Gower points from the Gatlin site (41KR621) located in Kerrville, Texas, was compared with the six specimens from the Icehouse site (Oksanen, et al. 2007). The mean average and standard deviation of stem length, base concavity depth and base width are shown in Table 22. The haft length and basal width were compared using a t-test. The base depth was not compared because of the small variation in the measurements that can result from measurement error, given the difficulty in measuring hundredths of a millimeter. The stem length and base width were measurements that were less likely to alter from resharpening and therefore represent the original dimensions.

Table 22. Gower point comparative measurements.

\begin{tabular}{ccc}
\hline Measurement & Icehouse & Gatlin \\
\hline Average Haft Length $(\mathrm{mm})$ & 15.36 & 13.14 \\
$\sigma$ Haft Length $(\mathrm{mm})$ & 3.83 & 2.37 \\
Average of Base Depth $(\mathrm{mm})$ & 2.67 & 3.97 \\
$\sigma$ Base Depth $(\mathrm{mm})$ & 1.30 & 1.24 \\
Average of Base Width $(\mathrm{mm})$ & 15.47 & 16.41 \\
$\sigma$ Base Width $(\mathrm{mm})$ & 1.99 & 2.04 \\
\hline
\end{tabular}

The results of the t-tests for the haft length between the two sites are $\mathrm{t}=-1.3707 ; \mathrm{df}=6$; $\mathrm{p}>.05$, assuming unequal variances. There is no significant difference between the two sites. Base width is similar, where $\mathrm{t}=1.034566 ; \mathrm{df}=34 ; \mathrm{p}>.05$, assuming equal variances, and there is no significant difference. At least with these two populations of Gower and Gower-like points, there is a consistency in the measurements of the hafted stem length and the base width and this consistency is maintained over an estimated 1000 years.

As noted in Chapter 3, there are a number of names for projectile points that are likely variations along a continuum of design. These points share stylistic traits to the Late Paleoindian lanceolate points, where types like the Thrall points have an indented base and parallel-sided stem that resembles Hoxie points, which co-occur in the same region (Bousman 1998b). The 
grading of Hoxie and Gower points as found as Wilson-Leonard (Dial, et al. 1998) appear to be more of a decline in flaking refinement, where once the basic outline and size parameters were established these were maintained for at least 1000 years with only minor variations that may be regional or group traits. Unfortunately, it is difficult to accurately date these deposits and the variations in the projectile points.

The Faunal Remains at the Icehouse Site. The faunal remains from the Icehouse site show how through the Early Archaic habitation of the site, the composition changed from 80 percent large to very large animal and 20 percent small animal to 80 percent small animal and 20 percent large animal. Comparable resolution showing change in the Early Archaic does not occur within the sites used for comparison, the Armstrong site and Wilson Leonard, and no comparable site could be found. Wilson Leonard has the most extensive reported Early Archaic faunal assemblage (Baker 1998) while the Armstrong site is in close proximity (Johnson, et al. 2002). The assemblage from Richard Beene (41BX835) Lower Medina deposits was also used for the comparison. Only identified taxon was used rather than unidentified mammalian fragments. The selected fauna allow a comparison between the assemblages using (Stiner and Munro 2002; Stiner, et al. 2000), where the depletion of turtles and tortoises gives way to exploiting rabbits and hares. In addition, it allows an examination of small game to large game procurement and the importance of a particular taxon to the diet. All of the sites are located near or along a source of water and therefore aquatic resources are expected in the assemblages.

Bison, deer, and antelope are the highest ranked prey species. Kelly (1995) demonstrated that Hadza men spent most of their time in pursuit of large game because of the potentially higher rate of return of meat for the time and energy expended $(1 \mathrm{~kg} / \mathrm{hr})$. The presence of abundant small game at a site can infer other participants in food production, namely women and 
children, and it may be that small game provided a substantial portion of the diet between successful bigger game hunts. Animal range is also another factor, with tortoises and turtles more likely to be collected in the immediate vicinity of the site, while hares and rabbits could be trapped, dug from burrows or hunted on an encounter basis (Stiner and Munro 2002). During the Magdalenian period in the western Mediterranean, small game procurement intensifies along with specialized big game hunting (Hockett and Haws 2002; Tortosa, et al. 2002). The specialized small game hunting of rabbit is interpreted as the result of population pressure and the diversification of the subsistence base. The totals and percentages are shown in Table 23 and Table 24.

Table 23. NISP counts of selected taxa for each site.

\begin{tabular}{|c|c|c|c|c|c|c|}
\hline Sites & Bison & $\begin{array}{l}\text { Deer/ } \\
\text { Antelope }\end{array}$ & Turtles & $\begin{array}{l}\text { Rabbits/ } \\
\text { Hares }\end{array}$ & Rodents & Totals \\
\hline Icehouse & 6 & 9 & 3 & 9 & 6 & 33 \\
\hline Armstrong & 8 & 16 & 2 & 2 & 6 & 34 \\
\hline $\begin{array}{l}\text { Richard Beene } \\
\text { Wilson-Leonard }\end{array}$ & 0 & 24 & 33 & 145 & 12 & 214 \\
\hline Early Archaic & 0 & 21 & 100 & 62 & 26 & 209 \\
\hline Totals & 14 & 70 & 138 & 218 & 50 & 490 \\
\hline
\end{tabular}

Table 24. Percentage contribution of taxa for each site.

\begin{tabular}{crrrrr}
\hline Sites & \multicolumn{3}{c}{ Deer/ } & \multicolumn{3}{c}{ Rabbits/ } \\
Bntelope & Turtles & \multicolumn{1}{c}{ Hares } & \multicolumn{1}{c}{ Rodents } \\
\hline Icehouse & $18.2 \%$ & $27.4 \%$ & $9.1 \%$ & $27.3 \%$ & $18.2 \%$ \\
Armstrong Site & $23.5 \%$ & $47.1 \%$ & $5.9 \%$ & $5.9 \%$ & $17.7 \%$ \\
Richard Beene & $0.0 \%$ & $11.2 \%$ & $15.4 \%$ & $67.8 \%$ & $5.6 \%$ \\
\hline Wilson-Leonard & & & & & \\
Early Archaic & $0.0 \%$ & $10.1 \%$ & $47.9 \%$ & $29.7 \%$ & $12.4 \%$ \\
\hline
\end{tabular}

Bison is found at two of the sites, while deer or antelope are found at all sites. The highest percentage contribution of rabbits and hare is at Richard Beene, and the lowest is at the Armstrong site; and while deer antelope is highest at the Armstrong site it is low at Richard 
Beene and Wilson-Leonard. When analyzed as adjusted residuals and graphed in Figure 44, it is easier to compare the assemblages. Both the Icehouse and Armstrong sites have significantly greater numbers of bison and deer/antelope than expected, lower turtles and rabbits and hares and more rodent. The significant difference in the Wilson-Leonard assemblage is the higher than expected turtle count, while at Richard Beene there is a surplus of rabbit and hares.

When combining OZ 1, 2 and 3, the Icehouse site has higher than expected large game, as does the nearby Armstrong site. Both of these sites are relatively small artifact assemblages when compared to both Richard Beene and especially Wilson-Leonard. The shift from large game to small game from OZ1 and 2 to $\mathrm{OZ3}$ at the Icehouse site is obscured if the total assemblage is compared. Larger sites such as Wilson Leonard and Richard Beene undoubtedly contain a greater number faunal biomass, the higher than expected counts for turtles at WilsonLeonard and rabbit and hare at Richard Beene may be the result of longer and larger group sizes, which created more opportunities for localized foraging. The turtles at Wilson-Leonard and rabbits and hares at Richard Beene may have been site specific resources and these smaller animals may have been major 


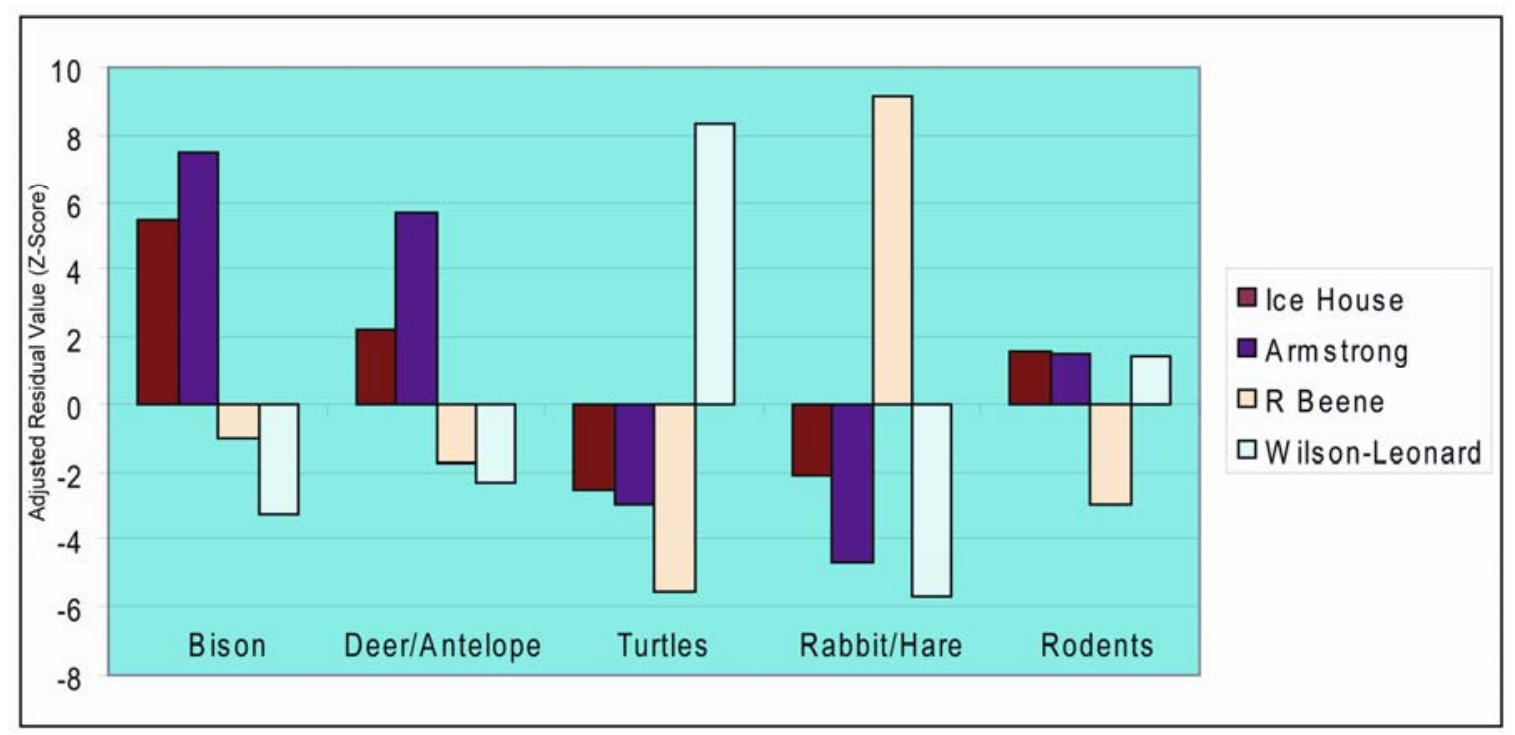

Figure 44. Adjusted residuals of the distribution of select fauna from four Early Archaic sites.

subsistence components in foraging strategy of the inhabitants. At the smaller Armstrong and Icehouse sites, the emphasis was on larger game hunting, with small game procured on an encounter basis.

The Icehouse Site and the Early Archaic. The Early Archaic in Central Texas is a poorly defined sub period, both at its inception and its conclusion, and some of these issues relate to how the Early Archaic defined. One of the most visible traits is the appearance and spread of specialized hot-rock cooking along the edge of the Balcones Escarpment and onto the Edwards Plateau (Collins, et al. 1990; Collins, et al. 1998). During this period, the lanceolate point tradition is finally replaced by a variety of split stem points indicating a shift towards a different method of hafting and increasingly diverse number of projectile point styles of varying uniformity. The significance of the Icehouse site is that it contains deposits associated with one type of projectile point, the Gower point. The estimated age of the deposits span 1000 years from ca. 7700 B.P. to 6650 B.P. and within the range were three occupation zones, separated by 
occasional alluvial depositions. The site was most intensively used in the earliest occupation zones, OZ1 and OZ2, and especially OZ1. During a period around 7700 B.P. site inhabitants successfully hunted bison and deer and they refitted their projectile points and made new bifacial tools from the abundant high quality local chert. Towards the end of the Early Archaic occupations at the Icehouse site, small game becomes more numerous in the faunal assemblage while the density of tool debris and the overall number and diversity of lithic tools declines. The visits to the Icehouse site declined in frequency, which may have resulted from a decrease in readily available big game.

In Figure 45, the Early Archaic components are compared to Central Texas pollen records, bison abundance and a population index. Immediately apparent is that bison are supposedly absent from or scarce within the region during most of the Early Archaic, and certainly during the Early Archaic occupations at the Icehouse site. The pollen record indicates an increase in grasslands, possibly because of decreasing rainfall and rise in temperature. This would have made the Balcones Escarpment and the Icehouse site an attraction because of a stable water supply, and as a nexus from which to exploit the resources of the Blackland Prairies and Coastal Plains to the east and south and the Edwards Plateau to the west. Using Prewitt's (n.d) indices for Central Texas populations, the Paleoindian period represents a base population against which the other periods are compared. A series of components and the estimated date range for each component is divided into the estimated number of sites from each component and multiplied by 100 . 


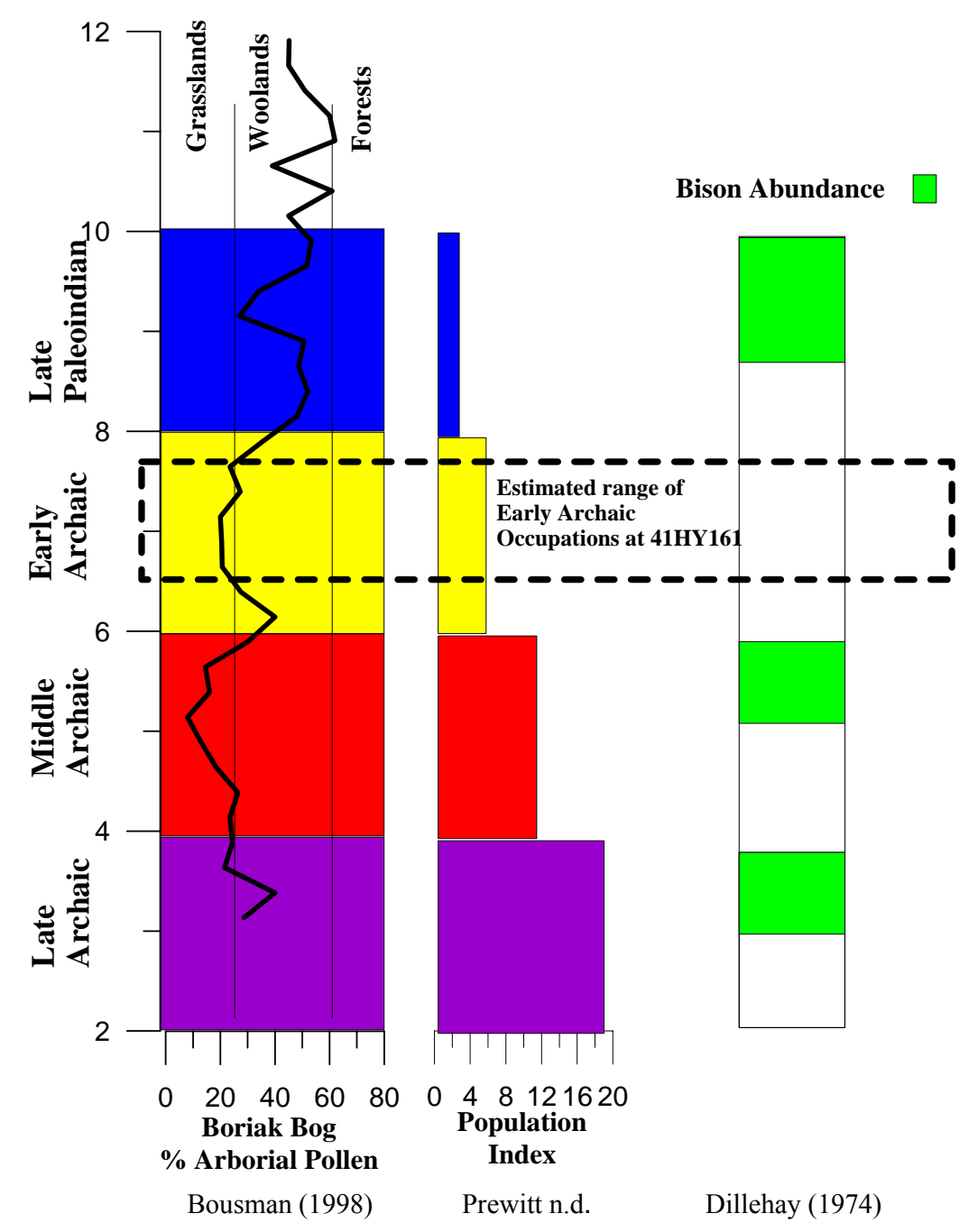

Figure 45. The Early Archaic components at 41HY161 compared to Central Texas pollen records, bison abundance, and a Central Texas prehistoric population index.

The resulting number is not an actual population but a estimate along a relative scale. From the Paleoindian through the Early Archaic periods there is an almost five-fold increase in population size. The increasing population during this period corresponds to the increasing regional diversity of split-stemmed projectile points and the development of what become smaller and smaller territories. The decrease in exotic non-local lithic materials declines during the Early Archaic, as group ranges decrease and territories are further developed. 
The Icehouse site is situated in a biologically and geologically resource rich region, and numerous groups utilized the area from Paleoindian time through the modern era. The Icehouse site is one of probably many local sites that were used to exploit these resources. The picture provided by the Icehouse site for the Early Archaic is one where lithic traditions change some forms, but retain an overall consistent and flexible technology. The diverse techniques used to make the Gower points show an adherence to a basic set of criteria, where once met, style is one of indifference or individual expression. Throughout, the people were highly mobile and used the Icehouse site as a place to hunt large and small game during short-duration stays. These were likely small groups, perhaps family members who used the Icehouse site as a special resource extraction center for hunting and refitting and replenishing lithic materials. With a growing population, concentrated in locales such as along the edge of the Balcones Escarpment, there would be increased pressure to expand the resource base as hunting pressure decreased locally available big game, and to also extend the hunting region into different areas, such as eastwards to the Blackland and Coastal Prairies. 


\section{APPENDIX A \\ RADIOCARBON RESULTS}

All of the radiocarbon samples were bone that was submitted to Beta Analytic Inc. from collagen extraction and dating of the collagen. Bone was the only abundant organic material available for radiometric dating. The results from Beta Analytic are presented in the following pages. 


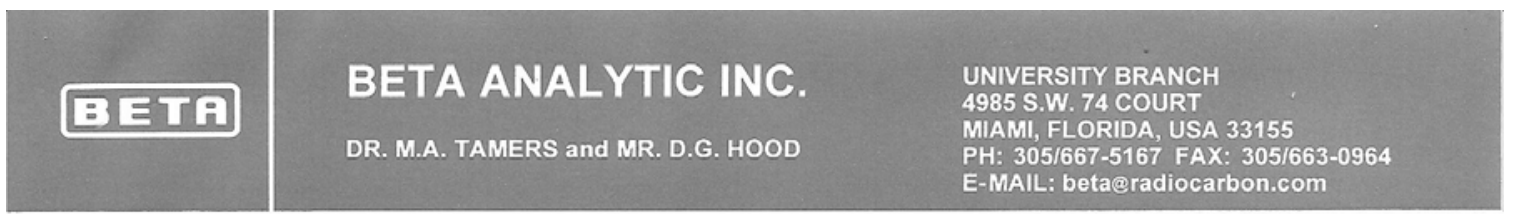

\section{REPORT OF RADIOCARBON DATING ANALYSES}

Dr. Britt Bousman

Report Date: 5/8/2006

Texas State University

Material Received: 4/3/2006

\begin{tabular}{|c|c|c|c|}
\hline Sample Data & $\begin{array}{l}\text { Measured } \\
\text { Radiocarbon Age }\end{array}$ & $\begin{array}{c}13 \mathrm{C} / 12 \mathrm{C} \\
\text { Ratio }\end{array}$ & $\begin{array}{c}\text { Conventional } \\
\text { Radiocarbon Age }{ }^{*}\end{array}$ \\
\hline $\begin{array}{l}\text { Beta - } 216027 \\
\text { SAMPLE : U2L1-41HY161 } \\
\text { ANALYSIS : AMS-Standard delivery } \\
\text { MATERIAL/PRETREATMENT : (b } \\
\text { 2 SIGMA CALIBRATION : }\end{array}$ & $\begin{array}{l}3370+/-40 \mathrm{BP} \\
\text { ollagen): collagen extrac } \\
1890 \text { to } 1680 \text { (Cal BP } 3\end{array}$ & $\begin{array}{l}-19.5 \mathrm{o} / \mathrm{oo} \\
\text { lkali }\end{array}$ & $3460+/-40 \mathrm{BP}$ \\
\hline $\begin{array}{l}\text { Beta - } 216028 \\
\text { SAMPLE : U6L7-41HY161 } \\
\text { ANALYSIS : AMS-Standard delivery } \\
\text { MATERIAL/PRETREATMENT : } \\
2 \text { SIGMA CALIBRATION : }\end{array}$ & $\begin{array}{l}\qquad 7600+/-60 \mathrm{BP} \\
\text { ollagen): collagen extrac } \\
6650 \text { to } 6430 \text { (Cal BP } 8\end{array}$ & $\begin{array}{l}-19.1 \mathrm{o} / \mathrm{oo} \\
\text { lkali }\end{array}$ & $7700+/-60 \mathrm{BP}$ \\
\hline $\begin{array}{l}\text { Beta - } 216029 \\
\text { SAMPLE : U9L3-41HY161 } \\
\text { ANALYSIS : AMS-Standard delivery } \\
\text { MATERIAL/PRETREATMENT : } \\
2 \text { SIGMA CALIBRATION : }\end{array}$ & $\begin{array}{l}7090+/-50 \mathrm{BP} \\
6080 \text { to } 5970(\mathrm{Cal} \mathrm{BP} 8\end{array}$ & $\begin{array}{l}-20.5 \mathrm{o} / \mathrm{oo} \\
\text { lkali } \\
\mathrm{AND} \mathrm{Cal} \mathrm{BC}\end{array}$ & $\begin{array}{l}\quad 7160+/-50 \mathrm{BP} \\
\text { (Cal BP } 7900 \text { to } 7870 \text { ) }\end{array}$ \\
\hline $\begin{array}{l}\text { Beta - } 216030 \\
\text { SAMPLE : U9L5-41HY161 } \\
\text { ANALYSIS : AMS-Standard delivery } \\
\text { MATERIAL/PRETREATMENT : (b } \\
2 \text { SIGMA CALIBRATION : }\end{array}$ & $\begin{array}{l}\quad 6560+/-50 \mathrm{BP} \\
\text { collagen): collagen extra } \\
5650 \text { to } 5490(\mathrm{Cal} \mathrm{BP} 7\end{array}$ & -19.8 o/oo & $6650+/-50 \mathrm{BP}$ \\
\hline
\end{tabular}

Dates are reported as RCYBP (radiocarbon years before present, "present" = 1950A.D.). By International convention, the modern reference standard was $95 \%$ of the C14 content of the Nationa Bureau of Standards' Oxalic Acid \& calculated using the Libby C14 half life (5568 years). Quoted errors represent 1 standard deviation satistics (68\% probilly) 8 are of the sample, background, and modern reference standards.

Measured $\mathrm{C} 13 / \mathrm{C} 12$ ratios were calculated relative to the PDB-1 international standard and the RCYBP ages were normalized to -25 per mil. If the ratio and age are accompanied by an (*), then the C13/C12 value was estimated, based on values typical of the material type. The quoted results are NOT calibrated to calendar years. Calibration to calendar years. Calibration to calendar years should be calculated using
the Conventional C14 age. 
CALIBRATION OF RADIOCARBON AGE TO CALENDAR YEARS

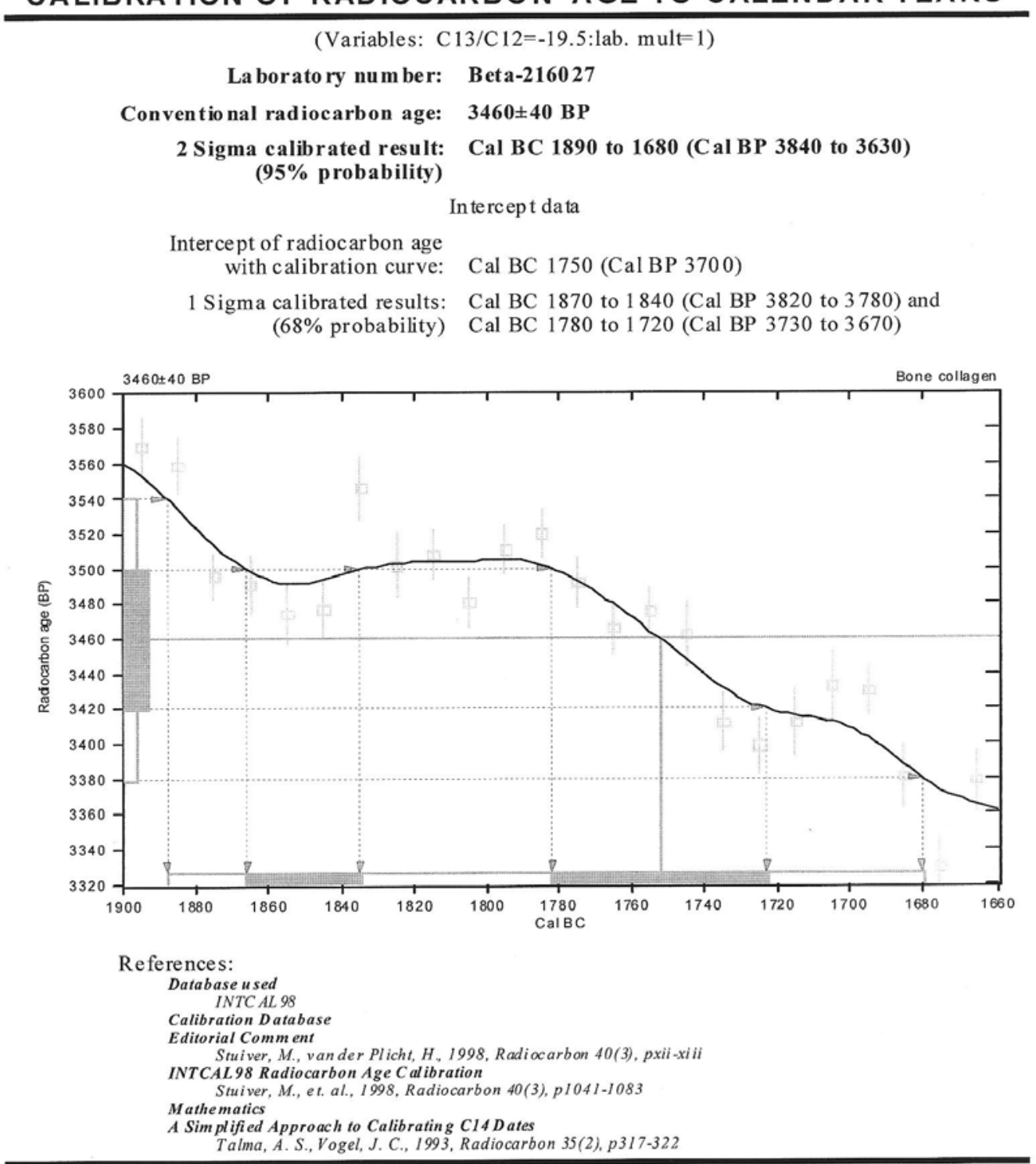

Beta Analytic Radiocarbon Dating Laboratory

4985 S.W. 7 4th Court, Miami, Florida 33155 - Tel: (305)667-5167 - Fax: (305)663-0964 - E-Mail: beta@radiocarbon.com 
CALIBRATION OF RADIOCARBON AGE TO CALENDAR YEARS

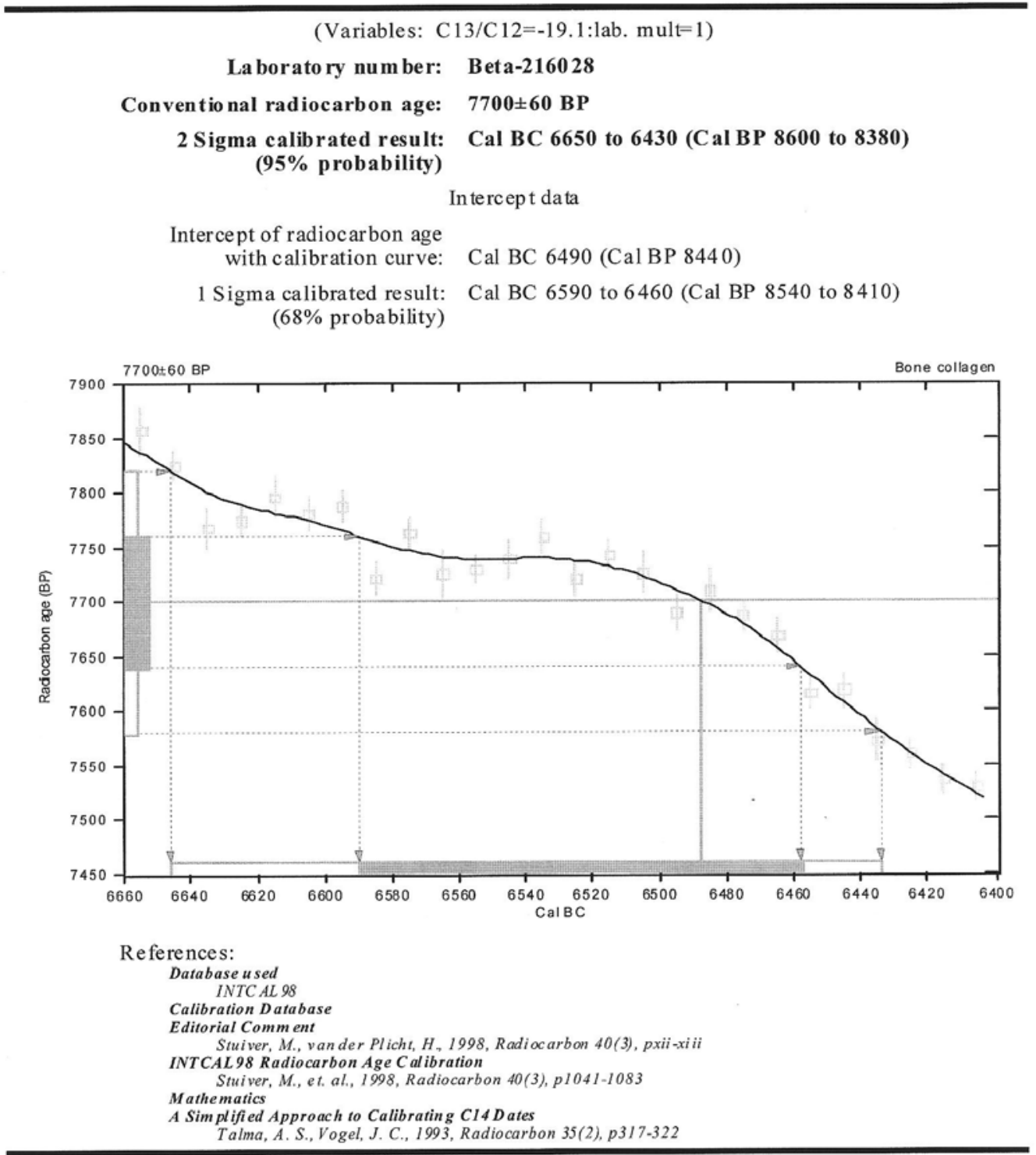

Beta Analytic Radiocarbon Dating Laboratory

4985 S.W. 7 4th Court, Miami, Florida $33155 \cdot$ Tel: (305)667.5167 • Fax: (305)663-0964 • E-Mail: beta@radiocarbon.com 


\section{CALIBRATION OF RADIOCARBON AGE TO CALENDAR YEARS}

(Variables: C13/C 12=-20.5:lab. mult $=1$ )

La borato ry number: Beta-216029

Conventional radiocarbon age: $\quad 7160 \pm 50 \mathrm{BP}$

2 Sigma calibrated results: Cal BC 6080 to 5970 (Cal BP 8030 to 7920 ) and (95\% probability) Cal BC 5950 to 5920 (Cal BP 7900 to 7870 )

Intercept data

Intercept of radiocarbon age with calibration curve: Cal BC 6010 (Cal BP 7960)

1 Sigma calibrated result: Cal BC 6050 to 5990 (Cal BP 8000 to 7940 ) (68\% probability)

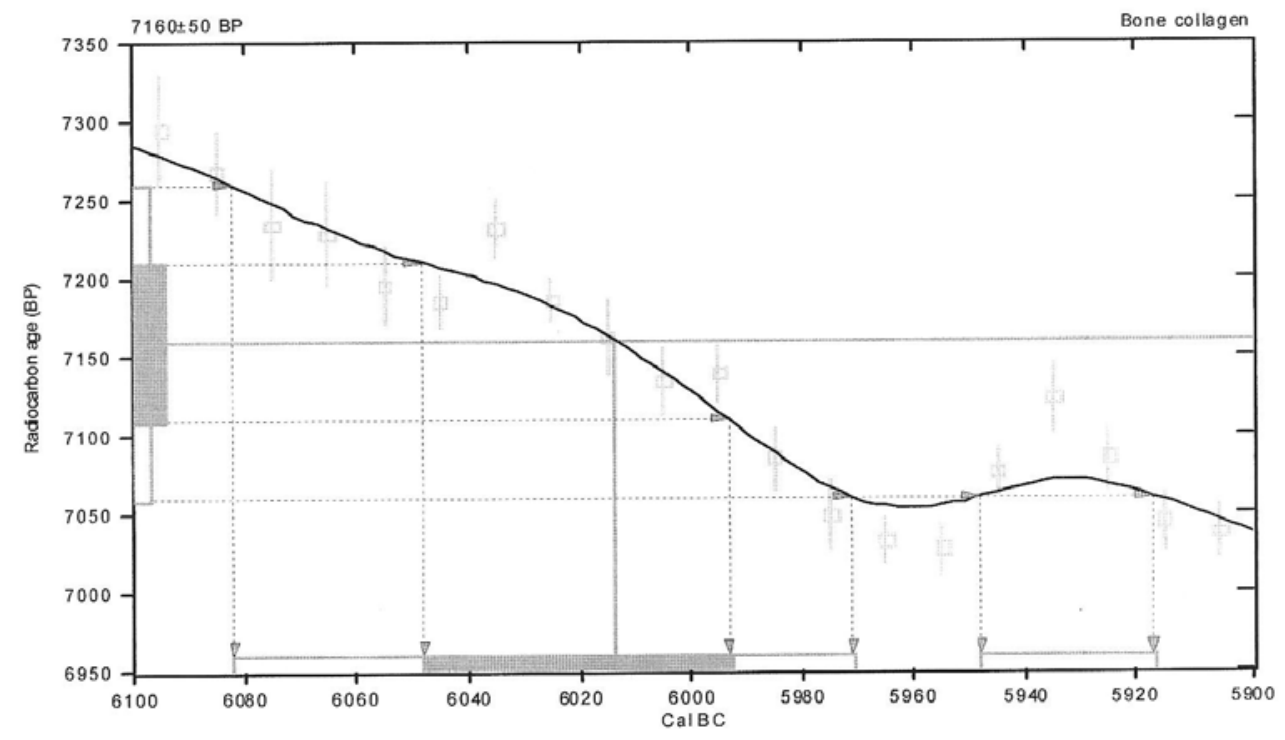

References:

Database used

Calibration D 98

Calibration Database

Editorial Comm ent
Stuiver, M., vander Plicht, H 1998, Radiocarbon 40(3), pxii-xiii

Stuiver, M., vander Plicht, $H_{.}, 1998$,
INTCAL 98 Radiocarbon Age Cal ibration

Stuiver, M., et. al., 1998, Radiocarbon 40(3), p1041-1083

Mathe matics

A Simplified Approach to Calibrating C14 Dates

Talma, A.S., Vogel, J. C., 1993, Radiocarbon 35(2), p317-322

Beta Analytic Radiocarbon Dating Laboratory

4985 S.W.74th Court, Miami, Florida $33155 \cdot$ Tel: (305)667.5167 • Fax: (305)663-0964 • E-Mail: beta@radiocarbon.com 


\section{CALIBRATION OF RADIOCARBON AGE TO CALENDAR YEARS}

(Variables: C13/C12=-19.8:lab. mult=1)

Laborato ry number: Beta-216030

Conventional radiocarbon age: $\quad 6650 \pm 50 \mathrm{BP}$

2 Sigma calibrated result: Cal BC 5650 to 5490 (Cal BP 7600 to 7440) (95\% probability)

In tercept data

Intercept of radiocarbon age

with calibration curve: Cal BC 5610 (Cal BP 7560)

1 Sigma calibrated result: Cal BC 5630 to 5520 (Cal BP 7580 to 7480 ) (68\% probability)

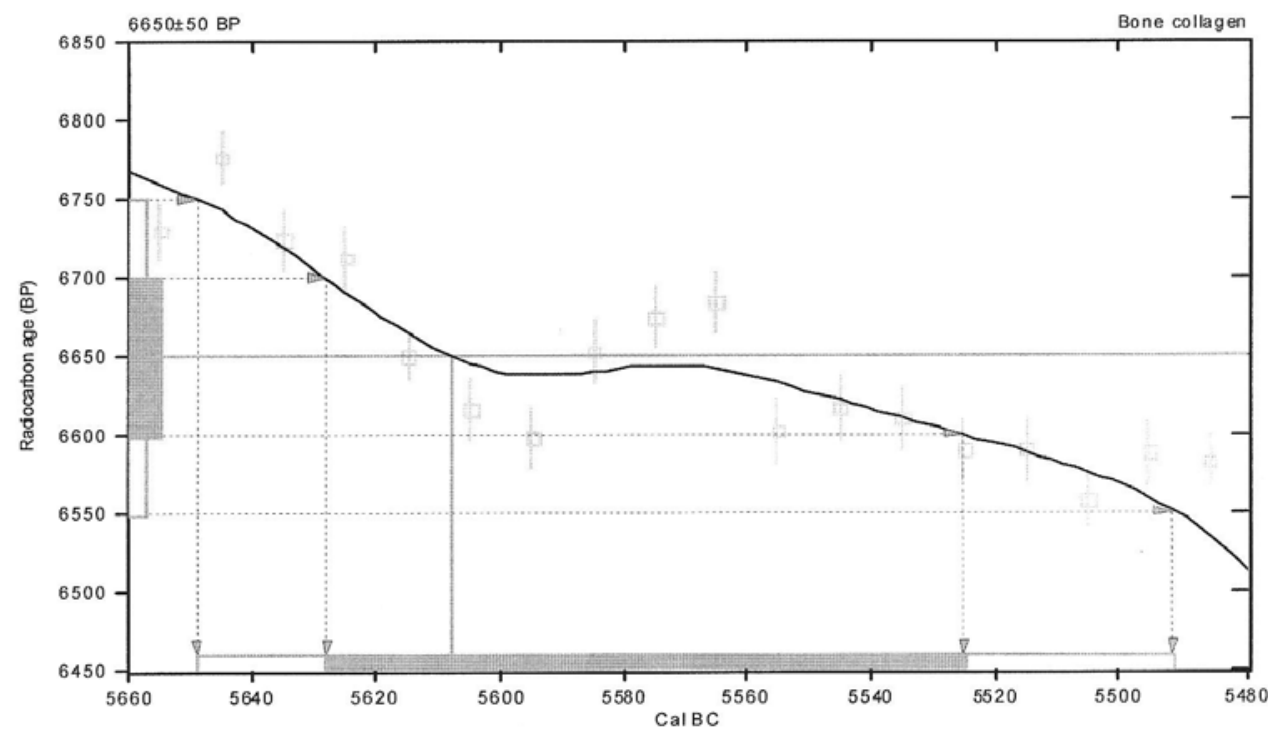

References:

Database used
INTC AL 98

Calibration Database

Editorial Comm ent

Stuiver, M., vander Plicht, H, 1998, Radiocarbon 40(3), pxii-xiii

INTCAL 98 Radiocarbon Age Calibration

Stuiver, M., et. al., 1998, Radiocarbon 40(3), p1041-1083

Mathe matics

A Simplified Approach to Calibrating C14 Dates

Talma, A. S., Vogel, J. C., 1993, Radiocarbon 35(2), p317-322

\section{Beta Analytic Radiocarbon Dating Laboratory}

4985 SW. 7 4th Court, Miami, Florida 33155 - Tel: (305)667-5167·Fax: (305)663-0964 - E-Mail: beta@radiocarbon.com 


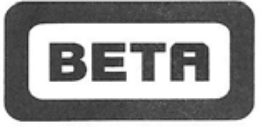

Consistent Accuracy ... Delivered On Time.
Beta Analytic Inc.

4985 SW 74 Court

Miami, Florida 33155 USA

Tel: 3056675167

Fax: $3056630 / 97$

Www.radiocarbon.com
Mr. Darden Hood Director

Mr. Ronald Hatfield Mr. Christopher Patrick Deputy Directors

\section{Final Report}

The final report package includes the final date report, a statement outlining our analytical procedures, a glossary of pretreatment terms, calendar calibration information, billing documents (containing balance/credit information and the number of samples submitted within the yearly discount period), and peripheral items to use with future submittals. The final report includes the individual analysis method, the delivery basis, the material type and the individual pretreatments applied. The final report has been sent by mail and e-mail (where available).

\section{Pretreatment}

Pretreatment methods are reported along with each result. All necessary chemical and mechanical pretreatments of the submitted material were applied at the laboratory to isolate the carbon which may best represent the time event of interest. When interpreting the results, it is important to consider the pretreatments. Some samples cannot be fully pretreated, making their ${ }^{14} \mathrm{C}$ ages more subjective than samples which can be fully pretreated. Some materials receive no pretreatments. Please look at the pretreatment indicated for each sample and read the pretreatment glossary to understand the implications.

\section{Analysis}

Materials measured by the radiometric technique were analyzed by synthesizing sample carbon to benzene $(92 \% \mathrm{C})$, measuring for ${ }^{14} \mathrm{C}$ content in one of 53 scintillation spectrometers, and then calculating for radiocarbon age. If the Extended Counting Service was used, the ${ }^{14} \mathrm{C}$ content was measured for a greatly extended period of time. AMS results were derived from reduction of sample carbon to graphite $(100 \% \mathrm{C})$, along with standards and backgrounds. The graphite was then detected for ${ }^{14} \mathrm{C}$ content in one of 9 accelerator-mass-spectrometers (AMS) .

\section{The Radiocarbon Age and Calendar Calibration}

The "Conventional ${ }^{14} \mathrm{C}$ Age $\left({ }^{*}\right)$ " is the result after applying ${ }^{13} \mathrm{C} /{ }^{12} \mathrm{C}$ correcitions to the measured age and is the most appropriate radiocarbon age. If an "*" is attached to this date, it means the ${ }^{13} \mathrm{C} /{ }^{12} \mathrm{C}$ was estimated rather than measured (The ratio is an option for radiometric analysis, but included on all AMS analyses.) Ages are reported with the units "BP" (Before Present). "Present" is defined as AD 1950 for the purposes of radiocarbon dating.

Results for samples containing more ${ }^{14} \mathrm{C}$ than the modern reference standard are reported as "percent modern carbon" ( $\mathrm{pMC}$ ). These results indicate the material was respiring carbon after the advent of thermo-nuclear weapons testing (and is less than $\sim 50$ years old).

Applicable calendar calibrations are included for materials between about 100 and 19,000 BP. If calibrations are not included with a report, those results were either too young, too old, or inappropriate for calibration. Please read the enclosed page discussing calibration. 


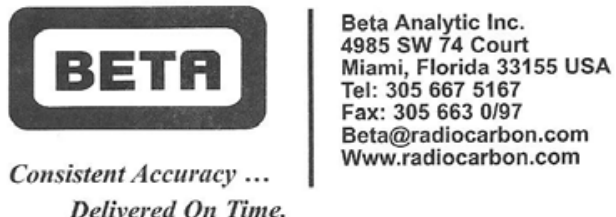

Delivered On Time,

\author{
Mr. Darden Hood \\ Director \\ Mr. Ronald Hatfield \\ Mr. Christopher Patrick \\ Deputy Directors
}

\section{Calendar Calibration at Beta Analytic}

Calibrations of radiocarbon age determinations are applied to convert BP results to calendar years. The short-term difference between the two is caused by fluctuations in the heliomagnetic modulation of the galactic cosmic radiation and, recently, large scale burning of fossil fuels and nuclear devices testing. Geomagnetic variations are the probable cause of longer-term differences.

The parameters used for the corrections have been obtained through precise analyses of hundreds of samples taken from known-age tree rings of oak, sequoia, and fir up to about 10,000 BP. Calibration using tree-rings to about $12,000 \mathrm{BP}$ is still being researched and provides somewhat less precise correlation. Beyond that, up to about $20,000 \mathrm{BP}$, correlation using a modeled curve determined from U/Th measurements on corals is used. This data is still highly subjective. Calibrations are provided up to about 19,000 years BP using the most recent calibration data available.

The Pretoria Calibration Procedure (Radiocarbon, Vol 35, No.1, 1993, pg 317) program has been chosen for these calendar calibrations. It uses splines through the tree-ring data as calibration curves, which eliminates a large part of the statistical scatter of the actual data points. The spline calibration allows adjustment of the average curve by a quantified closeness-of-fit parameter to the measured data points. A single spline is used for the precise correlation data available back to $9900 \mathrm{BP}$ for terrestrial samples and about $6900 \mathrm{BP}$ for marine samples. Beyond that, splines are taken on the error limits of the correlation curve to account for the lack of precision in the data points.

In describing our calibration curves, the solid bars represent one sigma statistics (68\% probability) and the hollow bars represent two sigma statistics (95\% probability). Marine carbonate samples that have been corrected for ${ }^{13} \mathrm{C} /{ }^{12} \mathrm{C}$, have also been corrected for both global and local geographic reservoir effects (as published in Radiocarbon, Volume 35, Number 1, 1993) prior to the calibration. Marine carbonates that have not been corrected for ${ }^{13} \mathrm{C} /{ }^{12} \mathrm{C}$ are adjusted by an assumed value of $0 \% 0$ in addition to the reservoir corrections. Reservoir corrections for fresh water carbonates are usually unknown and are generally not accounted for in those calibrations. In the absence of measured ${ }^{13} \mathrm{C} /{ }^{12} \mathrm{C}$ ratios, a typical value of $-5 \% 0$ is assumed for freshwater carbonates.

(Caveat: the correlation curve for organic materials assume that the material dated was living for exactly ten years (e.g. a collection of 10 individual tree rings taken from the outer portion of a tree that was cut. down to produce the sample in the feature dated). For other materials, the maximum and minimum calibrated age ranges given by the computer program are uncertain. The possibility of an "old wood effect" must also be considered, as well as the potential inclusion of younger or older material in matrix samples. Since these factors are indeterminant error in most cases, these calendar calibration results should be used only for illustrative purposes. In the case of carbonates, reservoir correction is theoretical and the local variations are real, highly variable and dependent on provenience. Since imprecision in the correlation data beyond 10,000 years is high, calibrations in this range are likely to change in the future with refinement in the correlation curve. The age ranges and especially the intercept ages generated by the program must be considered as approximations.) 
BETA ANALYYTIC INC. - 4985 SW 74 Court, Miami, Florida 33155 USA - Tel: 305-667-5167 - Fax 305-663-0964 - beta@ radiocarbon.com

PRETREATMENT GLOSSARY

Standard Pretreatment Protocols at Beta Analytic

Unless otherwise requested by a submitter or discussed in a final date report, the following procedures apply to pretreatment of samples submitted for analysis. This glossary defines the pretreatment methods applied to each result listed on the date report form (e.g. you will see the designation "acid/alkali/acid" listed along with the result for a charcoal sample receiving such pretreatment).

Pretreatment of submitted materials is required to eliminate secondary carbon components. These components, if not eliminated, could result in a radiocarbon date, which is too young or too old. Pretreatment does not ensure that the radiocarbon date will represent the time event of interest. This is determined by the sample integrity. Effects such as the old wood effect, burned intrusive roots, bioturbation, secondary deposition, secondary biogenic activity incorporating recent carbon (bacteria) and the analysis of multiple components of differing age are just some examples of potential problems. The pretreatment philosophy is to reduce the sample to a single component, where possible, to minimize the added subjectivity associated with these types of problems. If you suspect your sample requires special pretreatment considerations be sure to tell the laboratory prior to analysis.

\section{"acid/alkali/acid"}

The sample was first gently crushed/dispersed in deionized water. It was then given hot HCI acid washes to eliminate carbonates and alkali washes $(\mathrm{NaOH})$ to remove secondary organic acids. The alkali washes were followed by a final acid rinse to neutralize the solution prior to drying. Chemical concentrations, temperatures, exposure times, and number of repetitions, were applied accordingly with the uniqueness of the sample. Each chemical solution was neutralized prior to application of the next. During these serial rinses, mechanical contaminants such as associated sediments and rootlets were eliminated. This type of pretreatment is considered a "full pretreatment". On occasion the report will list the pretreatment as "acid/alkali/acid - insolubles" to specify which fraction of the sample was analyzed. This is done on occasion with sediments (See "acid/alkali/acid - solubles"

Typically applied to: charcoal, wood, some peats, some sediments, and textiles "acid/alkali/acid - solubles"

On occasion the alkali soluble fraction will be analyzed. This is a special case where soil conditions imply

That the soluble fraction will provide a more accurate date. It is also used on some occasions to verify the present/absence or degree of contamination present from secondary organic acids. The sample was first pretreated with acid to remove any carbonates and to weaken organic bonds. After the alkali washes (as discussed above) are used, the solution containing the alkali soluble fraction is isolated/filtered and combined with acid. The soluble fraction, which precipitates, is rinsed and dried prior to combustion.

"acid/alkali/acid/cellulose extraction"

Following full acid/alkali/acid pretreatments, the sample is bathed in (sodium chlorite) $\mathrm{NaClO}_{2}$ under very controlled conditions ( $\mathrm{Ph}=$ 3 , temperature $=70$ degrees $\mathrm{C}$ ). This eliminates all components except wood cellulose. It is useful for woods that are either very old or highly contaminated.

Applied to: wood

"acid washes"

Surface area was increased as much a possible. Solid chunks were crushed, fibrous materials were shredded, and sediments were dispersed. Acid (HCI) was applied repeatedly to ensure the absence of carbonates. Chemical concentrations, temperatures, exposure times, and number of repetitions, were applied accordingly with the uniqueness of each sample. The sample was not be subjected to alkali washes to ensure the absence of secondary organic acids for intentional reasons. The most common reason is that the primary carbon is soluble in the alkali. Dating results reflect the total organic content of the analyzed material. Their accuracy depends on the researcher's ability to subjectively eliminate potential contaminants based on contextual facts.

Typically applied to: organic sediments, some peats, small wood or charcoal, special cases 
PRETREATMENT GLOSSARY

Standard Pretreatment Protocols at Beta Analytic

(Continued)

"collagen extraction: with alkali or collagen extraction: without alkali

The material was first tested for friability ("softness"). Very soft bone material is an indication of the potential absence of the collagen fraction (basal bone protein acting as a "reinforcing agent" within the crystalline apatite structure). It was then washed in de-ionized water, the surface scraped free of the outer most layers and then gently crushed. Dilute, cold HCI acid was repeatedly applied and replenished until the mineral fraction (bone apatite) was eliminated. The collagen was then dissected and inspected for rootlets. Any rootlets present were also removed when replenishing the acid solutions. "With alkali" refers to additional pretreatment with sodium hydroxide $(\mathrm{NaOH})$ to ensure the absence of secondary organic acids. "Without alkali" refers to the $\mathrm{NaOH}$ step being skipped due to poor preservation conditions, which could result in removal of all available organics if performed.

Typically applied to: bones

"acid etch"

The calcareous material was first washed in de-ionized water, removing associated organic sediments and debris (where present). The material was then crushed/dispersed and repeatedly subjected to $\mathrm{HCI}$ etches to eliminate secondary carbonate components. In the case of thick shells, the surfaces were physically abraded prior to etching down to a hard, primary core remained. In the case of porous carbonate nodules and caliches, very long exposure times were applied to allow infiltration of the acid. Acid exposure times, concentrations, and number of repetitions, were applied accordingly with the uniqueness of the sample.

Typically applied to: shells, caliches, and calcareous nodules

"neutralized"

Carbonates precipitated from ground water are usually submitted in an alkaline condition (ammonium Hydroxide or sodium hydroxide solution). Typically this solution is neutralized in the original sample container, using deionized water. If larger volume dilution was required, the precipitate and solution were transferred to a sealed separatory flask and rinsed to neutrality. Exposure to atmosphere was minimal.

Typically applied to: Strontium carbonate, Barium carbonate

(i.e. precipitated ground water samples)

"carbonate precipitation"

Dissolved carbon dioxide and carbonate species are precipitated from submitted water by complexing them as ammonium carbonate. Strontium chloride is added to the ammonium carbonate solution and strontium carbonate is precipitated for the analysis. The result is representative of the dissolved inorganic carbon within the water. Results are reported as "water DIC".

Applied to: water

"solvent extraction"

The sample was subjected to a series of solvent baths typically consisting of benzene, toluene, hexane, pentane, and/or acetone. This is usually performed prior to acid/alkali/acid pretreatments.

Applied to: textiles, prevalent or suspected cases of pitch/tar contamination, conserved materials.

"none"

No laboratory pretreatments were applied. Special requests and pre-laboratory pretreatment usually accounts for this. 


\title{
APPENDIX B \\ VERTEBRATE FAUNAL IDENTIFICATION AND ANALYSIS OF REMAINS FROM 41HY161
}

\section{Vertebrate Faunal Remains from 41HY161}

\author{
Barbara A. Meissner
}

September 5, 2005

The vertebrate faunal collection from the Sessom Creek Project analyzed for this report consisted of a total of 393 bones weighing $197.34 \mathrm{~g}$ (Table 1). The bone recovered was identified to the extent possible, using the comparative collection at the Center for Archaeological Research at the University of Texas at San Antonio, with the kind permission of Dr. Steve A. Tomka, the Director.

Identifications were conservative. For example, bison-sized bone was not labeled Bison bison unless it could be positively differentiated from cattle (Bos Taurus) and horse (Equus caballos). After examination, specimens were bagged by Unit/Level and then by identification. Acid-free paper tags containing provenience information and bone identification were placed in each bag.

In general, the bone was highly fragmented. This and the poor condition of some of the bone (see below) resulted in only 22 bone identified to the genus taxonomic level (5.6 percent). The bone tended to be either in good condition (though highly fragmented) or in very poor condition. For the most part the poor condition seemed to be the result of the surface pitting caused by the microbiologic activity of bacteria and fungi. Some bone was so severely pitted that it could have been the result of chewing, swallowing, and subsequent elimination by either humans or canids, however, extreme cases of biological pitting can resemble this and differentiating the two processes in these extreme cases is difficult (Shaffer 1995). 
Table 1: Identified Bone

\begin{tabular}{|c|c|c|c|}
\hline Scientific Name & Common Name & Ct. & Wgt. (g) \\
\hline \multicolumn{4}{|c|}{ MAMMALIA } \\
\hline \multicolumn{4}{|c|}{ Artiodactyla } \\
\hline \multirow[t]{3}{*}{ Odocoileus virginiana } & White-tail deer & 5 & 7.45 \\
\hline & Unidentified Artiodactyls & 4 & 1.86 \\
\hline & Total Artiodactyls & 9 & 9.31 \\
\hline \multicolumn{4}{|c|}{ Carnivora } \\
\hline Canis sp. & Probably dog or coyote & 2 & 9.02 \\
\hline \multirow[t]{2}{*}{ Procyon lotor } & Raccoon & 1 & 0.16 \\
\hline & Total Carnivores & 3 & 9.18 \\
\hline \multicolumn{4}{|c|}{ Lagomorphia } \\
\hline Lepus californicus & Blacktailed Jackrabbit & 4 & 2.95 \\
\hline \multirow[t]{2}{*}{ Sylvilagus sp. } & Cottontailed Rabbit & 5 & 0.56 \\
\hline & Total Rabbits & 9 & 3.51 \\
\hline \multicolumn{4}{|c|}{ Rodentia } \\
\hline Geomys sp. & Gophers & 1 & 0.19 \\
\hline Sigmodon sp. & Cotton rats & 2 & 0.16 \\
\hline \multirow[t]{3}{*}{ Sciurus sp. } & Tree squirrels & 1 & 0.37 \\
\hline & Unidentified Rodents & 3 & 0.38 \\
\hline & Total Rodents & 7 & 1.10 \\
\hline \multicolumn{4}{|c|}{ Unidentified Mammals } \\
\hline & Rat/Rabbit-Sized & 12 & 1.85 \\
\hline & Deer-sized & 51 & 71.85 \\
\hline & Cow/Bison-Sized & 6 & 13.65 \\
\hline & Unknown & 279 & 82.40 \\
\hline & Total unidentified Mammals & 348 & 169.75 \\
\hline & TOTAL MAMMALS & 376 & 192.85 \\
\hline \multicolumn{4}{|c|}{ AVES } \\
\hline \multicolumn{4}{|c|}{ Galliformes } \\
\hline & Unidentified Galliforms & 1 & 0.19 \\
\hline & Total Galliforms & 1 & 0.19 \\
\hline \multicolumn{4}{|c|}{ Unidentified Birds } \\
\hline & Unidentified birds & 11 & 2.98 \\
\hline & TOTAL BIRDS & 12 & 3.17 \\
\hline \multicolumn{4}{|c|}{ REPTILIA } \\
\hline \multicolumn{4}{|c|}{ Testudines } \\
\hline \multirow[t]{4}{*}{ Emydidae } & Box/Slider Turtles & 1 & 0.84 \\
\hline & Unidentified Turtle & 2 & 0.31 \\
\hline & Total Turtle & 3 & 1.15 \\
\hline & TOTAL REPTILES & 3 & 1.15 \\
\hline \multicolumn{4}{|c|}{ OSTEICTHYES } \\
\hline Lepisoteuss sp. & Gar & 2 & 0.17 \\
\hline & TOTAL FISH & 2 & 0.17 \\
\hline & TOTAL BONE & 393 & 197.34 \\
\hline
\end{tabular}


Some bone $(\mathrm{n}=39)$ exhibited a slight encrustation with what appeared to be a thin film of calcium carbonate. In some cases this encrustation has sealed small amounts of a brown sediment to the bone. The majority of these (34/39) were found in Level 4 or below. However, in each case, there were other bones in the same level with no evidence of this slight incrustation. All such bones are highly fragmented.

The bones identified to the genus taxonomic level represent 9 genera, and with the exception of 2 fragmented gar (Lepisosteus sp.) scales, are all mammals (Table 1). Unidentifiable turtle and bird bones were also present. One bird bone was from the order Galliformes, which includes turkeys, quail and prairie chickens. The size of the bone suggests it was probably the latter (Tympanuchus sp.). If so it would have been the Greater Prairie Chicken (T. cupido), a species once common over all but the western-most habitats in Texas, but now highly endangered. Only one sub-species, Attwater's Prairie-Chicken (T. c. attwaterii) still lives in Texas, limited to two small areas along the Gulf coast, and is now considered critically endangered (The Nature Conservancy 2004).

Only one turtle bone could be identified to the family taxonomic level (Table 1). The family Emydidae includes box turtles and pond sliders. The small number of turtles in this collection is surprising, given the close proximity to water resources.

Whitetail deer (Odocoileus virginianus), jackrabbit (Lepus californicus), and cottontail rabbit (Sylvilagus sp.) are the most common identified bone in the collection, together representing 63.6 percent of the total identified bone. This suggests they were the main source of meat for the inhabitants of the area, although the raccoon (Procyon lotor), squirrel (Sciurus sp.) and cotton rat (Sigmodon sp.) may have provided a portion of the diet as well. In addition there were six bones of a bison-sized animal, indicating the possibility of at least some bison in the diet, although the very small numbers make it unlikely that bison represented significant portion of the diet.

A fragment of a canid mandible found in Level 5 of Unit 2 showed extreme tooth wear and arthritic changes, especially excessive bone growth on the condyle. This strongly suggests the animal was very old at the time of death. This is unlikely in a wild animal, and makes it probable that the animal was a dog (Canis familiaris) rather than a coyote (C. latrans). 
One bone tool tip was identified in the collection, in Level 3 of Unit 9 (Figure 1). This tool showed preliminary shaping but appears not to have been finished, possibly because this tip broke off the main bone during manufacture.

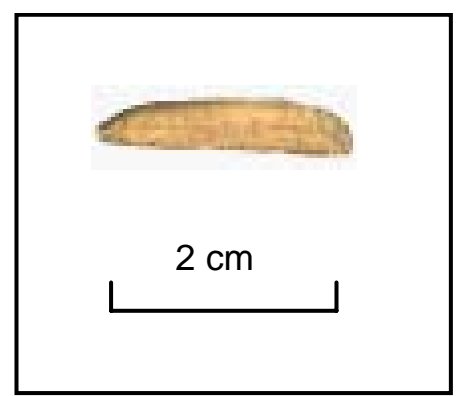

Figure 1: Unfinished bone tool tip from Unit 9, Level 3.

In summary, this is a very small collection of bone, most of which was in a highly fragmented condition. There is a pronounced variability in the condition of the bone, even within unit/levels. Most of the bone shows extensive pitting, probably caused by microbiological activity, but in some cases possibly the result of chewing and eating by canids or humans. Other bone is in good condition, though most of this is also highly fragmented. The long bones of deer and deer-zed artiodactyls, for instance, show considerable breakage that occurred while the bone was still fresh, indicating that they were broken open for extraction of marrow.

Generally, it appears that the major components of the meat diet were deer and rabbits, however, the small size of this collection should be taken into consideration and considerable caution should be used in making statements about the meat diet represented by this collection.

\section{References Cited}

Nature Conservancy 2004 Greater Prairie-Chicken. The Nature Conservancy. Available online at http://nature.org/magazine/summer2002/unlucky13/animals/art7428.html. Accessed 9/5/05.

\section{Shaffer, B. S.}

1995 Analysis of Vertebrate Fauna. In Past Cultures and Climates at Jonas Terrace, 41ME29, Medina County, Texas, by L. Johnson, pp. 306-325. Report No. 40. Office of the State Archeologist, Texas Department of Transportation and Texas Historical Commission, Austin. 


\section{APPENDIX C \\ LITHIC ARTIFACT DESCRIPTIONS FROM $41 H Y 161$}

\section{Projectile points}

Specimen 5-7A

Unit 5 Level 7

N 1001.43 E 1001.64 El 97.15m

The specimen is a Gower point with the proximal end terminating in a combination impact and snap fracture above the shoulder. The haft is slightly convex to straight sided and constricting at the neck and the notched base. The notch was formed by the removal of a single large flake on one side and three flake scars on the obverse. The left barb is missing from an impact perpendicular to the lateral margin. The right barb notch is almost parallel to the stem and constricts slightly at the neck.

The overall flaking pattern on the stem and the remaining portion of blade is random. The stem is dulled by the removal of small 1-2mm long flakes. Additional flake scars along the lateral edges of the stem are step fractures that could be caused by hafting damage or moving in a haft (Andrefsky Jr. 1998). Small 1 to $2 \mathrm{~mm}$ conchoidal flake scars are also on the obverse stem face. These scars are on the highest ridge of the face and would be subject to the type of wear patterning expected from hafting (Odell 2004:153). The right lateral margin has been resharpened at the shoulder of the barb suggesting that the blade width at the haft end has narrowed from resharpening, and becoming more parallel to the stem. 
The specimen is made from gray, opaque, fine grain Edwards chert that has the vitreous feel of heat treating. This type of chert would have been available along the edge of the Balcones Escarpment and on the nearby Edwards Plateau. No heat treated flake of this material was recovered in the debitage, and this specimen is the finest grained material recovered from the site.

Specimen 9-6B

Unit 9 Level 6

N 1000.90 E 1000.42 El 97.286

The specimen is a Gower point. The proximal end terminates in a transverse fracture and impact scars on the obverse face. The base is notched with an expanding stem. The base notch was created by the initial removal of a single flake on the reverse side. Three vertical flake scars on the obverse face further defined and thinned the base at the notch. Small flake scars, less than $2 \mathrm{~mm}$ in length follow the notch on the reverse face. Larger scalar scars, up to $3 \mathrm{~mm}$ wide and 4 $\mathrm{mm}$ long thin the obverse face of the notch. The basal ears thinned with narrow, small, 2 to $3 \mathrm{~mm}$ in length, flake scars. The barb notches are formed like the base, with a large flake removed on one face and a series of smaller scalar flakes from the other face.

Flake patterning is random to sub parallel. The flake scars are narrower than the remaining flake scars on Specimen 5-7A, and appear to be from resharpening since they occur along previously damaged portions of the blade edge along the right margin. The 
same long and thin flake scars are on alternate edges and faces and the edges have a developing alternate bevel. This type of resharpening was likely performed while the point was hafted since the bevel is not on the haft element. On narrow bifaces, alternate beveling is a technique that allows a sharp edge to be maintained by maintaining a higher width to thickness ratio than regular, equal bifacial sharpening. Repeated resharpening has developed a flared profile between the blade and the barb giving the blade a triangular profile.

The breakage pattern suggests that the specimen was damaged in use and then discarded. Extensive resharpening of the tip would have shortened the overall length of the tool while increasing the profile angle of the lateral edges. Not enough length was left to create a new tip. The specimen, therefore, was likely discarded being too small to be used as a hafted puncturing or cutting tool.

The material is a fine grain tan gray chert that is commonly observed in artifacts along the edge of the Balcones and escarpment. The chert has the appearance of heat treating, however the specimen does not have a smooth, vitreous feel.

Specimen $6-7 \mathrm{x}$

Unit 6 Level 7

N 1001.98 E 1000.88 El 97.12

The specimen is the base of split stemmed point that most resembles a Gower or Gower/Hoxie variant. A slight flaring at the upper left margin suggests that the specimen is the haft element that has been broken from the blade. The break is a bending or snap fracture and using the specimen to pry could produce a similar fracture. The degree of finish on the specimen, including the finish of the base using vertical, parallel, flakes in the notch, and that both the stem and the notch have been smoothed and have small flake scars consistent with 
hafting damage suggest that the specimen was part of a finished tool. The basal thinning resembles the other Gower specimens and it differs primarily in the depth of the notch.

The material is tan gray, fine grained chert that was probably heat treated based upon the appearance and feel of the chert. Two scenarios to account for the specimen are: the specimen represents a lost projectile, the shaft end, or that it broke at the haft and blade junction and was then discarded as a new tip was installed.

These three specimens represent the deepest, identifiable and provenienced points from the site. All three vary in base dimensions such as basal width and may represent the same style of points along a continuum.

9-5X

Unit 9 Level 5

The specimen is a point base from a bifurcate stem projectile point. It resembles a Gower/Hoxie variant, having the stem resembling a Gower and a base with a shallow concavity thinned like a Hoxie point. The stem is broken in a snap fracture at what is likely the neck. An additional impact fracture has removed a portion of the left margin and part of both faces. The stem is slightly expanding and the base and stem are ground. The base is unifacially thinned creating an offset base. The flaking pattern on the stem is indeterminate. The specimen is made from a fine grain tan chert that feels heat treated. The breakage pattern on the base suggests that it was broken while still hafted.

Specimen 9-2N

Unit 9 Level 2

N 1000.02 E 1000.25 El 97.635 
The specimen is a Gower projectile point that has been extensively resharpened. The base is slightly expanding and is thinned by a large flake on one face and several smaller flakes on the opposing face. The fracture patterns at the distal end and the left lateral margin are consistent with frontal impact. Additional scars from the distal break continue down the ventral the obverse surface. The left margin at the shoulder has been removed by a burin spall such as from a frontal impact.

The lack of strong shoulders and the alternate beveling indicate that the specimen was extensively resharpened. Compared to Gower specimens from Wilson Leonard the specimen is smaller, with a shallower concavity (Dial, et al. 1998:344). The flaking is random. The material is a fine grain tan gray chert and a small amount of grayish patination occurs at the basal tips. Calcium carbonate precipitate occurs on all surfaces.

Specimen $\mathrm{X}-2$

N 1000 E 1000 El 97.946

The specimen was recovered during the initial leveling of the block surface in the southwest corner of Unit 9. Originally it was thought to be a newly resharpened Hoxie point since the stems of Pedernales and Early Archaic bifurcate points are similar. However, it is more similar to abnormal Pedernales type points as seen from the Gault site near Florence in Bell County, although this specimen is considerably smaller. The affiliation with the Late Archaic is further reinforced by a radiocarbon date from below the point dating to $3460+/-40$ B.P., and a stratigraphic break in the soil magnetic susceptibility.

The point is intact and the blade is bifacially serrated with small pressure flakes of 1$2 \mathrm{~mm}$ in width and extending approximately $2 \mathrm{~mm}$ into the edge. The distal tip ends in a needle- 
like point. The flaking is random patterned and collateral, forming a meandering central arras on both faces.

Specimen X1

Surface

The specimen is a well made lanceolate point that resembles an Angostura point. The base is slightly concave and there is no evidence of edge grinding on the base. The stem on one margin is lightly ground. The flaking pattern is oblique sub-parallel on one face and sub-parallel on the other and the outline of the point as asymmetric because of resharpening. The resharpening has been bifacial and there is no alternate beveling. The tip has not been resharpened and there remains a small impact flake scar.

The material is tan gray, fine grain chert with some degree of internal patination to a gray. There are small $1-2 \mathrm{~mm}$ white inclusions. The regular flake patterning and the reduction of the stem, with flaking from the lateral margins, indicate that the point is lanceolate. The basal concavity and basal depth created through minimal bifacial flaking.

The specimen is additional evidence that the location was occupied during the Paleoindian/Archaic transition, which includes a probable Thrall point from earlier excavations by the Center for Archaeological Research (Lyle, et al. 2000).

Unit 6 Level 1

N 1001.02 E 1000.87 El 97.77

The specimen is a bifurcate stem base that resembles Gower and Hoxie bifurcate stem bases. The stem is expanding and the base is bifacially thinned. The basal ears have been ground, while the basal notch is not ground. The proximal fracture is from bending and impact 
stresses and occurs where the stem meets the blade. As with the other stemmed bifurcate specimens from the Icehouse site, the specimen shows the variety of basal forms.

The material is tan gray fine grain chert that is heat treated. The specimen is similar to the numerous Early Archaic bifurcate stem fragments recovered from the Wilson-Leonard site (Dial, et al. 1998). There, the authors noted that many of the proximal fragments were broken at the stem and haft juncture, and that the fractures were usually complex with bending breaks and burin breaks. The breakage pattern suggests that the specimen was broken while hafted and subsequently removed from the hafting element.

\section{Bifaces}

Specimen 6-7Y

Unit 6 Level 7

N 1001.57 E 1000.84 El 97.19m

The specimen is a late stage biface preform or more likely a recycled tool that is missing the right lateral margin. The possibility that is a recycled or rejuvenated tool is the small size of the biface, the angled profile of the specimen, and the extensive flake scaring on both surfaces beneath the edge sharpening flakes. The specimen does not appear to have been a projectile point. The right distal margin has been resharpened including a the removal of a small $5 \mathrm{~mm}$ hard hammer flake that has thinned the edge too much and almost removed the distal tip. The break runs from the distal tip to the proximal base and appears to be a bending or snap fracture. The base is at an oblique angle to the remaining left lateral margin and has been dulled by abrasion. The preparation is more likely to be platform preparation for further thinning $\mathrm{g}$ since several attempts were made to remove a knot of resistant material. The specimen has been hafted at some point since the edge has smoothed and rounded flake scars beneath the thinning attempts. 
The final fracture that removed the right edge was preceded by a plunging flake removed from the same edge but near the proximal end. The specimen has a slight curvature in its profile and the portion that they were attempting to thin may be the remnant platform of the original flake blank. The original flake patterning appears to be irregular and both hard and soft hammer scars are visible. The material is a tan gray chert with small fossil inclusions that contributed to the failure to further thin the biface.

Specimen 6-7N

Unit 6 Level 7

N 1001.03 E 1000.12 El 97.14-97.16m

The specimen is a large bifacially worked hard hammer flake that still retains the initial striking platform. The size of the platform indicates that the flake probably produced using a hammer stone. The distal tip is patinated white and is part of the external cortex. Both lateral margins have trimmed use wear segments that appear after an attempt to thin the biface failed. Biface thinning flakes were removed from the lateral edges into the center of the biface, with some flakes almost completely crossing the surface. The bulb of percussion has been removed in this fashion. Two large flakes were detached from the original platform and both of these flakes hinged out and removed a segment of the left margin. These flakes were preceded by the removal of another hinge flake from the lateral margin and perpendicular to the two flake scars.

There is no evidence of hafting although the specimen is large enough to be comfortably held away from the two sharpened edge segments. The material is a tan gray fine grain chert. The white cortex at the distal end is a weathered upland cortex. The specimen appears to be a failure to thin biface that was subsequently used as a tool. The location and appearance of the use wear and edge trimming suggest the edges were used for cutting. 
Specimen 5-7B

Unit 5 Level 7

N 1001.37 E 1001.02 El 97.245m

The specimen is a blocky medial fragment that retains a medial edge. Based upon the cross section profile, the specimen is fractured longitudinally at the center and the breakage pattern indicates the fragment was broken at least twice in separate events. The fragment is from an intermediate stage biface where hard hammer flakes have been detached from both faces. The flakes traveled a short length, less than $10 \mathrm{~mm}$, into the interior of face. A portion of the original ventral flake surface is still visible.

The material is a tan gray fine grained chert with fossil inclusions and is a material widely seen in the debitage. Although the two major flake scars form a burin edge, there is no evidence that it was utilized, nor is there any evidence that burin spalls were detached.

Specimen 7-7Y

Unit 7 Level 7

N 1000.62 E 1003.36 El 97.27

The specimen is a fragment from the corner of a biface that includes part of a proximal end and lateral edge. The biface was either a late stage biface or completed tool. The distal end fracture is a snap fracture and the right lateral edge is a burin type removal where the platform is the proximal snap fracture. The resulting burin tip does not appear to be used. The specimen has a longitudinal curvature that suggests that it was manufactured from a flake.

The material is a tan gray fine grain chert with fossiliferous inclusions. The specimen tapers at the proximal end which has been thinned, suggesting it may have been hafted. Edge damage along the left margin could be from hafting.

Specimen 9-7F 


\section{Unit 9 Level 7}

N 1000.37 E 1000.04 El 97.145

Specimen $9-7 \mathrm{~F}$ is a lateral margin fragment of an early stage biface that is a knapping error thinning flake. The flake ends in a plunging hinge termination and the detachment of the flake would have made the remaining biface very thin and likely resulted in breaking the preform. A small portion of weathered upland cortex remains on the dorsal face. The material is a tan gray fine grain chert that has developed a whitish blue patination.

Specimen 6-5A

Unit 6 Level 5

N 1001.27 E 1001.47 El 97.39

The specimen is a Stage Three thinned biface preform. The specimen is made from a hard hammer flake and retains the platform, although the bulb of percussion has been removed. The outline is ovate to sub-triangular with the base of the biface at the proximal end of the flake. The proximal end is not thinned giving the profile of the specimen a wedge shape. Both faces have soft hammer flake scars extending past the centerline. On the ventral face there are numerous shorter indeterminate flake scars that extend approximately $10 \mathrm{~mm}$ onto the surface before hinging out. Fractures in the material seem to have stopped the propagation of these flakes resulting in lines of hinge scars. Although the specimen appears to be an unfinished tool, both lateral edges have traces of possible use wear. A portion of the tip has an impact scar.

The specimen is made from the tan gray chert found in local assemblages. The distal tip has patinated to a whitish blue. Portions of the specimen have regular parallel patterned flake scars. A large flake scar at the distal end has removed too much edge to further thin the base. Small patches of calcium carbonate adhere on both surfaces. The specimen is middle to late 
stage biface that may have been utilized. The remaining flake characteristics give an idea of the size of blanks being used for biface manufacturing.

Specimen 3-5A

Unit 3 Level 5

N 1002.62 E 1000.36 El 97.39

The specimen is a small sub-rectangular/triangular biface fragment that may have been a completed tool that was damaged and an attempt was made to rejuvenate the left lateral margin. The distal end terminates in a complex bending/snap fracture. A denticulate pattern of four hard hammer scars are on the left margin, all removed from the same face. These scars cross previous narrow, long, finishing flakes. While this may be an attempt to repair a damaged edge, the denticulate edge may have been the intended result. The proximal end is straight and $28.11 \mathrm{~mm}$ long and as long as the remaining right margin. The base is thinned by small 2-3 mm wide flakes removed parallel to each other and extending approximately $3 \mathrm{~mm}$ into the face. Both faces had similar scarring. The right lateral margin was finished with larger flakes greater than $3 \mathrm{~mm}$ wide and extending 5 to $8 \mathrm{~mm}$ onto the faces.

The material is the fine grain tan gray chert found throughout the assemblage and in local assemblages. The thinning of the base suggests that the tool was intended to be hafted. As a form the specimen resembles bifacial knife-like tools found at Wilson-Leonard (Dial and Collins 1998:551)

Specimen 9-4B

Unit 9 Level 4

N 1000.47 E 1000.11 El 97.438

The specimen is the distal tip of a well thinned late stage biface preform. The edge flaking and sinuosity indicates it is a Late Stage 3 or Stage 4 biface, lacking final thinning and 
edge sharpening. The break is a snap fracture straight across the biface. The material is a fine grain tan gray chert that has patinated to a gray tan in parts and has calcium carbonate precipitates adhering to both surfaces.

Specimen 2-2B

Unit 2 Level 2

N 1002.43 E 1001.72 El 97.635

The specimen is a nearly completed bipointed-shaped Stage 4 biface. A slight curvature in the profile and a thinned bulb of percussion indicates the blank was a hard hammer flake. Flaking is random with some flakes almost crossing across the surface. At the thicker of the two ends, termed the proximal in this instance, there was a failed attempt to remove a high portion of the proximal face that looks like the remnant flake blank platform. At this point, the biface was becoming too narrow for the remaining thickness. Further attempts to remove the section would probably break the biface. The trimming on the lateral edges is consistent with platform preparation for further thinning and to create a regular tool edge. These short hard hammer flakes are unifacial. Although the specimen was unfinished, there are indications that it was utilized. The material is fine grain tan gray chert with small fossil inclusions. Calcium carbonate precipitates adhere in the flake scars on all surfaces.

Specimen 6-3C

Unit 6 Level 3

N 1001.17 E 1000.03 El 97.56

The specimen is the largest biface recovered from the excavations and is a preform that has been initially thinned, making it a Stage 3 biface. The original blank was a large hard hammer flake and a portion of the platform remains. In outline, it is sub-triangular resembling a 
gouge; however, it does not appear to have been utilized as an adze or gouge. Reduction was done using a hard hammer that left negative bulbs around the circumference of the biface.

Numerous step fractures around on the obverse side left margin are from failures to further thin the biface. There are numerous large $10 \mathrm{~mm}$ size circular fossils in the chert that may have created flaws that disrupted flake propagation. The material is grayish fine grain chert with the grayish-white inclusions.

\section{Flake Tools}

Specimen 9-6C

Unit 9 Level 6

N 1000.85 E 1000.85 El 97.283

The specimen is a hard hammer flake with half of the dorsal surface still covered in weathered upland cortex. The dorsal surface is a prominent ridge that creates two steep sided lateral edges of approximately 50 degrees. The left lateral margin has been trimmed of cortex creating a steep sided edge. This specimen resembles several steep sided flake tools recovered from the Early Archaic component at the Armstrong Site approximately 3 miles to the east (Oksanen and Schroeder 2002:126).

These types of tools frequently have multiple use wear segments such as notches and beaked tips, although this specimen is minimally modified. The material is tan and honey colored chert seen throughout the assemblage. The shape of the flake suggests that it was detached from a corner of a tabular core.

Specimen 6-6C

Unit 6 Level 6

N1001.48 E 1000.41 E1 97.22 
The specimen is a flake distal tip. The size and thickness of the specimen indicates that it was a hard hammer flake. The edge angle of the lateral margins is approximately 35 degrees. Both edges have edge modification and use wear. The right margin is heavily patinated and encrusted in calcium carbonate while the left margin is less patinated and calcium carbonate coverage occurs is patchy. The dorsal end is a tip that has been trimmed on either side. A pronounced central arras divides the dorsal surface in half. The proximal end is a bending fracture and no modification was made on the proximal end.

The prominent features are a notch on the left margin and the shaped proximal end and a smaller, worn, spur forms the distal end of the notch. The notch and proximal lateral edge appears to be trimmed to isolate or create the spur. The proximal tip and the worn spur are also similar to multiuse tools found at the Armstrong Site where high powered microscopy use wear identified whittling damage in specimen T19-1 (Schroeder 2002: 29). The degree of patination would likely obscure high power microscopic use wear. The remaining segment of the left lateral edge from the notch to the proximal end is lightly serrated from use. The chert is a medium to fine grain tan chert found in the assemblage here and at other local sites.

\section{Specimen 6-5B}

Unit 6 Level 5

N 1000.53 E 1000.82 El 97.335

The specimen is a flake medial fragment with parallel, small $1 \mathrm{~mm}$ retouch along the left margin ventral side. The right margin is a bending fracture. Both ends terminate in snap fractures that were applied from opposing directions. The trimmed edge is slightly concave, 2 $\mathrm{mm}$, and does not extend beyond the breaks. 
The material is fine grain tan gray chert. The portion of cortex is a weathered upland cortex. There is a large flake scar on the dorsal face that extends off the face and preceded the breaks.

Specimen 9-7A

Unit 9 Level 7

N 1000.97 E 1000.27 El 97.206

The specimen is a complete hard hammer flake that ends in a slight hinge and feather termination. The utilized and shaped part of the flake is the right distal end where a spur is isolated at the distal end by a $24 \mathrm{~mm}$ wide, shallow, notch, and trimming on the proximal side of the spur. The spur is slightly rounded at the tip and the notch is also trimmed and lightly rounded. The material is a gray chert found in this assemblage and other local assemblages. Portions of weathered upland cortex remain on the dorsal side, which is also patinated.

Specimen $5-70$

Unit 5 Level 7

N 1001.93 E 1001.65 El 97.19

The specimen is a complete soft hammer flake that has two segments of macro use wear. The use wear consists of small regular flake scars on both lateral margins, the type of scarring noted by Keeley (1980) and Vaughn (1985). The specimen is actually a utilized flake rather than a formal tool.

The chert is a tan chert with small fossil inclusions that is common in the immediate region. Although other debitage may have been utilized as expedient tools, this specimen is the only one examined that had discernable traces of use wear.

Specimen 9-3X

Unit 9 Level 3 
The specimen is a flake fragment of a trimmed flake. The trimming continues beyond the break. The specimen is fractured at the proximal and distal ends and the left margin as if the specimen had shattered. The unifacial trimming/edge damage is along $18 \mathrm{~mm}$ of the remaining edge. The material is a fine grain grayish tan chert that is likely a slightly patinated sample of the common tan gray chert.

\section{Cores}

Specimen 5-7P

Unit 5 Level 7

N 1001.30 E 1001.72 El 97.16 m

Specimen 5-7P is a discoidal core where flakes have been removed around the circumference of the core toward the center. The core is crudely bifacial and the flaking is not patterned. Platforms have been prepared by hard hammer trimming. The negative bulbs of percussion on the core are from hard hammer impacts and flake removals. The longest flake scar is approximately $36 \mathrm{~mm}$ in length.

The material is a grayish tan chert that is beginning to patinate a whitish gray. The material is upland chert that is available locally. The small size of the last flakes removed suggests that the core was exhausted and then discarded.

Specimen 4-7A

Unit 4 Level 7

N 1001.41 E 1003.72 El 97.26

The specimen is a blocky fragment from a core. Flake scars occur in different directions on different surfaces suggesting it is part of a multidirectional core. The surface is lightly crazed with impact cracks and portions are covered with calcium carbonate. The block is two 
fragmentary to determine maximum flake scar dimensions, although it too appears to be part of an exhausted and discarded core.

Specimen 9-3Z

Unit 9 Level 3

The specimen is a multidirectional core. Negative bulbs are from hard hammer removals, and the length of these flakes average approximately $15 \mathrm{~mm}$. A small spur projects $8 \mathrm{~mm}$ from the edge that has been deliberately enhanced by flake removal notches on either side. On the same side is a smaller spur only $2 \mathrm{~mm}$ in length that may be a dulled spur.

The material is fine grain tan chert that occurs as river cobbles in the area. There is a small portion that has white patination and calcium carbonate precipitates are present. The specimen is an exhausted core that was recycled into a spurred tool

Specimen 9-3Y

Unit 9 Level 3

The specimen is a multidirectional core of fine to coarse grain opaque tan chert. Calcium carbonate encrusts several of the flake surfaces. Numerous knots of step fractures stopped flake removals in numerous directions. What remains of the core has inclusions of coarse grain material that made further reduction impractical. The specimen is an exhausted core that was not recycled like other core specimen 9-3Z, also from Unit 9 Level 3. The type of chert is noted in the assemblage and in the assemblage of the Late Paleoindian and Early Archaic components at the Armstrong site.

\section{Burins and Burin Spalls}

Specimen 6-6X

Unit 6 Level 6 
El 97.22-97.32

The specimen is burin created on a flake tool fragment. A portion of the original hard hammer flake bulb of percussion remains at what would be the distal tip of a tool or proximal end of a flake. The proximal tool end is a hinge fracture that was the platform for removing the right lateral margin. The left margin is retouched with small flakes of $1 \mathrm{~mm}$ and less along the dorsal surface.

The specimen represents approximately 50 percent of the original tool size based upon flake characteristics. The material is the locally observed tan gray chert that is usually fine to medium grain. This specimen has been heated and has a vitreous feel and a slight reddish hue. It is unknown whether the tool was deliberately broken to form the burin platform.

Specimen 6-6A

Unit 6 Level 6

N 1001.50 E 1000.39 El 97.312

The specimen is a burin spall from a unifacial flake tool. These types of flakes are regarded as resharpening or rejuvenation flakes where the edge of a worn tool is removed and a new working edge is created, or they are a deliberate process to create a burin tool or burin core from an available tool. The extent of the edge modification indicates the parent tool was a finished, formal, unifacial tool. The short 2-3 mm flake scars along the edge terminate in step fractures. The edge is has use wear or is trimmed with sub millimeter continuous flaking.

The direction of the burin impact is from the proximal end. A flake was removed perpendicular to the original uniface edge to create the platform for the burin spall. The material is grayish tan fine grain chert. A small amount of cortex on the dorsal side is weathered upland cortex. Calcium carbonate adheres to all surfaces. 
Specimen 6-4C

Unit 6 Level 4

N 1001 E 1000.37 E1 97.465

The specimen is a burin made on the proximal fragment of a large hard hammer flake. There are two burin surfaces, approximately $35 \mathrm{~mm}$ and $23 \mathrm{~mm}$. There are two burin edges, at the right margin and left margin. Spalls were removed parallel and perpendicular to the platform. The shorter length spalls were driven toward the flake platform. The specimen is burned and has fine heat crazing that obscures edge damage at the burins. The material is likely the fine grain tan gray chert. Calcium carbonate precipitates adhere to all surfaces.

\section{Core tools}

Specimen 2-1A

Unit 2 Level 1

N 1002.84 E 1001.67 El 97.73

The specimen is a large, naturally backed core tool. Large hard hammer flakes, 40 to 50 $\mathrm{mm}$ wide and $50 \mathrm{~mm}$ long have been removed from one end, leaving the opposite end untouched. The removals are bifacial and have created a bit end with an edge angle of approximately 75 degrees. The bit edge is damaged with step fractures that are not from platform preparation.

The material is a medium grain tan chert and the cortex is a thin, lightly weathered upland cortex. The cortex is thin suggesting that the cobble was not exposed on the surface for a long period of time. Calcium carbonate precipitates encrust several surfaces. The medium grain structure and toughness of the chert makes it difficult to flake. With an abundance of high quality fine grain chert available locally and close to the Icehouse location, the cobble was probably selected for these desired characteristics. It is the largest artifact recovered during the excavations. 


\section{APPENDIX D}

\section{LITHIC MEASUREMENTS}




\section{REFERENCES CITED}

Abbot, P. L. and C. M. Woodruff (editors)

1986 The Balcones Escarpment: Geology, Hydrology, Ecology and Social Development in Central Texas. Geological Society of America, San Diego.

Adams, W. Y. and E. W. Adams

1991 Archaeological Typology and Practical Reality: A Dialectical Approach to Artifact Classification and Sorting. The University Press, Cambridge, Cambridge.

Adkins, W. S.

1990 The Mesozoic Systems in Texas. In The Geology of Texas, edited by E. H. Sellards, W. S. Adkins and F. B. Plummer, pp. 239-516. Ninth ed. The University of Texas Bulletin No. 3232: August 22, 1932. vol. I: Stratigraphy. University of Texas at Austin, Austin.

Aery, D. A.

2007 Organization of Lithic Technology in Archaic Texas: An Example from $41 \mathrm{HY} 160$ in San Marcos, Texas. Unpublished Master's thesis. Texas State University-San Marcos.

Alley, R. B., J. Marotzke, W. D. Nordhaus, J. T. Overpeck, D. M. Peteet, R. A. Pielke Jr, R. T. Pierrehumbert, P. B. Rhines, T. F. Stocker, L. D. Talley and J. M. Wallace 2003 Abrupt Climate Change. Science 299(5615):2005-2011.

Amick, D. S.

1994 Folsom Diet Breadth and Land Use in the American Southwest. In 59th Annual Meeting of the Society for American Archaeology, Anaheim.

1996 Regional Patterns of Folsom Mobility and Land Use in the American Southwest. World Archaeology 27(3):411.

Anderson, D. G. and G. T. Hanson

1988 Early Archaic Settlement in the Southeastern United States: A Case Study. American Antiquity 53(2):262-286. 
Anderson, P. M., C. W. Barnosky, P. J. Bartlein, P. J. Behling, L. Brubaker, E. J. Cushing, J. Dodson, B. Dworetsky, P. J. Guetter, S. P. Harrison, B. Huntley, J. E. Kutzbach, V. Markgraf, R. Marvel, M. S. McGlone, A. Mix, N. T. Moar, J. Morley, R. A. Perrott, G. M. Peterson, W. L. Prell, I. C. Prentice, J. C. Ritchie, N. Roberts, W. F. Ruddiman, M. J. Salinger, W. G. Spaulding, F. A. Street-Perrott, R. S. Thompson, P. K. Wang, T. W. III, M. G. Winkler and H. E. W. Jr.

1988 Climatic Changes of the Last 18,000 Years: Observations and Model Simulations. Science 241(4869):1043-1053.

Andrefsky Jr., W. 1998 Lithics: Macroscopic Approaches to Analysis. Cambridge University Press, Cambridge.

Antevs, E.

1955 Geologic-Climatic Dating in the West. American Antiquity 20(4):317-335.

Archer, S.

1984 The Distribution of Photosynthetic Pathway Types on a Mixed-Grass Prairie Hillside. American Midland Naturalist 111(1):138-142.

Baccus, J. T., H. M. Becker, T. R. Simpson and R. W. Manning 2000 Mammals of the Freeman Ranch, Hays County, Texas. Texas State University-San Marcos.

Badgley, C. and D. L. Fox 2000 Ecological Biogreography of North American Mammals: Species Density and Ecological Structure in Relation to Environmental Gradients. Journal of Biogeography 27(6):1437-1467.

Baker, B. W.

1998 Vertebrate Faunal Remains from the 1/4 Inch and 1/8 Inch Screens. In Wilson-Leonard: An 11,000-Year Archeological Record of Hunter-Gatherers in Central Texas, edited by M. B. Collins, pp. 1463-1508. vol. V: Special Studies. Texas Archeological Research Laboratory, University of Texas at Austin: Texas Dept. of Transportation, Environmental Affairs Division, Austin.

Balakrishnan, M., C. J. Yapp, D. J. Meltzer and J. L. Theler 2005 Paleoenvironment of the Folsom Archaeological Site, New Mexico, USA, Approximately 10,500 14c Yr B.P. As Inferred from the Stable Isotope Composition of Fossil Land Snail Shells. Quaternary Research 63(1):31. 
Balinsky, R.

1998 Pleistocene to Holocene Microvertebrate Fauna and Its

Paleoenvironmental Significance. In Wilson-Leonard: An 11,000-Year

Archeological Record of Hunter-Gatherers in Central Texas, edited by M. B.

Collins, pp. 1515-1541. vol. V: Special Studies. Texas Archeological Research

Laboratory, University of Texas at Austin: Texas Dept. of Transportation, Environmental Affairs Division, Austin.

Banks, L. D.

1990 From Mountain Peaks to Alligator Stomachs. Memoir \#4. Oklahoma Anthropological Society.

Barnes, V. E.

1974 Geologic Atlas of Texas, Seguin Sheet. In Geologic Atlas of Texas, edited by W. L. Fisher. Donald Clinton Barton Memorial ed. Bureau of Economic Geology, The University of Texas at Austin, Austin.

Bartington Instruments LTD

2003 Operation Manual for Ms2 Magnetic Susceptibility System.

Bartram, L. E.

1993 Perspectives on the Skeletal Part Profiles and Utility Curves from Eastern Kalahari Ethnoarchaeology. In From Bones to Behavior: Ethnoarchaeological and Experimental Contributions to the Interpretation of Faunal Remains, edited by J. Hudson, pp. 115-137. Center for Archaeological Investigations Southern Illinois University at Carbondale, Carbondale.

Batt, C. M. and S. J. Dockrill

1998 Magnetic Moments in Prehistory: Integrating Magnetic Measurements with Other Archaeological Data from the Scatness Multiperiod Settlement. Archaeological Prospection 5(4):217-227.

Batte, C. D.

1984 Soil Survey of Comal and Hays Counties. United States Department of Agriculture, Soil Conservation Service and Texas Agricultural Experimental Station.

Bentley, R. A. and H. D. G. Maschner 2001 Stylistic Change as a Self-Organized Critical Phenomenon: An Archaeological Study in Complexity. Journal of Archaeological Method and Theory 8(1):35-66. 
Bettinger, R. L.

1987 Archaeological Approaches to Hunter-Gatherers. Annual Review of Anthropology 16:121-142.

1991 Hunter-Gatherers: Archaeological and Evolutionary Theory. Plenum Press, New York.

Bettinger, R. L. and M. A. Baumhoff

1982 The Numic Spread: Great Basin Cultures in Competition. American Antiquity 47(3):485-503.

Binford, L. R.

1978a Dimensional Analysis of Behavior and Site Structure: Learning from an Eskimo Hunting Stand. American Antiquity 43(3):330-361.

1978b Nunamiut Ethnoarchaeology. Academic Press, New York.

1980 Willow Smoke and Dogs' Tails: Hunter-Gatherer Settlement Systems and Archaeological Site Formation. American Antiquity 45(1):4-20.

1981 Bones: Ancient Men and Modern Myths. Academic Press, Inc., San Diego.

1984 Faunal Remains from Klasies River Mouth. Academic Press, Orlando, FL.

2001 Constructing Frames of Reference: An Analytical Method for Archaeological Theory Building Using Hunter-Gatherer and Environmental Data Sets. University of California Press, Berkley.

Binford, L. R. and S. R. Binford

1966 A Preliminary Analysis of Functional Variability in the Mousterian of Levallois Facies. American Anthropologist Special Publication 68(2):238-295.

Birket, M. D.

1984 Geology. In Soil Survey of Comal and Hays Counties, edited by C. D. Batte, pp. 83-84. United States Department of Agriculture, Soil Conservation Service and Texas Agricultural Experimental Station.

Bisson, M. S. 
2000 Nineteenth Century Tools for Twenty-First Century Archaeology? Why the Middle Paleolithic Typology of Francois Bordes Must Be Replaced. Journal of Archaeological Method and Theory Vol. 7(No. 1):1-48.

Black, S. L., J. W. Karbula, C. D. Frederick and C. G. Mear 1998 Archeology Along the Wurzbach Parkway. Module 5, Testing and Geoarcheological Evaluation at the Number-6 Site (41BX996) and Other Sites. Studies in Archeology / Texas Archeological Research Laboratory, the University of Texas at Austin; 29; Variation: Studies in Archeology (Austin, Tex.); 29. Texas Archeological Research Laboratory, The University of Texas at Austin, Austin, Texas.

Bleed, P.

1986 The Optimal Design of Hunting Weapons: Maintainability or Reliability. American Antiquity 51(4):737-747.

Blum, M. D., R. S. Toomey III and J. S. Valastro 1994 Fluvial Response to Late Quaternary Climatic and Environmental Change, Edwards Plateau, Texas. Palaeogeography, Palaeoclimatology, Palaeoecology 108:1-21.

Bomar, G. W. 1985 Texas Weather. University of Texas Press, Austin.

Boone, J. L., III 1987 Defining and Measuring Midden Catchment. American Antiquity 52(2):336-345.

Bousman, C. B. 1993 Hunter-Gatherer Adaptations, Economic Risk, and Tool Design. Lithic Technology 18(1\&2):59-86.

1998a Paleoenvironment Change in Central Texas: the Palynological Evidence. Plains Anthropologist 42(164):201-219.

1998b Late Paleoindian Archeology. In Wilson-Leonard: An 11,000-Year Archeological Record of Hunter-Gatherers in Central Texas, edited by M. B. Collins, pp. 161-202. vol. I: Introduction, Background and Synthesis. V vols. Texas Archeological Research Laboratory, University of Texas at Austin: Texas Dept. of Transportation, Environmental Affairs Division. 
Bousman, C. B., M. B. Collins, P. Goldberg, T. Stafford, J. Guy, B. W. Baker, D. G. Steele, M. Kay, A. Kerr, G. Fredlund, P. Dering, V. Holliday, D. Wilson, W. Gose, S. Dial, P. Takac, R. Balinsky, M. Masson and J. F. Powell 2002 The Paleoindian-Archaic Transition in North America: New Evidence from Texas. Antiquity 76(294):980-991.

Bousman, C. B. and D. L. Nickels in prep Archaeological Testing at the Texas River Center in San Marcos, Hays County, Texas. Center for Archaeological Studies, Texas State University-San Marcos, San Marcos.

Bousman, C. B., D. L. Nickels, K. Shubert, B. Meissner, I. Guiterrez Sr. and V. Richardson

2003 Archaeological Testing of the Burleson Homestead at 41HY37, Hays County, Texas. Archaeological Studies Report Report 4. Center for Archaeological Studies-Texas State University, San Marcos, Texas.

Bradbury, A. P. and P. J. Carr 1999 Examining Stage and Continuum Models of Flake Debris Analysis: An Experimental Approach. Journal of Archaeological Science 26:105-116.

Brune, G.

2002 Springs of Texas. Second ed. Texas a\&M University Agricultural Series V. Texas A\&M University Press, College Station.

Butzer, K. W.

1982 Archaeology as Human Ecology. Cambridge University Press, Cambridge.

Cannon, M. D. and D. J. Meltzer

2004 Early Paleoindian Foraging: Examining the Faunal Evidence for Large Mammal Specialization and Regional Variability in Prey Choice. Quaternary Science Reviews 23(18-19):1955.

Caran, S. C.

1998 Quaternary Paleoenvironment Reconstruction. Plains Anthropologist 43(164):111-124.

Caran, S. C. and V. R. Baker 1986 Flooding Along the Balcones Escarpment, Central Texas. In The Balcones Escarpment: Geology, Hydrology, Ecology and Social Development in Central 
Texas, edited by P. L. Abbot and C. M. Woodruff, pp. 1-14. Geological Society of America, San Diego.

Caran, S. C. and C. Hubbs

1994 Chapter 6: Fishes. In Birds and Other Wildlife of South Central Texas, edited by E. A. Kutac and S. C. Caran, pp. 131-146. University of Texas Press, Austin.

Carr, J. T.

1967 The Climate and Physiography of Texas. Texas Water Development Board.

Carr, P. J. and A. P. Bradbury

2001 Flake Debris Analysis, Levels of Production, and the Organization of Technology. In Lithic Debitage: Context, Form, Meaning, edited by W. Andrefsky Jr. The University of Utah Press, Salt Lake City.

Cecil, P. F. and D. P. Greene 2006 Handbook of Texas Online, S.V. "Hays County" Http://Www.Tshaonline.Org/Handbook/Online/Articles/Hh/Hch11.Html.

Clarke, G. K. C., D. W. Leverington, J. T. Teller and A. S. Dyke 2004 Paleohydraulics of the Last Outburst Flood from Glacial Lake Agassiz and the 8200 Bp Cold Event. Quaternary Science Reviews 23(3/4):389-407.

Collins, M. B.

1995 Forty Years of Archeology in Central Texas. Bulletin of the Texas Archeological Society 66:361-400.

1999 Clovis Blade Technology: A Comparative Study of the Keven Davis Cache, Texas. University of Texas Press, Austin.

2004 Archeology in Central Texas. In The Prehistory of Texas, edited by T. K. Perttula, pp. 101-126. Texas A\&M University, College Station.

Collins, M. B., B. Ellis and C. Dodt-Ellis 1990 Excavations at the Camp Pearl Wheat Site (41kr243): An Early Archaic Campsite on Town Creek, Kerr County, Texas. Texas Archeological Research Laboratory, The University of Texas at Austin. 
Collins, M. B., J. Guy and S. Dial

1998 The Archaic Period, 8800 to 1300 B.P. In Wilson-Leonard: An 11,000-

Year Archeological Record of Hunter-Gatherers in Central Texas, edited by M. B. Collins, pp. 211-270. Studies in Archeology; 31; Report / Archeology Studies Program; 10; Variation: Studies in Archeology (Austin, Tex.);31.; Report (Texas. Dept. Of Transportation. Archeology Studies Program);10. vol. I. V vols. Texas Archeological Research Laboratory, University of Texas at Austin: Texas Dept. of Transportation, Environmental Affairs Division, Austin, Texas.

Collins, O. B., F. E. Smeins and D. H. Riskind

1975 Plant Communities of the Blackland Prairie of Texas. In Prairie: A Multiple View (Proceedings of the North American Prairie Conference, No. 4), edited by M. K. Wali, pp. 75-88. University of North Dakota Press, Grand Forks.

Collins, S. L.

1987 Interaction of Disturbances in Tallgrass Prairie: A Field Experiment. Ecology 68(5):1243-1250.

Cotterell, B. and J. Kamminga

1987 The Formation of Flakes. American Antiquity 52(4):675-708.

Crawford, D. D.

1965 The Granite Beach Site, Llano County, Texas. Bulletin of the Texas Archeological Society 36:71-97.

Crockford, R. H. and I. R. Willett

2001 Application of Mineral Magnetism to Describe Profile Development of Toposequences of a Sedimentary Soil in South-Eastern Australia. Australian Journal of Soil Research 39:927-949.

Crowther, J.

2003 Potential Magnetic Susceptibility and Fractional Conversion Studies of Archaeological Soils and Sediments. Archaeometry 45(4):685-701.

Davis, W. B.

1974 The Mammals of Texas. Bulletin No. 41. Texas Parks and Wildlife Department, Austin. 
Davis, W. B. and D. J. Schmidly

1997 The Mammals of Texas - Online Edition. Texas Tech University.

Dean, W. E., R. M. Forester and J. P. Bradbury

2002 Early Holocene Change in Atmospheric Circulation in the Northern Great Plains: An Upstream View of the 8.2 Ka Cold Event. Quaternary Science Reviews 21(16/17):1763-1776.

Decker, S., S. L. Black and T. Gustavson 2000 The Woodrow Heard Site, 41uv88: A Holocene Terrace Site in the Western Balcones Canyonlands of Southwestern Texas. Studies in Archeology 33. Texas Archeological Research Laboratory. University of Texas at Austin. Archeology Studies Program,Report 14. Environmental Affairs Division. Texas Department of Transportation.

Dial, S. W. and M. B. Collins

1998 Bifaces, Bifacial Tools, Perforators, Burins, and Spalls. In WilsonLeonard: An 11,000-Year Archeological Record of Hunter-Gatherers in Central Texas. Volume Ii: Chipped Stone Artifacts, edited by M. B. Collins, pp. 537-596. Tarl Studies in Archeology 31; Texas Department of Transportation Archeology Studies Program Report 10. vol. II. V vols. Texas Archeological Research Laboratory, University of Texas at Austin: Texas Dept. of Transportation, Environmental Affairs Division, Austin, Texas.

Dial, S. W., A. C. Kerr and M. B. Collins 1998 Projectile Points. In Wilson-Leonard: An 11,000-Year Archeological Record of Hunter-Gatherers in Central Texas. Volume II: Chipped Stone Artifacts, edited by M. B. Collins, pp. 313-347. vol. II. V vols. Texas Archeological Research Laboratory, University of Texas at Austin: Texas Dept. of Transportation, Environmental Affairs Division, Austin, Texas.

Diamond, D. D. and F. E. Smeins 1985 Composition, Classification and Species Response Patterns of Remnant Tallgrass Prairies in Texas. American Midland Naturalist 113(2):294-308.

Dibble, H. L.

1997 Platform Variability and Flake Morphology: A Comparison of Experimental and Archaeological Data and Implications for Interpreting Prehistoric Lithic Technological Strategies. Lithic Technology 22(2):150-270. 
Dillehay, $\mathrm{T}$.

1974 Late Quaternary Bison Populations on the Southern Plains. Plains Anthropologist 19(64):180-196.

Dockall, J. E. and C. D. Pevny 2005 Lithic Assemblages: Transitions of Holocene Technological Organization at the Richard Beene Site. In Archaeological and Paleoecological Investigations at the Richard Beene Site 41BX831: South Central Texas, edited by A. V. Thoms and R. D. Mandel, pp. 175-228. Reports of Investigations No. 8. Center for Ecological Archaeology, Texas A\&M University, College Station.

Dyksterhuis, E. J.

1946 The Vegetation of the Fort Worth Prairie. Ecological Monographs 16(1):1-29.

Ehleringer, J. R., N. Buchmann and L. B. Flanagan 2000 Carbon Isotope Ratios in Belowground Carbon Cycle Processes. Ecological Applications 10(2):412-422.

Ehleringer, J. R. and R. K. Monson 1993 Evolutionary and Ecological Aspects of Photosynthetic Pathway Variation. Annual Review of Ecology and Systematics 24:411-439.

Ellis, C., A. C. Goodyear, D. F. Morse and K. B. Tankersley 1998 Archaeology of the Pleistocene-Holocene Transition in Eastern North America. Quaternary International 49/50:151-166.

Everitt B. S.

1977 The Analysis of Contingency Tables. Chapman and Hall, London.

Fiedel, S. J.

2005 Man's Best Friend - Mammoth's Worst Enemy? A Speculative Essay on the Role of Dogs in Paleoindian Colonization and Megafaunal Extinction. World Archaeology: Archaeology of North America 37(1):11-25.

Flenniken, J. J. and A. W. Raymond 1986 Morphological Projectile Point Typology: Replication Experimentation and Technological Analysis. American Antiquity 51(3):603-614. 
Ford, J. A. and G. R. Willey

1941 An Interpretation of the Prehistory of the Eastern United States. American Anthropologist 43(3, Part 1):325-363.

Ford, O. A. and A. S. Lyle

1998 Archaeological Investigation of a Spring Lake Lot for Joe's Crab Shack Parking. The University of Texas at San Antonio Archaeological Survey Report, No.277. Center for Archaeological Research.

Foster, W. C.

1995 Spanish Expeditions into Texas, 1689-1768. University of Texas at Austin, Austin.

Fowler, N. L. and D. W. Dunlap 1986 Grassland Vegetation of the Eastern Edwards Plateau. American Midland Naturalist 115(1):146-155.

Frederick, C. D. 2007 Chapter 6: Paleoenvironment and Site Formation Processes. In The Gatlin Site, 41kr621, Kerr County Texas, Data Recovery Report, edited by B. A. Houk, E. R. Oksanen and K. A. Miller, pp. 6.1-6.21. vol. I. SWCA, Inc., Austin, Texas.

Frederick, C. D., M. D. Glasscock, H. Neff and C. M. Stevenson 1994 Evaluation of Chert Patination as a Dating Technique: A Case Study from Fort Hood, Texas. Archeological Resource Management Series, Research Report No. 32. United States Army, Fort Hood, Tex.

Frison, G.

1978 Prehistoric Hunters of the High Plains. Academic Press, New York.

Frye, R. G., K. L. Brown and C. A. McMahan 1984 The Vegetation Types of Texas. Texas Parks and Wildlife, Austin.

Garber, J. F., S. Bergman, B. Dickinson, R. W. Hays III, J. Simpson and J. Stefanoff 1983 Excavations at Aquarena Springs, San Marcos, Texas. La Tierra 11(3):2838.

Garber, J. F. and D. M. Glassman 
1992 Excavation of Human Remains from the Fish Pond Site, 41HY161, in San Marcos, Hays County, Texas. Texas Antiquities Permit Number 338. Department of Sociology/Anthropology, Southwest Texas State University.

Garber, J. F. and M. D. Orloff

1984 Excavations at 41HY37: An Archaic Site on the Balcones Escarpment in San Marcos, Texas. La Tierra 10(2):31-37.

Gibson, D. J.

1989 Effects of Animal Disturbance on Tallgrass Prairie Vegetation. American Midland Naturalist 121(1):144-154.

Giesecke, J.

1998 Faunal Analysis: An Independent Study. Department of Anthropology,Texas State University-San Marcos.

Goelz, M.

1999 Geoarchaeological Assessment of the Texas River Center, San Marcos, Texas. Prewitt and Associates, Inc.

Goman, M. and D. S. Leigh 2004 Wet Early to Middle Holocene Conditions on the Upper Coastal Plain of North Carolina, USA. Quaternary Research 61:256-264.

Goode, G. T.

2002 Appendix D: An Analysis of Stone Artifacts from the Armstrong Site 41CW54. In Data Recovery at the Armstrong Site (41CW54) Caldwell County, Texas. Volume I: Background, Methods, and Site Context. Texas Antiquities Permit \#2250., edited by E. A. Schroeder and E. R. Oksanen, pp. 151-226. Paul Price Associates, Inc., Austin, Texas.

Gräslund, B.

1981 The Background to C.J. Thomsen's Three Age System. In Toward a History of Archaeology, edited by G. Daniel, pp. 45-68. Thames and Hudson, London.

Grayson, D. K. and D. J. Meltzer

2002 Clovis Hunting and Large Mammal Extinction: A Critical Review of the Evidence. Journal of World Prehistory 16(4):313.

Grimley, D. A., L. R. Follmer, R. E. Hughes and P. A. Solheid 
2003 Modern, Sangamon and Yarmouth Soil Development in Loess of Unglaciated Southwestern Illinois. Quaternary Science Reviews 22(2-4):225.

Grimshaw, T. W. and C. M. Woodruff

1986 Structural Style in an En Echelon Fault System, Balcones Fault Zone, Central Texas: Geomorphic and Hydrologic Implications. In The Balcones Escarpment: Geology, Hydrology, Ecology and Social Development in Central Texas, edited by J. T. Abbot and C. M. Woodruff, pp. 71-76. Geological Society of America, San Diego.

Hampton, N.

1994 Chapter 5: Amphibians and Reptiles. In Birds and Other Wildlife of South Central Texas, edited by E. A. Kutac and S. C. Caran, pp. 113-130.

Hanesch, M. and R. Scholger 2005 The Influence of Soil Type on the Magnetic Susceptibility Measured Throughout Soil Profiles. Geophysical Journal International 161(1):50-56.

Harvey, A. M., G. Foster, J. Hannam and A. E. Mather 2003 The Tabernas Alluvial Fan and Lake System, Southeast Spain: Applications of Mineral Magnetic and Pedogenic Iron Oxide Analyses Towards Clarifying the Quaternary Sediment Sequences. Geomorphology 50(1-3):151.

Hayden, B.

1989 From Chopper to Celt: The Evolution of Resharpening Techniques. In Time, Energy and Stone Tools, edited by R. Torrence, pp. 7-16. Cambridge University Press, New York.

Hester, T. R. 1995 The Prehistory of South Texas. Bulletin of the Texas Acraheological Society 66:427-459.

2004 The Prehistory of South Texas. In The Prehistory of Texas, edited by T. K. Perttula, pp. 127-151. Texas A\&M University Press, College Station.

Hockett, B. and J. A. Haws

2002 Taphonomic and Methodological Perspectives of Leporid Hunting During the Upper Paleolithic of the Western Mediterranean Basin. Journal of Archaeological Method and Theory 9(3):269-302.

Hodder, I.

1992 Theory and Practice in Archaeology. Routledge, New York. 
Holliday, V. T.

2000 Folsom Drought and Episodic Drying on the Southern High Plains from 10,900-10,200 14c Yr B.P. Quaternary Research 53:1-12.

Jackson, S. T., R. S. Webb, K. H. Anderson, J. T. Overpeck, T. Webb Iii, J. W. Williams and B. C. S. Hansen

2000 Vegetation and Environment in Eastern North America During the Last Glacial Maximum. Quaternary Science Reviews 19(6):489.

Jackson, S. T. and J. W. Williams

2004 Modern Analogs in Quaternary Paleoecology: Here Today, Gone Yesterday, Gone Tomorrow? Annual Review of Earth \& Planetary Sciences 32(1):495-537.

Jochim, M. A.

1988 Optimal Foraging and the Division of Labor. American Anthropologist 90(1):130-136.

Johnson, E. (editor)

1987 Lubbock Lake: Late Quaternary Studies on the Southern High Plains. Texas A\&M University Press, College Station, Texas.

Johnson, E., S. Baxevanis and S. Willet

2002 Appendix E: Taphonomy of the Armstrong Vertebrate Faunal Assemblage. In Data Recovery at the Armstrong Site (41CW54) Caldwell County, Texas. Volume I: Background, Methods, and Site Context. Texas Antiquities Permit \#2250., edited by E. A. Schroeder and E. R. Oksanen. Paul Price Associates, Inc. PPA Cultural Resources Report Number 0284., Austin, Texas.

Johnson, E. and T. V. Holliday 1983 Comments on "Large Springs and Early American Indians" by Joel Shiner. Plains Anthropologist 29(103):65-75.

Johnson, L.

1991 Early Archaic Life at the Sleeper Archaeological Site, 41BC65 of the Texas Hill Country, Blanco County, Texas. Publications in Archaeology Rept. No. 39. Texas State Dept. of Highways and Public Transportation, Highway Design Division, Austin, Tex.

Johnson, L. and G. T. Goode 
1995 Past Cultures and Climates at the Jonas Terrace Site, 41me29 of Medina County, Texas. Office of the State Archeologist Report No. 40. Texas Dept. of Transportation: Texas Historical Commission, Austin.

Jordanova, N., E. Petrovsky, M. Kovacheva and D. Jordanova 2001 Factors Determining Magnetic Enhancement of Burnt Clay from Archaeological Sites. Journal of Archaeological Science 28(11):1137-1148.

Kaiser, J.

1998 Bison Prime Prairie Biodiversity. Science 280(5364):677.

Kaplan, H. and K. Hill 1992 The Evolutionary Ecology of Food Acquistion. In Evolutionary Ecology and Human Behavior, edited by E. A. Smith and B. Winterhalder, pp. 167-201. Aldine de Gruyter, New York.

Karbula, J. W. 2000 Investigations at the Eckols Site (41tv528): A Stratified Prehistoric Terrace Site on Barton Creek in Travis County, Texas. Unpublished Ph.D. Dissertation. University of Texas at Austin.

Kastnig, E. H.

1986 Cavern Development in the New Braunfels Area, Central Texas. In The Balcones Escarpment: Geology, Hydrology, Ecology and Social Development in Central Texas, edited by J. T. Abbot and C. M. Woodruff Jr, pp. 91-100. Geological Society of America, San Diego.

Keeley, L. H.

1980 Experimental Determination of Stone Tool Uses: A Microwear Analysis. University of Chicago Press.

1982 Hafting and Retooling: Effects on the Archaeological Record. American Antiquity 47(4):798-809.

Kelly, R. L.

1988a Three Sides of a Biface. American Antiquity 53(4):717-734.

1992 Mobility/Sedentism: Concepts, Archaeological Measures, and Effects. Annual Review of Anthropology 21:43-66.

1995 The Foraging Spectrum: Diversity in Hunter-Gatherer Lifeways. Smithsonion Institution Press, Washington. 
Kemp, K. A. and E. Derbyshire 1998 The Loess Soils of China as Records of Climatic Change. European Journal of Soil Science 49:525-539.

Kerr, A. C. and S. W. Dial 1998 Statistical Analysis of Unfluted Lanceolate and Early Bifarcate Stem Projectile Points. In Wilson-Leonard: An 11,000-Year Archeological Record of Hunter-Gatherers in Central Texas, edited by M. B. Collins, pp. 447-507. vol. II:Chipped Stone Artifacts. Texas Archeological Research Laboratory, University of Texas at Austin: Texas Dept. of Transportation, Environmental Affairs Division, Austin.

Kintigh, K. W. 2006 Boone: Boone's Measure of Assemblage Heterogeneity (Homogeneity). In Tools for Quantitative Archaeology: Programs for Quantitative Analysis in Archaeology. Keith W. Kintigh, Tempe.

Klein, R. G. and K. Cruze-Uribe 1984 The Analysis of Animal Bones from Archaeological Sites. University of Chicago Press, Chicago.

Klejn, L. S.

1982 Archaeological Typology. Translated by P. Dole. B.A.R. International Series 153. British Archaeological Reports, Oxford.

Kovanen, D. J. and D. J. Easterbrook 2002 Timing and Extent of Allerod and Younger Dryas Age (Ca. 12,500-10,000 $14 \mathrm{c}$ Yr B.P.) Oscillations of the Cordilleran Ice Sheet in the Fraser Lowland, Western North America. Quaternary Research 57(2):208.

Krieger, A. D.

1944 The Typological Concept. American Antiquity 9(3):271-288.

Kuehn, S. R.

1998 New Evidence for Late Paleoindian-Early Archaic Subsistence Behavior in the Western Great Lakes. American Antiquity 63(3):457-476.

Kuhn, S. L.

1994 A Formal Approach to the Design and Assembly of Mobile Toolkits. American Antiquity 59(3):426-442. 
Kutac, E. A.

1994 Chapter 3: Birds. In Birds and Other Wildlife of Central Texas: A Handbook, edited by E. A. Kutac and S. C. Caran, pp. 47-102. University of Texas at Austin, Austin.

Kutac, E. A. and S. C. Caran 1994 Birds and Other Wildlife of Central Texas: A Handbook. University of Texas at Austin, Austin.

Larkin, T. J. and G. W. Bomar 1983 Climatic Atlas of Texas. Texas Department of Water Resources.

Liu, X. M., P. Hesse, J. Beget and T. Rolph 2001 Pedogenic Destruction of Ferrimagnetics an Alaskan Loess Deposits. Australian Journal of Soil Research 39:99-115.

Lyle, A. S., C. E. Horrell, S. A. Tomka and D. A. Cargill 2000 Archaeological Testing at the Headwaters of the San Marcos River: Southwest Texas State University Raw Water Supply Project. Archaeological Survey Report, No. 293. Center for Archaeological Research, San Antonio.

Lyman, R. L.

1994 Vertebrate Taphonomy. Cambridge University Press, Cambridge.

2003 The Influence of Time Averaging and Space Averaging on the Application of Foraging Theory in Zooarchaeology. Journal of Archaeological Science, (30):595-610.

Lyndon B. Johnson School of Public Affairs

1978 Preserving Texas' Natural Heritage: A Report by the Natural Heritage Policy Research Project. Lyndon B. Johnson School of Public Affairs at the University of Texas at Austin.

MacArthur, R. H. and E. R. Pianka 1966 On Optimal Use of a Patchy Environment. American Naturalist 100(916):603-609.

Mace, R. E. and E. S. Angle 
2004 Chapter 1: Aquifers of the Edwards Plateau. In Aquifers of the Edwards Plateau. Report 360, edited by R. E. Mace, E. S. Angle and W. F. Mullican III. Texas Water Development Board, Austin.

Macphail, R. I., G. M. Cruise, M. J. Allen, J. Linderholm and P. Reynolds 2004 Archaeological Soil and Pollen Analysis of Experimental Floor Deposits; with Special Reference to Butser Ancient Farm, Hampshire, Uk. Journal of Archaeological Science 31(2):175-191.

Madrigal, C. T. and S. D. Capaldo 1999 White-Tailed Deer Marrow Yields and Late Archaic Hunter-Gatherers. Journal of Archaeological Science 26:241-249.

Madrigal, C. T. and J. Z. Holt 2002 White-Tailed Deermeat and Marrow Return Rates and Their Application to Eastern Woodlands Arheology. American Antiquity 67(4):745-759.

Magiera, T., Z. Strzyszcz, A. Kapicka and E. Petrovsky 2006 Discrimination of Lithogenic and Anthropogenic Influences on Topsoil Magnetic Susceptibility in Central Europe. Geoderma 130(3/4):299-311.

Maher, B. A. and R. Thompson 1995 Paleorainfall Reconstructions from Pedogenic Magnetic Susceptibility Variations in the Chinese Loess and Paleosols. Quaternary Research 44:383-391.

Maher, B. A., H. M. Yu, H. M. Roberts and A. G. Wintle 2002 Holocene Loess Accumulation and Soil Development at the Western Edge of the Chinese Loess Plateau: Implications for Magnetic Proxies of Paleorainfall. Quaternary Science Reviews 22:445-451.

2003 Holocene Loess Accumulation and Soil Development at the Western Edge of the Chinese Loess Plateau: Implications for Magnetic Proxies of Paleorainfall. Quaternary Science Reviews 22:445-451.

Marean, C. W. and N. Cleghorn 2003 Large Mammal Skeletal Element Transport: Applying Foraging Theory in a Complex Taphonomic System. Journal of Taphonomy 1(1):15-42.

Marwick, B. 
2005 Element Concentrations and Magnetic Susceptibility of Anthrosols: Indicators of Prehistoric Human Occupation in the Inland Pilbara, Western Australia. Journal of Archaeological Science 32(9):1357-1368.

Mason, J. B.

2003 Analysis of Site Structure and Post Depositional Disturbance at Two Early Holocene Components, Richard Beene Site (41BX831), Bexar County, Texas, Texas A\&M.

McKinney, W. W.

1981 Early Holocene Adaptations in Central and Southwestern Texas: The Problem of the Paleoindian-Archaic Transition. Bulletin of the Texas Archeological Society 52:91-120.

Meltzer, D. J.

1999 Human Responses to the Middle Holocene (Altithermal) Climates on the North American Great Plains. Quaternary Research 52:404-416.

Meltzer, D. J. and B. D. Smith

1986 Paleoindian and Early Archaic Subsistence Strategies in Eastern North America. In Foraging, Collecting, and Harvesting: Archaic Period Subsistence and Settlement in the Eastern Woodlands, edited by S. W. Neusius, pp. 3-31. Occasional Paper / Center for Archaeological Investigations, Southern Illinois University at Carbondale; No. 6; Variation: Occasional Paper (Southern Illinois University at Carbondale. Center for Archaeological Investigations); No. 6. Center for Archaeological Investigations, Southern Illinois University at Carbondale], [Carbondale, Ill.

Metcalfe, D. and K. R. Barlow 1992 A Model for Exploring the Optimal Trade-Off between Field Processing and Transport. American Anthropologist 94(2):340-356.

Metcalfe, D. and K. T. Jones 1988 A Reconsideration of Animal Body-Part Indicies. American Antiquity, 53(3):486-504.

Monahan, C. M.

1998 The Hadza Carcass Transport Debate Revisited and Its Archaeological Implications. Journal of Archaeological Science 25(5):405. 
Morey, D. F.

2006 Burying Key Evidence: The Social Bond between Dogs and People. Journal of Archaeological Science 33:158-175.

Morey, D. F. and M. D. Wiant

1992 Early Holocene Domestic Dog Burials from the North American Midwest. Current Anthropology 33(2).

Neck, R. W.

1986 The Balcones Fault Zone as a Major Zoogeographic Feature. In The Balcones Escarpment: Geology, Hydrology, Ecology and Social Development in Central Texas, edited by J. T. Abbot and C. M. Woodruff Jr, pp. 35-40.

Geological Society of America, San Diego.

Newby, P., J. Bradley, A. Spiess, B. Shuman and P. Leduc 2005 A Paleoindian Response to Younger Dryas Climate Change. Quaternary Science Reviews 24(1-2):141.

Nordt, L. C.

1992 Archaeological Geology of the Fort Hood Military Reservation, Fort Hood, Texas. Delivery Order 8. Contract DACA-63-87-R-0155 ed. vol. 25. Department of the Army.

2004 Late Quaternary Alluvial Stratigraphy of a Low-Order Tributary in Central Texas, USA and Its Response to Climate and Sediment Supply. Quaternary Research 62(3):289-300.

in prep Chapter 6: Geology, Landscape Evolution, and Geoarchaeology. In Archaeological Testing at the Texas River Center in San Marcos, Hays County, Texas, edited by D. L. Nickels and C. B. Bousman. Center for Archaeological Studies, Texas State University-San Marcos, San Marcos.

Nordt, L. C., T. W. Boutton, C. T. Hallmark and M. R. Waters 1994 Late Quaternary Vegetation and Climate Changes in Central Texas Based on the Isotopic Composition of Organic Carbon41(1):109.

Nordt, L. C., T. W. Boutton, J. S. Jacob and R. D. Mandel 2002 C4 Plant Productivity and Climate-Co2 Variations in South-Central Texas During the Late Quaternary. Quaternary Research 58(2):182-188.

Novekosky, B. J. and P. R. W. Popkin 
2005 Canidae Volume Bone Mineral Density Values: An Application to Sites in Western Canada. Journal of Archaeological Science 32:1677-1690.

Ode, D. J., L. L. Tieszen and J. C. Lerman 1980 The Seasonal Contribution of C3 and C4 Plant Species to Primary Production in a Mixed Prairie. Ecology 61(6):1304-1311.

Odell, G. H.

1994 Prehistoric Hafting and Mobility in the North American Midcontinent: Examples from Illinois. Journal of Anthropological Archaeology 13(1):51.

2000 Stone Tool Research at the End of the Millenium: Procurement and Technology. Journal of Archaeological Research 8(4):269-331.

2001 Stone Tool Research at the End of the Millenium: Classification, Function, and Behavior. Journal of Archaeological Research 9(1):45-100.

2004 Lithic Analysis. Klewer Academic/Plenum Publishers, New York.

Odell, G. H. and F. Cowan

1986 Experiments with Spears and Arrows on Animal Targets. Journal of Field Archaeology 13(2):195-212.

Ogden, A. E., R. A. Quick and S. R. Rothermel 1986 Hydrochemistry of the Comal, Hueco, and San Marcos Springs, Edwards Aquifer, Texas. In The Balcones Escarpment: Geology, Hydrology, Ecology and Social Development in Central Texas, edited by J. T. Abbot and C. M. Woodruff Jr, pp. 115-130. Geological Society of America, San Diego.

Oksanen, E. R., M. C. Cody and K. A. Miller 2007 Occupation Zone 2. In The Gatlin Site, 41KR621, Kerr County Texas, Data Recovery Report, edited by B. A. Houk, E. R. Oksanen and K. A. Miller, pp. 10.1-10.48. SWCA, Inc., Austin.

Oksanen, E. R., T. R. Hester, H. J. Shafer and M. C. Cody 2007 Chapter 8: Technology. In The Gatlin Site, 41kr621, Kerr County Texas, Data Recovery Report, edited by B. A. Houk, E. R. Oksanen and K. A. Miller, pp. 8.1-8.51. vol. I. II vols. SWCA, Inc., Austin. 
Oksanen, E. R. and E. A. Schroeder

2002 Archeological Testing of Four Prehistoric Sites Along the GuadalupeBlanco River Authority's San Marcos Raw Water Pipeline, Caldwell and Hays Counties, Texas. Paul Price Associates, Austin, Tex.

Osmond, C. B.

1987 Photosynthesis and Carbon Economy of Plants. New Phytologist 106(1, Frontiers of Comparative Plant Ecology):161-175.

Owen, J. G.

1990 An Analysis of the Spatial Structure of Mammalian Distribution Patterns in Texas. Ecology 71(5):1823-1832.

Parry, W. J. and R. L. Kelly 1987 Expedient Core Technology and Sedentism. In The Organization of Core Technology, edited by J. Johnson and C. Morrow, pp. 285-304. Westview Press, Boulder.

Paruelo, J. M. and W. K. Lauenroth 1996 Relative Abundance of Plant Functional Types in Grasslands and Shrublands of North America. Ecological Applications 6(4):1212-1224.

Peltier, W. R.

2005 On the Hemispheric Origins of Meltwater Pulse 1a. Quaternary Science Reviews 24(14-15):1655-1671.

Pennak, R. W.

1989 Fresh-Water Invertebrates of the United States: Protozoa to Mollusca. Wiley, New York.

Peters, C., M. J. Church and C. Mitchell 2001 Investigation of Fire Ash Residues Using Mineral Magnetism. Archaeological Prospection 8(4):227-237.

Peters, C. and R. Thompson 1999 Supermagnetic Enhancement, Superparamagnetism, and Archaeological Soils. Geoarchaeology 14(5):401-413.

Phillips, P. and G. R. Willey 
1953 Method and Theory in American Archeology: An Operational Basis for Culture-Historical Integration. American Anthropologist 55(5, Part 1):615-633.

Prewitt, E. R.

1981 Archeological Investigations at the Loeve-Fox, Loeve, and Tombstone Bluff Sites in the Granger Lake District of Central Texas. Archaeology Program: Institute of Applied Sciences, North Texas State University, Denton, Texas.

1995 Distributions of Typed Projectile Points in Texas. Bulletin of the Texas Archeological Society 66:83-173.

Prikryl, D. J.

1990 Lower Elm Fork Prehistory: A Redefinement of Cultural Concepts and Chronologies Along the Trinity River, North-Central Texas. Report 37. Office of the State Archeologist, Texas Historical Commission, Austin.

Pyke, G. H.

1984 Optimal Foraging Theory: A Critical Review. Annual Review of Ecology and Systematics 15:523-575.

Pyke, G. H., H. R. Pulliam and E. L. Charnov

1977 Optimal Foraging: A Selective Review of Theory and Tests. Quarterly Review of Biology 52(2):137-154.

Reineck, H.-E. and I. B. Singh 1980 Depositional Sedimentary Environments, with Reference to Terrigenous Clastics. 2d, rev. and updated ed. New York, Berlin.

Ricklis, R. A.

2004 Prehistoric Occupation of the Central and Lower Texas Coast. In The Prehistory of Texas, edited by T. K. Perttula, pp. 155-180. Texas A\&M University Press, College Station.

Ringstaff, C. W. 2000 A Study of Landform Evolution and Archaeological Preservation at Site 41HY165, San Marcos, Texas. Unpublished Master's thesis. Texas State University-San Marcos.

Riskind, D. H. and O. B. Collins 
1975 The Blackland Prairie of Texas: Conservation of Representative Climax Remnants. In Prairie: A Multiple View (Proceedings of the North American Prairie Conference, No. 4), edited by M. K. Wali, pp. 361-368. University of North Dakota Press, Grand Forks.

Riskind, D. H. and D. D. Diamond

1986 Communities of the Edwards Plateau of Texas: An Overview Emphasizing the Balcones Escarpment Zone between San Antonio and Austin with Special Attention to Landscape Contrasts and Natural Diversity. In The Balcones Escarpment: Geology, Hydrology, Ecology and Social Development in Central Texas, edited by P. L. Abbot and C. M. Woodruff, pp. 21-32. Geological Society of America, San Diego.

Roberts, N.

1991 The Holocene: An Environmental History. Basil Blackwell Ltd, Cambridge.

Rodden, J.

1981 The Development of the Three Age System: Archaeology's First Paradigm. In Toward a History of Archaeology, edited by G. Daniel, pp. 51-68. Thames and Hudson, London.

Rolland, N. and H. L. Dibble

1990 A New Synthesis of Middle Paleolithic Variability. American Antiquity 55(3):480-499.

Royall, D.

2001 Use of Mineral Magnetic Measurements to Investigate Soil Erosion and Sediment Delivery in a Small Agricultural Catchment in Limestone Terrain. Catena 46:15-34.

Sackett, J. R.

1981 From De Mortillet to Bordes: A Century of French Palaeolithic Research. In Toward a History of Archaeology, edited by G. Daniel, pp. 85-112. Thames and Hudson, London.

Schiffer, M. B.

1983 Toward the Identification of Formation Process. American Antiquity, 48(4):675-706.

Schmidly, D. J. 
2004 The Mammals of Texas: Revised Addition. Sixth ed. University of Texas Press, Austin.

Schmitt, D. N. and K. D. Lupo

1995 On Mammalian Taphonomy, Taxonomic Diversity, and Measuring

Subsistence Data in Zooarchaeology. American Antiquity, 60(3):495-514.

Schroeder, E. A.

2002 Data Recovery at the Armstrong Site (41CW54), Caldwell County, Texas. Volume Ii: Cultural Interpretations. Texas Antiquities Permit \#2250. Ppa

Cultural Resources Report 0330. Paul Price Associates, Inc., Austin.

Schroeder, E. A. and E. R. Oksanen

2002 Data Recovery at the Armstrong Site (41CW54) Caldwell County, Texas. Volume I: Background, Methods, and Site Context. Texas Antiquities Permit \#2250. Paul Price Associates, Inc. PPA Cultural Resources Report Number 0284., Austin, Texas.

Sellards, E. H., W. S. Adkins and F. B. Plummer 1990 The Geology of Texas. Ninth ed. The University of Texas Bulletin No. 3232: August 22, 1932 I: Stratigraphy. University of Texas at Austin, Austin.

Shafer, H. J.

1963 Test Excavations at the Youngsport Site: A Stratified Terrace Site in Bell County, Texas. Bulletin of the Texas Archeological Society 34:57-81.

Shiner, J. L.

1983 Large Springs and Early American Indians. Plains Anthropologist 28(99):1-7.

Shott, M. J.

1989 On Tool Class Use Lives and the Formation of Archaeological Assemblages. American Antiquity 54(1):9-30.

Shuman, B., T. Webb III, P. Bartlein and J. W. Williams 2002 The Anatomy of a Climatic Oscillation: Vegetation Change in Eastern North America During the Younger Dryas Chronozone. Quaternary Science Reviews 21(16-17):1777-1792. 
Singer, M. J., K. L. Verosub, P. Fine and J. TenPas

1996 A Conceptual Model for the Enhancement of Magnetic Susceptibility in Soils. Quaternary International 34-36:243-248.

Slade Jr., R. M. 1986 Large Rainstorms Along the Balcones Escarpment in Central Texas. In The Balcones Escarpment: Geology, Hydrology, Ecology and Social Development in Central Texas, edited by P. L. Abbot and C. M. Woodruff, pp. 15-19. Geological Society of America, San Diego.

Smeins, F. E. and D. D. Diamond 1983 Remnant Grasslands of the Fayette Prairie, Texas. American Midland Naturalist 110(1):1-13.

Smith, E. A. and B. Winterhalder 1992 Natural Selection and Decision-Making: Some Fundamental Principles. In Evolutionary Ecology and Human Behavior, edited by E. A. Smith and B. Winterhalder, pp. 25-60. Aldine de Gruyter, New York.

Smith, J. M.

1978 Optimization Theory in Evolution. Annual Review of Ecology and Systematics 9:31-56.

Soil Science Academy of America 2005 Internet Glossary of Soil Science Terms. Crop Science Society of America, American Society of Agronomy, Soil Sciences Academy of America.

Stafford, T. W.

1998 Chapter 25: Radiocarbon Stratigraphy. In Wilson-Leonard: An 11,000Year Archeological Record of Hunter-Gatherers in Central Texas, edited by M. B. Collins, pp. 1039-1066. Studies in Archeology; 31; Report / Archeology Studies Program; 10; Variation: Studies in Archeology (Austin, Tex.);31.; Report (Texas. Dept. Of Transportation. Archeology Studies Program);10. vol. V. Texas Archeological Research Laboratory, University of Texas at Austin: Texas Dept. of Transportation, Environmental Affairs Division, Austin, Texas. 
Stenseth, N. C.

1981 Optimal Food Selection: Some Further Considerations with Special

Reference to the Grazer-Hunter Distinction. American Naturalist 117(4):457-475.

Stiner, M. C. and N. D. Munro

2002 Approaches to Prehistoric Diet Breadth, Demography, and Prey Ranking Systems in Time and Space. Journal of Archaeological Method and Theory 9(2):181-214.

Stiner, M. C., N. D. Munro and T. A. Surovell

2000 The Tortoise and the Hare: Small-Game Use, the Broad-Spectrum Revolution, and Paleolithic Demography. Current Anthropology 41(1):39-73.

Story, D. A.

1985 Adaptive Strategies of Archaic Cultures of the West Gulf Coastal Plain. In Prehistoric Food Production in North America, edited by R. I. Ford, pp. 19-56. Anthropological Papers No. 75. Museum of Anthropology, University of Michigan, Ann Arbor.

Strong, H. M.

1938 A Land Use Record in the Blackland Prairies of Texas. Annals of the Association of American Geographers 28(2):128-136.

Strong, W. L. and L. V. Hills

2005 Late-Glacial and Holocene Palaeovegetation Zonal Reconstruction for Central and North-Central North America. Journal of Biogeography 32:10431062.

Suhm, D. A. and E. B. Jelks (editors)

1962 Handbook of Texas Archeology: Type Descriptions. Bulletin Number Four ed. The Texas Archeological Society and the Texas Memorial Museum, Austin.

Tankersley, K. B.

1998 Variation in the Early Paleoindian Economies of Late Pleistocene Eastern North America. American Antiquity 63(n1):7(14).

Taylor, W. P. and D. W. Lay 1944 Ecological Niches Occupied by Rabbits in Eastern Texas. Ecology 25(1):120-121. 
Tennis, C. L. H. R. J.

1996 Archaic Land Use of Upper Leon Creek Terraces: Archaeological Testing in Northern Bexar County, Texas. Archaeological Survey Report No. 234. Center for Archaeological Research, University of Texas at San Antonio, San Antonio, Texas.

Texas Parks and Wildlife Department

2005 Chapter V: Species and Habitat Assessments and Conservation Strategies. In Texas' Comprehensive Wildlife Conservation Strategy: Draft.

Thoms, A. V.

1993 Knocking Sense from Old Rocks: Typologies and the Narrow Perspective of the Angostura Point Type. Lithic Technology 18(1\&2):16-27.

2005 Archaeological Records at the Richard Beene Site: Summary and Synthesis. In Archaeological and Paleoecological Investigations at the Richard Beene Site 41BX831, edited by A. V. Thoms and R. D. Mandel, pp. 337-380. vol. Reports on Investigations No. 8. Center for Ecological Archaeology, Texas A\&M University, College Station, Texas.

Thoms, A. V., D. D. Kuehn, B. W. Olive, J. E. Dockall, P. A. Clabaugh and R. D. Mandel

1996 Early and Middle Holocene Occupations at the Richard Beene Site: The 1995 Southern Texas Archaeological Association Field School Project. La Tierra: 8-36.

Tomka, S. A.

2001 The Effect of Processing Requirements on Reduction Strategies and Tool Form: A New Perspective. In Lithic Debitage: Context, Form, Meaning, edited by W. A. Andrefsky Jr., pp. 207-254. The University of Utah Press, Salt Lake City.

Toomey III, R. S. and S. C. Caran 1994 Chapter 4: Mammals. In Birds and Other Wildlife of South Central Texas, edited by E. A. Kutac and S. C. Caran, pp. 103-112. University of Texas Press, Austin.

Torrence, R.

1989 Retooling: Towards a Behavioral Theory of Stone Tools. In Time, Energy, and Stone Tools, edited by R. Torrence, pp. 57-66. Cambridge University Press, Cambridge. 
1989 Re-Tooling: Towards a Behavioral Theory of Stone Tools. In Time, Energy, and Stone Tools, edited by R. Torrence, pp. 57-66. Cambridge University Press, Cambridge.

Tortosa, J. E. A., V. V. Bonilla, M. P. Ripoll, V. R. Martinez and C. P. Guillem 2002 Big Game and Small Prey: Paleolithic and Epipaleolithic Economy from Valencia (Spain). Journal of Archaeological Method and Theory 9(3):215-268.

U.S. Department of Agriculture and Natural Resources Conservation Service 2003 National Soil Survey Handbook, Title 430-Vi.

Vaughan, P. C. 1985 Use-Wear Analysis of Flaked Stone Tools. University of Arizona Press, Tucson, Ariz.

Walters, I.

1985 Bone Loss: One Explicit Quantitative Guess. Current Anthropology, 26(5):642-643.

Waters, M. R.

1992a Principles of Geoarchaeology. The University of Arizona Press, Tucson.

1992b Principles of Geoarchaeology: A North American Perspective. University of Arizona Press, Tucson.

Wesolowsky, A. B., T. R. Hester and D. R. Brown

1976 Archeological Investigations at the Jetta Court Site (41tv151) Travis

County, Texas. Bulletin of the Texas Archeological Society 47:25-87.

Weston, D. G.

2002 Soil and Susceptibility: Aspects of Thermally Induced Magnetism within the Dynamic Pedological System. Archaeological Prospection 9(4):207-215.

Whittaker, J. C.

1994 Flintknapping: Making and Understanding Stone Tools. University of Texas Press, Austin.

Wiessner, P.

1982 Beyond Willow Smoke and Dogs' Tails: A Comment on Binford's Analysis of Hunter-Gatherer Settlement Systems. American Antiquity 47(1):171178. 
1983 Style and Social Information in Kalahari San Projectile Points. American Antiquity 48(2):253-276.

Winterhalder, B.

1983 Opportunity-Cost Foraging Models for Stationary and Mobile Predators. American Naturalist 122(1):73-84.

Wobst, H. M.

1977 Stylistic Behavior and Information Exchange. In For the Director:

Research Essays in Honor of James B. Griffin, edited by C. E. Cleland, pp. 317342. vol. 61. Museum of Anthropology, University of Michigan, Ann Arbor, Michigan.

Woodruff, C. M. and J. T. Abbot 1986 Stream Piracy and Evolution of the Edwards Aquifer Along the Balcones Aquifer Along the Balcones Escarpment, Central Texas. In The Balcones Escarpment: Geology, Hydrology, Ecology and Social Development in Central Texas, edited by J. T. Abbot and C. M. J. Woodruff, pp. 77-90. Geological Society of America, San Diego.

Yu, Z. and H. E. Wright Jr.

2001 Response of Interior North America to Abrupt Climate Oscillations in the North Atlantic Region During the Last Deglaciation. Earth-Science Reviews 52(4):333-369. 